FINAL REPORT

\title{
INTERFACIAL AREA TRANSPORT AND REGIME TRANSITION IN COMBINATORIAL CHANNELS
}

\author{
Submitted to \\ The U.S. Department of Energy
}

By

Seungjin Kim

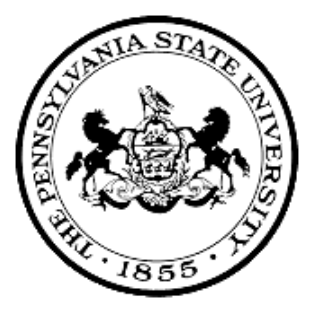

The Pennsylvania State University

Department of Mechanical and Nuclear Engineering 230 Reber Building • University Park, PA 16802

Phone: (814) 867-1783 • Fax: (814) 865-8499

January 2011 


\section{ACKNOWLEDGEMENT}

This research is supported by the Department of Energy through Nuclear Engineering

Education Research (NEER) Program (Award number: NERI DE-FC07-07ID14807) from 07/01/2007 through 12/31/2010. 


\section{TABLE OF CONTENTS}

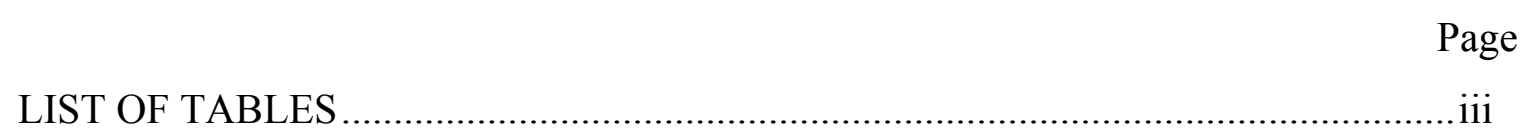

LIST OF FIGURES ......................................................................................

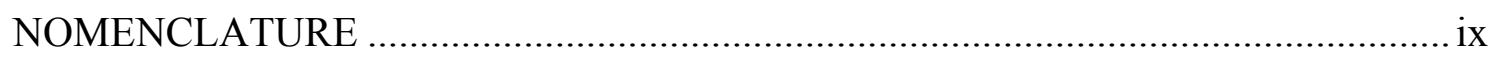

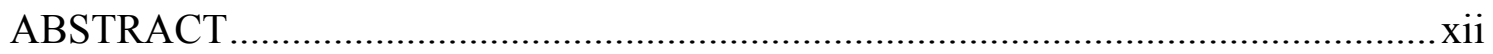

EXECUTIVE SUMMARY ............................................................................

CHAPTER 1. RESEARCH BACKGROUND ........................................................ 1

CHAPTER 2. DESIGN OF COMBINATORIAL TWO-PHASE FLOW FACILITY ... 3

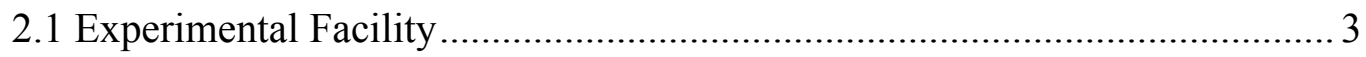

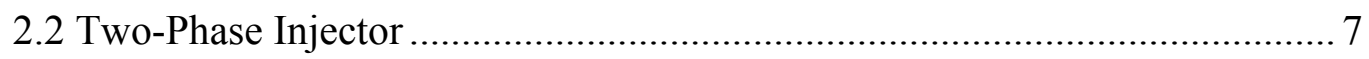

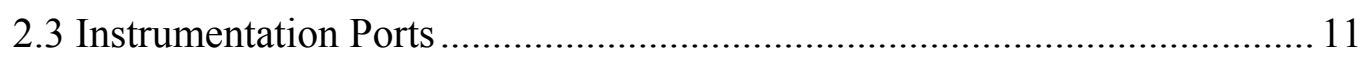

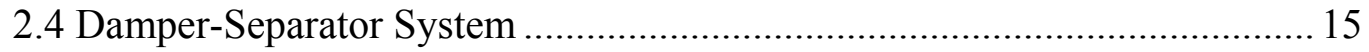

2.5 Design Considerations on Basic Components ......................................... 18

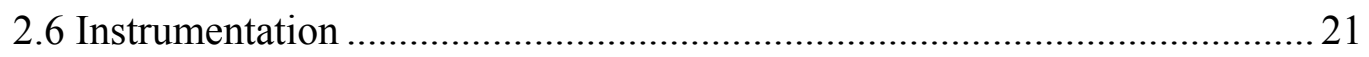

CHAPTER 3. EXPERIMENTAL STUDIES …......................................................... 25

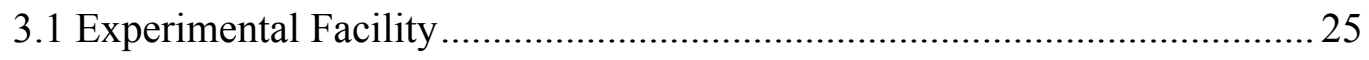

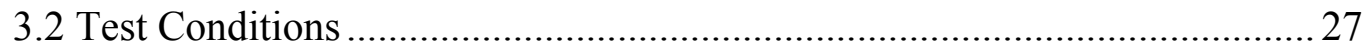

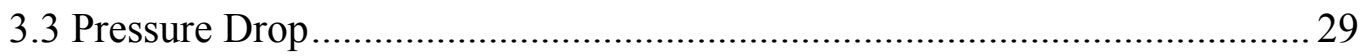

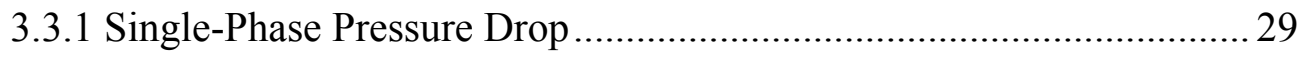

3.3.2 Two-Phase Pressure Drop ........................................................... 32

3.3.3 Two-Phase Pressure Drop Correlation.............................................. 35 


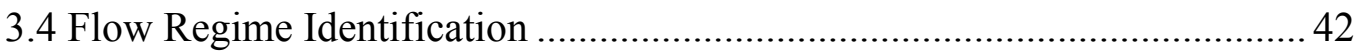

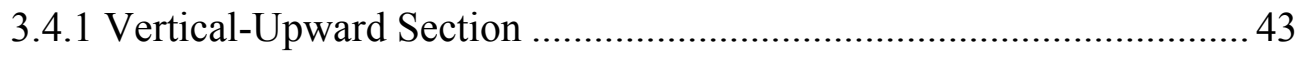

3.4.2 Horizontal Section ..................................................................... 44

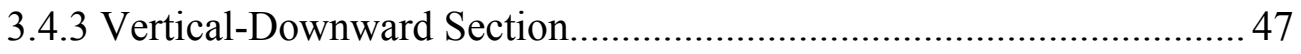

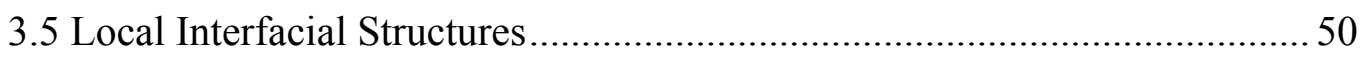

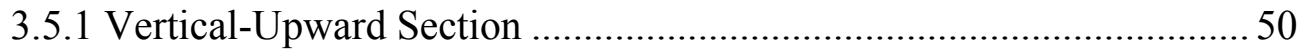

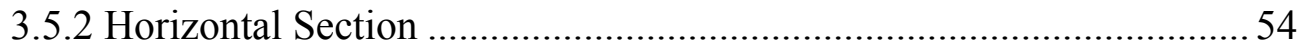

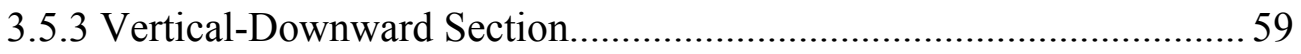

3.6 One-Dimensional Transport of Interfacial Structures................................ 64

3.6.1 Void Fraction and Interfacial Area Concentration............................. 64

3.6.2 Bubble Velocity and Bubble Sauter Mean Diameter......................... 68

3.7 Counter-current Flow Limitation in Combinatorial Channels..................... 70

CHAPTER 4. INTERFACIAL AREA TRANSPORT ….......................................... 74

4.1 Model Predictions in Vertical-Upward Section......................................... 76

4.2 Model Predictions in Vertical-Downward Section ................................... 78

CHAPTER 5. SUMMARY AND RECOMMENDATIONS .................................... 79

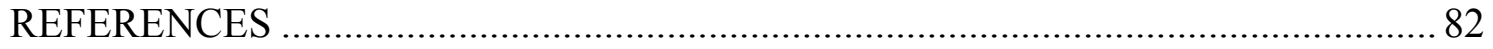

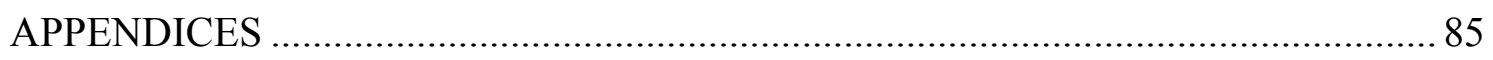

A.1 Local Interfacial Structures in Vertical-Upward Section in Combinatorial

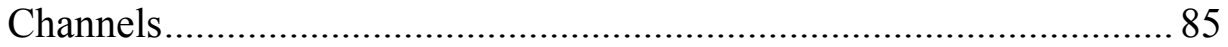

A.2 Local Interfacial Structures in Horizontal Section in Combinatorial

Channels 92

A.3 Local Interfacial Structures in Vertical-Downward Section in Combinatorial Channels.

A.4 Development of Three-Dimensional Profiles along the Combinatorial

Channels 


\section{LIST OF TABLES}

Table

Page

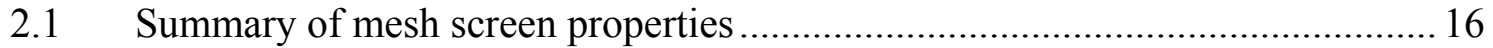

3.1 Six different test conditions used to obtain local two-phase flow parameters.... 28

4.1 Coefficients in bubble interaction terms .................................................... 76 


\section{LIST OF FIGURES}

Figure

Page

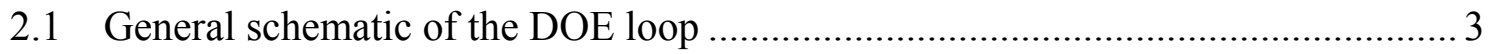

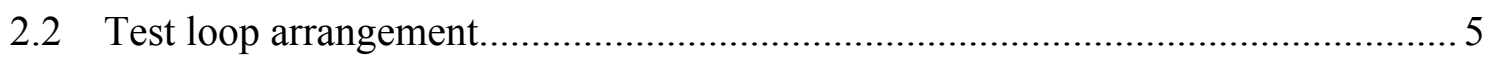

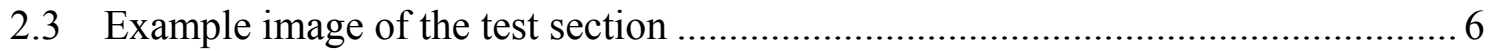

2.4 Three-dimensional view of supporting block-vertical and horizontal test section.. 7

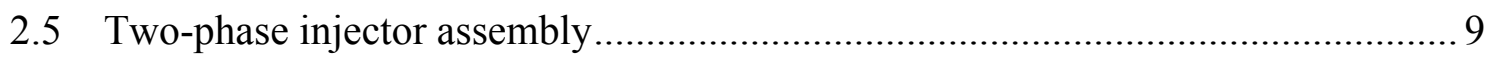

2.6 Reducing glass section connecting injector to test section .............................. 10

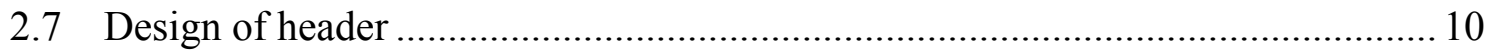

2.8 Schematic of horizontal probe port................................................................ 12

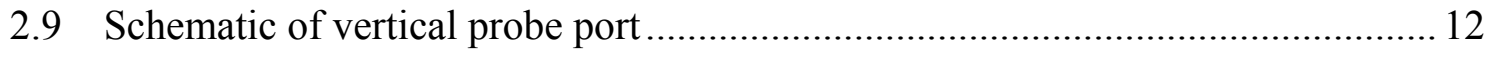

2.10 Probe port plug and cover plate with conductivity probe ................................. 14

2.11 Probe port plug and cover plate without conductivity probe ............................... 14

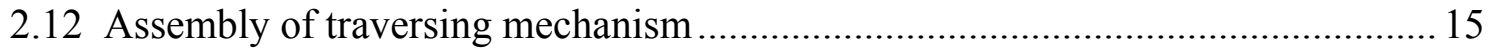

2.13 Support plate for unislide and support block for conductivity probe .................. 15

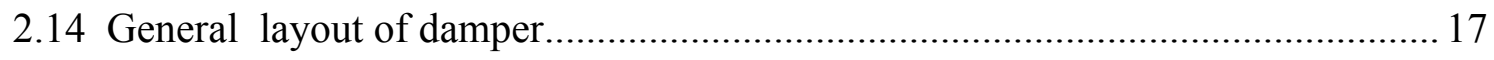

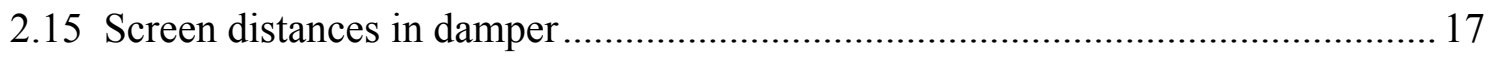

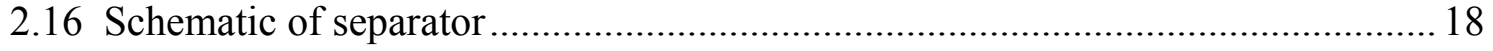

2.17 General Schematic of Accumulator Support Structure..................................... 20

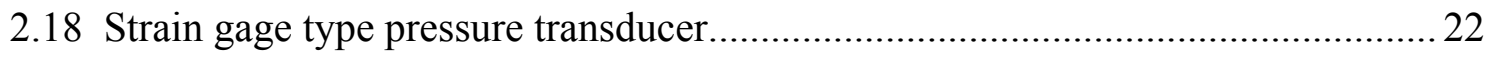

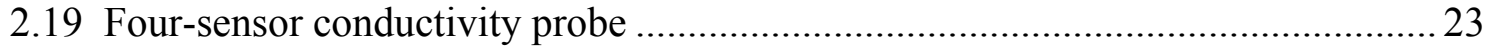

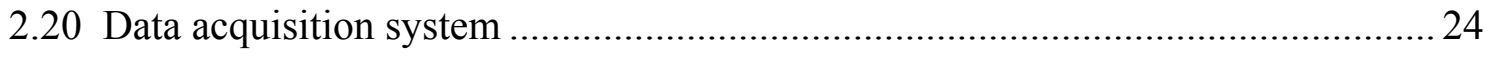

3.1 Simplified schematic diagram of combinatorial two-phase flow facility .............25

3.2 Simplified schematic diagram of combinatorial two-phase flow facility showing

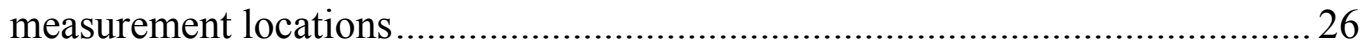

3.3 Photographic image of the measurement port used in vertical sections along with the conductivity probe installed ...................................................... 27

3.4 Comparison of local superficial gas velocity, $\mathrm{j}_{\mathrm{g}, \text { loc }}$ measured by the flow measured by the flow meter with $\left\langle\alpha v_{\mathrm{g}}>\right.$ acquired by the conductivity probe ... 29 
Figure

Page

3.5 Comparison of single-phase liquid pressure measured by the pressure transducer and theoretical predictions

3.6 Single-phase liquid frictional pressure drop along combinatorial channels

3.7 Two-phase pressure drop across 90-degree vertical elbow for constant liquid flow rate, $\mathrm{j}_{\mathrm{f}}=2.0 \mathrm{~m} / \mathrm{s}$ and increasing gas flow rates

3.8 Two-phase pressure drop across 90-degree vertical elbows for constant liquid

flow rate $\mathrm{j}_{\mathrm{f}}=3.0 \mathrm{~m} / \mathrm{s}$ and increasing gas flow rates......

3.9 Two-phase pressure drop across 90-degree vertical elbows for constant liquid flow rate, $\mathrm{j}_{\mathrm{f}}=3.0 \mathrm{~m} / \mathrm{s}$ and increasing gas flow rates

3.10 Zoomed-in view of the pressure drop across a) 90-degree vertical-upward elbow b) 90-degree vertical downward elbow for constant liquid flow rate, $\mathrm{j}_{\mathrm{f}}=3.0 \mathrm{~m} / \mathrm{s}$ and increasing gas flow rates

3.11 Comparison of two-phase pressure drop along vertical-upward section with

Lockhart-Martinelli prediction.

3.12 Comparison of two-phase pressure drop along horizontal section with Lockhart-

Martinelli prediction 36

3.13 Comparison of two-phase pressure drop along vertical-downward section with Lockhart-Martinelli prediction.

3.14 Comparison of two-phase pressure drop between ports P1 and P10 with Lockhart-Martinelli prediction.

3.15 Comparison of two-phase pressure drop across 90-degree vertical-upward elbow with newly developed correlation predictions

3.16 Comparison of two-phase pressure drop across 90-degree vertical-downward elbow with newly developed correlation predictions

3.17 Comparison of two-phase pressure drop across 90-degree horizontal elbow with newly developed correlation predictions

3.18 Comparison of two-phase pressure drop across 45-degree horizontal elbow with newly developed correlation predictions 
Figure

Page

3.19 High-speed images obtained at $2000 \mathrm{fps}$, showing the development of two-phase flow structure across the vertical-upward elbow

3.20 Flow regime map at port P3 (60D downstream of inlet) in vertical section compared with flow regime map for vertical two-phase flow by Mishima-Ishii44

3.21 Modified horizontal two-phase flow regime map at port P4 (3D downstream of the vertical elbow)

3.22 Modified horizontal two-phase flow regime map at port P7 (90D downstream of the vertical elbow)

3.23 Modified horizontal two-phase flow regime map at port P9 (147D downstream of the vertical elbow)

3.24 Modified horizontal two-phase flow regime map at port P10 (177D downstream of the vertical elbow)

3.25 Modified flow regime map for vertical downward two-phase flow at port P11 (3D downstream of the vertical-downward elbow)

3.26 Modified flow regime map for vertical downward two-phase flow at port P14 (66D downstream of the vertical-downward elbow)

3.27 Effect of development length on flow regime transition for vertical downward two-phase flow

3.28 Local void fraction and interfacial area concentration at different axial locations along the vertical upward section for Run $4\left(\mathrm{j}_{\mathrm{f}}=3.0 \mathrm{~m} / \mathrm{s}, \mathrm{j}_{\mathrm{g}, \mathrm{atm}}=0.14 \mathrm{~m} / \mathrm{s}\right) \ldots \ldots .51$

3.29 Local profiles of void fraction and interfacial area concentration for a constant liquid flow rate, $\mathrm{j}_{\mathrm{f}}=3.0 \mathrm{~m} / \mathrm{s}$ and increasing gas flow rates, at different axial locations along the vertical upward section

3.30 Local profiles of bubble Sauter mean diameter and bubble velociy for a constant liquid flow rate, $\mathrm{j}_{\mathrm{f}}=3.0 \mathrm{~m} / \mathrm{s}$ and increasing gas flow rates, at different axial locations along the vertical upward section 
3.31 a) The measurement scheme used to obtain local two-phase flow parameters in the horizontal section b) Instrumentation port for horizontal two-phase flow measurements

3.32 Local profiles of void fraction and interfacial area concentration for Run 4, $\mathrm{j}_{\mathrm{f}}=3.0 \mathrm{~m} / \mathrm{s}$ and $\mathrm{j}_{\mathrm{g}, \mathrm{atm}}=0.14 \mathrm{~m} / \mathrm{s}$, measured at port P4 (3D downstream of vertical elbow) for different azimuthal directions

3.33 Three-dimensional profile and contour plot of void fraction at port P4 for Run4 $\left(\mathrm{j}_{\mathrm{f}}=3.0 \mathrm{~m} / \mathrm{s}\right.$ and $\left.\mathrm{j}_{\mathrm{g}, \mathrm{atm}}=0.35 \mathrm{~m} / \mathrm{s}\right)$

3.34 Three-dimensional profile and contour plot of interfacial area concentration at port P4 for Run4 $\left(\mathrm{j}_{\mathrm{f}}=3.0 \mathrm{~m} / \mathrm{s}\right.$ and $\left.\mathrm{j}_{\mathrm{g}, \mathrm{atm}}=0.35 \mathrm{~m} / \mathrm{s}\right)$.

3.35 Flow visualization at port P4 (3D downstream of the vertical-upward elbow) for two different flow conditions.

3.36 Three-dimensional profile and contour plot of interfacial area concentration at port P5 (L/D = 33 downstream of vertical-upward elbow) for Run6 $\left(\mathrm{j}_{\mathrm{f}}=3.0 \mathrm{~m} / \mathrm{s}\right.$ and $\left.\mathrm{j}_{\mathrm{g}, \mathrm{atm}}=0.35 \mathrm{~m} / \mathrm{s}\right)$

3.37 Three-dimensional profiles of measured local void fraction at ports P7 and P10 (93D and 177D downstream of vertical-upward elbow) for Run6 $\left(j_{\mathrm{f}}=3.0 \mathrm{~m} / \mathrm{s}\right.$ and $\left.\mathrm{j}_{\mathrm{g}, \mathrm{atm}}=0.35 \mathrm{~m} / \mathrm{s}\right) \ldots$

3.38 Co-ordinate system and measurement scheme for vertical downward two-phase flow (flow direction is into the page).

3.39 Local profiles of void fraction and interfacial area concentration for Run6 $\left(\mathrm{j}_{\mathrm{f}}=3.0 \mathrm{~m} / \mathrm{s}\right.$ and $\left.\mathrm{j}_{\mathrm{g}, \mathrm{atm}}=0.35 \mathrm{~m} / \mathrm{s}\right)$, measured at port P11 (3D downstream of the vertical-downward elbow) for different azimuthal directions

3.40 Three-dimensional profiles of measured void fraction and interfacial area concentration at port P11 for Run6 $\left(\mathrm{j}_{\mathrm{f}}=3.0 \mathrm{~m} / \mathrm{s}\right.$ and $\left.\mathrm{j}_{\mathrm{g}, \mathrm{atm}}=0.35 \mathrm{~m} / \mathrm{s}\right)$..

3.41 Radial profiles of local void fraction and interfacial area concentration at port

P12 for Run6 $\left(\mathrm{j}_{\mathrm{f}}=3.0 \mathrm{~m} / \mathrm{s}\right.$ and $\left.\mathrm{j}_{\mathrm{g}, \mathrm{atm}}=0.35 \mathrm{~m} / \mathrm{s}\right) \ldots$ 
Figure

3.42 Radial profiles of local void fraction and interfacial area concentration at port P14

for Run6 $\left(\mathrm{j}_{\mathrm{f}}=3.0 \mathrm{~m} / \mathrm{s}\right.$ and $\left.\mathrm{j}_{\mathrm{g}, \mathrm{atm}}=0.35 \mathrm{~m} / \mathrm{s}\right)$.

3.43 Development of three-dimensional profiles of measured void fraction along the combinatorial two-phase flow channels for Run $4\left(\mathrm{j}_{\mathrm{f}}=3.0 \mathrm{~m} / \mathrm{s}\right.$ and $\mathrm{j}_{\mathrm{g}, \mathrm{atm}}=0.35$ $\mathrm{m} / \mathrm{s})$

3.44 Axial development of area averaged void fraction for a constant liquid flow rate, $\mathrm{j}_{\mathrm{f}}=2.0 \mathrm{~m} / \mathrm{s}$ and increasing gas flow rates

3.45 Axial development of area averaged interfacial area concentration for a constant liquid flow rate, $\mathrm{j}_{\mathrm{f}}=2.0 \mathrm{~m} / \mathrm{s}$ and increasing gas flow rates

3.46 Axial development of area averaged void fraction for a constant liquid flow rate, $\mathrm{j}_{\mathrm{f}}=3.0 \mathrm{~m} / \mathrm{s}$ and increasing gas flow rates

3.47 Axial development of area averaged interfacial area concentration for a constant liquid flow rate, $\mathrm{j}_{\mathrm{f}}=3.0 \mathrm{~m} / \mathrm{s}$ and increasing gas flow rates

3.48 Axial development of void-weighted bubble velocity for flow conditions with a) constant liquid flow rate, $\mathrm{j}_{\mathrm{f}}=2.0 \mathrm{~m} / \mathrm{s} \mathrm{b}$ ) constant liquid flow rate, $\mathrm{j}_{\mathrm{f}}=3.0 \mathrm{~m} / \mathrm{s} .69$

3.49 Axial development of void-weighted bubble Sauter mean diameter for flow conditions with a) constant liquid flow rate, $\mathrm{j}_{\mathrm{f}}=2.0 \mathrm{~m} / \mathrm{s}$ b) constant liquid flow rate, $\mathrm{j}_{\mathrm{f}}=3.0 \mathrm{~m} / \mathrm{s}$ 70

3.50 Curves of constant pump head required to achieve counter-current flow in the vertical-downward section of combinatorial channels

3.51 Curve of constant pump head required to achieve counter-current flow in vertical-downward section of combinatorial channels

4.1 Comparison of model and data for Runs 4, 5 and 6 in vertical-upward section.... 76

4.2 Comparison of model and data for Runs 4, 5 and 6 in vertical-upward section.... 77

4.3 Comparison of model and data for Runs 1, 2 and 3 in vertical-upward section.... 78

4.4 Comparison of model and data for Runs 4, 5 and 6 in vertical-upward section.... 78 


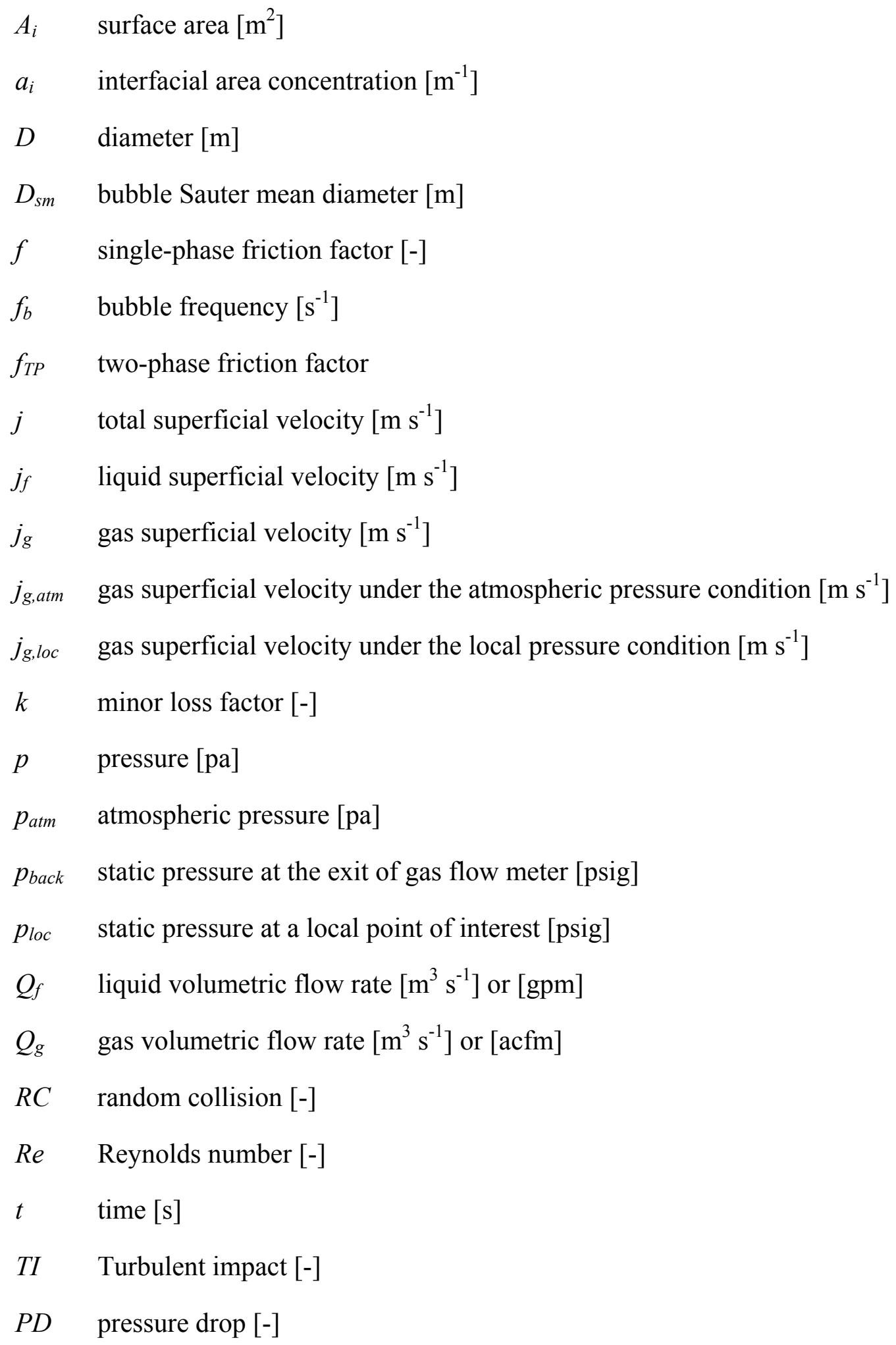


$P h \quad$ phase change [-]

$u_{b} \quad$ bubble velocity $\left[\mathrm{m} \mathrm{s}^{-1}\right]$

$u_{r} \quad$ relative velocity $\left[\mathrm{m} \mathrm{s}^{-1}\right]$

$u_{t} \quad$ turbulent velocity $\left[\mathrm{m} \mathrm{s}^{-1}\right]$

$V \quad$ volume $\left[\mathrm{m}^{3}\right]$

$v_{m} \quad$ mixture velocity $\left[\mathrm{m} \mathrm{s}^{-1}\right]$

$V G \quad$ velocity gradient [-]

We Weber number [-]

$W e_{c r} \quad$ Critical Weber number [-]

$X \quad$ Martinelli parameter [-]

\section{GREEK SYMBOL}

$\varepsilon \quad$ turbulent energy dissipation rate $\left[\mathrm{m}^{2} \mathrm{~s}^{-3}\right]$

$\phi_{f}^{2} \quad$ two-phase frictional multiplier [-]

$\alpha \quad$ gas void fraction [-]

$\mu \quad$ dynamic viscosity $\left[\mathrm{Kg} \mathrm{m}^{-1} \mathrm{~s}^{-1}\right]$

$\mu_{m} \quad$ mixture dynamic viscosity $\left[\mathrm{Kg} \mathrm{m}^{-1} \mathrm{~s}^{-1}\right]$

\section{MATHEMATICAL SYMBOL}
\langle\rangle area average
$\langle\langle\rangle\rangle$ void weighted area average

\section{SUBSCRIPTS}

$1 \quad$ group 1

2 group 2 
atm atmospheric condition

$b \quad$ bubble

$f \quad$ liquid phase

$g \quad$ gas phase

$i \quad$ interface

loc local

$M \quad$ minor loss 


\begin{abstract}
This study investigates the geometric effects of 90-degree vertical elbows and flow configurations in two-phase flow. The study shows that the elbows make a significant effect on the transport characteristics of two-phase flow, which includes the changes in interfacial structures, bubble interaction mechanisms and flow regime transition. The effect of the elbows is characterized for global and local two-phase flow parameters. The global two-phase flow parameters include two-phase pressure, interfacial structures and flow regime transition. In order to characterize the frictional pressure drop and minor loss across the vertical elbows, pressure measurements are obtained across the test section over a wide range of flow conditions in both single-phase and two-phase flow conditions. A two-phase pressure drop correlation analogous to Lockhart-Martinelli correlation is proposed to predict the minor loss across the elbows. A high speed camera is employed to perform extensive flow visualization studies across the elbows in vertical upward, horizontal and vertical downward sections and modified flow regime maps are proposed. It is found that modified flow regime maps immediately downstream of the vertical upward elbow deviate significantly from the conventional flow regime map. A qualitative assessment of the counter-current flow limitation characteristics specific to the current experimental facility is performed.

A multi-sensor conductivity probe is used to measure local two-phase flow parameters such as: void fraction, bubble velocity, interfacial area concentration and bubble frequency. The local measurements are obtained for six different flow conditions at ten measurement locations along axial direction of the test section. Both the vertical-upward and vertical-downward elbows have a significant impact on bubble distribution, resulting in, a bimodal distribution along the horizontal radius of the tube cross-section and migration of bubbles towards the inside of the elbow curvatures immediately downstream of the vertical-upward and vertical-downward elbows, respectively. The elbow effect decays further downstream of the elbow and bubbles migrate to more conventional distribution patterns. The axial transport of void fraction and interfacial area concentration shows that the elbows promote bubble disintegration. Preliminary comparisons between the interfacial area transport model and the experimental data for verticalupward and vertical downward section are also presented.
\end{abstract}




\section{EXECUTIVE SUMMARY}

Geometric effects of 90-degree vertical elbows and flow configurations in two-phase flow are investigated. The experimental database is established in the combinatorial two-phase flow channels which consist of both vertical-horizontal test sections made out of $50.8 \mathrm{~mm}$ ID acrylic pipes connected by 90-degree vertical glass elbows. The design considerations of important components of combinatorial channels are also presented. The facility is designed such that all the conceivable vertical-to-horizontal and horizontal-to-vertical flow configurations can be achieved by simple manipulation of valves to change the flow direction.

The present study is divided largely into two topics in view of the geometric effects of 90degree elbows, namely; the effects on global two-phase flow parameters and the effects on the local two-phase flow parameters. The global two-phase flow parameters include two-phase pressure drop and flow regime transition. Effect of the elbows on two-phase pressure drop is characterized by an additional drop due to minor losses. As such, a simple model analogous to Lockhart-Martinelli model is developed to predict the two-phase pressure drop across the elbows. Additionally, modified flow regime maps from flow visualization are proposed, which account for geometric effects of elbows in both the vertical-upward to horizontal and horizontal to vertical-downward two-phase flow configurations. Additional experimental investigation is performed to study the counter-current flow limitation (CCFL) characteristics specific to the current experimental facility. The experiments are performed via flow visualization in the vertical downward section.

A four-sensor conductivity probe is used to obtain local two-phase flow parameters such as: void-fraction, interfacial area concentration, bubble velocity and bubble frequency. A total of six different flow conditions within the bubbly flow regime in the vertical-upward section are used to establish the local database along the combinatorial channels. This leads to a total of approximately 3,500 local data points. It is found that the presence of the 90 -degree verticalupward elbow leads to a bimodal bubble distribution at measurement location immediately downstream of the elbow in the horizontal section. It is speculated that this is caused by the secondary flow generated by the elbow in the plane perpendicular to the main flow direction. The elbow effect on the bubble distribution decays by approximately 30 diameters downstream 
of the elbow. Similarly, the vertical-downward elbow affects the bubble distribution immediately downstream of the elbow causing the bubbles to move towards the inside of the elbow curvature. One-dimensional transport of the interfacial structures shows that the elbows promote bubble disintegration in general. This result is also supported by the flow visualization study. 


\section{RESEARCH BACKGROUND}

In a nuclear system, the coolant flows through channels of different sizes and orientations interconnected via various junctions and flow restrictions. Under postulated reactor accident conditions, two-phase flow may develop and undergo significant changes in interfacial structure, which results in drastic transitions in flow regime and hence the transport phenomena. There is a lack of experimental data and knowledge of the mechanisms that govern two-phase flow through flow restrictions. Such limitations present shortcomings in the thermal-hydraulic analysis of nuclear reactor systems. Experimental studies are crucial to improve the understanding of the effects of flow restrictions on two-phase flow.

In general, macroscopic field equations and constitutive relations using a continuous formulation are used to represent physical problems in two-phase flow. Advanced mixture models such as drift-flux model (Zuber and Findlay, 1965) have been extensively used. However, a more detailed treatment of two-phase motion is possible through the two-fluid model (Ishii, 1975). The two-fluid model is formulated by considering each phase separately in terms of two sets of conservation equations governing the mass, momentum and energy for each phase. In addition, interaction terms which couple the transport of mass, momentum and energy of each phase across the interface appear in the field equations. These interfacial transfer terms are directly related to the interfacial area concentration and the local transfer mechanisms. Therefore, an accurate model for the interfacial area is essential in view of the two-fluid model formulation. The lack of proper mechanistic models for the interfacial structure and the interfacial transfer processes lead to inaccurate predictions of these phenomena, and thus becomes a major concern in the current two-phase flow modeling practice.

In the current nuclear reactor system analysis codes, the interfacial area concentrations are calculated by the flow regime dependent correlations. The use of steady-state based flow regime transition criteria imposes significant defects in modeling the interfacial structure transient or changes at the entrance (or junctions) because they are not capable of representing the changes in interfacial structures dynamically. Mortensen (1995) and Kelly (1997) identified shortcomings related to the flow regime based static approach, which can be summarized as: 
a) Since the flow regime transition criteria are algebraic relations for steady-state, fully developed flows, they reflect neither the true dynamic nature of changes in the interfacial structure, nor the gradual regime transition.

b) The compound errors due to the two-step flow regime based method can be significant.

c) The existing flow regime dependent correlations and criteria are valid in limited parameter ranges for certain operational conditions. Often the geometric scale effects are not taken into account correctly. Hence, these models may cause significant discrepancies, artificial discontinuities and numerical instability.

Therefore, to better represent the effects of interfacial structure and regime transition, a mathematical model that can take into account the dynamic change of the interfacial structure is consistent with the two-fluid model.

The interfacial area transport equation can dynamically predict the changes of interfacial area concentration via mechanistically modeled source and sink terms. Therefore, the artificial bifurcation related to the flow regime transition in the conventional model can be eliminated. Furthermore, since it dynamically models the two-phase flow evolution across flow regime transition boundaries, it prevents artificial discontinuities. As such, a dynamic approach is particularly important to two-phase flow in channels that are interconnected via various junctions, because the two-phase flow in such condition undergoes a significant change in its interfacial structures. Therefore, the use of interfacial area transport equation in analyzing the interfacial transfer and regime transition is not only rational, but it can also make a significant improvement in thermal-hydraulic reactor system analysis.

Separate-effects experiments are performed in the combinatorial channels to study the geometric effects of 90-degree vertical elbows and flow configurations in two-phase flow. The experimental results obtained with this facility will provide a fundamental understanding on the geometric effects of the vertical elbows on two-phase flow transport and in the regime transition mechanisms. Moreover, the database established in this study can be used to develop predictive models applicable to the safety analysis of reactor systems. 


\section{DESIGN OF COMBINATORIAL TWO-PHASE FLOW FACILITY}

The DOE test facility is designed to simulate various air water two-phase flow conditions through channels of differing orientations. The test loop consists of horizontal and vertical sections made out of acrylic pipes with an inner diameter of $50.8 \mathrm{~mm}$, as shown in Figure 2.1. The maximum lengths of the horizontal and vertical sections are $9.45 \mathrm{~m}$ and $3.35 \mathrm{~m}$ yielding development lengths of 186 and $66 \mathrm{~L} / \mathrm{D}$, respectively. This test facility is capable of producing bubbly to annular flow in both the horizontal and vertical directions. In addition, through the use of two injection systems, co-current as well as counter-current flow conditions can be investigated with the present design. As shown in the layout, if the green valves are open and the orange valves are closed, the flow will travel as indicated by the green arrow. Similarly, if the orange valves are open and the green valves are closed, then the flow will travel as indicated by the orange arrow.

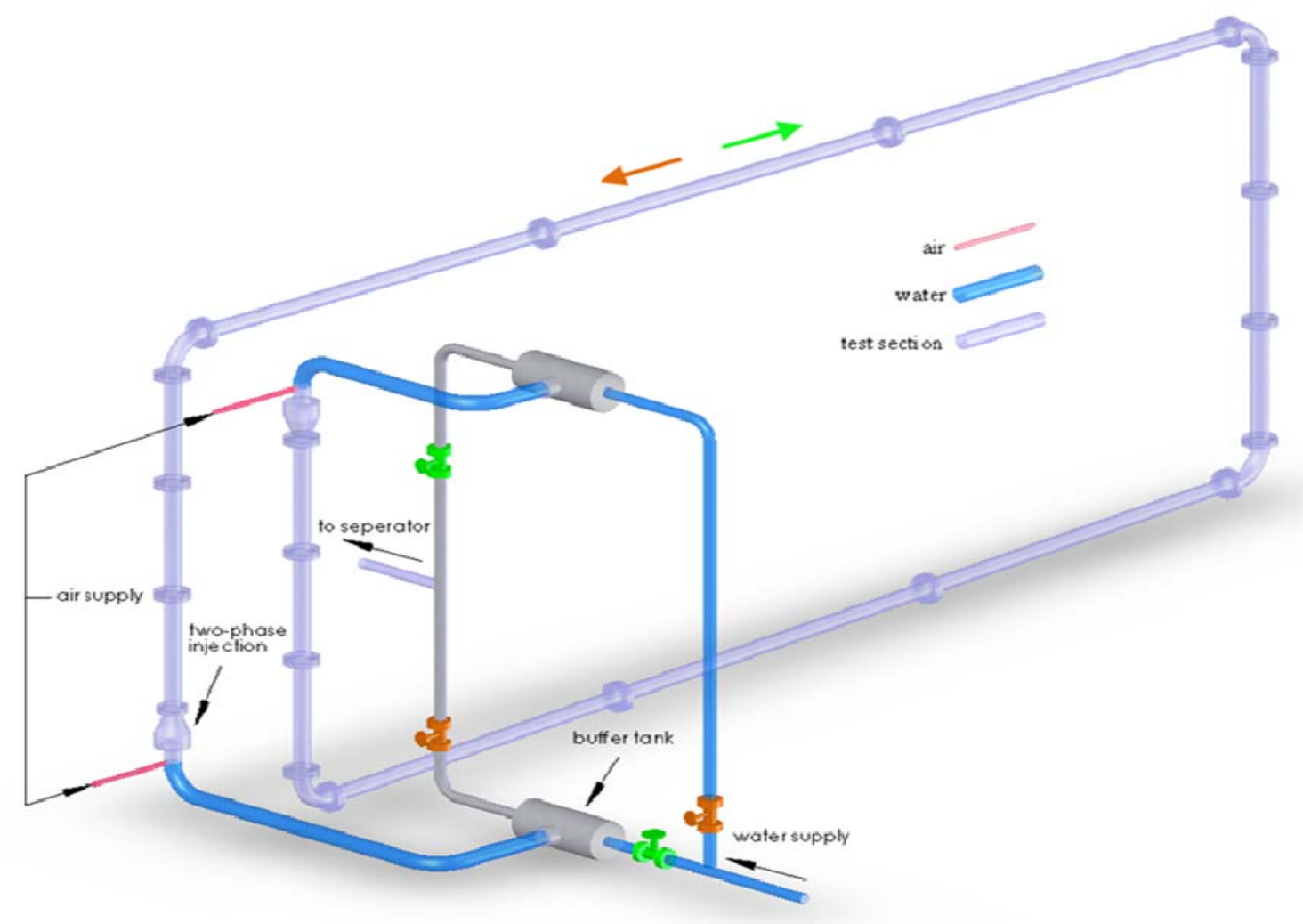

Figure 2.1 General Schematic of the DOE-Loop 


\subsection{Test Sections}

The test loop comprises of five legs, two horizontal and three vertical legs. Each section is made out of acrylic pipe segments of various lengths which are then connected through flanges as described below. The acrylic pipes allow for flow visualization as well as various optical methods to measure different parameters.

Horizontal Sections: the top horizontal section has three $1.219 \mathrm{~m}$ segments and three $1.524 \mathrm{~m}$ segments and the bottom section is made out of four $1.219 \mathrm{~m}$ segments and one $1.524 \mathrm{~m}$ segment.

Vertical Sections: the first vertical section with injector in the upward direction is made out of one $0.304 \mathrm{~m}$ and two $1.219 \mathrm{~m}$ segments. The second vertical section (rightmost) has one 0.762 $\mathrm{m}$ and two $1.219 \mathrm{~m}$ segments while the third vertical section (injector in downward direction) has one $0.304 \mathrm{~m}$ and two $1.067 \mathrm{~m}$ segments.

The segments are glued to the flanges on both the ends and the flanges are bolted to each other using four $5 / 8$ inch bolt holes. All the flanges are made out of $0.152 \mathrm{~m}$ outer diameter acrylic sheets. The flanges used to connect the vertical pipes are $2.5 \mathrm{~cm}$ thick and have four $5 / 8$ inch bolt holes. Fourteen of the vertical section flanges have grooves for $1 / 8$ inch o-ring and the rest four are without the o-ring. An important change in the design of the horizontal flanges is the thickness, which is increased to $3.8 \mathrm{~cm}$. This provides more surface area for gluing, thus increasing the strength of the flange against shear stresses which will be significantly higher in horizontal test sections. Sixteen of these flanges have grooves for $1 / 8$ inch o-ring and the rest twenty are without o-ring.

A detailed view of the test loop arrangement is shown in Figure 2.2. There are six horizontal measurement ports and nine vertical measurement ports as shown below Also, as it can be seen, there are three vertical legs and two horizontal legs in the test loop. An example image of the test section is also shown in Figure 2.3. In that particular test section, the flange facing the reader has an o-ring groove while the flange in the other end has no groove for the o-ring. The o-rings are basically used to seal the gaps to prevent leakage. The locations of flanges are chosen in such a way that the measurement ports can be moved to any flange-to-flange connection as required. 

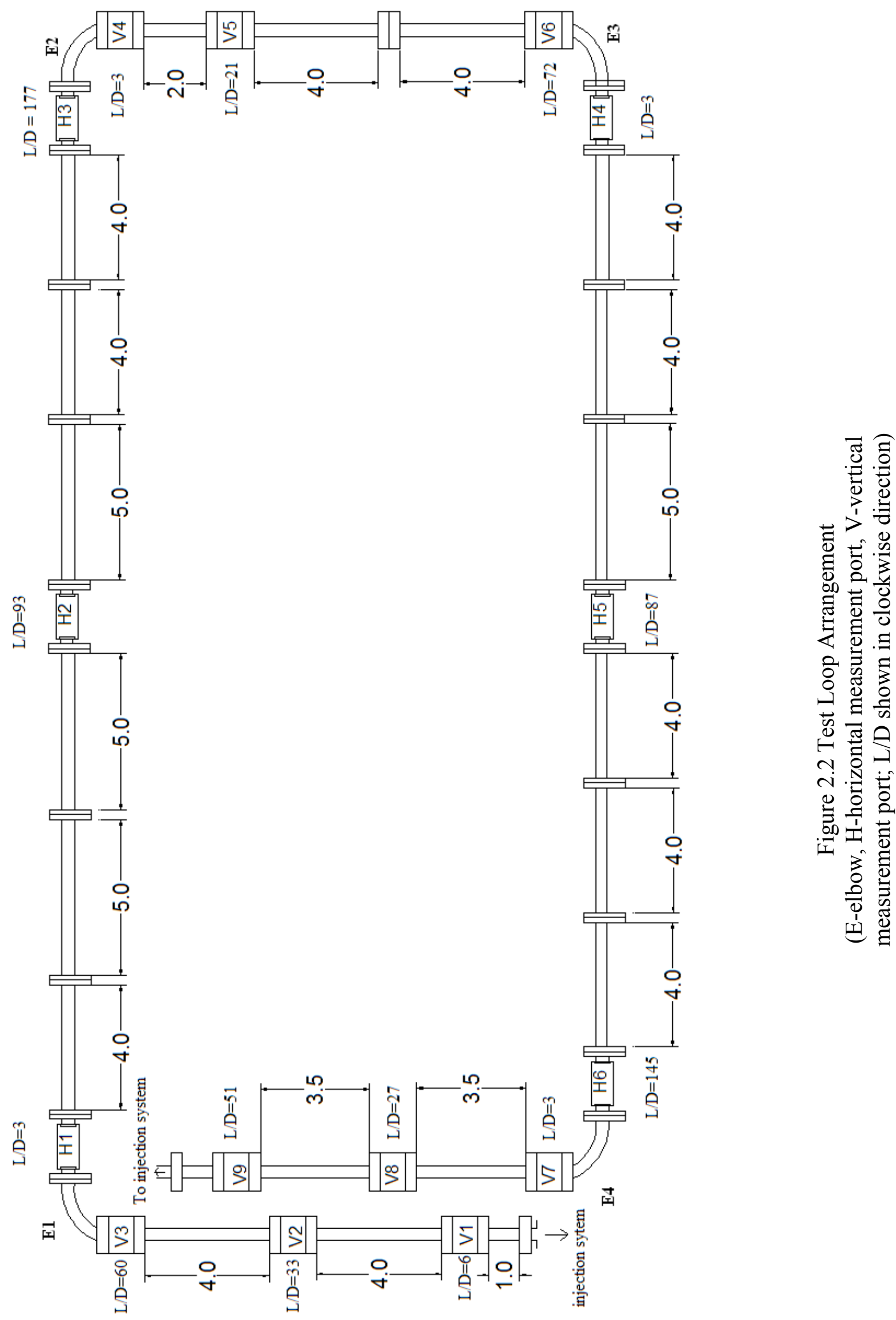


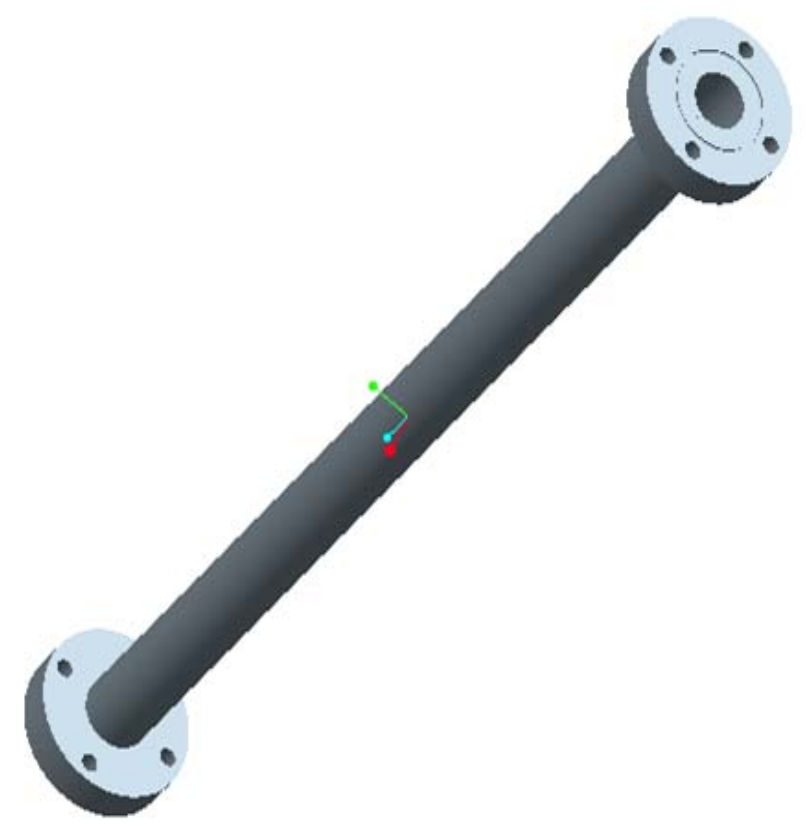

Figure 2.3 Example Image of Test Section

\subsubsection{Supporting Block for Test Section}

\section{Vertical Test Section Connector:}

The connectors as shown in Fig. 2.4 are used to install the test section, support them and keep them perfectly vertical. The vertical connector consists of two $3.8 \mathrm{~cm}$ thick acrylic blocks namely the top and the bottom block. Each block has a semicircular groove of $8.9 \mathrm{~cm}$ diameter to assemble them on the test section. The top block is $20.3 \mathrm{~cm}$ wide and $7.6 \mathrm{~cm}$ high. Two slanted faces are shaved along its top corners with an angle of 60 degrees with the top face. The purpose of these faces is to provide flat surface to insert Teflon threaded rods. The bottom block is 20.3 $\mathrm{cm}$ wide and $7 \mathrm{~cm}$ high. Its bottom face has $1 / 4$ inch hole tapped for $1 / 4-16$ Teflon rods. The top and the bottom blocks are connected through 1/4 inch bolts which are then bolted to spring nuts in the strut channel. The connector assembly sits on the strut channel connected to the main structure. Three Teflon threaded rods of 1/4 - 16 each, at an angle of 120 degree from the other, are used for the fine adjustment of the vertical test section. Teflon rods are used to prevent any scratching and damage to the test section that might occur from other material. 


\section{Horizontal Test Section Connector:}

The design of these connectors is much simple compared to the vertical connectors. It consists of two blocks $12.7 \mathrm{~cm}$ wide, $5.1 \mathrm{~cm}$ high and $3.8 \mathrm{~cm}$ deep. Each block has a semicircular groove of $7 \mathrm{~cm}$ diameter. The blocks are connected to each other through $1 / 4 \mathrm{inch}$ bolts and the whole assembly is then connected to the strut channel. Rubber sheet of $3 \mathrm{~mm}$ thickness is used for damping and protection of the test section from vibrations. This rubber sheet is kept in the groove through which the test loop runs. The adjustments for height and straightness are done by moving the strut channel on the main structure and then finally shimming it by putting metal washers underneath the horizontal connectors.
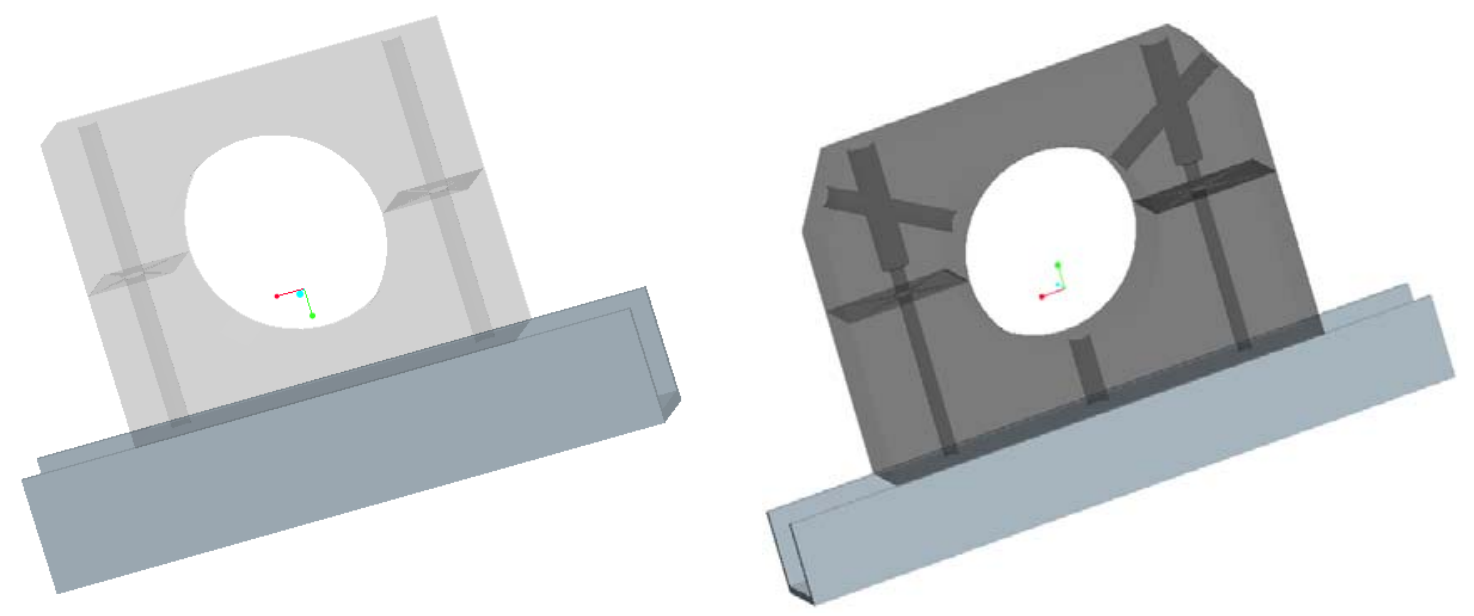

Figure 2.4 Three Dimensional View of the Supporting Block for Vertical and Horizontal Test Sections respectively

\subsection{Two - Phase Injection}

\subsubsection{Two-Phase Injection System}

The two-phase injection system consists of two injectors with one vertically upward and the other vertically downward configuration installed in adjacent vertical legs. The two-phase injection system utilizes a double annulus configuration and sparger as shown in the Fig. 2.5. The sparger is a $1.9 \mathrm{~cm}$ outer diameter tube which is installed at the center of the auxiliary 
(inner) pipe. The top six inches of the sparger, denoted as the grey region in the figure, is a porous tip with pore size of ten microns capable of generating 1-2 mm diameter bubbles.

Both auxiliary (inner) and the main (outer) annulus are made out of acrylic pipes. The auxiliary annulus pipe has $3.2 \mathrm{~cm}$ inner diameter, $0.6 \mathrm{~cm}$ thickness and a length of $30.5 \mathrm{~cm}$ yielding a development length of $11.5 \mathrm{~L} / \mathrm{D}$. A small flow rate is supplied around the sparger within the inner pipe which allows for the bubbles of uniform size to be sheared from the sparger. The flow condition in the test section can be varied via the flow rate in the main (outer) annulus, which has a $7.6 \mathrm{~cm}$ ID, $0.6 \mathrm{~cm}$ thickness and $26.7 \mathrm{~m}$ length pipe having an L/D of 6 . This satisfies the criterion that the injector should have a minimum of $5 \mathrm{~L} / \mathrm{D}$ for the flow to be fully developed. The main annulus is supplied through three $3.8 \mathrm{~cm}$ ID injection pipes. One header is used to buffer the flow from one inlet line (from the pump) into the three main injection lines. The three injection lines are chosen to help in reducing the non-uniformity and swirling of the flow in the main annulus. They are chosen such that the sum of the areas of all three injection lines is greater than the cross-sectional area of the test section. This configuration minimizes the effect of flow on the bubble diameter. The constant inlet bubble size is desirable for consistent modeling of the interfacial area transport with multiple flow conditions. The injector in turn is connected to the main test section through a glass reducer. The area for main flow in the reducer is almost equal to the area of cross-section for the inner annulus. This prevents the formation of high and low pressure regions within the reducer and hence ensures uniformity in the size of bubbles entering the test section. This in turn prevents the bubbles from getting sucked into the auxiliary pipe.

The main and the auxiliary pipes are glued to a $19.1 \mathrm{~cm}$ OD and $2.5 \mathrm{~cm}$ thick circular flange, which also has a $0.6 \mathrm{~cm}$ hole for drainage. The flange in turn sets on top of a one square foot 0.125 inch thick stainless steel plate. A $1 / 8^{\text {th }}$ inch O-ring is used to seal the flange to the plate. A $3.8 \mathrm{~cm}$ diameter stainless steel tee is welded to the bottom of the plate. One of the arms of the tee supplies the auxiliary flow. The welding of the elbow is preferred instead of using a threaded elbow, to keep the whole sparger assembly as straight as possible. It is done so that the slight tilt due to the pitch of the thread is avoided and the sparger assembly is kept as vertical as possible. Also the three injection lines are threaded through saddles before passing onto the test section. 
The saddles are used because the acrylic used for the test section is thin and cannot be threaded. Moreover, this gives more surface area for gluing it to the test section.

\subsubsection{Sparger Assembly}

The sparger is a $1.9 \mathrm{~cm}$ outer diameter tube which is installed at the center of the auxiliary (inner) pipe. The top $15.2 \mathrm{~cm}$ of the sparger, denoted as the dark region in the figure, is a porous tip with pore size of ten microns capable of generating 1-2 mm diameter bubbles. The sparger tube is $48.3 \mathrm{~cm}$ long (excluding the porous region). Figure 2.5 shows the assembly of the sparger and Fig. 2.6 shows the glass reducer used to connect the injector to the test section. The stainless steel tee is welded to a $5.1 \mathrm{~cm}$ to $2.5 \mathrm{~cm}$ reducer, which is again welded to a $4.5 \mathrm{~cm} \mathrm{long,} 2.5 \mathrm{~cm}$ diameter stainless steel tube. The sparger tube passes straight through this assembly and is sealed by a $2.5 \mathrm{~cm}$ by $1.9 \mathrm{~cm}$ Swagelok nut, which is then connected to the air line through a check valve. The check valve allows flow only in one direction; so this prevents the backflow of air or water into the airline.

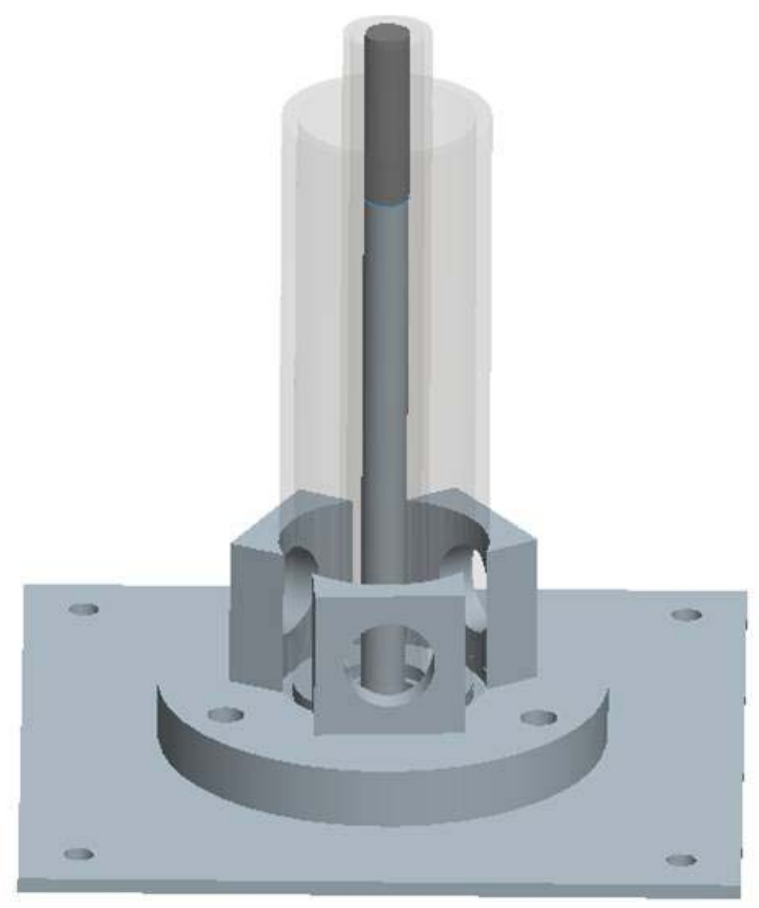

Figure 2.5. General Schematic of Two-Phase Injector 


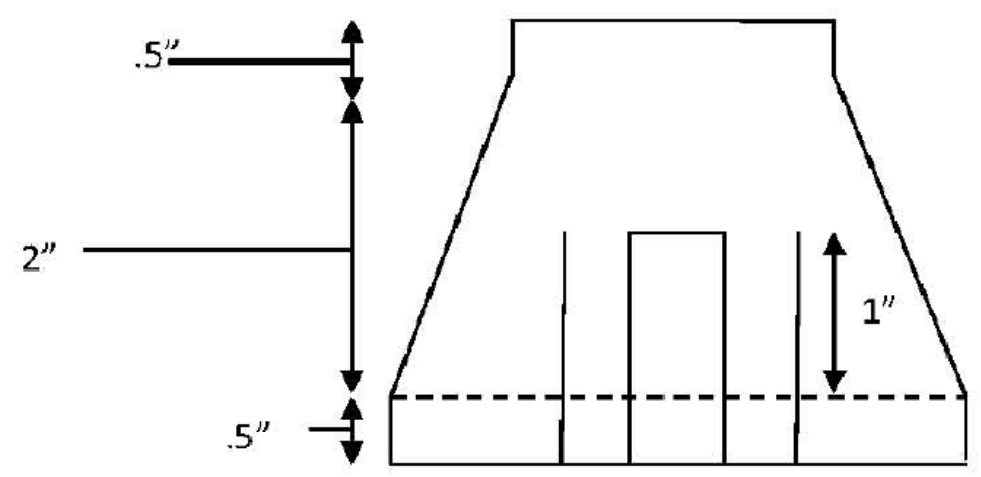

Figure 2.6. Reducing Glass Section connecting Injector to Test Section

\subsubsection{Header Design}

Water from the tanks is pumped to the headers which in turn supply it to the test section. The loop consists of two headers, located approximately at the two injector heights respectively. The main purpose of the headers is to supply a constant and uniform flow rate to the test section and act as buffers. The headers are made out of $91.4 \mathrm{~cm}$ long, $15.2 \mathrm{~cm}$ inner diameter PVC pipes. The $15.2 \mathrm{~cm}$ to $7.6 \mathrm{~cm}$ reducing hex bushings at the ends of the header allow them to be connected to $7.6 \mathrm{~cm}$ inlet/outlet. The headers are connected to injectors through three $3.8 \mathrm{~cm}$ flexible tubing. The three outlet holes are located at equal distances along the header length. This arrangement provides uniform flow to the injector. The drainage from the headers is provided by a $1.2 \mathrm{~cm}$ drain hole located at the bottom of each header. Figure 2.7 shows the schematic of the header.
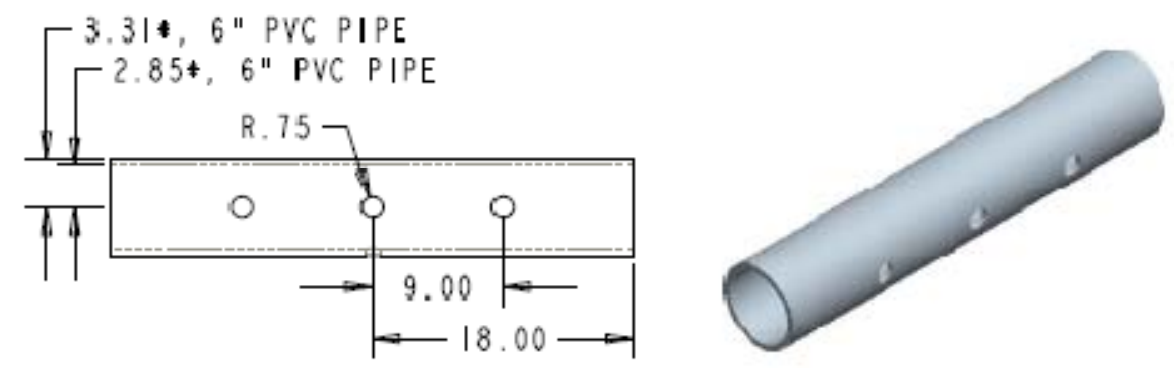

Figure 2.7. Design of the Header 


\subsection{Instrumentation Ports}

\subsubsection{Design of Instrumentation Ports}

Due to the symmetric and asymmetric distribution of the two-phase flow in the vertical and horizontal sections respectively, two different measurement ports are designed. The port is made from a $15.2 \mathrm{~cm}$ diameter acrylic rod with the pipe diameter bored into it. A flat face has been shaved on all the ports to facilitate the flow visualization using high speed imaging device. The flat face reduces the distortion due to the pipe curvature.

\section{Horizontal Instrumentation Port}

In the horizontal pipe sections, buoyancy tends to make the gas phase agglomerate in the upper portion of the pipe, making the phase distribution asymmetric. Hence, in order to obtain the area averaged values, the horizontal port is designed to take measurements at different angles in the vertical plane by traversing the probe. The port is made out of an acrylic rod which is $\mathbf{1 5 . 2}$ $\mathrm{cm}$ long and has an outer diameter of $15.2 \mathrm{~cm}$. A $5.1 \mathrm{~cm}$ hole is bored through the port to match the test section. Two rectangular faces are shaven on the port one of which serves for flow visualization and the other for setting the conductivity probe and the pressure tap. Four 5/8 inch bolt holes run along the length of the main body around its circumference. Figure 2.8 shows the schematic of the main probe body.

The measurement port is connected to the test section on both the sides through an additional mechanism which allows it to be rotated along the axis of the test section. A smaller flange has holes drilled along its circumference at 22.5 degrees which allows us to control the rotation of the horizontal probe port using a spring loaded mechanism. The small flange is connected the main port body using the bolts that run along the body of the measurement port. A 1/8 inch oring, made out of EPDM rubber, is used to seal the flange to the probe body. The EPDM rubber coated o-ring has an advantage of being easy to rotate against the acrylic flange compared to the regular rubber o-ring, while still retaining its compressibility. The regular flange is then connected to the test section. This probe body is bolted along its length between two of these parts using two additional flanges matching the cross-section of the probe body. 


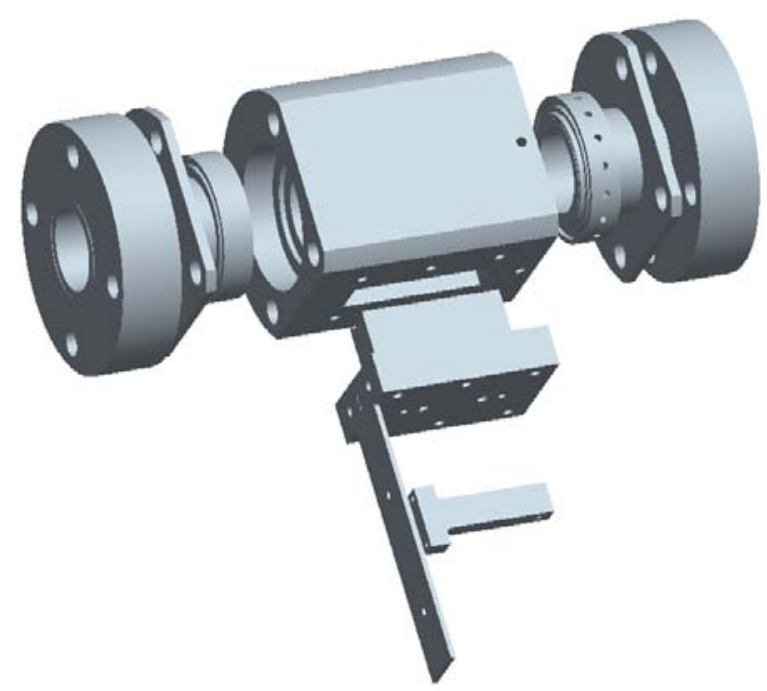

Figure 2.8. General Schematic of Horizontal Instrumentation Port

Vertical Instrumentation Port

The two phase flow distribution in vertical (upward and downward) direction is nearly symmetric and hence allows for measurements in any direction along one radius to obtain area averaged values. This eliminates the need for the measurement port to be rotational. The design of the vertical port as shown in Fig. 2.9 is very similar to the horizontal port except that it does not include the mechanism for rotation.

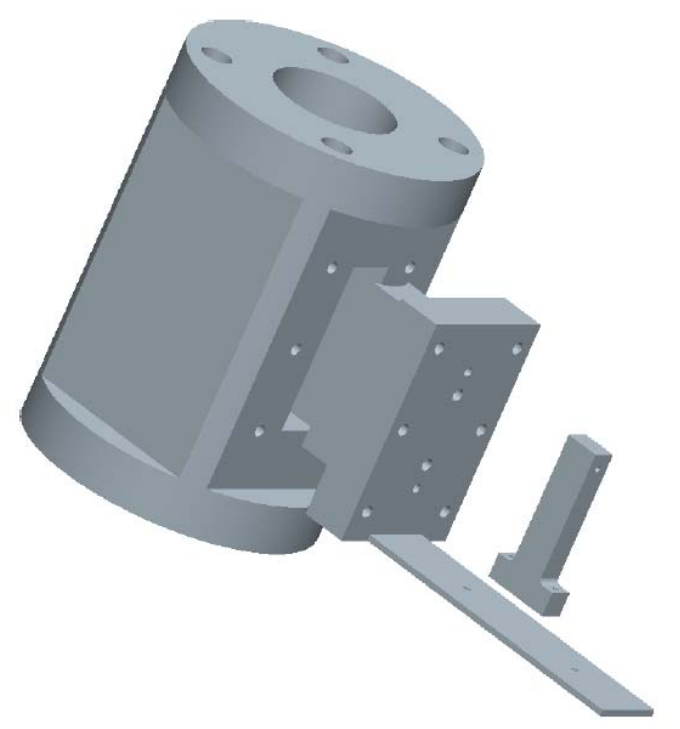

Figure 2.9. General Schematic of Vertical Instrumentation Port 


\subsubsection{Positioning of the Instrumentation Ports}

Horizontal section: There are two horizontal sections (top and bottom). Each section has three horizontal measurement ports. Going clockwise along the test loop, the ports are positioned at 3, 93 and $177 \mathrm{~L} / \mathrm{D}$ along the top section and at 3,87 and 145 L/D along the bottom section from their respective elbows. Moving counterclockwise the positions are 3, 87 and $177 \mathrm{~L} / \mathrm{D}$ along the top and 3,81 and 145 L/D along the bottom section from their respective elbows. The test facility is capable of achieving several other L/D combinations along the horizontal section. The other L/D combinations are: for going clockwise along the test loop, 33, 63, 123 and 147 in the top horizontal section and 33, 57, 105 and 129 in the bottom section; for going counterclockwise, 33, 57, 117 and 147 along the top and 33, 57, 111 and 135 along the bottom section.

Vertical section: There are three vertical sections with each section having three measurement ports. Going clockwise from the leftmost vertical section, the ports are positioned at 6,33 and $60 \mathrm{~L} / \mathrm{D}$ along the first section, at 3,21 and $72 \mathrm{~L} / \mathrm{D}$ along the second vertical section and at 3,27 and 51 L/D along the third vertical section. Moving counterclockwise the positions are 3, 30 and $57 \mathrm{~L} / \mathrm{D}$ along the first, at 3, 54, $72 \mathrm{~L} / \mathrm{D}$ along the second and at 6, 30 and $54 \mathrm{~L} / \mathrm{D}$ along the third vertical section. There are a total of 24 measurement positions possible along the test section.

\subsubsection{Probe Port Plug and Cover Plate}

One of the shaved off faces of the measurement ports is used to install conductivity probe and the pressure tap. Each measurement port has a plug that sets in a rectangular slot. There are two different designs for the plugs. Out of 15 plugs for the measurement ports, 3 are designed to carry both conductivity probe and pressure tap and the rest of them carry just the pressure tap. According to their designs the plugs have 1/8 inch hole for the conductivity probe, 1/16 inch hole for the pressure tap and two 1/4 inch -20 NPT screw taps. Each plug has a corresponding probe body cover plate, which is used to seal this entire assembly. In order to support the conductivity probe, the cover plates for the plugs with conductivity probe are made $2.5 \mathrm{~cm}$ thick while, the rest of them are made $6 \mathrm{~mm}$ thick. Each cover plate is connected to the measurement port using 
six 1/4 inch screws and sealed against the probe port body using 1/8 inch o-ring. Each plug and corresponding cover plate is interchangeable and can be used on any of the measurement ports. Figure 2.10 and 2.11 shows the schematic of the designs for plugs and the corresponding cover plate.
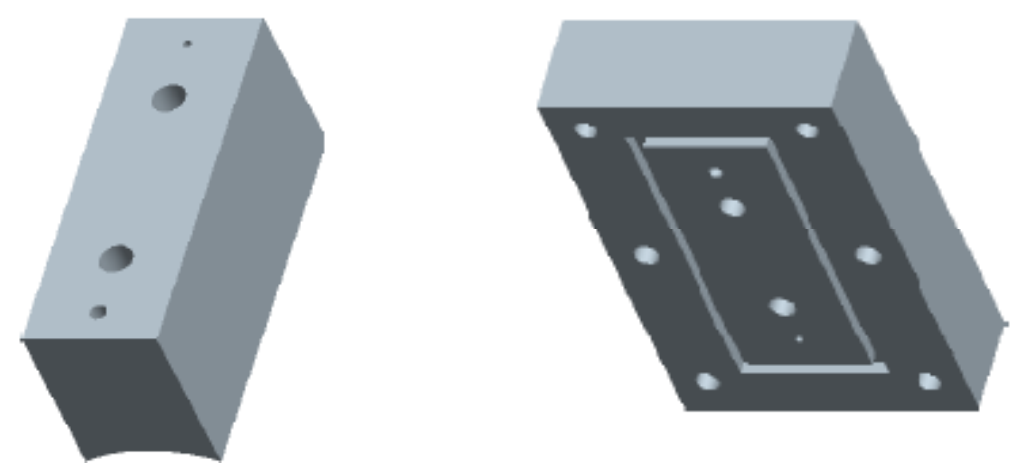

Figure 2.10. Plug and Cover Plate for Port with Conductivity Probe
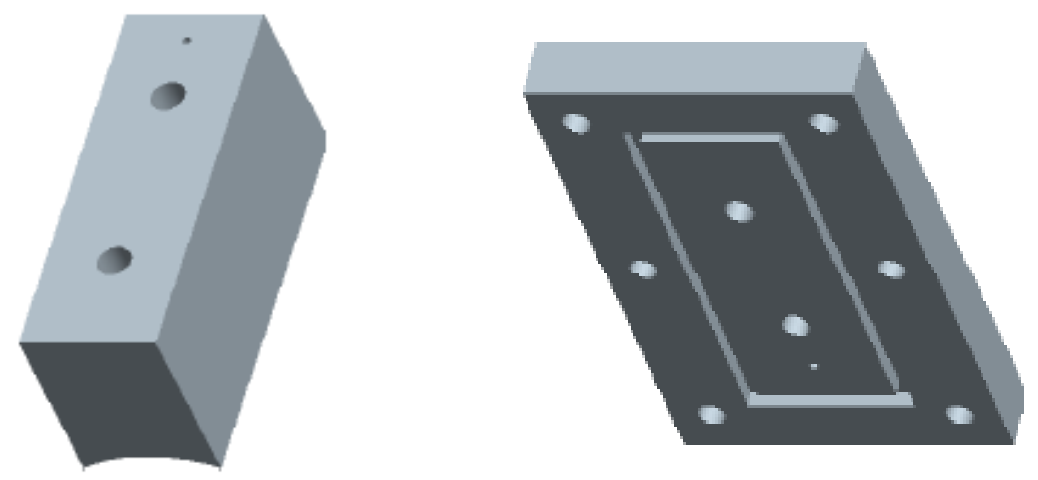

Figure 2.11. Plug and Cover Plate for Port without Conductivity Probe

\subsubsection{Traversing Mechanism}

The traversing mechanism for the conductivity probe consists of a unislide which allows for measurements accurate to $0.01 \mathrm{~mm}$. The unislide used is $15.2 \mathrm{~cm}$ long and $3.8 \mathrm{~cm}$ wide. It ensures that the probe can be traversed all across the test section. An aluminum T shaped mount is used to attach the unislide to the measurement port. The T portion of the mount is screwed to the front of the probe port cover. Another T-shaped part, called the conductivity probe mounting block, is mounted on the unislide. This block is used to support and connect the conductivity probe to the unislide. Figs. 2.12 and 2.13 show the general schematic of these parts. 


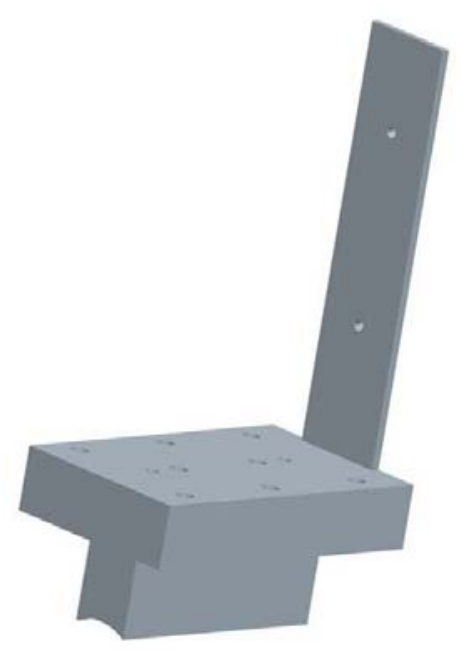

Figure 2.12. Assembly of the Plug, Cover-Plate and Traversing Mechanism
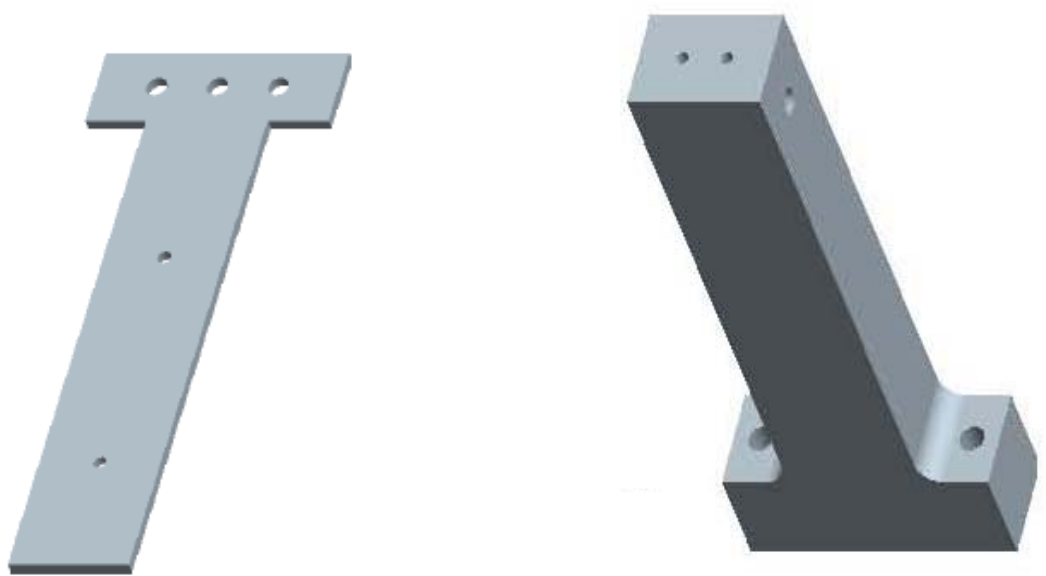

Figure 2.13 Design of Support Plate for Unislide, and Supporting Block for Conductivity Probe respectively

\subsection{The Damper and Separator System}

The separation of the two phases is very important once the flow starts to go back to the accumulator. Otherwise it will lead to cavitation of the pump when it sucks in water mixed with air. So a damper and separator system is used to separate the phases before it flows back to the accumulator. 


\subsubsection{The Damper}

Due to the high inertia of the flow in the test loop, it is desirable to condition the flow for more effective phase separation. The damper is used to slow down the flow and break large gas pockets to finer bubbles before they enter the separator. It is installed at a height of $4.5 \mathrm{~m}$ from the floor level. The water from the test section is directed to the damper through two $7.6 \mathrm{~cm}$ inlet pipes. A $106 \mathrm{~L}$ polyethylene tank, with dimensions of $0.787 \mathrm{~m}$ length, $0.445 \mathrm{~m}$ width and 0.321 $\mathrm{m}$ height, is used as the main body of the damper. This tank has two inlets to prevent the formation of the large eddies towards the corners of the tank as shown in Figure 2.14.

Series of three wire mesh screens of different wire diameter are installed along the length of the damper to effectively break up the large gas bubbles as well as to reduce the inertia of the two phase flow. Table 2.1 summarizes the dimensions of the different screens and other important parameters. Heavy duty aluminum is used for framing these wire mesh screens. The screens are located at $0.127 \mathrm{~m}, 0.406 \mathrm{~m}$ and $0.61 \mathrm{~m}$ respectively from the inlet. These spacing are based on 200 wire diameter ratio, which relates to the decay length after the screen to the wire diameter used in the screen (Sparks and Hoelscher, 1962). The flow is directed through three meshes of three different sizes. The size of the each hole in the successive mesh screen also keeps decreasing in the direction of the flow as it can be seen in the table below. This decrease in size facilitates the breaking of the larger bubbles first, then the smaller bubbles and then the breaking of still smaller bubbles. Finally the flow is directed to the separator through a $15.2 \mathrm{~cm}$ outlet at the bottom of the damper.

Table 2.1: Summary of Mesh Screen Properties

\begin{tabular}{|c|c|c|c|}
\hline Mesh Size & Square Side (cm) & Open Area (\%) & Wire Diameter (cm) \\
\hline $3 \times 3$ & 0.709 & 70.1 & 0.137 \\
\hline $4 \times 4$ & 0.531 & 69.9 & 0.104 \\
\hline $5 \times 5$ & 0.419 & 68.1 & 0.089 \\
\hline
\end{tabular}




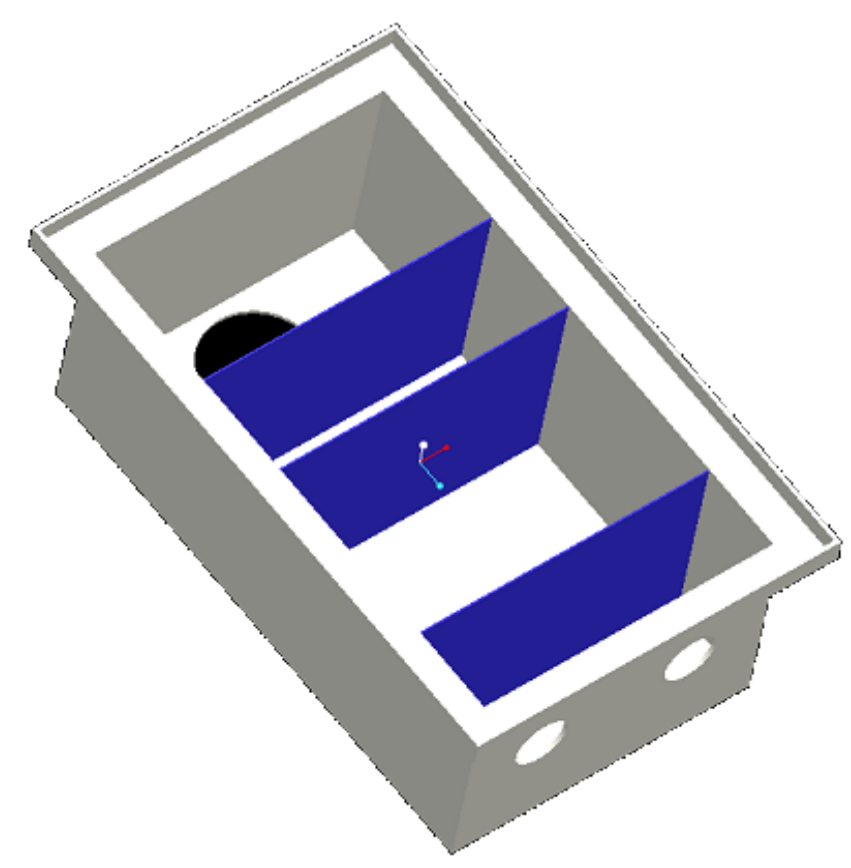

Figure 2.14. General Layout of the Damper

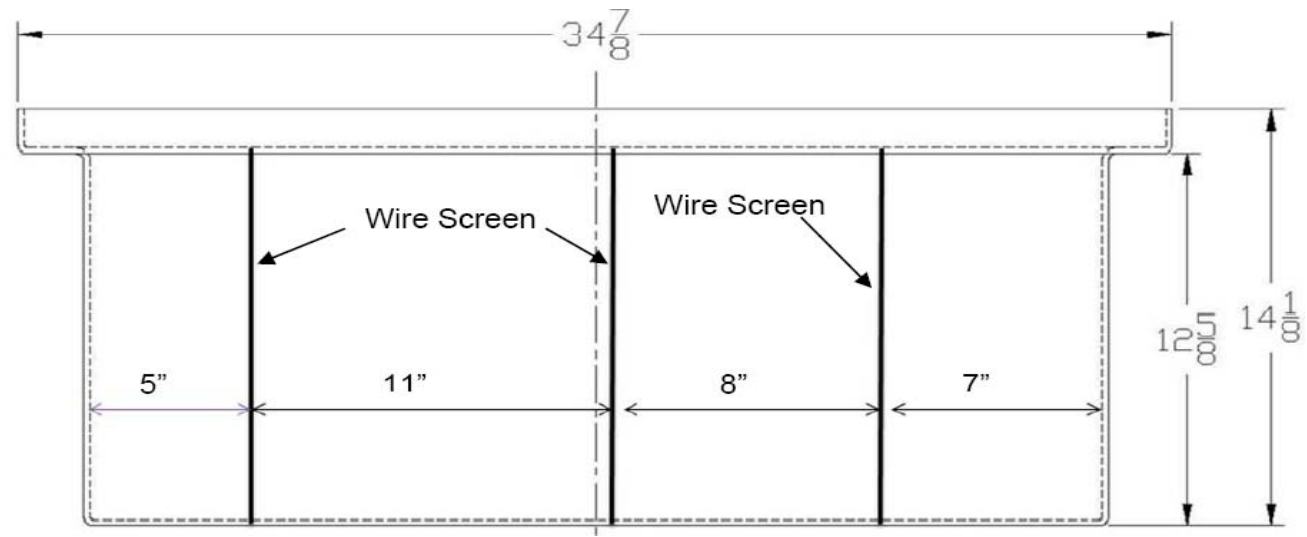

Figure 2.15. Screen Distances in the Damper

\subsubsection{The Separator}

The water from the test section goes back to the main accumulator and is re-circulated back in the test section. It is undesirable to have air mixed with water in the accumulator, since it can cause severe cavitations in the pump. The separator is used effectively to separate the two phases before it enters the main accumulator. A tank similar to the damper is used for its main body. 
Two-phase flow enters the separator through a $15.2 \mathrm{~cm}$ inlet. Two obstruction plates with a series of different sized holes are placed along the length of the separator. The total area of holes in the plates is equal to the cross-sectional area of the inlet. The plates are $22.9 \mathrm{~cm}$ and $15.2 \mathrm{~cm}$ high and cover the entire width of the tank. These plates slow down the flow significantly and help in the separation of the two phases. The flow gets stagnated and the gas starts rising, thus leading to the separation of the phases. A $15.2 \mathrm{~cm}$ diameter and $30.5 \mathrm{~cm}$ long chimney is used to eliminate the mist from the separator. This mist is directed back to the accumulator. Finally water is directed to the main accumulator through a $15.2 \mathrm{~cm}$ outlet at the bottom of the separator. The separator and damper act in combination to separate the two-phase flow and slow down the flow significantly. Figure 2.16 shows the schematic of the separator and the plates.

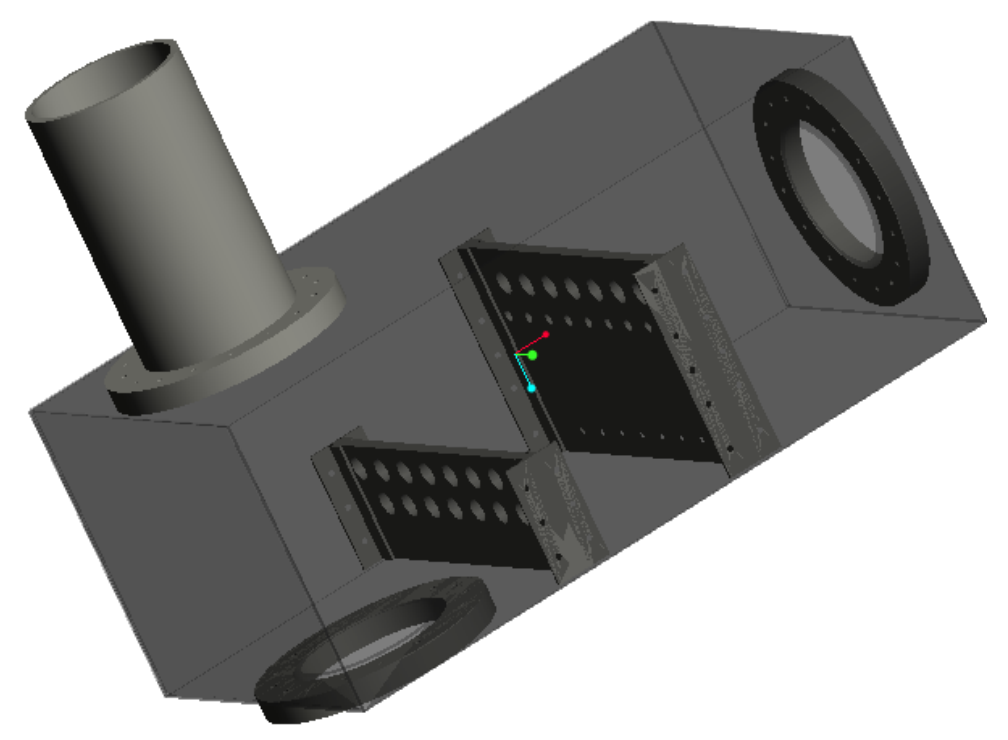

Figure 2.16. Three Dimensional View of the Separator

\subsection{Design Considerations on Basic Components}

The basic components can be mainly subdivided into two sections: the air - water delivery system, the instrumentation system and the data acquisition system. The former comprises of the air compressor, water pump, accumulator, flow meters for both water and air, and magnetic flowmeter while the instrumentation system primarily consists of magnetic flowmeter, pressure transducer, high-speed movie camera and four-sensor conductivity probe. 


\subsubsection{Air - Water Delivery System}

\section{Air Compressor}

Air is supplied to the test loop through a Quincy QGB15V air compressor. It is a $15 \mathrm{HP}$ rotary screw compressor with an inlet capacity of 56.8 ACFM and a full load operating pressure of $689.475 \mathrm{kPa}(100 \mathrm{psi})$. The compressor supplies air to a $1514 \mathrm{~L}$ pressurized air tank, which then passes to another $0.454 \mathrm{~m}^{3}$ pressurized air tank, and finally to the injector through air pipeline. The two air tanks are required to keep the pressure fluctuations as minimal as possible so that the flow rate remains constant. The air compressor is fitted with a dryer and two filters the pre filter and the post filter. The pre and post filters are to remove any oil or small particles from the air. The dryer removes any humidity in the air.

\section{Water Pump}

A minimum liquid flow rate of $5 \mathrm{~m} / \mathrm{s}$ through a $5.1 \mathrm{~cm}$ inner diameter pipe is required to create bubbly flow regime (Taitel and Duckler, 1976) Based on the above criteria the pump is chosen to provide a flow rate of at least $7 \mathrm{~m} / \mathrm{s}$. The net head for the test section at this flow condition is calculated to be $27 \mathrm{~m}$ of water. To be conservative in accounting for the various flow restrictions in the piping system and the other components such as headers, injectors, separator and damper, the net head for the whole system is doubled to be $54 \mathrm{~m}$ of water.

A 60 HP Dean Model PH-2140 pump with $0.215 \mathrm{~m}$ impeller is used for this test facility in order to generate $7 \mathrm{~m} / \mathrm{s}$ in a possible $0.102 \mathrm{~m}$ pipe in the future. For the current $5.1 \mathrm{~cm}$ configuration it is capable of producing a maximum of $24.7 \mathrm{~m} / \mathrm{s}$ liquid flow rate through the test section. The pump is run by a variable frequency drive, which allows for the flow rate to be varied. The Net Positive Suction Head (NPSH) for the pump is $12.1 \mathrm{~m}$, which is greater than the required NPSH of $9.14 \mathrm{~m}$, the pump is capable of operating successfully without any cavitations.

\section{Accumulator Design}

In order to provide enough inlet pressure for the pump to prevent cavitation, the accumulator is designed to remain two-thirds full when the test facility is in operation. Approximately 231.9 
$\mathrm{L}$, of water is required to completely fill the test facility (this includes the test loop and the major components only). A water tank (or the accumulator) with a capacity of $2270 \mathrm{~L}$ is chosen for the facility keeping the above design criteria in consideration. The tank, which is $1.219 \mathrm{~m}$ in diameter and $2.4384 \mathrm{~m}$ in height, maintains a positive pressure of $12.1 \mathrm{~m}$ on the pump, to prevent cavitation, and provides a large buffer for the flow.

\section{Structural Support for the Accumulator}

The support structure is designed to carry the weight of the fully filled water tank with $6 \mathrm{~mm}$ maximum deflection in the supporting beams. The minimum requirement for the structure is to carry that load with a factor of safety of 2. Figure 2.17 shows the general schematic of the support structure for the water tank. The base of the structure is entirely made out of double channel strut beams. The dimensions of the base of the structure are $1.219 \mathrm{~m}$ by $1.219 \mathrm{~m}$ by $1.219 \mathrm{~m}$. The water tank sits on a $1.905 \mathrm{~cm}$ thick plywood platform so that it does not bulge down in between the beams.

A caged structure made out of single channel strut beams, surrounds the tank above the platform from all the sides. This structure is made $3 / 4^{\text {th }}$ the height of the tank to prevent the tipping of the water tank due to high inertia of the liquid flowing in. The designed structure has a factor of safety of 32 for the compressive load and 2.7 for the shear stress. Due to the significant weight of the water tank, the level of the beams is to with 0.1 degree of horizontal to prevent any tipping.
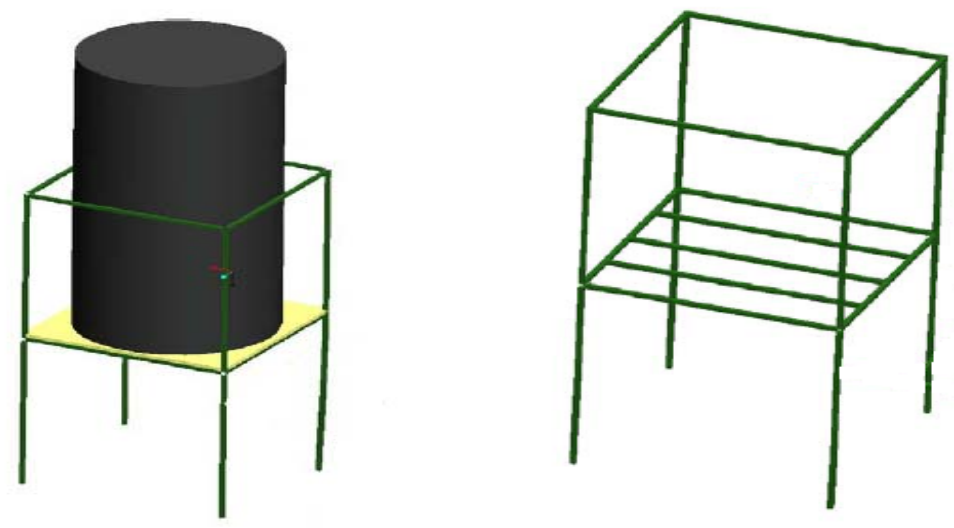

Figure 2.17. General Schematic of Accumulator Support Structure 


\section{Flow Meters}

The test facility employs both rotameters and electromagnetic flow meter for water flow measurements. The magnetic flow meter is employed only for flow rates greater than $1 \mathrm{~m} / \mathrm{s}$ because of their low sensitivity for smaller flow rates. For flow rate measurement less than $1 \mathrm{~m} / \mathrm{s}$ which in test facility comes out to be $4.543 \times 10^{-3} \mathrm{~m}^{3} / \mathrm{sec}(1 \mathrm{~m} / \mathrm{s}$ flowing through a pipe with inner diameter $7.6 \mathrm{~cm}$ ), a combination of rotameters (four $1300 \mathrm{~cm}^{3} / \mathrm{sec}$ rotameters, two $600 \mathrm{~cm}^{3} / \mathrm{sec}$ rotameters and one $300 \mathrm{~cm}^{3} / \mathrm{sec}$ rotameter is employed. The magnetic flow meter is capable of measurements up to $0.05 \mathrm{~m}^{3} / \mathrm{sec}$ with an accuracy of $0.5 \%$ of the flow rate as well as $0.5 \%$ of the velocity of setting range. Similarly for the air flow measurements, specific rotameters are employed. A combination of three rotameters with range of 60 to $600 \mathrm{scfh}$, two rotameters with range of 40 to $500 \mathrm{scfh}$, and rotameters with range of 20 to $200 \mathrm{scfh}, 10$ to $100 \mathrm{scfh}$ and 0.5 to 5 scfh each, are employed to achieve a minimum flow rate of $0.5 \mathrm{scfh}$ and a maximum flow rate of $3105 \mathrm{scfh}$ in the test loop.

\section{Water Filtration System}

Prior to filling the accumulator with water, a filtration system is employed to ensure that the quality of the water in the experimental is high. The water is filtered by a charcoal filter followed by two mixed resin bed filters before entering the water tank. The charcoal filter removes the dust or the dirt particles while the resin filters removes the ions from the water. The water is then again filtered after running through the pump before being separated and entering either a magnetic flow meter or the water rotameters. This filter in the pipeline is to remove any dirt or dust that enters the system after the initial filtration.

\subsection{Instrumentation}

\subsubsection{Pressure Transducer}

For pressure measurement a Yamatake ST300 series differential pressure transducer is available. For differential pressure measurement this transducer has an accuracy of $0.5 \%$ between $0.75 \mathrm{kPa}$ and $5 \mathrm{kPa}$ and an accuracy of $0.1 \%$ between $5 \mathrm{kPa}$ and $50 \mathrm{kPa}$. The pressure 
transducer is also capable of measuring local gauge pressure. The pressure transducer converts pressure into an electrical output. The benefit of a pressure transducer is quickly recognized in that the measurement no longer depends on an objective measurer but on an electrical signal generated by the device. One type of typical pressure transducer has a diaphragm inside the device that has strain gages attached to it.

Consider an open cavity separated into two volumes by a diaphragm, as shown in Figure 2.18. The device allows the pressure from one port to enter on one side of the diaphragm and the pressure from the other port to enter on the opposite side of the diaphragm. When pressure is applied to the diaphragm, deflection may occur. The deflection of the diaphragm is interpreted by the strain gages attached to its surface and these gages then in turn provide an electrical output based on the deflection of the diaphragm.

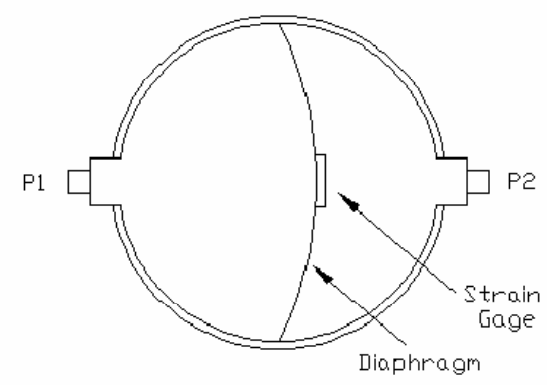

Figure 2.18. Strain gage type pressure transducer

If $\mathrm{P}_{1}=\mathrm{P}_{2}$, there is no deflection, because the force on each side of the diaphragm is balanced. However, if the forces on each side of the diaphragm are not balanced, then a differential pressure reading, $\mathrm{P}_{2}-\mathrm{P}_{1}$ will be output. When one of the pressures is atmospheric (when one end is open to atmosphere), the local gauge pressure at the point, where the other end is located, is obtained.

\subsubsection{High Speed Imaging Camera}

In order to carry out flow visualization analysis, the Photron 512 PCI FASTCAM is used. It has full resolution with 512 x 512-pixels, operation to 2000 frames per second (fps) and reduced 
resolution up to $32000 \mathrm{fps}$. The camera sets on a mount and the mount is attached to a railing system that follows the path of the test section to allow for flow visualization at any position in the test section. The camera can be slid up and down for the vertical and from side to side in the horizontal railings respectively.

\subsubsection{Four Sensor Conductivity Probe}

A four sensor conductivity probe is used to acquire the time-averaged local two-phase flow parameters of the bubbles. It can acquire the following parameters - void fraction, interfacial area concentration, bubble frequency and bubble velocity. This probe has wide applications, which also includes acquiring data even when the size of the bubbles become larger and they are no longer spherical in shape. A T-shaped mounting block is used to support and connect the probe to the unislide. The unislide ensures that the probe can be traversed all across the test section. Figure 2.19 shows the details of the four sensor conductivity probe.

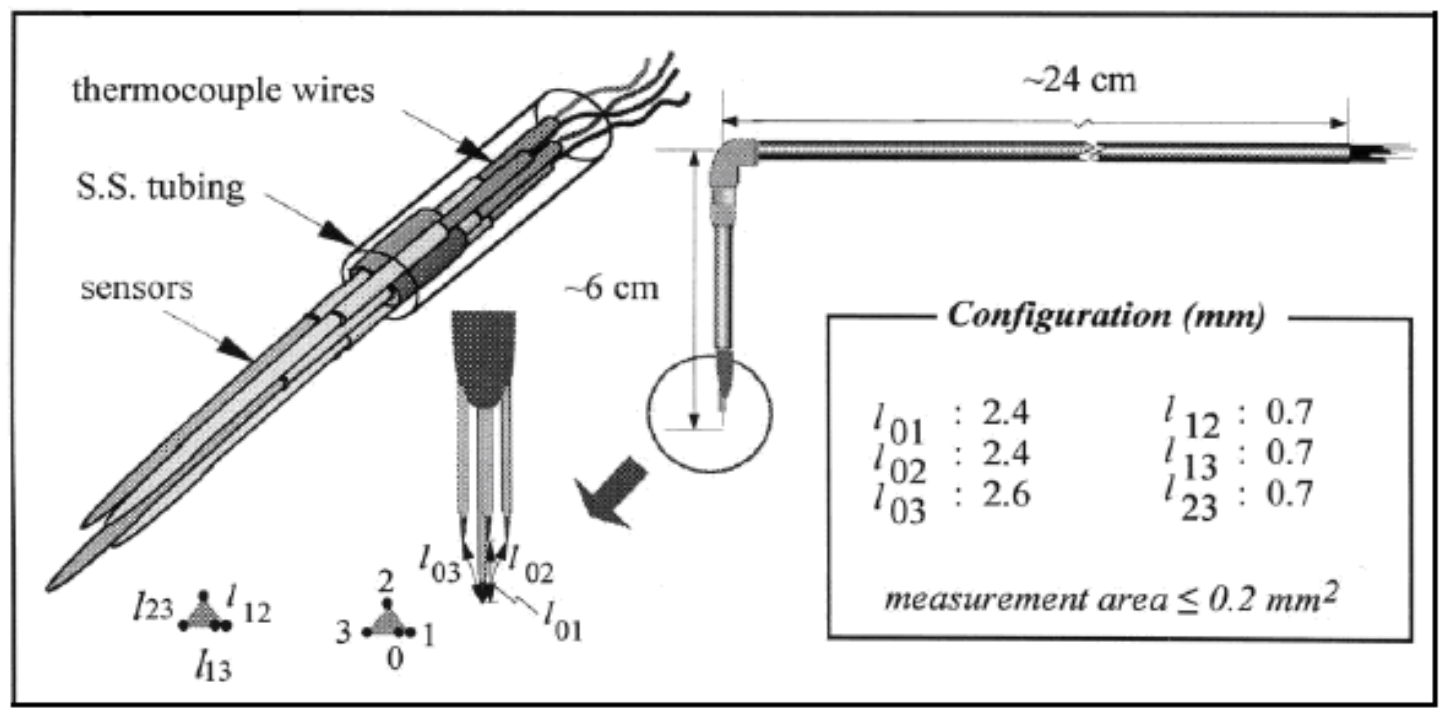

Figure 2.19. Four sensor conductivity probe

\subsubsection{Data Acquisition System}

The data acquisition system consists of the National Instruments card- PCI 6259 which is included in the shielded SCB-68 box. The PCI 6259 is a high speed multifunction M series data 
acquisition (DAQ) board optimized for superior accuracy at fast sampling rates. It has 32 analog 16-bit inputs with sample rate of 1.25 million samples per second (MS/s) for single channel and $1 \mathrm{MS} / \mathrm{s}$ for multichannel inputs.

The SCB-68 is a noise rejecting shielded I/O connector block for use with 68-pin M Series DAQ devices. Figure 2.20 shows the block which shields the DAQ board.

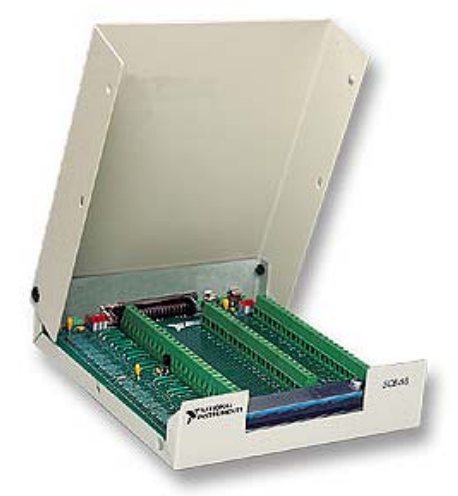

Figure 2.20. Data Acquisition System 


\section{EXPERIMENTAL STUDIES}

\subsection{Experimental Facility}

The experimental facility consists of both vertical-horizontal test sections made out of 50.8 $\mathrm{mm}$ inner diameter acrylic pipes connected by 90 -degree vertical glass elbows. A schematic of the test facility is shown in Fig. 3.1. The lengths of vertical and horizontal sections are $3.35 \mathrm{~m}$ and $9.45 \mathrm{~m}$, yielding development lengths of 66 and 186 diameters, respectively. A laser level system and a digital level are used to ensure the alignment of both vertical and horizontal test sections. The facility is designed such that all the conceivable vertical-to-horizontal and horizontal-to-vertical flow configurations can be achieved by simple manipulation of valves to change the flow direction. As such vertical-upward or vertical-downward two-phase flow can be introduced via injection system A or injection system B in Fig. 3.1, respectively. In the present study, injection A is utilized to provide vertical-upward two-phase flow conditions at the inlet, and injector B serves as an exit. Additionally, the two-phase injector system is designed such that the bubbles at the inlet remain approximately constant at all flow conditions.

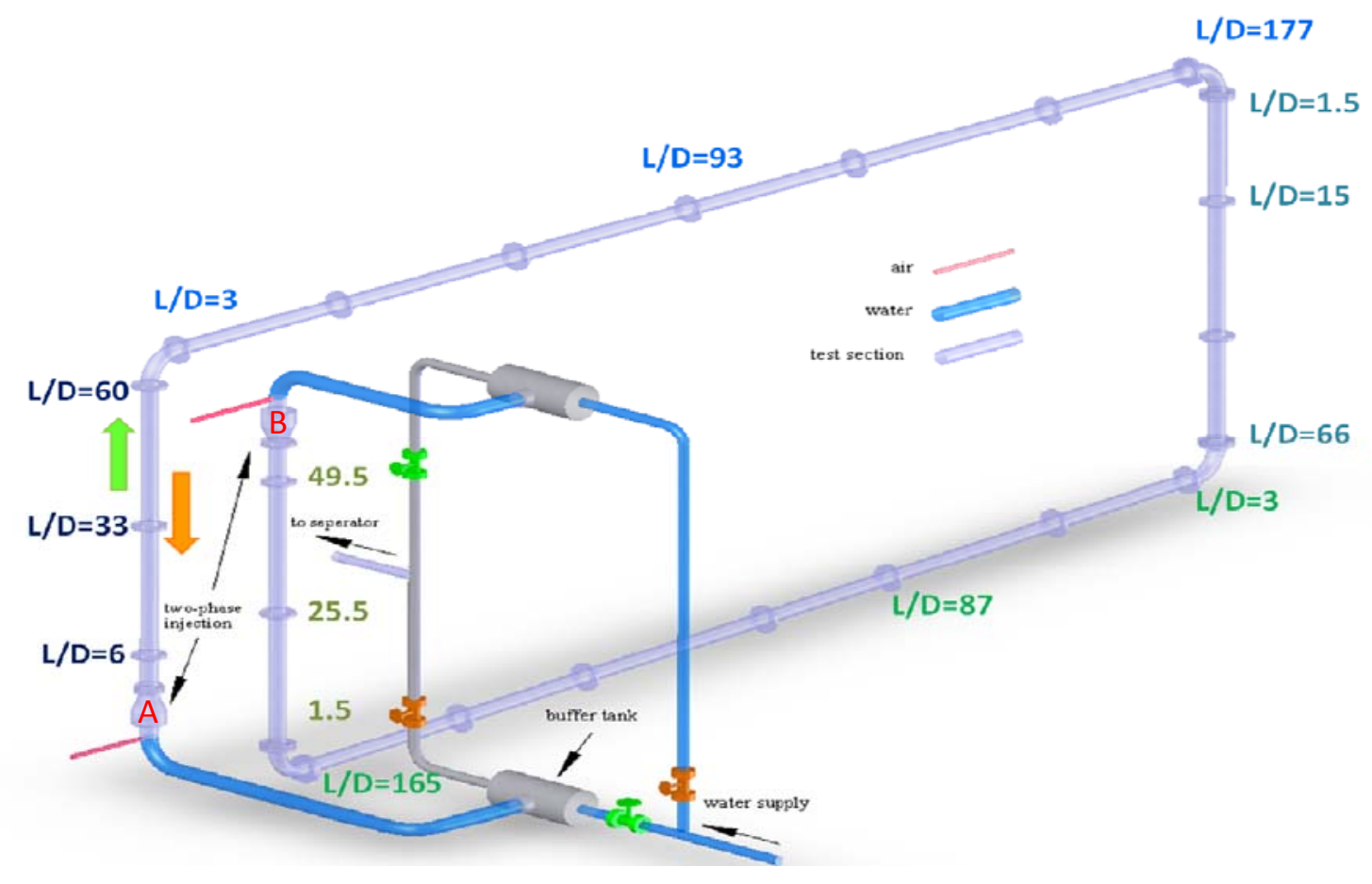

Figure 3.1 Simplified schematic diagram of combinatorial two-phase flow facility 
Filtered and de-ionized water is supplied to the test section from a 600 gallon accumulator tank by a $60 \mathrm{HP}$ centrifugal pump. An air compressor supplies dry air at a pressure of 80 psig to an air accumulator. The use of a two stage system is employed to damp any pressure fluctuations as air to being supplied to the two-phase injection units. Rotameters and a magnetic flowmeter measure the water flow rate with a set of air-rotameters to control the air flow rate. The magnetic flow meter has an accuracy of $\pm 0.5 \%$ of the flow rate while the water and air rotameters have an accuracy of $\pm 2 \%$ and $\pm 3 \%$ of the full scale reading, respectively. At the exit of the loop, before water returns to the accumulator, a two-stage damper-separator system is installed to reduce the inertia of the flow and to break up any large gas pockets.

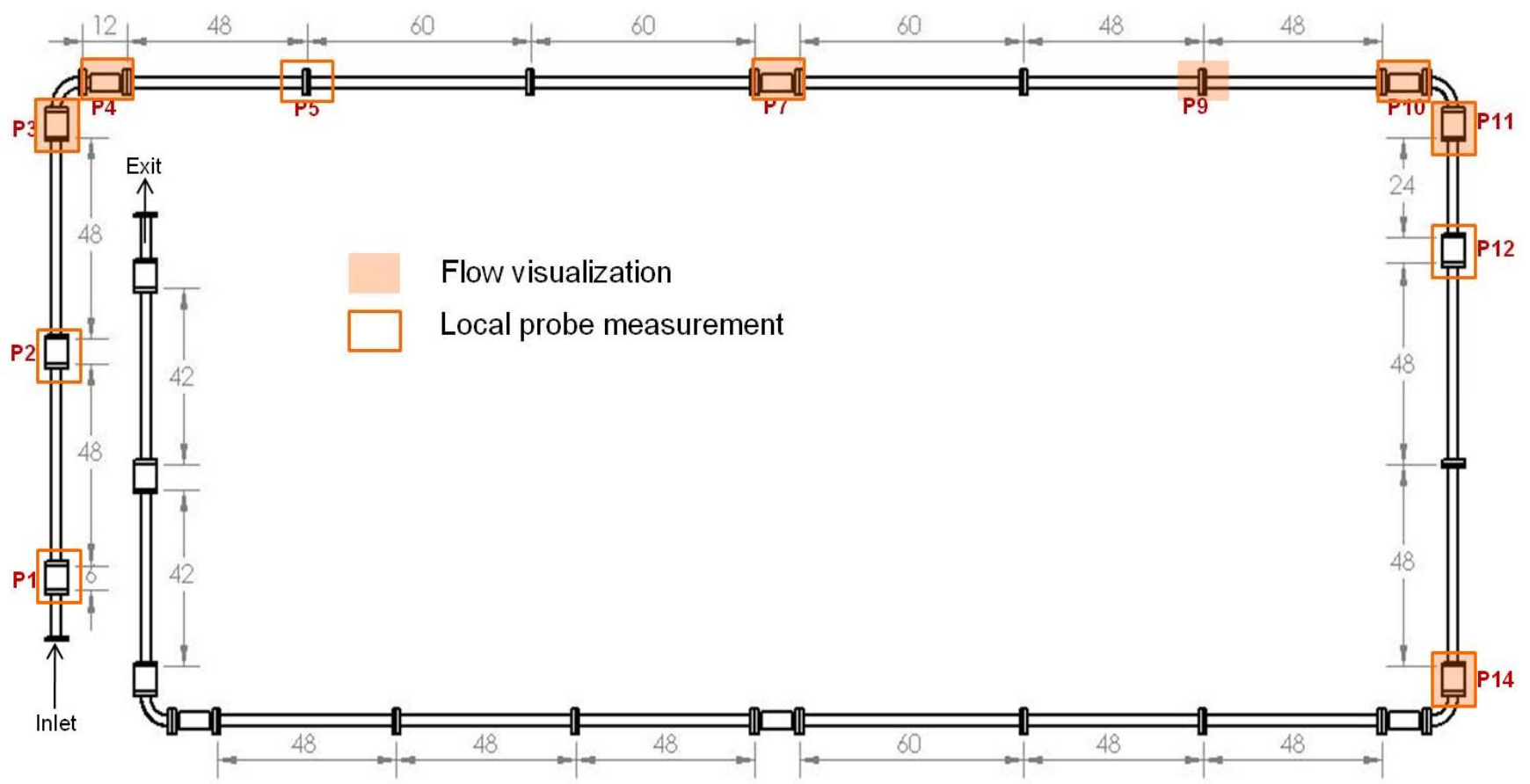

Figure 3.2 Simplified schematic diagram of combinatorial two-phase flow facility showing measurement locations

Along the test section 24 measurement locations with a total of 15 moveable measurement ports are available as shown in Fig. 3.2. These measurement ports are designed to facilitate pressure measurement, local conductivity probes, optical and flow visualization instrumentation. Each measurement port is made from a solid acrylic rod with part of the outer surface machined flat to minimize optical distortion and provide an ideal condition for both flow visualization and 
the optical instrumentation application. A photographic image of the instrumentation port with a four-sensor conductivity probe installed is shown in Fig. 3.3. The traversing unit shown in the figure is used to accurately position the conductivity probe at different local positions in the pipe cross-section.

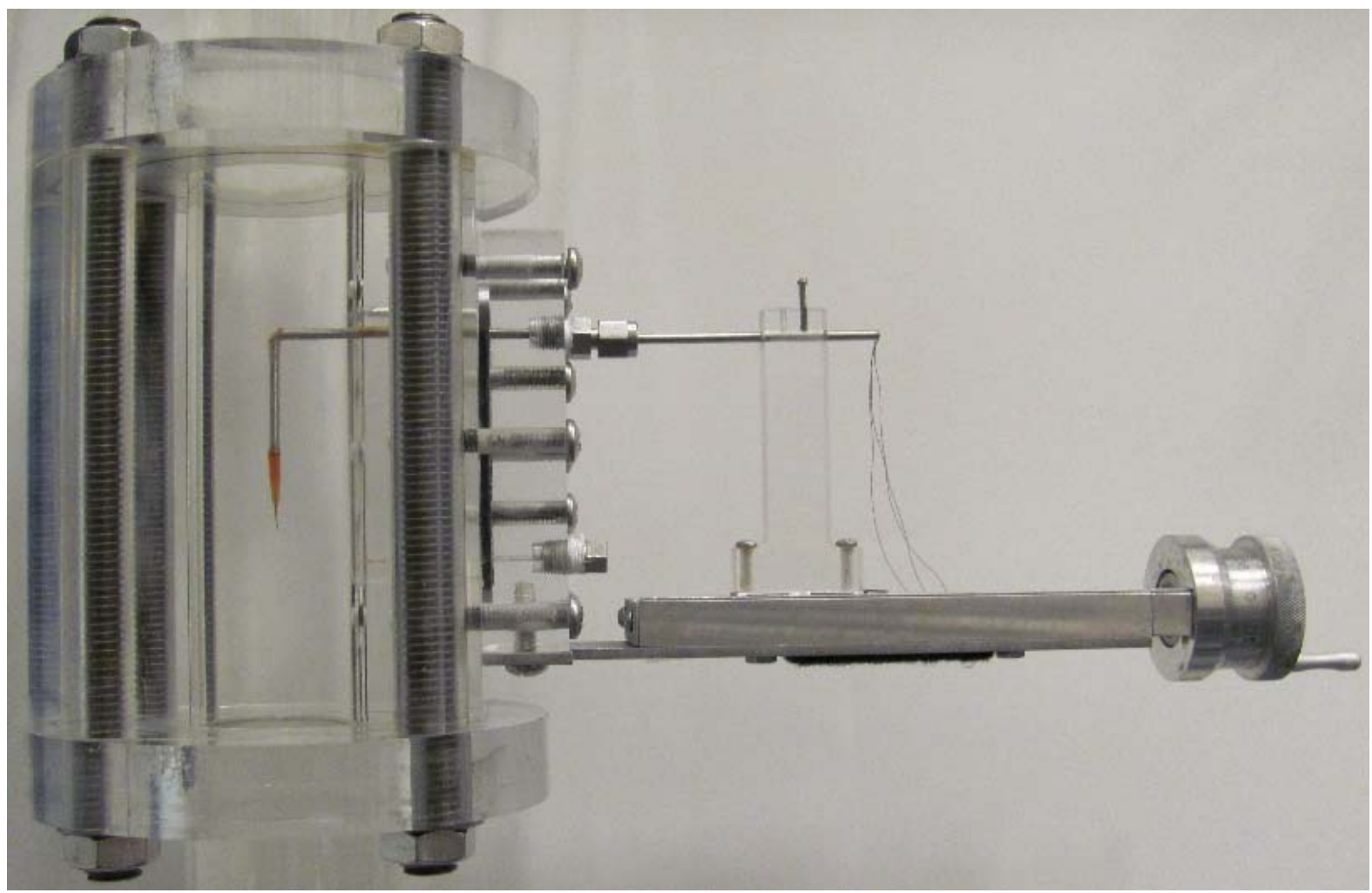

Figure 3.3 Photographic image of the measurement port used in vertical sections along with the conductivity probe installed

\subsection{Test Conditions}

A total of six different flow conditions as shown in Table-3.1 are chosen to obtain local twophase flow parameters. The flow conditions are selected to be within or near bubbly flow regime in the vertical upward section and horizontal section. The test conditions are chosen within bubbly flow regime because it is relatively simple to develop an interfacial area transport equation for bubbly flows and hence serves as effective preliminary studies. It should be noted, that the vertical elbow has a significant effect on the flow regime transition and hence conventional flow regime transition boundaries cannot be applied. As such the flow regime at 
each measurement location is based on the modified flow regime maps based on extensive flow visualization study.

Table 3.1 Six different test conditions used to obtain local two-phase flow parameters

\begin{tabular}{|c|c|c|}
\hline Flow Condition & $j_{f}[\mathrm{~m} / \mathrm{s}]$ & $j_{g, a t m}[\mathrm{~m} / \mathrm{s}]$ \\
\hline Run1 & 2.0 & 0.14 \\
\hline Run2 & 2.0 & 0.23 \\
\hline Run3 & 2.0 & 0.34 \\
\hline Run4 & 3.0 & 0.14 \\
\hline Run5 & 3.0 & 0.23 \\
\hline Run6 & 3.0 & 0.35 \\
\hline
\end{tabular}

To benchmark the probe measurements the local superficial gas velocity at each port, calculated from the flow meter and local gage pressure measurements, are compared with that measured by the probe via:

$$
\left\langle j_{g}\right\rangle_{l o c}=\left\langle\alpha v_{g}\right\rangle_{l o c}
$$

The statistical error associated with the measurement using a double-sensor conductivity probe is approximately $\pm 7 \%$ (Wu and Ishii, 1999). The error may arise from various factors such as bubble lateral motion, bubble velocity fluctuations, probe spacing and intrusiveness of the probe. A detailed analysis on the errors due to the probe can be found in studies by $\mathrm{Wu}$ and Ishii (1999). The result is shown in Fig. 2, and they are in relatively good agreement with each other within $\pm 10 \%$ difference. The combined error of $\pm 10 \%$ is due to measurement errors in the flowmeters, and the pressure transducer, and statistical error in the probe. It should be noted that many conditions have a higher percentage of disagreement. This is because the above benchmarking is accurate only for bubbly flows. Many flow conditions which are within bubbly flow regime in the vertical upward section changes to plug or slug flow in the horizontal section 
and vertical downward section. Under such conditions the error in the pressure measurement increases significantly which causes an error in prediction of local superficial gas velocity.

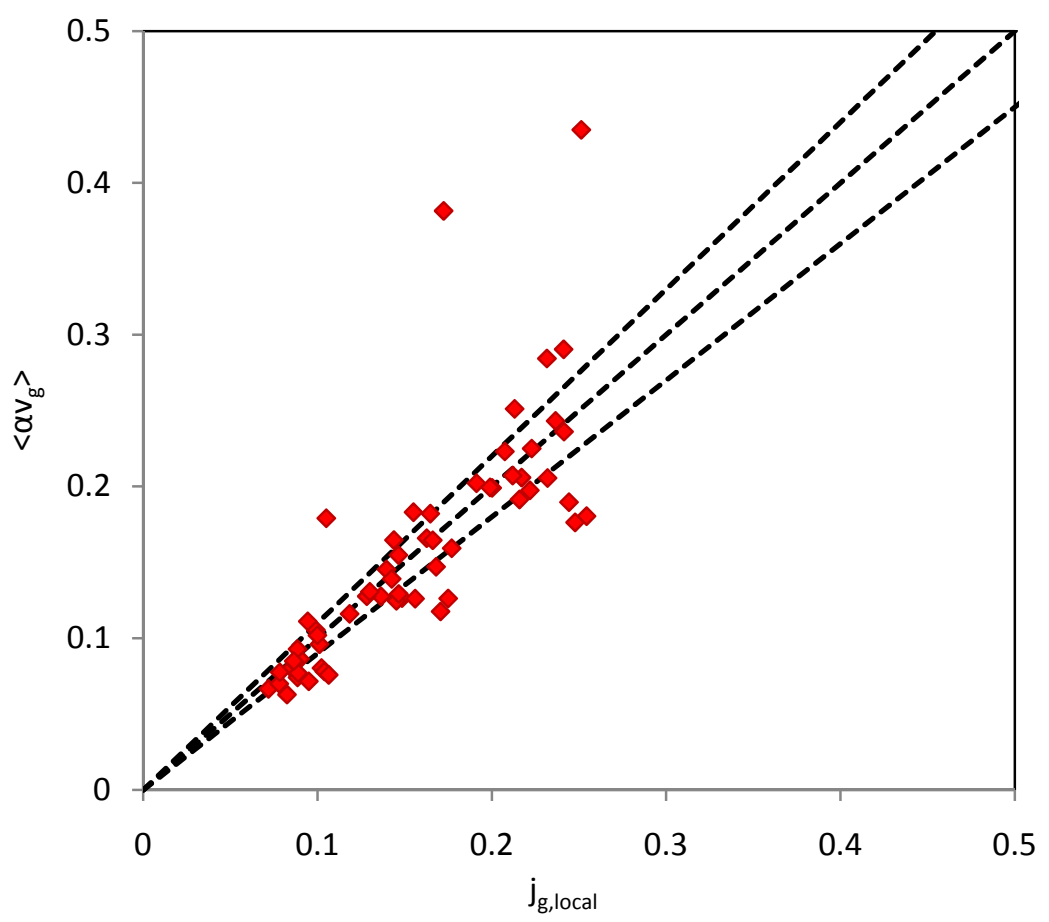

Figure 3.4 Comparison of local superficial gas velocity, $\mathrm{j}_{\mathrm{g}, \text { loc }}$ measured by the flow meter with $\left\langle\alpha \mathrm{v}_{\mathrm{g}}\right\rangle$ acquired by the conductivity probe, dotted lines represent $\pm 10 \%$ (the conditions with highest deviation belong to Runs 1, 2 and 3 at P11)

\subsection{Pressure Drop}

In order to characterize the frictional and minor losses along the test section, pressure measurements are obtained in both single-phase and two-phase flow conditions. A differential pressure transducer with an accuracy of $\pm 1 \%$ of the reading is used to measure pressure along the test section.

\subsubsection{Single-phase Pressure Drop}

Differential pressure is measured for four single-phase liquid flow conditions at nine axial locations along the test section. The measurement locations in the vertical upward section include ports P1, P2 and P3 located 6D, 33D and 60D downstream of the inlet respectively. In 
the horizontal section the measurements are obtained at ports P4, P7 and P10 located 3D, 93D and 177D downstream of the vertical upward elbow respectively. In the vertical downward section measurement locations include ports P11, P12 and P14 located 3D, 16D and 66D downstream of the vertical downward elbow. Port P1, located 6D downstream of the inlet is chosen as reference. Hence, the local gauge pressure at all other port locations is obtained by:

$$
P_{i}=P_{1}-\rho g h-\Delta P_{1 i}
$$

Where, ' $P_{i}$ ' represents the local gauge pressure at the $i^{\text {th }}$ port location and ' $1 i$ ' represents the differential pressure between port $\mathrm{P} 1$ and the $i^{\text {th }}$ port. Here, the term $\Delta P_{1 i}$ is measured by the differential pressure transducer. The differential pressure between two measurement locations can be represented as summation of frictional, minor and acceleration pressure drop. The pressure drop due to acceleration is very small and can be neglected. Hence, the theoretical expression for $\Delta P_{1 i}$ is given by eq. 3 .

$$
\Delta P_{1 i}=f\left(\frac{L}{D}\right) \frac{\rho v^{2}}{2}+\left(\sum k \frac{\rho v^{2}}{2}\right)
$$

Where $f$, $(L / D), \rho, v$, and $k$ denote the friction factor, development length, fluid density, fluid velocity and minor loss factor, respectively. In eq. 3 the first term on the right hand side represents the frictional pressure drop and the second term represents the minor loss. The term due to minor loss is accounts for the vertical elbows along the test sections. The friction factor, $f$ is obtained from the conventional Blasius correlation for turbulent flows (Blasius, 1913):

$$
f=0.316 R e_{d}^{-1 / 4} \quad 4000<R e_{d}<10^{5}
$$

The minor loss term in Eq. 3 is included only when the loss due to the vertical elbow needs to be taken into account. The minor loss factor, $k$, for a $90^{\circ}$ bend with single-phase water flow can be obtained from Ito (1960) as:

$$
k \approx 0.388 \alpha\left(\frac{R}{d}\right)^{0.84} R e_{d}^{-0.17}
$$

Where,

$$
\alpha=0.95+4.42\left(\frac{R}{d}\right)^{-1.96} \geq 1
$$

The single-phase water pressure drop across the 90-degree vertical elbows for the vertical-tohorizontal-to-vertical section is shown in Fig. 3.5. The experimental pressure drop data is 
compared with the theoretical pressure drop. It is found that the experimental data agree well with the theoretical predictions within $\pm 5 \%$ difference. Moreover, Fig. 3.6 shows the frictional and minor losses for the same flow conditions. The frictional pressure loss increases along the axial flow direction. The pressure drop across the vertical elbows is characterized by a steep change in pressure gradient which is caused by the minor loss across the elbows.

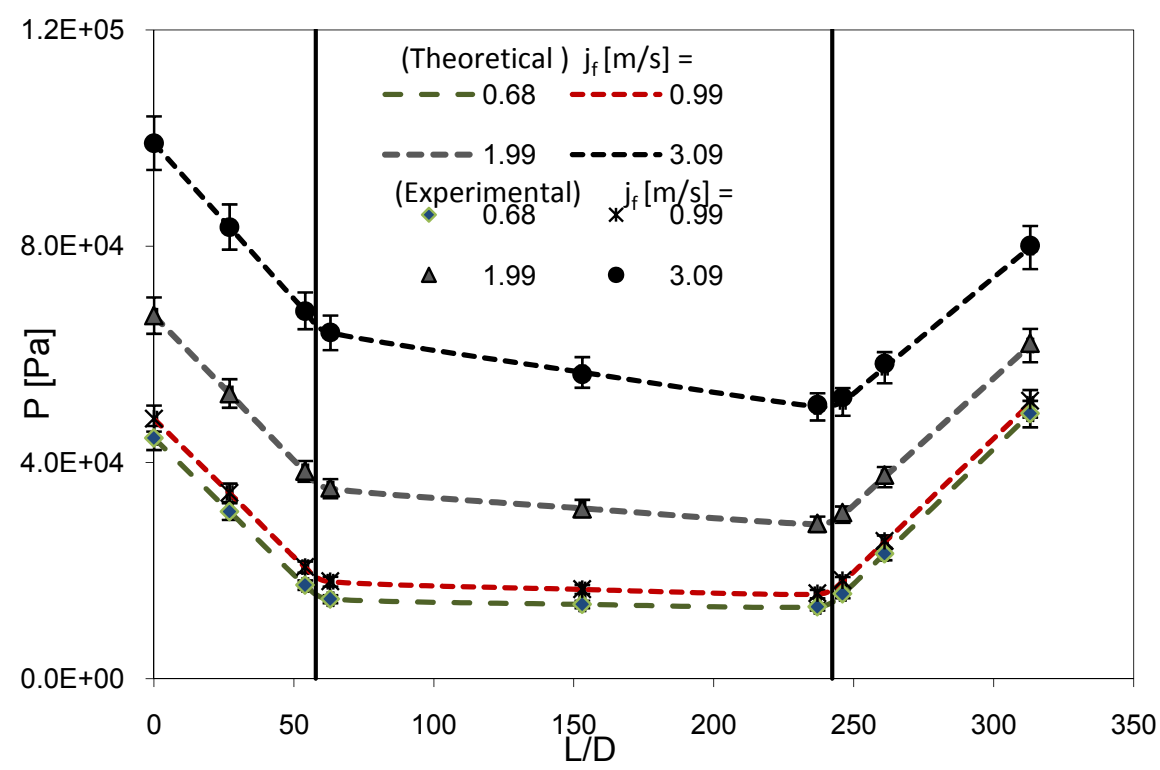

Figure 3.5 Comparison of single-phase liquid pressure measured by the pressure transducer and theoretical predictions

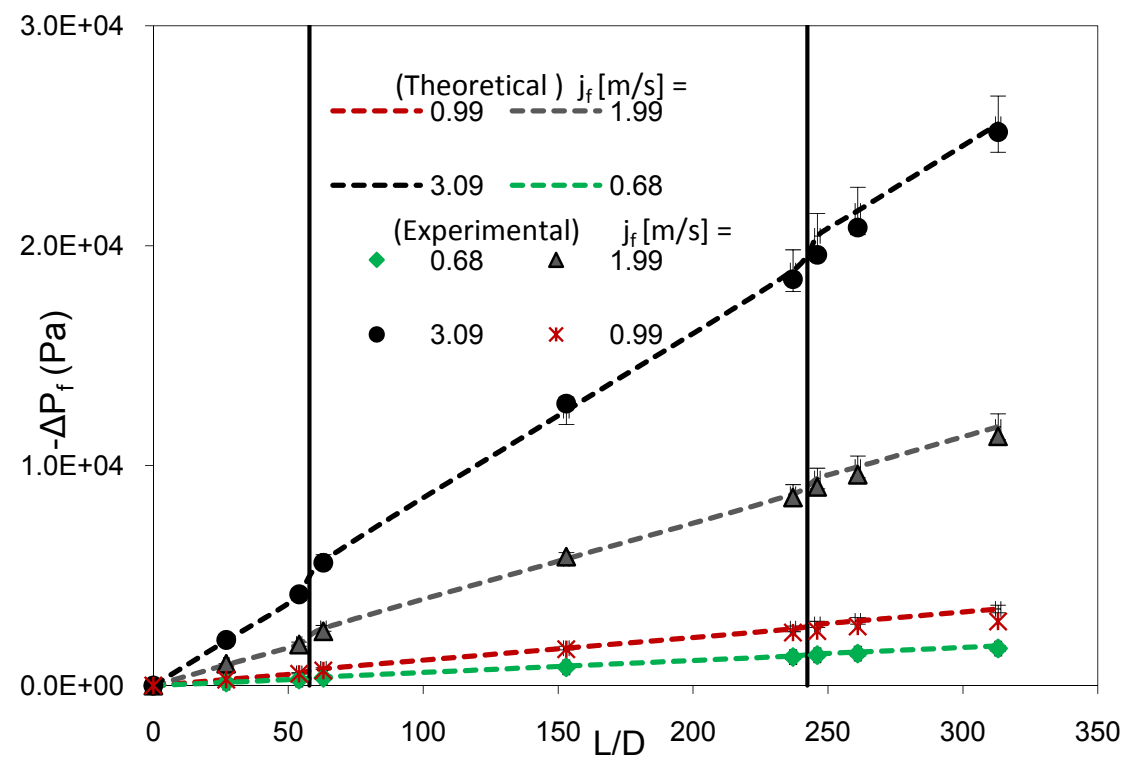

Figure 3.6 Single-phase liquid frictional pressure drop along combinatorial channels 


\subsubsection{Two-phase Pressure Drop}

Two-phase pressure drop is measured at ten axial locations along the test section for six different flow conditions. The measurement locations correspond to ports P1, P2 and P3 located $6 \mathrm{D}, 33 \mathrm{D}$ and $60 \mathrm{D}$ downstream of the inlet in the vertical upward section. In the horizontal section the measurement locations correspond to ports P4, P5, P7 and P10 located 3D, 30D, 90D and 177D respectively, downstream of the vertical upward elbow. Measurement locations in the vertical downward section correspond to ports P11, P12 and P14 located 2.5D, 18D and 60D respectively, downstream of the vertical downward elbow.

Figure 3.7 and 3.8 shows the plot of local gauge pressure along the axial direction of the test section for flow conditions with constant liquid flow rates of $2.0 \mathrm{~m} / \mathrm{s}$ and $3.0 \mathrm{~m} / \mathrm{s}$, respectively. In each figure the vertical lines represent the elbow location and hence subdivide the plot into vertical upward, horizontal and vertical downward section, respectively in the direction of increasing development length. In the vertical upward section, the pressure drops because of the frictional pressure drop and hydrostatic head loss. The steep pressure gradient observed in this section is due to the two-phase mixture hydrostatic head loss. The pressure drop between port P3 and P4 denotes the loss across the vertical-upward elbow and has contributions from minor loss, hydrostatic head and frictional pressure drop. Compared to the vertical upward section and elbow region, the pressure gradient along the horizontal section is small because the pressure drop occurs only due to frictional loss. Similar to the vertical-upward elbow, the pressure drop across the vertical-downward elbow has contributions from minor loss, frictional loss and hydrostatic head. However, there is a gain in the pressure due to hydrostatic head and hence the net effect is an increase in the local gauge pressure. Similarly, in the vertical downward section, the contributions arise from frictional pressure loss and hydrostatic head gain leading to an increase in the overall gauge pressure. 


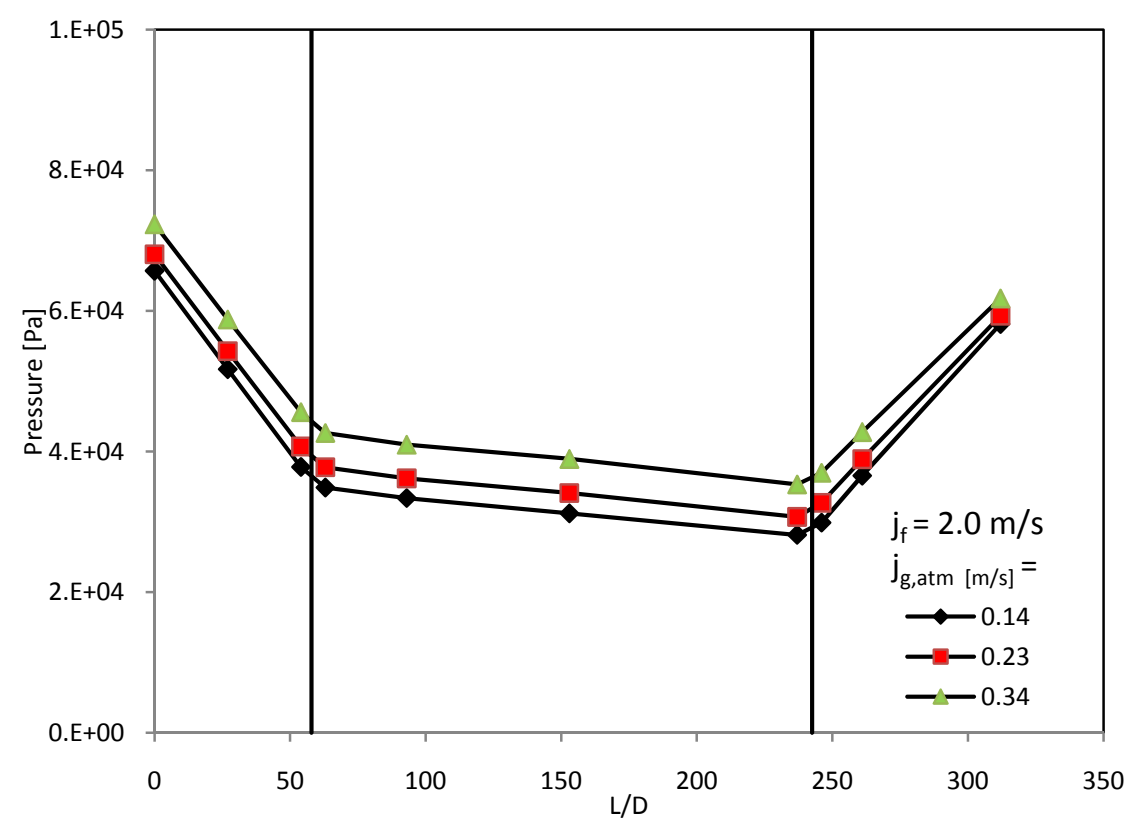

Figure 3.7 Two-phase pressure drop across 90-degree vertical elbows for constant liquid flow rate, $\mathrm{j}_{\mathrm{f}}=2.0 \mathrm{~m} / \mathrm{s}$ and increasing gas flow rates

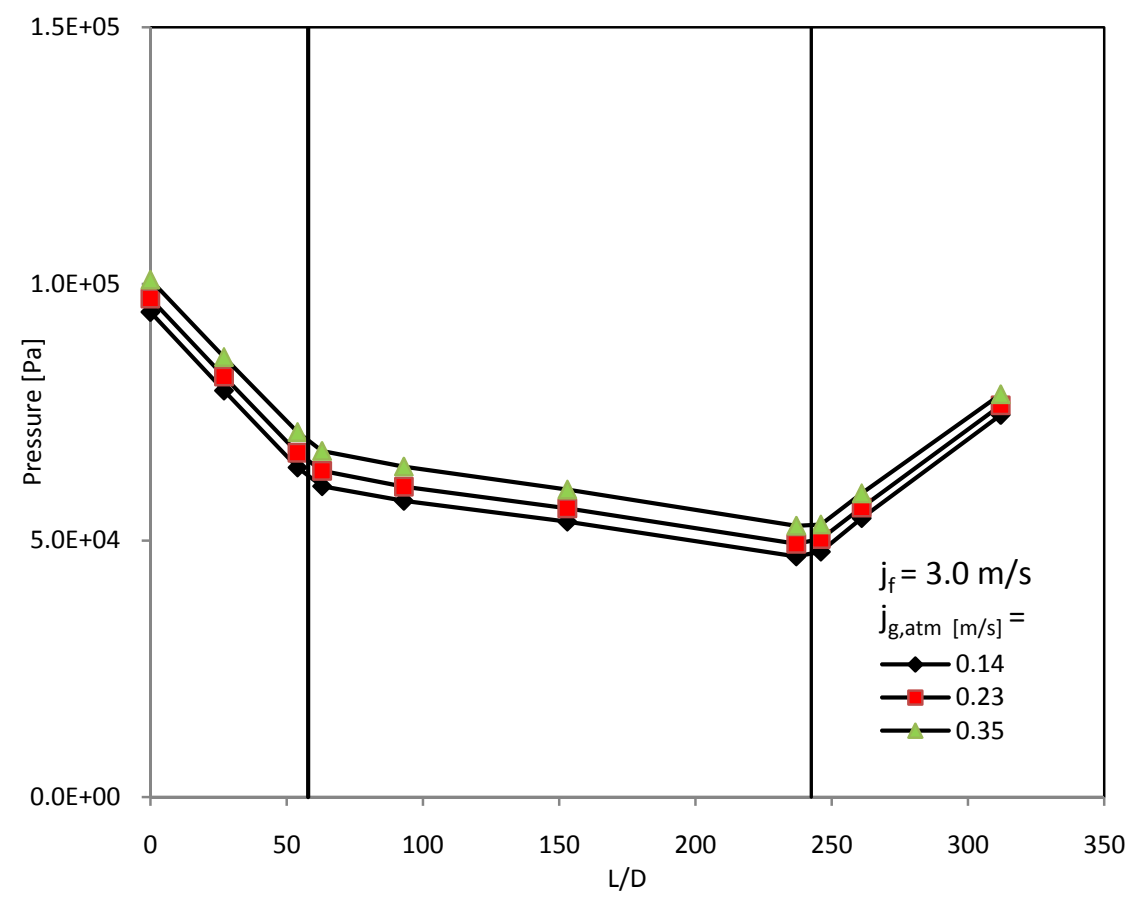

Figure 3.8 Two-phase pressure drop across 90-degree vertical elbows for constant liquid flow rate, $\mathrm{j}_{\mathrm{f}}=3.0 \mathrm{~m} / \mathrm{s}$ and increasing gas flow rates 
In order to isolate the contributions due to frictional and minor loss along the test section, Fig. 3.9 shows the plot of pressure drop without the hydrostatic head versus development length. Again the vertical lines represent the location of the elbows and differentiate vertical-upward, horizontal and vertical-downward section. As expected, it is observed that frictional pressure drop increases with increase in the development length. Moreover, the elbow regions between ports $\mathrm{P} 3$ and $\mathrm{P} 4$ for the vertical upward elbow and P10 and P11 for vertical downward elbow are characterized by a steeper gradient. The steeper pressure gradient is due to the additional minor loss occurring across the elbows. Figure 3.10 highlights the elbow region and shows the pressure drop across both vertical-upward and vertical-downward elbows.

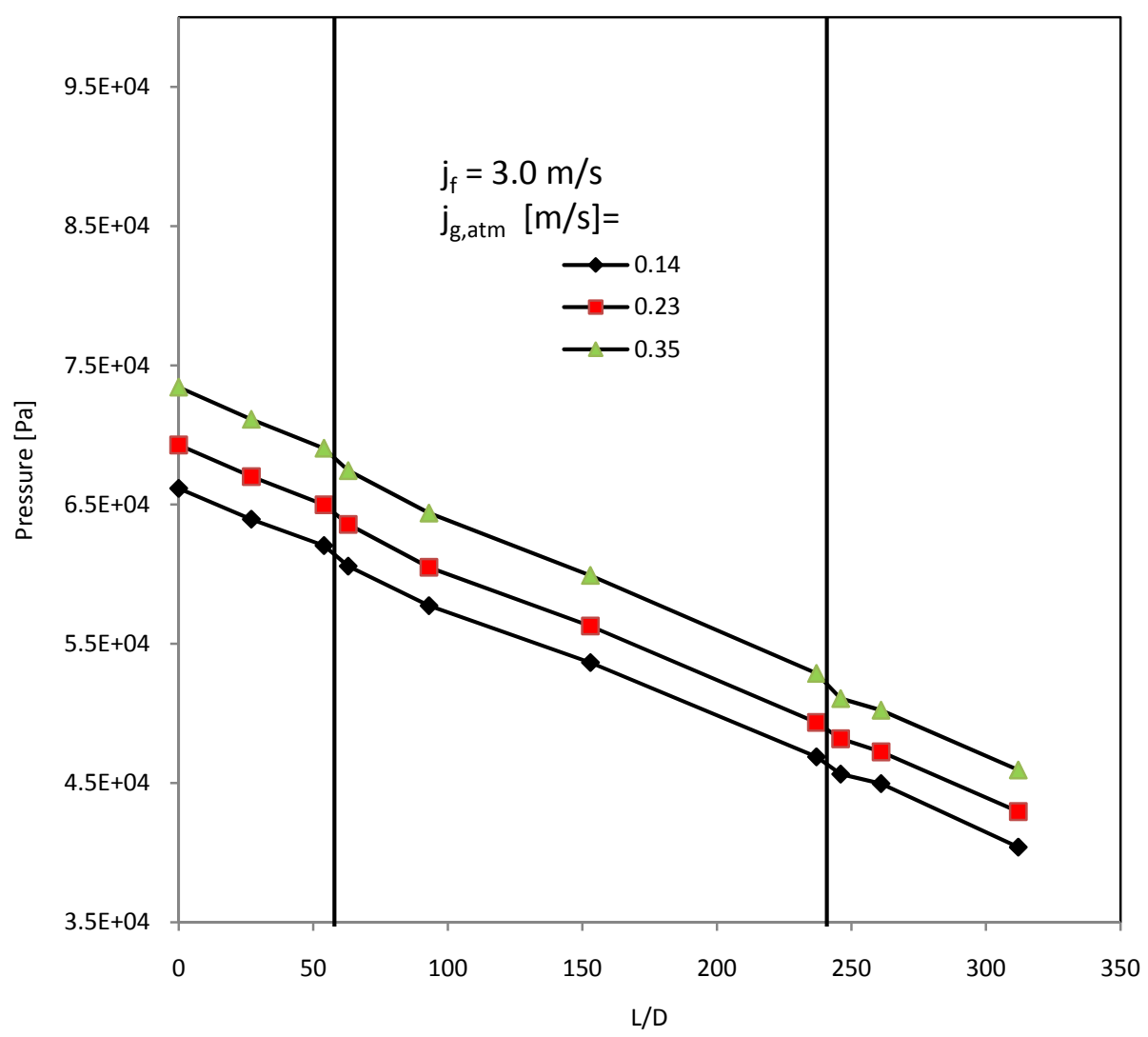

Figure 3.9 Two-phase pressure drop across 90-degree vertical elbows after isolating the hydrostatic head for constant liquid flow rate, $\mathrm{j}_{\mathrm{f}}=3.0 \mathrm{~m} / \mathrm{s}$ and increasing gas flow rates 

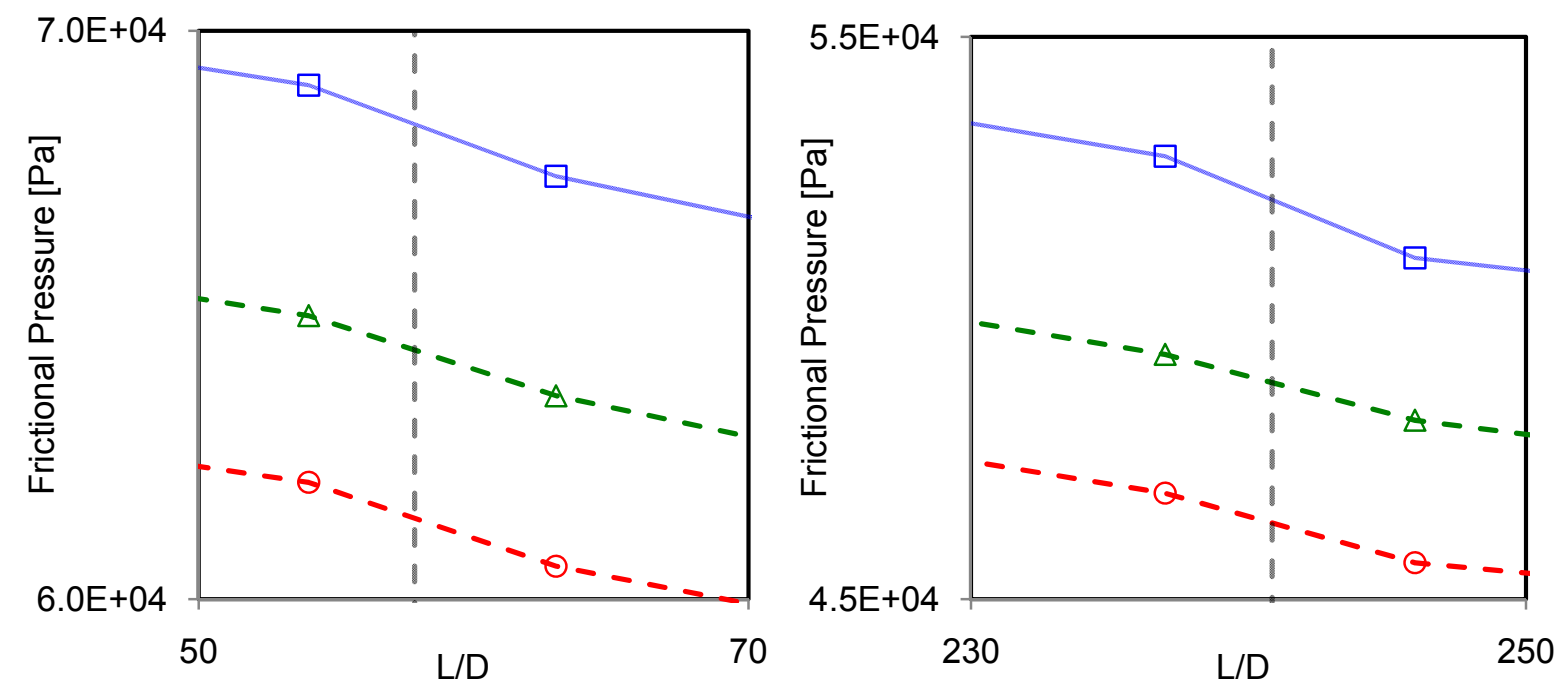

Figure 3.10 Zoomed-in view of the pressure drop across a) 90-degree vertical-upward elbow b) 90-degree vertical downward elbow

\subsubsection{Two-Phase Pressure Drop Correlation}

The conventional two-phase pressure drop correlation as postulated by Chisholm (1967) and generally referred to as Lockhart \& Martinelli correlation is given by eq. 3-7. Here two-phase frictional pressure drop is written as the summation of each of the single-phase frictional pressure drop and a term representing the pressure drop due to the combination of the two fluids moving together simultaneously. Dividing eq. 3-7 by the single phase liquid frictional pressure drop leads us to the familiar expression in eq. 3-8 in terms of two-phase multiplier $\left(\varnothing^{2}\right)$ and Lockhart \& Martinelli parameter $X$. In eq. 3-8 $C$ is the constant whose numerical value is found to be 20 for horizontal two-phase flow (Chisholm, 1967).

$$
\begin{aligned}
& \left(\frac{d p}{d z}\right)_{F}^{2 \emptyset}=\left(\frac{d p}{d z}\right)_{F}^{f}+\left(\frac{d p}{d z}\right)_{F}^{g}+C\left[\left(\frac{d p}{d z}\right)_{F}^{f}\left(\frac{d p}{d z}\right)_{F}^{g}\right]^{1 / 2} \\
& \emptyset^{2}=1+\frac{1}{X^{2}}+\frac{C}{X}
\end{aligned}
$$

Figures 3.11 and 3.12 shows the comparison of two-phase pressure in the vertical-upward section and horizontal section, respectively with Lockhart-Martinelli prediction. It should be noted that the numerical value of $\mathrm{C}$ varies depending on the flow configuration and is found to be 40 for the vertical-upward section. 


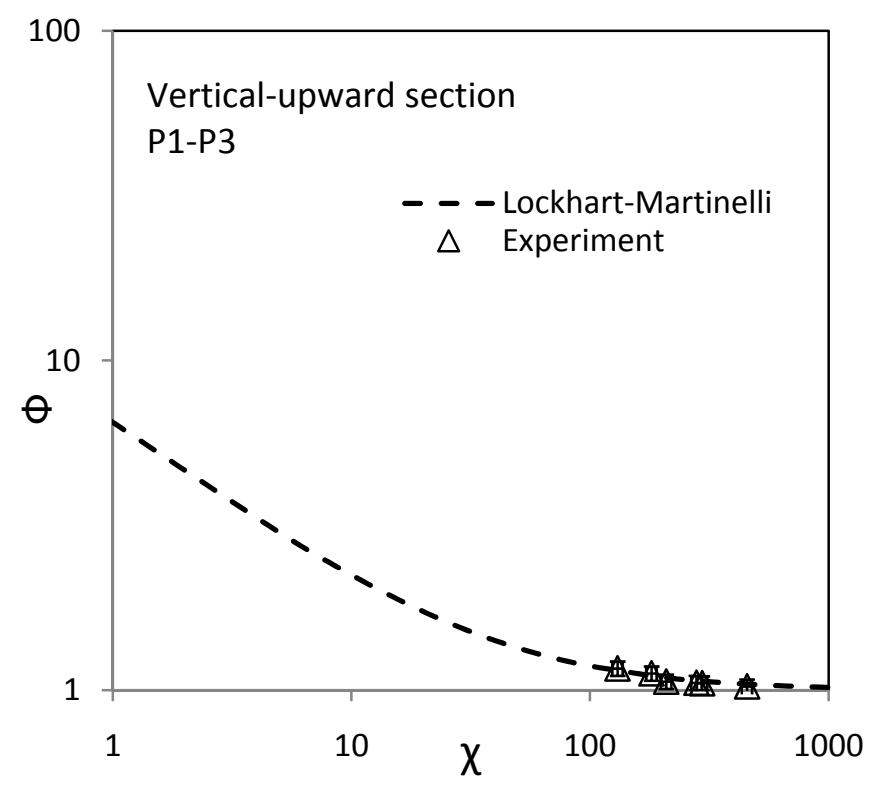

Figure 3.11 Comparison of two-phase pressure drop along vertical upward section with Lockhart-Martinelli prediction

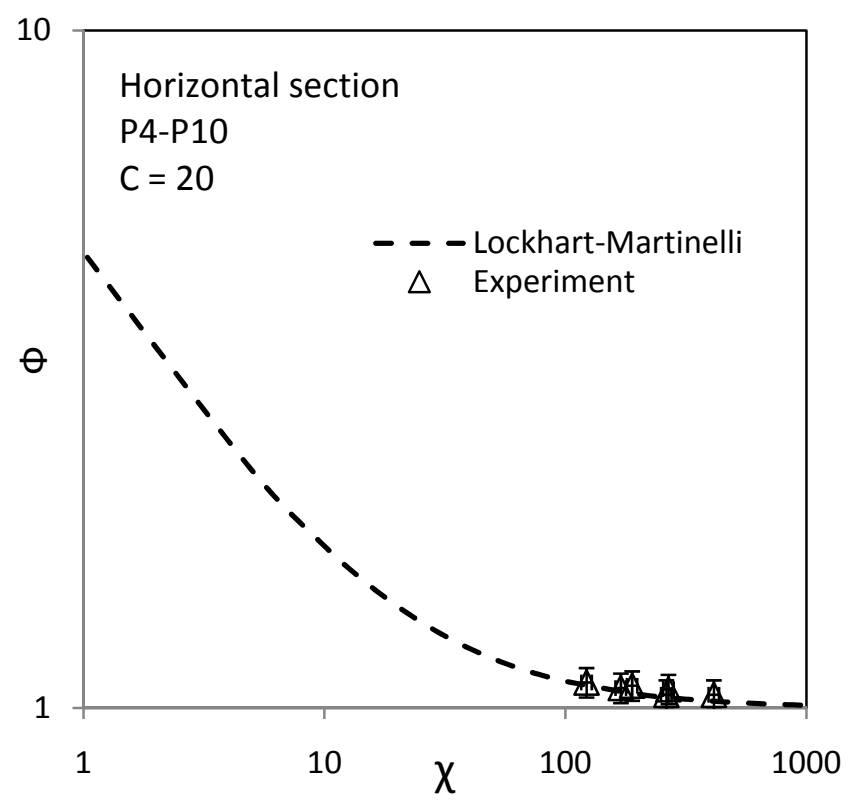

Figure 3.12 Comparison of two-phase pressure drop along horizontal section with LockhartMartinelli prediction

Figures 3.13 and 3.14 shows the prediction of two-phase pressure in the vertical downward section and overall pressure drop, respectively. It should be noted that the best fit in the vertical 
downward flow is obtained for a value of $\mathrm{C}=10$, which is contrary to the expected value of $\mathrm{C}=$ 40. This demonstrates that the value of $\mathrm{C}$ not only depends on the flow configuration but also on flow direction. Moreover, the overall pressure drop between ports P1 and P10 can be best predicted with a value of $\mathrm{C}=30$.

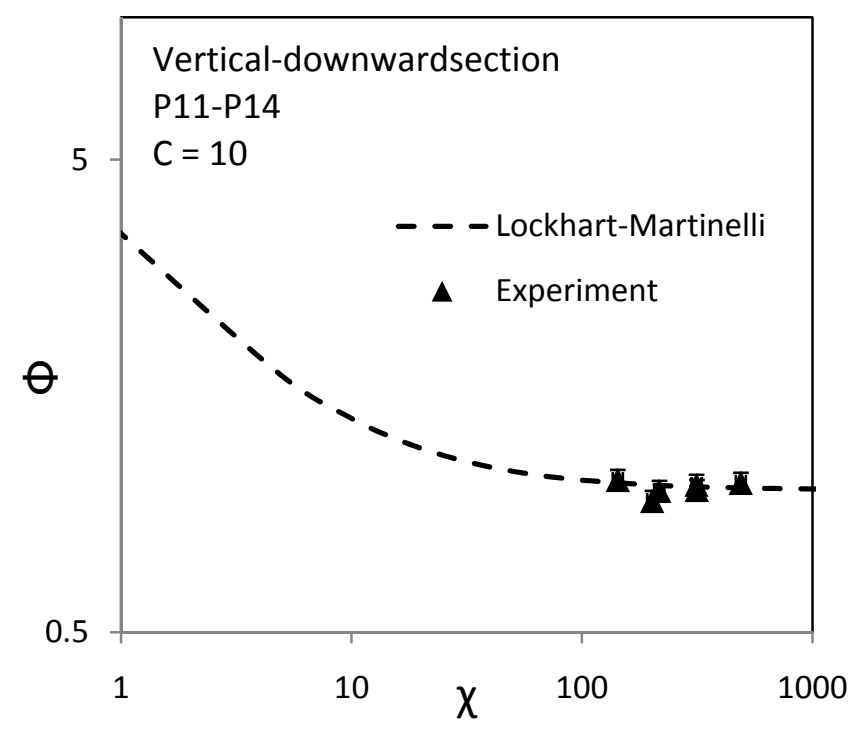

Figure 3.13 Comparison of two-phase pressure drop along vertical-downward section with Lockhart-Martinelli prediction

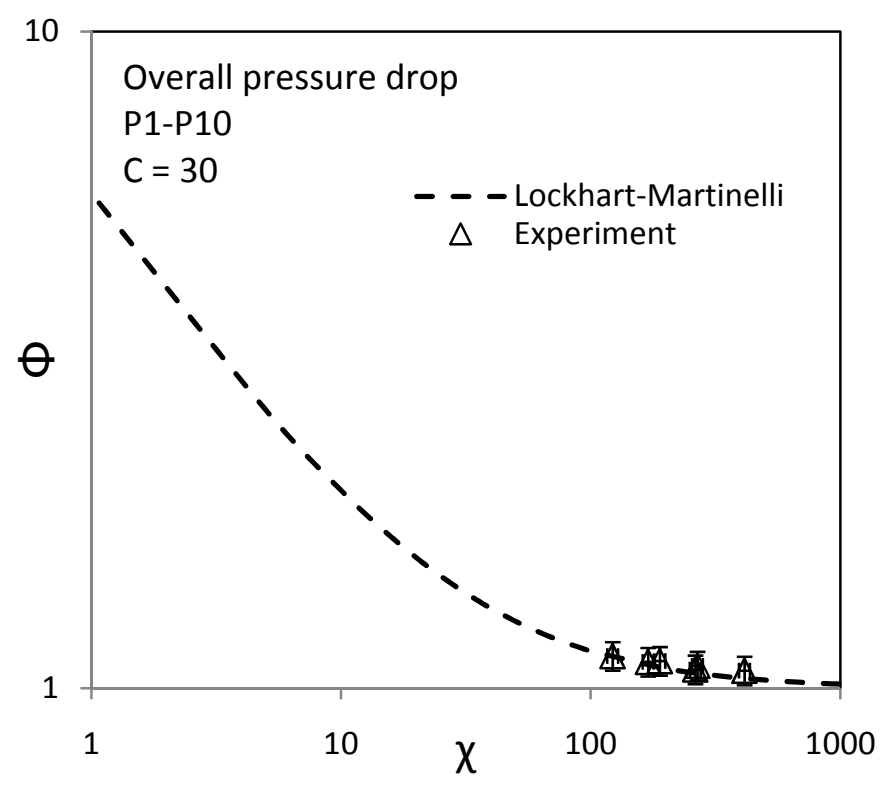

Figure 3.14 Comparison of overall two-phase pressure drop between ports P1 and P10 with Lockhart-Martinelli prediction 
Prediction of two-phase pressure drop along straight pipes as well as across the flow restrictions is one of the challenging problems with several applications. Most of the efforts in past were directed towards predicting two-phase pressure drop in straight pipe sections. Kim et. al. (2010) presented a model similar to the Lockhart and Martinelli correlation to predict pressure drop across horizontal elbows. A simple model based on the Lockhart and Martinelli correlation is proposed here to predict the pressure drop across the elbows. Total two-phase pressure drop across the elbow is divided into contributions due to the frictional pressure drop and the minor loss as shown in eq. 3-9. The two-phase frictional pressure drop is expressed in terms of frictional pressure drop due each of the single-phase components and a combination of the twophases as shown in eq. 3-10. Division of eq. 3-10 by single-phase liquid pressure drop yields a familiar equation in terms of two-phase flow multiplier and Lockhart-Martinelli parameter as well as an additional term for minor loss across the elbow as shown in eq. 3-11.

$\left(\frac{d p}{d z}\right)_{T o t a l}^{2 \varnothing}=\left(\frac{d p}{d z}\right)_{F}^{2 \varnothing}+\left(\frac{d p}{d z}\right)_{M}^{2 \varnothing}$

$\left(\frac{d p}{d z}\right)_{T o t a l}^{2 \emptyset}=\left(\frac{d p}{d z}\right)_{F}^{f}+\left(\frac{d p}{d z}\right)_{F}^{g}+C\left[\left(\frac{d p}{d z}\right)_{F}^{f}\left(\frac{d p}{d z}\right)_{F}^{g}\right]^{1 / 2}+\left(\frac{d p}{d z}\right)_{M}^{2 \emptyset}$

$\emptyset^{2}=1+\frac{1}{X^{2}}+\frac{C}{X}+\frac{1}{X_{M}^{2}}$

Where, $\quad \emptyset^{2}=\frac{\left(\frac{d p}{d z}\right)_{T o t a l}^{2 \varnothing}}{\left(\frac{d p}{d z}\right)_{F}^{f}}$ and $\quad X^{2}=\frac{\left(\frac{d p}{d z}\right)_{F}^{f}}{\left(\frac{d p}{d z}\right)_{F}^{g}} \quad$ and $\quad X_{M}^{2}=\frac{\left(\frac{d p}{d z}\right)_{F}^{f}}{\left(\frac{d p}{d z}\right)_{M}^{2 \varnothing}}$

The frictional pressure drop for single-phase fluid can be obtained using the Fanning equation as shown in eq. 4.

$\left(\frac{d p}{d z}\right)_{F}^{k}=\frac{2 f}{D} \rho_{k} j_{k}^{2}$

Where, the friction factor $f$ is given by:

$$
f=m R e^{-n}
$$

In the current formulation, the minor loss across the elbow is formulated similar to the minor loss in single-phase flow using the minor loss coefficient, $k$ as shown in eq. 3-14. However, the 
fluid properties are replaced with the mixture properties and fluid velocity is replaced with the total superficial velocity.

$$
\left(\frac{d p}{d z}\right)_{M}^{2 \varnothing}=\frac{k}{L} \frac{\rho_{m} j^{2}}{2}
$$

Where, $\rho_{m}$ is the mixture density and $j$ is the total superficial velocity as shown below

$$
\begin{gathered}
\rho_{m}=\alpha \rho_{g}+(1-\alpha) \rho_{f} \\
j=j_{g}+j_{f}
\end{gathered}
$$

The above correlation is developed for pressure drop across the elbows. Hence, Fig. 3.15 shows the pressure drop predictions between ports P3 and P4, i.e. across the vertical upward elbow. Two-phase pressure measurements across the elbow from the experiment are plotted against the model predictions. The best fit for the experimental data is obtained at $\mathrm{C}=80$ and $\mathrm{k}$ $=0.04$ and the absolute average error is found to be $3.8 \%$. Similarly, for the pressure drop across vertical downward elbow the best fit is obtained at $\mathrm{C}=80$ and $\mathrm{k}=0.2$ and the absolute average error is found to be $8.4 \%$.

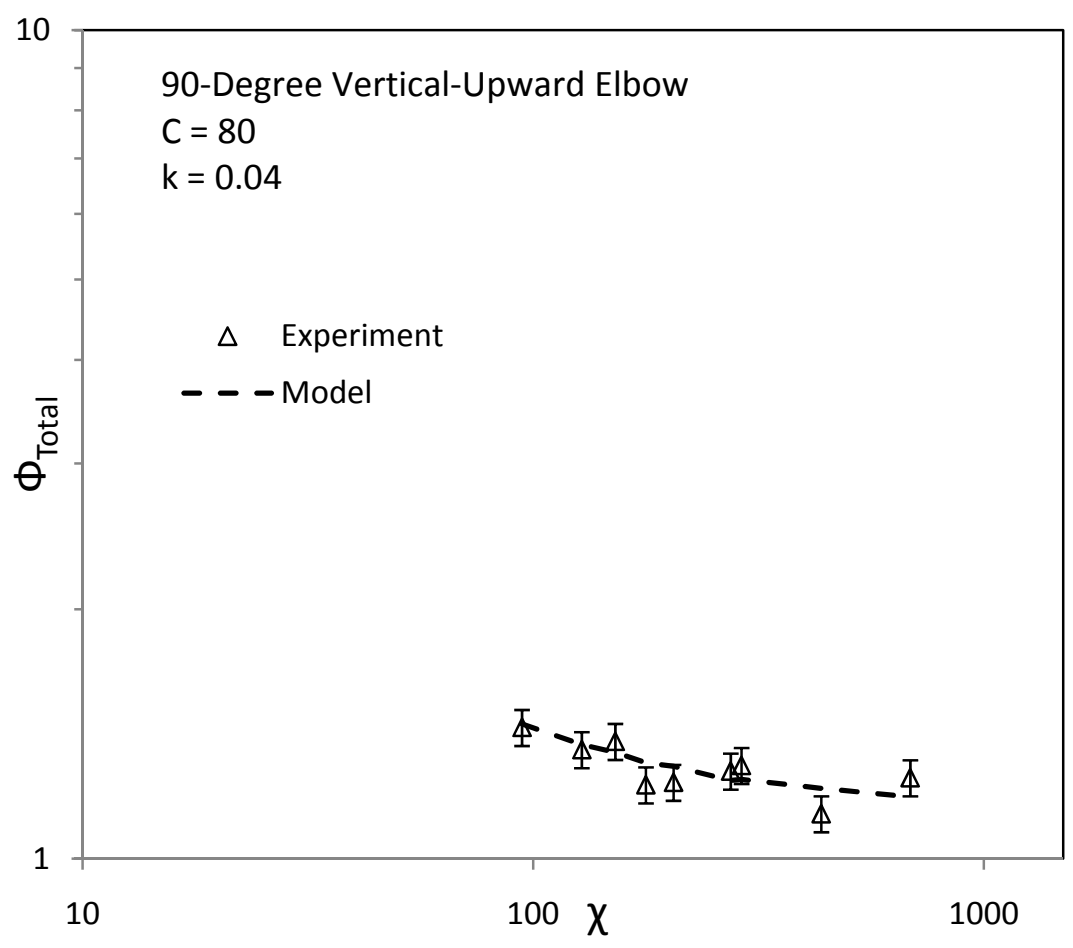

Figure 3.15 Comparison of two-phase pressure drop across 90-degree vertical-upward elbow with newly developed correlation predictions 


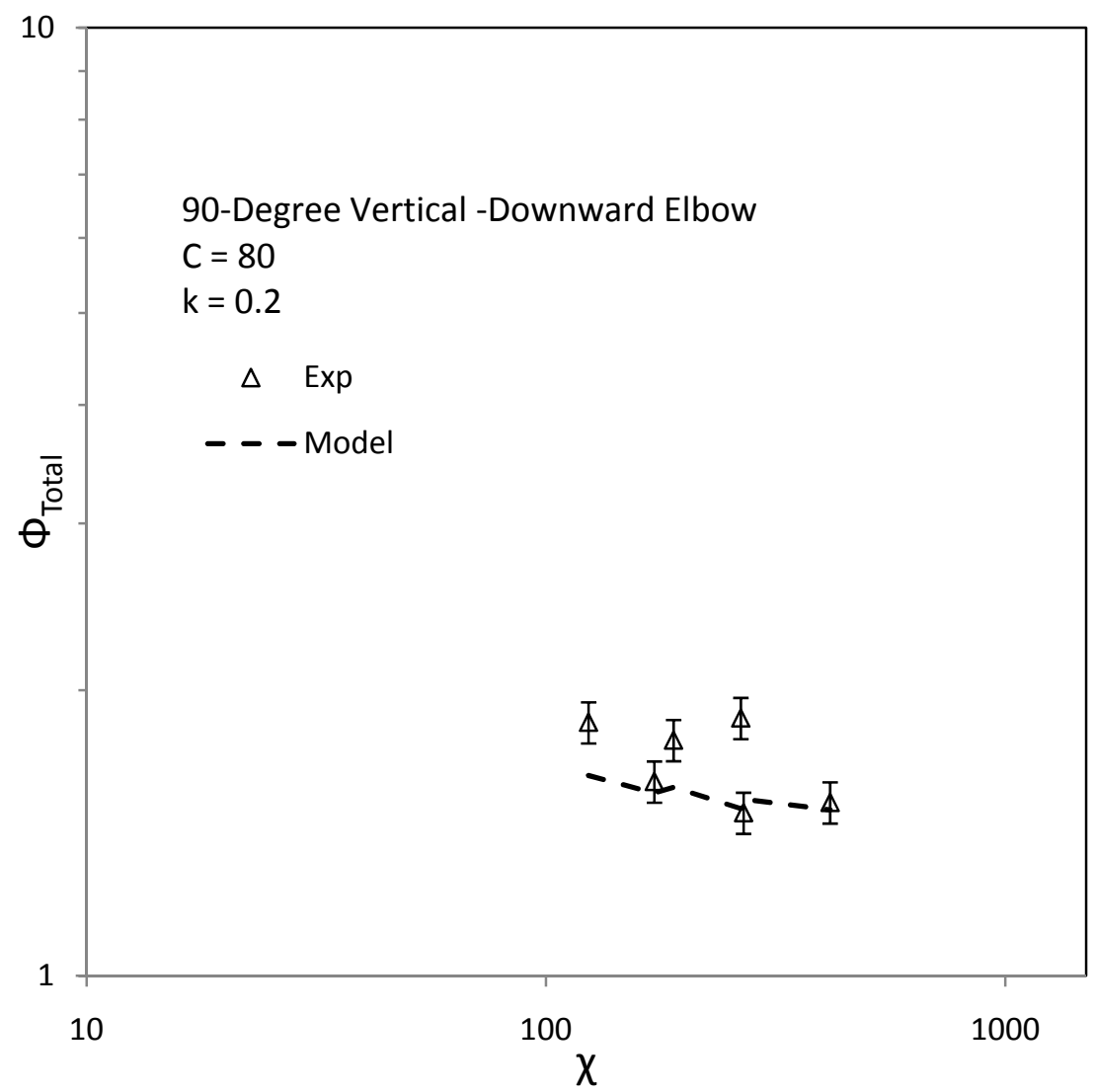

Figure 3.16 Comparison of two-phase pressure drop across 90-degree vertical-downward elbow with newly developed correlation predictions

The newly developed correlation is also used to predict the pressure drop data obtained from previous experiments (Kim et al., 2010) across 90-degree and 45-degree horizontal elbows in bubbly two-phase flow conditions. Figure 3.17 and 3.18 show the comparison between the new correlation and the experimental data for 90-degree and 45-degree horizontal elbows, respectively. The best agreement is obtained for $\mathrm{C}=80$ for both the elbows and $\mathrm{k}=0.58$ and 0.35 for 90 -degree and 45 -degree elbow, respectively. The absolute average error is found to be $2.1 \%$ and $1.35 \%$ for 90 -degree and 45 -degree horizontal elbow, respectively. 


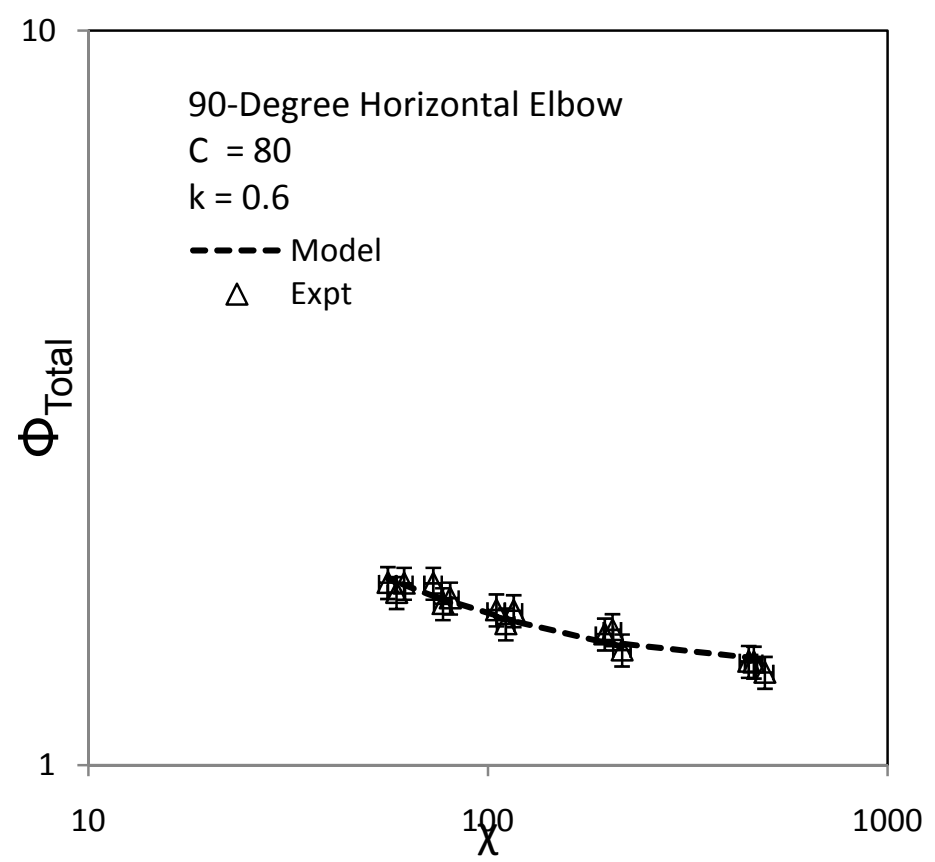

Figure 3.17 Comparison of two-phase pressure drop across 90-degree horizontal elbow with newly developed correlation predictions

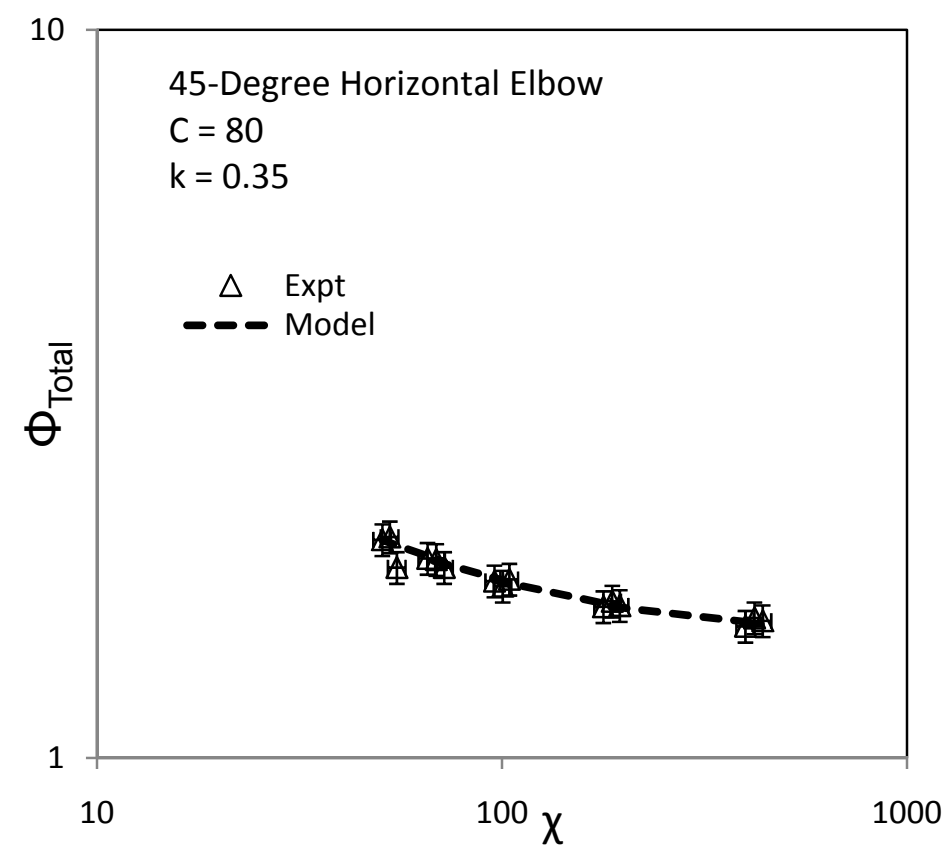

Figure 3.18 Comparison of two-phase pressure drop across 45-degree horizontal elbow with newly developed correlation predictions 
It is observed that in all the above cases, a good agreement with the experiment is obtained by keeping a constant value of $\mathrm{C}=80$ and varying the minor loss coefficient, k. Furthermore, the value of $\mathrm{C}=80$ is higher across the elbows compared to the value of $\mathrm{C}=20$ for straight pipes in the conventional Lockhart-Martinelli correlation. It is speculated that the higher value of $\mathrm{C}$ is because of the following factors:

- Buoyancy effect due to change in the flow orientation

- Irreversible work performed due to bubble interaction promoted by the elbow and interaction between the two phases as they move across the elbow

- Pressure drop due to distribution of the dispersed phase (bubbles tend to follow the secondary flow streamlines)

\subsection{Flow Regime Identification}

To analyze the two-phase flow at a basic level, it is necessary to classify different patterns of phase distribution that are specifically similar for different pipe sizes and fluid properties. Traditionally different flow patterns or the regimes have been described based on the experimental observations. Extensive flow visualization is performed at various axial locations along the test section in order to study the geometric effects of 90-degree vertical elbows as well as geometric configurations on two-phase flow regime transition. A comprehensive set of flow conditions chosen to span bubbly and slug flow regime in the vertical upward section are investigated at different axial locations along the test section. The measurement locations include: port P3 located in the vertical upward section at 60D downstream of the inlet, ports P4, P7, P9 and P10 located in the horizontal section at 3D, 90D, 147D and 177D downstream of the vertical upward elbow, respectively and ports P11 and P14 located in the vertical downward section at 3D and 66D downstream of the vertical downward elbow, respectively.

Figure 3.19 shows a typical high speed image highlighting the effect of the 90-degree vertical upward elbow on two-phase flow structure. Here, $(\mathrm{L} / \mathrm{D})_{\mathrm{V}}$ denotes the development length in the vertical section from the inlet and $(\mathrm{L} / \mathrm{D})_{\mathrm{H}}$ denotes the development length in the horizontal section downstream of the vertical elbow. As evident from the top image, a cap-bubble in the vertical section gets broken into smaller bubbles as it passes through the elbow region. Further 
downstream of the elbow, these smaller bubbles migrate towards the top wall of the pipe and coalesce to form a plug bubble. This shows that in general, the elbow causes break-up of the large bubbles and hence immediately downstream of the elbow we can expect the flow regimes to shift towards bubbly flow.
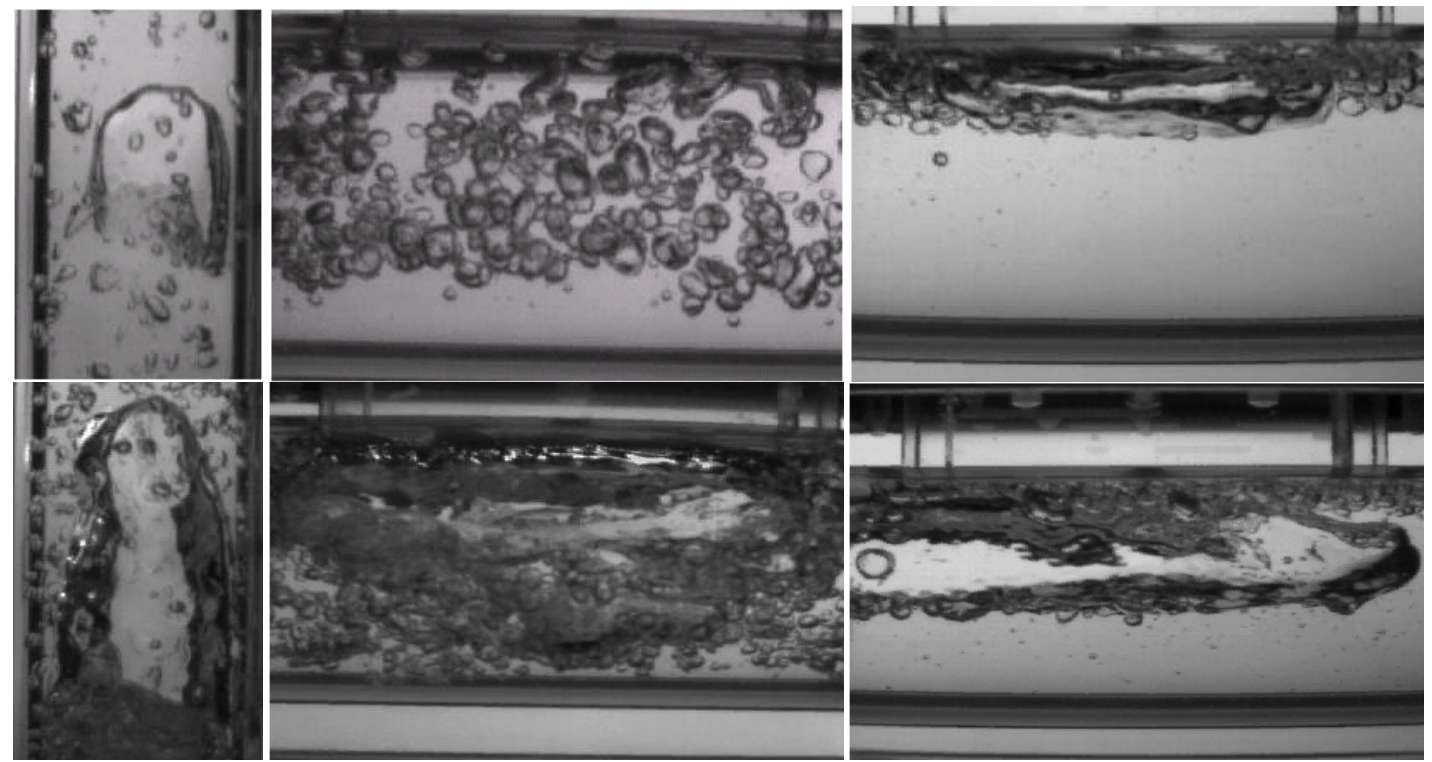

Figure 3.19 High-speed images obtained at $2000 \mathrm{fps}$, showing the development of two-phase flow structure across the vertical-upward elbow

\subsubsection{Vertical-Upward Section:}

Figure 3.20 shows the comparison of the flow visualization in the vertical-upward section at port P3 (60D downstream of the injection) with the flow regime transition boundaries suggested by Mishima and Ishii (1984). The flow regime transition boundaries obtained from the experiment are found to be in good agreement with the conventional theoretical flow regime transition boundaries. This shows, as expected, that the elbow has negligible effect on the flow regime transition at upstream locations. 


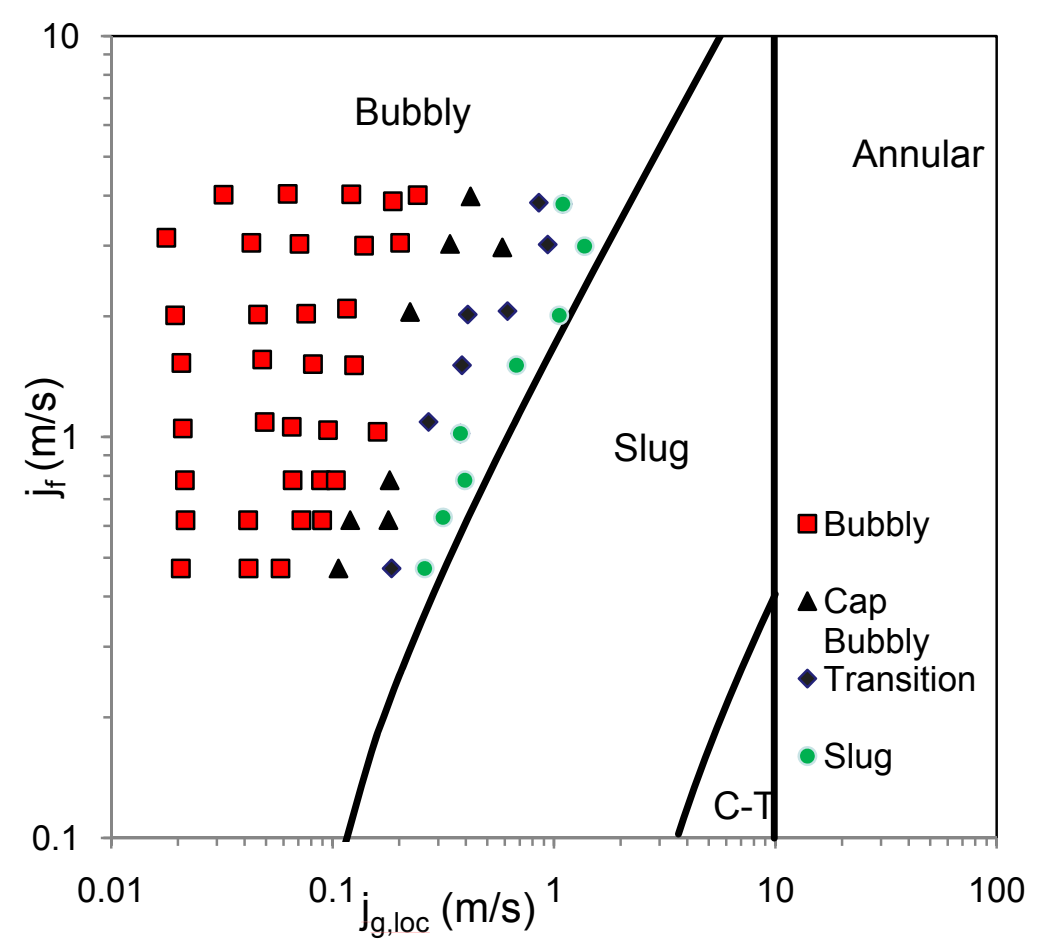

Figure 3.20 Flow regime map at port P3 (60D downstream of inlet) in vertical section compared with flow regime map for vertical two-phase flow by Mishima-Ishii (1974)

\subsubsection{Horizontal Section}

The flow visualization results in the horizontal section are compared with the flow regime maps suggested by Mandhane et. al. (1974). Figure 3.21 shows the modified flow regime map at port P4, located at 3D downstream of the vertical elbow. The solid lines represent the modified flow regime boundaries and the dashed lines represent the conventional flow regime boundaries. As mentioned earlier, the elbow causes the breakup of large bubbles. Hence, the bubbly flow regime exists even at lower liquid flow rates and extends into the conventional plug flow regime. It is speculated that the secondary flow in the elbow causes bubble disintegration. Moreover, the elbow generated turbulence causes the slug flow regime to occurs at lower gas flow rates and extend into the conventional plug flow regime. It is important to note that in the nuclear reactors the development length downstream of the flow restrictions is very small and hence modified flow regime maps are required to accurately identify the flow pattern. 


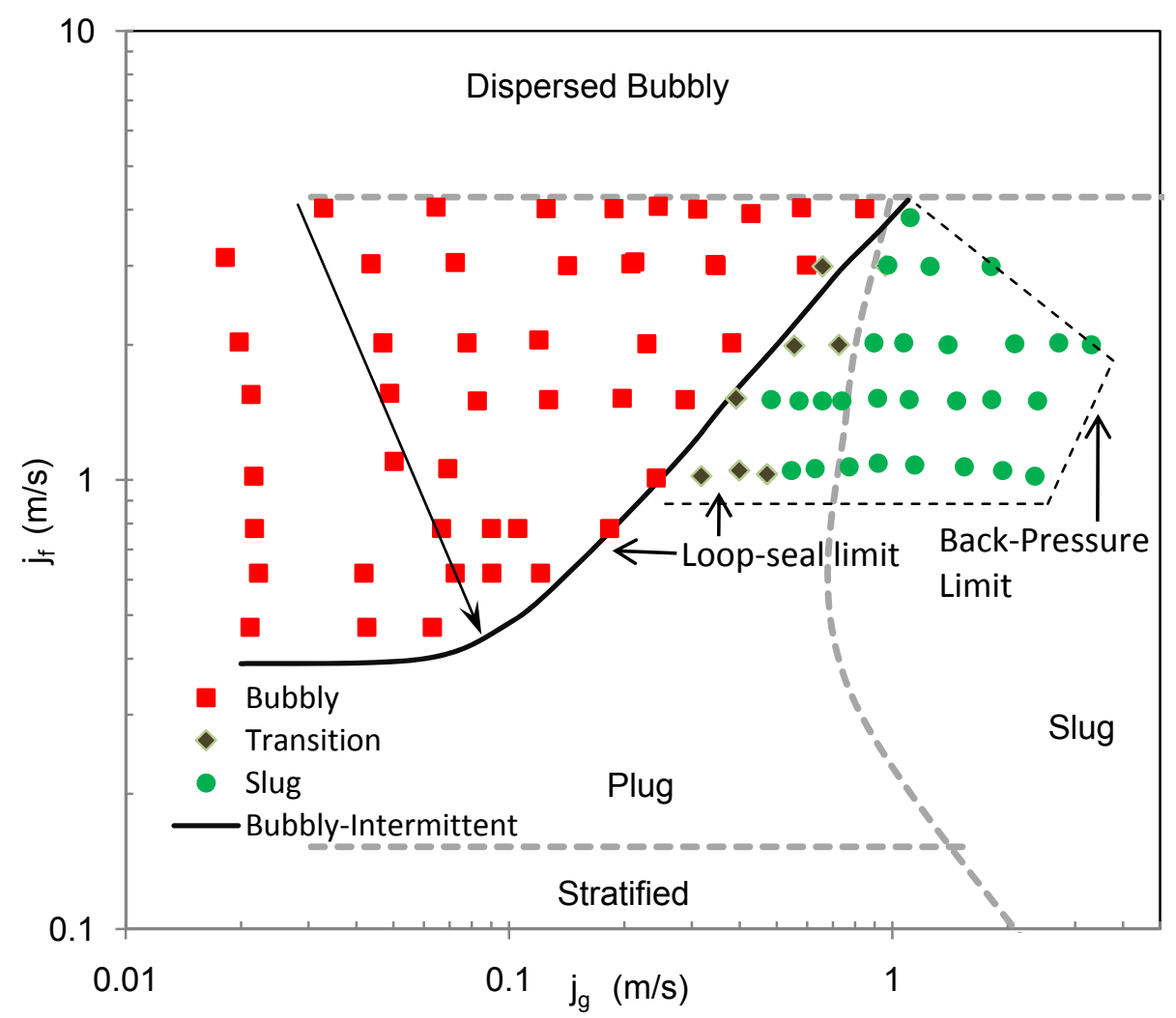

Figure 3.21 Modified horizontal two-phase flow regime map at port P4 (3D downstream of the vertical elbow)

Figure 3.22 shows the modified flow regime map at port P7, located 90D downstream of the vertical elbow. The two-phase flow becomes more developed by this measurement location. The bubbles tend to rise towards the upper pipe wall and coalesce in the process. This causes the bubbly flow regime to move towards the higher liquid flow rates and conventional flow regime boundary. Moreover, the slug flow boundary recedes towards the conventional boundary and the plug flow regime starts to appear again.

The effect of development length on the flow regime transition boundaries is shown in Figs. 3.23 and 3.24 corresponding to the modified flow regime maps at P9 and P10, located 147D and $177 \mathrm{D}$ downstream of the vertical elbow. It is observed that the modified flow regime boundaries migrate towards the conventional flow regime boundaries. However, significant elbow effect is present even at a development length of 177D. It is assumed that the modified flow regime 
boundaries would converge with the conventional flow regime boundaries further downstream. It also suggests that horizontal two-phase flow requires more than $180 \mathrm{D}$ to fully develop.

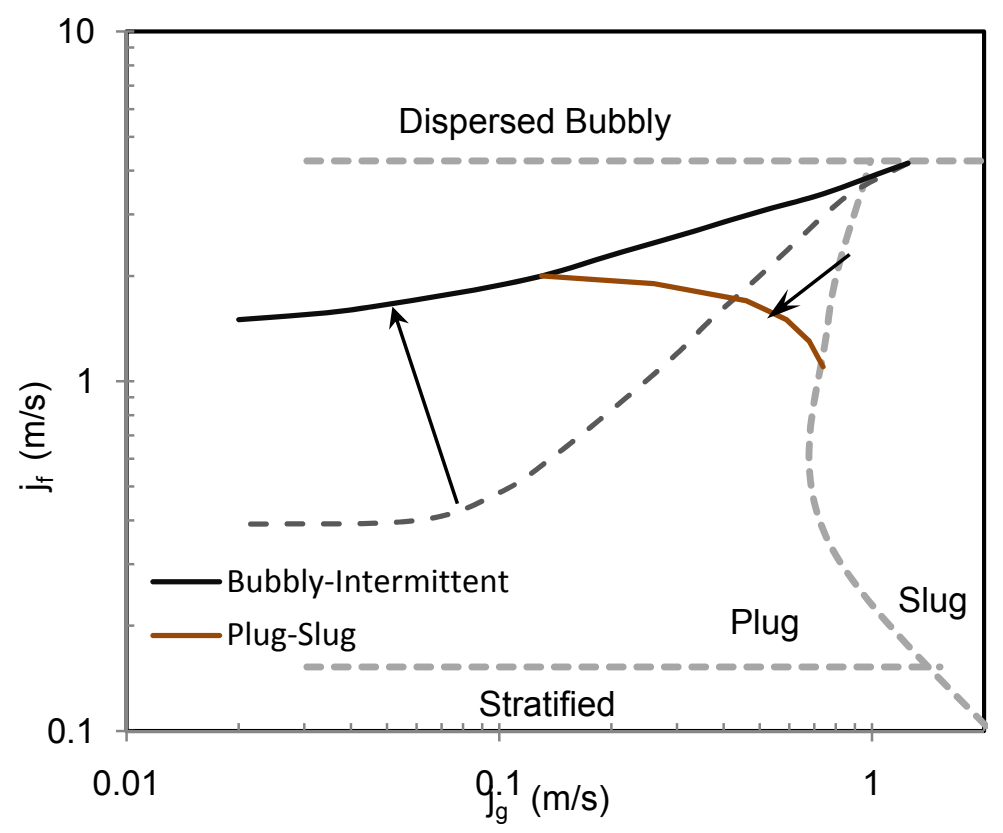

Figure 3.22 Modified horizontal two-phase flow regime map at port P7 (90D downstream of the vertical elbow)

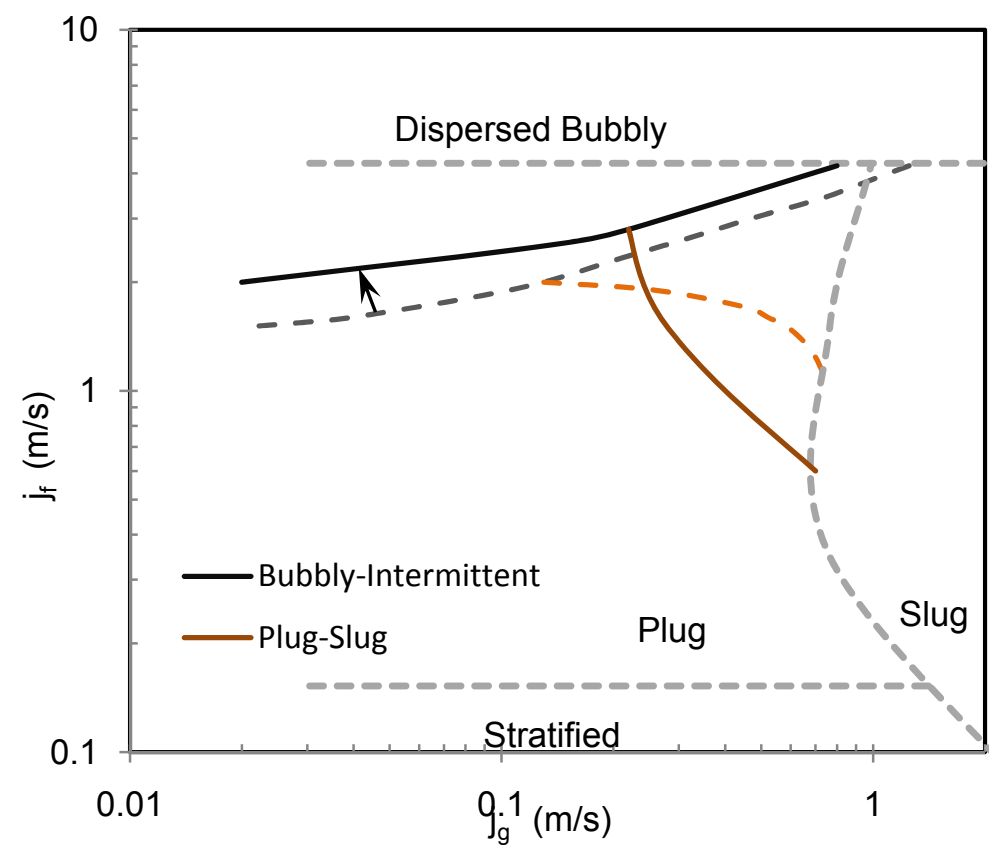

Figure 3.23 Modified horizontal two-phase flow regime map at port P9 (147D downstream of the vertical elbow) 


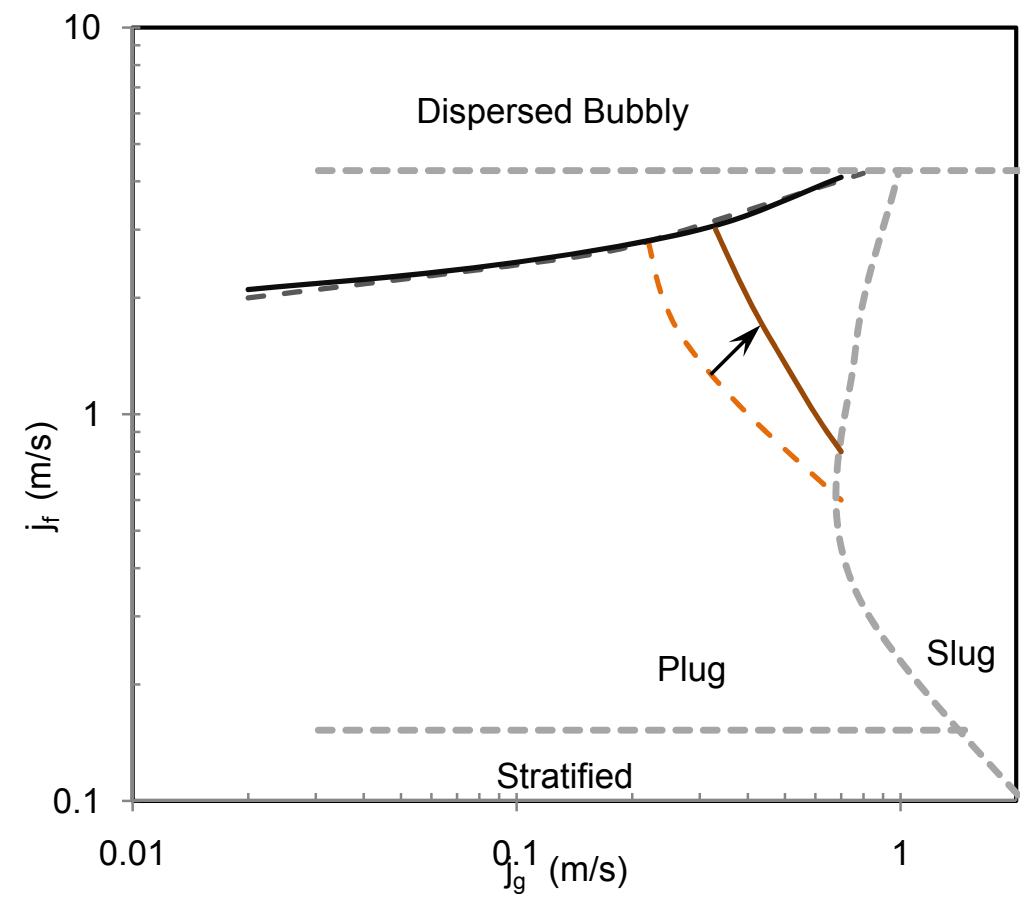

Figure 3.24 Modified horizontal two-phase flow regime map at port P10 (177D downstream of the vertical elbow)

\subsubsection{Vertical-Downward Section}

As mentioned earlier, flow visualization is performed at two axial locations in the vertical downward section. Flow visualization at port P11 $(\mathrm{L} / \mathrm{D}=2.5)$ shows the effect of the vertical downward elbow on flow regime transition and at port P14 $(\mathrm{L} / \mathrm{D}=66)$ demonstrates the effect of development length in the vertical downward two-phase flow. The flow visualization results are then compared with flow regime map for vertical downward flow obtained by Kim et. al. (2004). Figure 3.25 shows the vertical downward flow regime map at port P11. It is observed that there is a prominent transition region between bubbly and slug flow regime. Within this region elongated bubbles with shapes similar to Taylor bubble are observed, however, the bubbles do not occupy the entire pipe cross-section. Moreover, slug flow regime occurs in the region occupied by churn-turbulent flow in conventional flow regime map. This happens because compared to conventional two-phase injector, vertical downward elbow serves as injection in the current study. Moreover, this shows the effect of the elbow in vertical downward flow regime transition. 


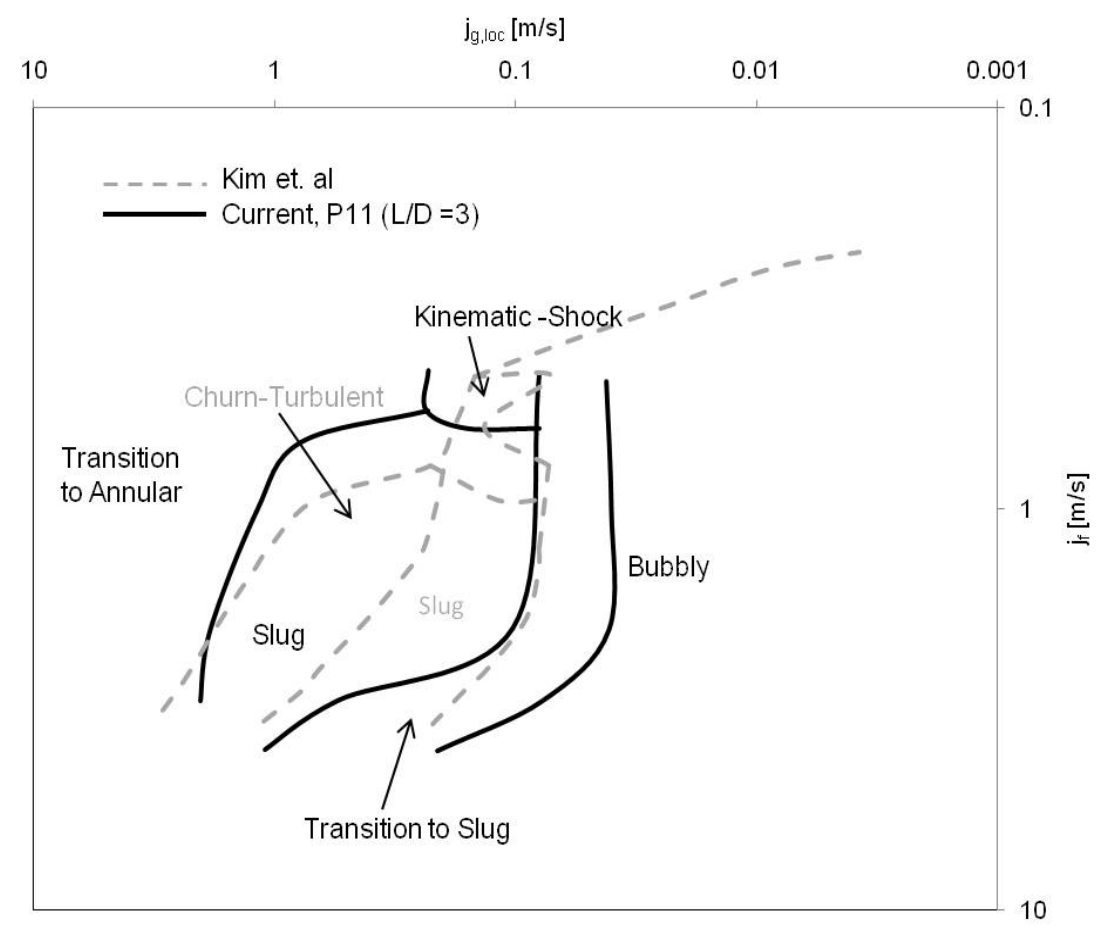

Figure 3.25 Modified flow regime map for vertical downward two-phase flow at port P11 (3D downstream of the vertical-downward elbow)

Figure 3.26 shows the flow regime map for vertical-downward two-phase flow at port P14 located 66D downstream of the vertical-downward elbow. The effect of development length can clearly be seen as the flow regime transition boundaries approach the conventional boundaries. A major difference from the conventional flow regime map is lack of churn turbulent flow and presence of a prominent transition to slug region in the modified flow regime map. This difference arises due to different two-phase flow injection and method of flow regime identification. The effect of development length on flow regime transition in vertical-downward two-phase flow is shown in Fig. 3.27. 


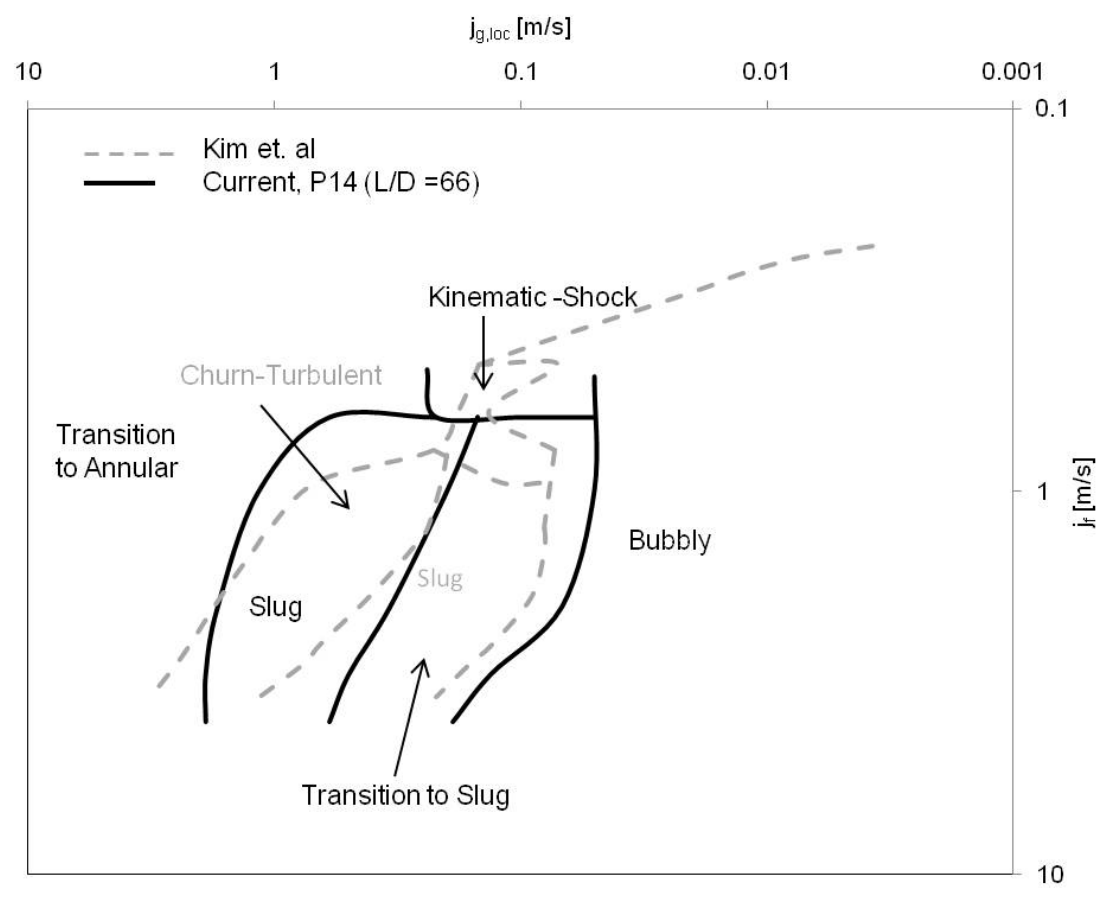

Figure 3.26 Modified flow regime map for vertical downward two-phase flow at port P14 (66D downstream of the vertical-downward elbow)

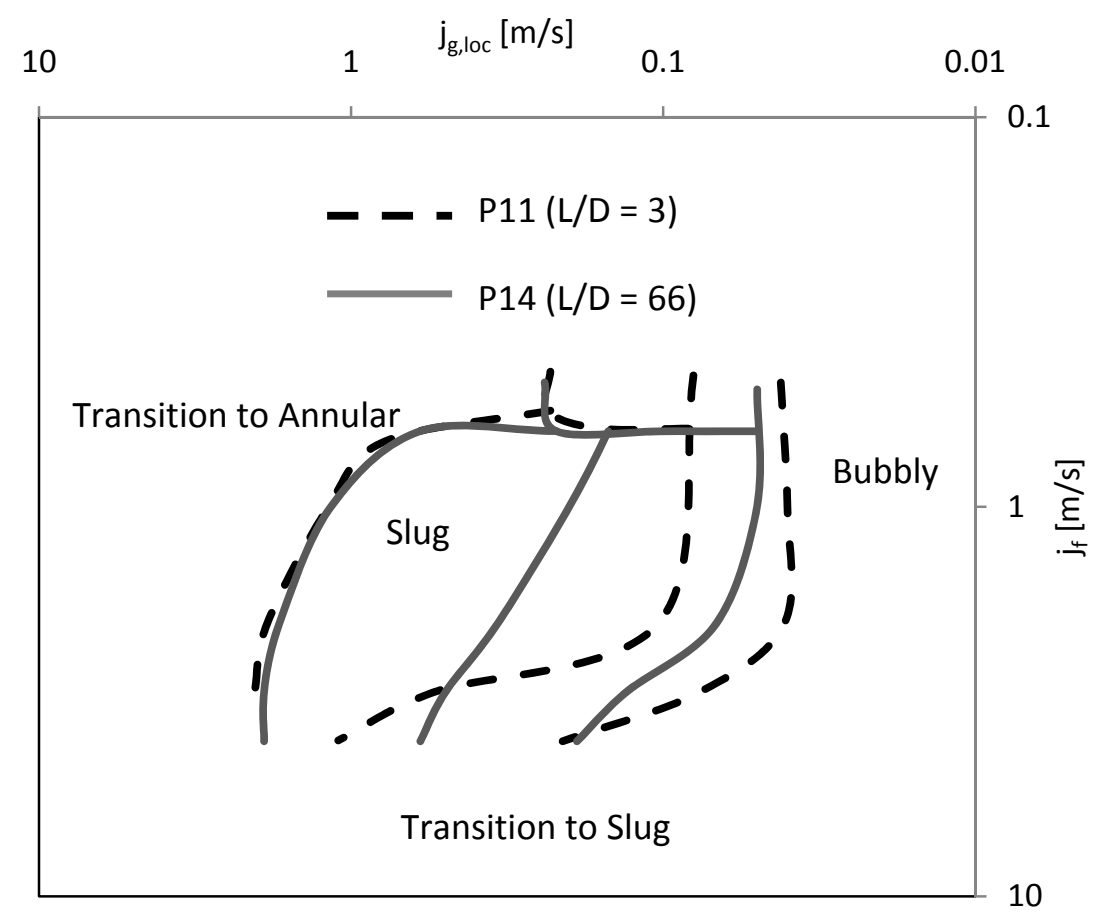

Figure 3.27 Effect of development length on flow regime transition for vertical downward twophase flow 


\subsection{Local Interfacial Structures}

A four-sensor conductivity probe is used to measure local two-phase flow parameters along the test section. The measured parameters include void fraction, bubble velocity, interfacial area concentration and bubble frequency. In total, local two-phase flow parameters are measured at ten different axial locations along the test section. Accordingly, the analysis is divided into measurements in the vertical upward section, horizontal section (downstream of the vertical upward elbow) and vertical downward section (downstream of the vertical downward elbow).

\subsubsection{Vertical-Upward Section}

In the vertical upward section, local measurements are obtained at ports P1, P2 and P3 located at 6D, 33D and 54D downstream of the inlet. Bubble distribution in the vertical upward section is found to be axisymmetric and hence local measurements are obtained only along half diameter of the pipe cross-section. Figure 3.28 shows the local profiles of void fraction and interfacial area concentration different at ports $\mathrm{P} 1, \mathrm{P} 2$, and $\mathrm{P} 3$ for a constant liquid flow rate of $3.0 \mathrm{~m} / \mathrm{s}$ and increasing gas flow rate.

Development of the local profiles of void fraction and interfacial area concentration along the vertical section for Run 4 corresponding to liquid flow rate, $\mathrm{j}_{\mathrm{f}}=3.0 \mathrm{~m} / \mathrm{s}$ and gas flow rate, $\mathrm{j}_{\mathrm{g}, \mathrm{atm}}=$ $0.14 \mathrm{~m} / \mathrm{s}$. As can be seen from the figure, at port P1 (L/D $=6$ from inlet) local void fraction has a center-peaked profile. The two-phase flow is not fully developed at this measurement location and hence includes some inlet effects. Further downstream of the inlet, at port P2 (L/D = 33 from inlet) bubbles migrate towards the pipe wall and as a result local void fraction has a wallpeaked profile. As the flow progresses further downstream of the inlet, at port P3 ( $L / D=60$ from inlet) the bubbles start migrating towards the centre of the pipe once again. This creates a flat local void fraction profile for the lower gas flow rate conditions and a centre-peaked profile for flow conditions with higher gas flow rate. The average bubble size increases as the flow progresses in the vertical section and these larger bubbles have a tendency to migrate towards the centre of the pipe cross-section. The major reason for increase in the bubble size for the present experimental conditions is pressure drop along the vertical section. Since, the measurements are 
made under bubbly flow conditions the interfacial area concentration profiles are similar to the void fraction profiles.
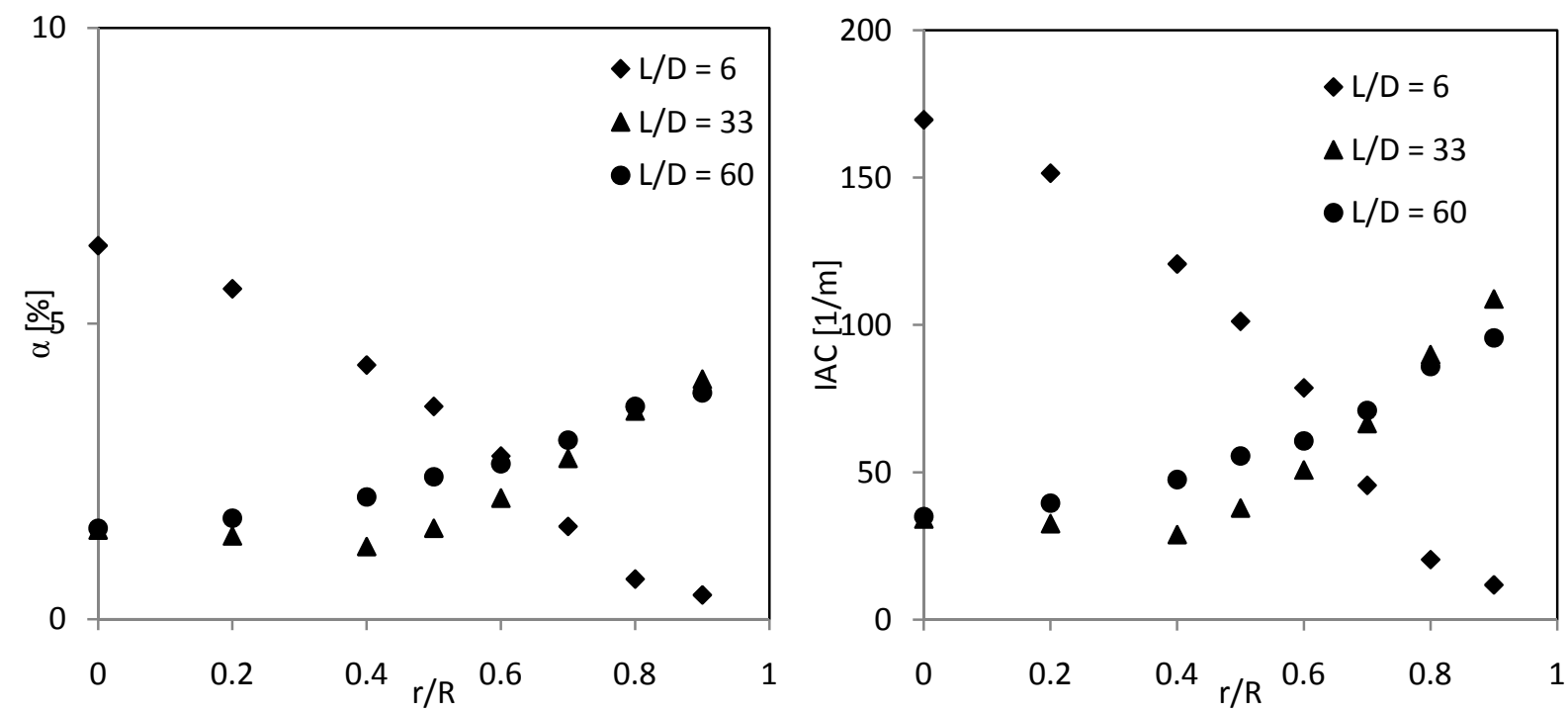

Figure 3.28 Local void fraction and interfacial area concentration at different axial locations along the vertical upward section for Run $4\left(\mathrm{j}_{\mathrm{f}}=3.0 \mathrm{~m} / \mathrm{s}, \mathrm{j}_{\mathrm{g}, \mathrm{atm}}=0.14 \mathrm{~m} / \mathrm{s}\right)$

\subsubsection{Effect of Gas Flow Rate}

Effect of gas flow rate on interfacial structures in the vertical section is shown in Fig. 3.29. In this figure local profiles of void fraction and interfacial area concentration at different axial locations along the vertical section is shown for a constant liquid flow rate, $\mathrm{j}_{\mathrm{f}}=3.0 \mathrm{~m} / \mathrm{s}$ and increasing gas flow rate. In general, as expected the increasing the gas flow rate increases the local void fraction. Moreover, it also affects the bubble distribution across the pipe crosssection. As evident from the figure, the bubble distribution and hence the local void fraction profiles are centre peaked at port $\mathrm{P} 1$ (L/D $=6$ from inlet) for all the flow conditions. Similarly, the bubble distribution and the local void fraction profiles are wall peaked at port P2 (L/D = 33 from inlet). However, at port P3 ( $\mathrm{L} / \mathrm{D}=60$ from inlet) the bubble distribution changes with increasing gas flow rate. It is found that the bubble distribution and hence the void fraction profile changes from wall peaked to flat profile and then to centre peaked profile with increasing gas flow rate. Again, the interfacial area concentration profiles are similar to the void fraction profiles. 

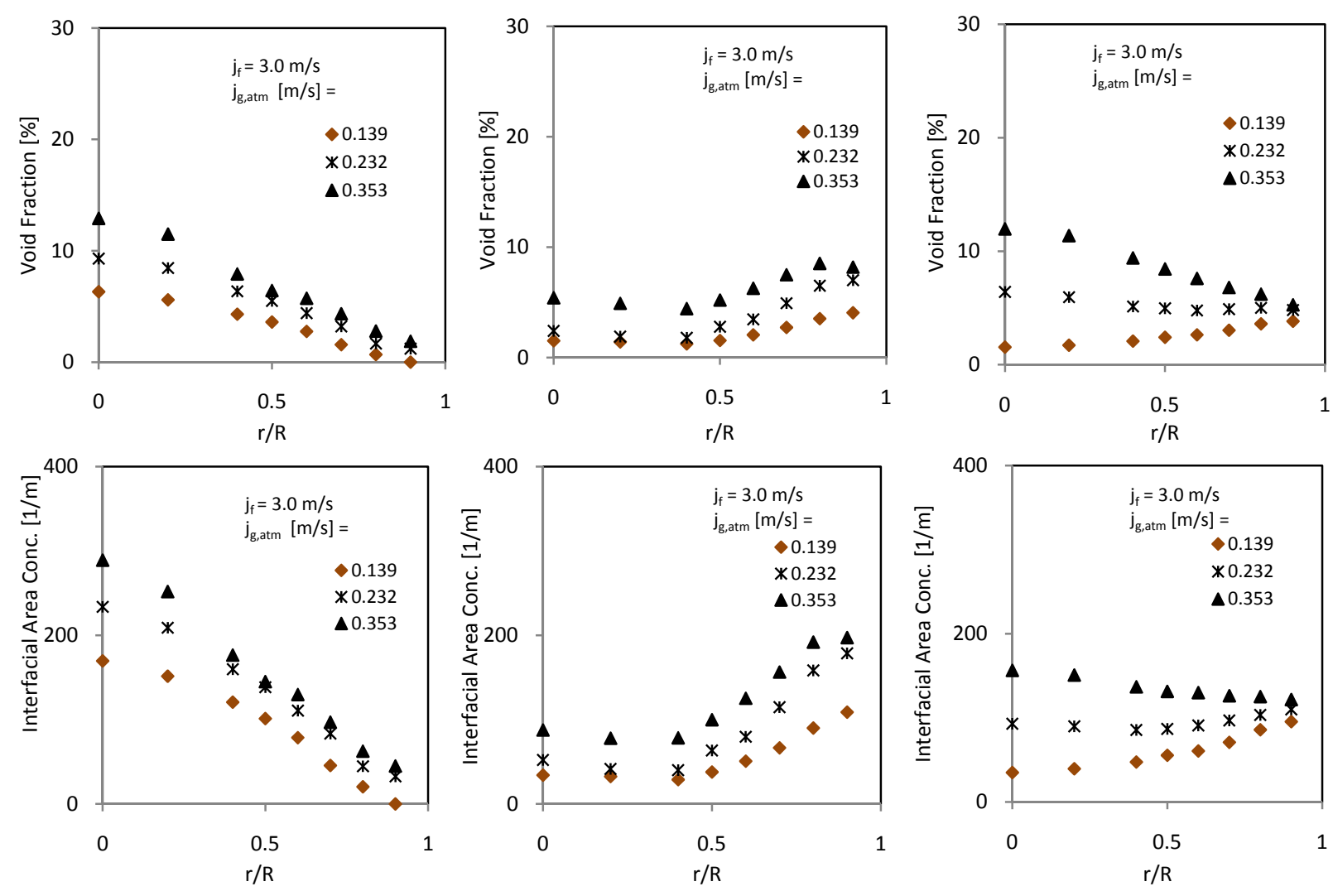

$$
(L / D)_{V}=6
$$

$(L / D)_{V}=33$

$(L / D)_{V}=60$

Figure 3.29 Local profiles of void fraction and interfacial area concentration for a constant liquid flow rate, $\mathrm{j}_{\mathrm{f}}=3.0 \mathrm{~m} / \mathrm{s}$ and increasing gas flow rates, at different axial locations along the vertical upward section

\subsubsection{Bubble velocity and bubble Sauter mean diameter}

Figure 3.30 shows the local profiles of bubble velocity and bubble Sauter mean diameter along the vertical upward section for a constant liquid flow rate, $\mathrm{j}_{\mathrm{f}}=3.0 \mathrm{~m} / \mathrm{s}$ and increasing gas flow rates. In general, increasing the gas flow rate has negligible effect on the bubble velocity at any axial location along the vertical upward section. In vertical upward section, bubble velocity follows the liquid velocity profile. The bubble velocity profile develops from a flat to parabolic centre peaked profile as the flow develops in the vertical upward section. 
The bubble Sauter mean diameter, in general increases with increasing gas flow rate at any axial location and increase in the development length. The pressure drops along the development length and causes the bubbles to expand which causes increase in the bubble DSM. Since, the flow is still developing at port P1 $(\mathrm{L} / \mathrm{D}=6)$, the bubbles size have a uniform distribution across the pipe cross-section. However, as the flow develops in the vertical-upward section, the larger bubbles tend migrate towards the centre of the pipe cross-section and the smaller bubbles towards the pipe wall.
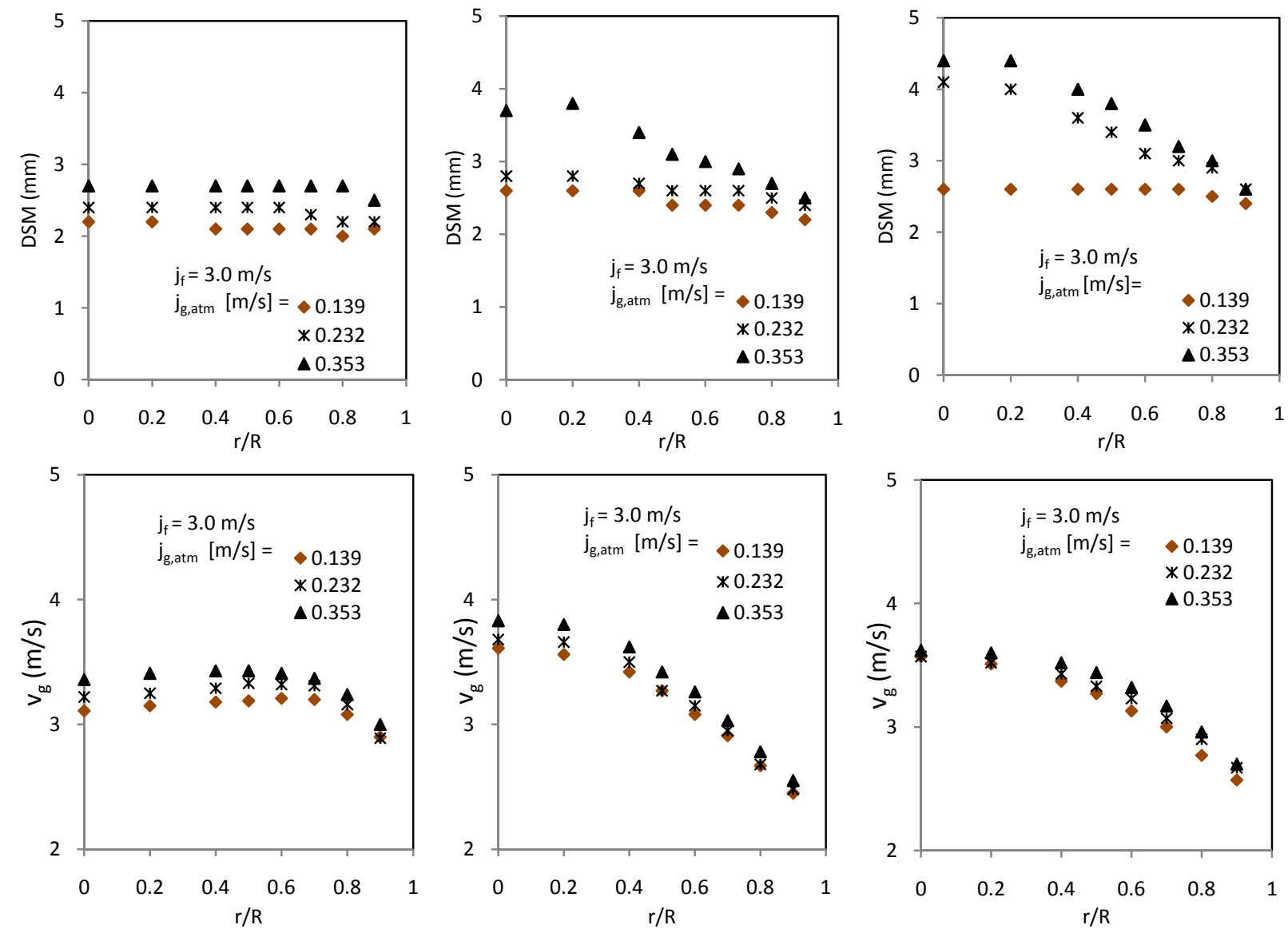

Figure 3.30 Local profiles of bubble Sauter mean diameter and bubble velocity for a constant liquid flow rate, $\mathrm{j} f=3.0 \mathrm{~m} / \mathrm{s}$ and increasing gas flow rates, at different axial locations along the vertical upward section 


\subsubsection{Horizontal Section:}

The local two-phase flow parameters in the horizontal section are measured at four measurement ports P4, P5, P7 and P10 located at development lengths of 3D, 30D, 90D and 170D downstream of the vertical upward elbow. Unlike vertical section, the bubble distribution in the horizontal section is asymmetric due to the buoyancy and elbow effects. Hence, local measurements are obtained across the entire pipe cross-section. The horizontal measurement port, shown in Fig. 3.31-b, is designed such that it can be rotated at 22.5-degree intervals in the azimuthal direction. The measurement scheme used in the horizontal section is shown in Fig. 3.31-a. Here, $r / R_{V}$ and $r / R_{H}$ denotes the vertical and horizontal axis of measurement of the pipe cross-section respectively. The direction of flow is perpendicular to the plane in the outward direction. At each of the 8 angular positions, the conductivity probe is traversed to fifteen different radial positions. Hence, at a given axial location and for a given flow condition a total of 120 local data points is measured across the entire pipe cross-section.
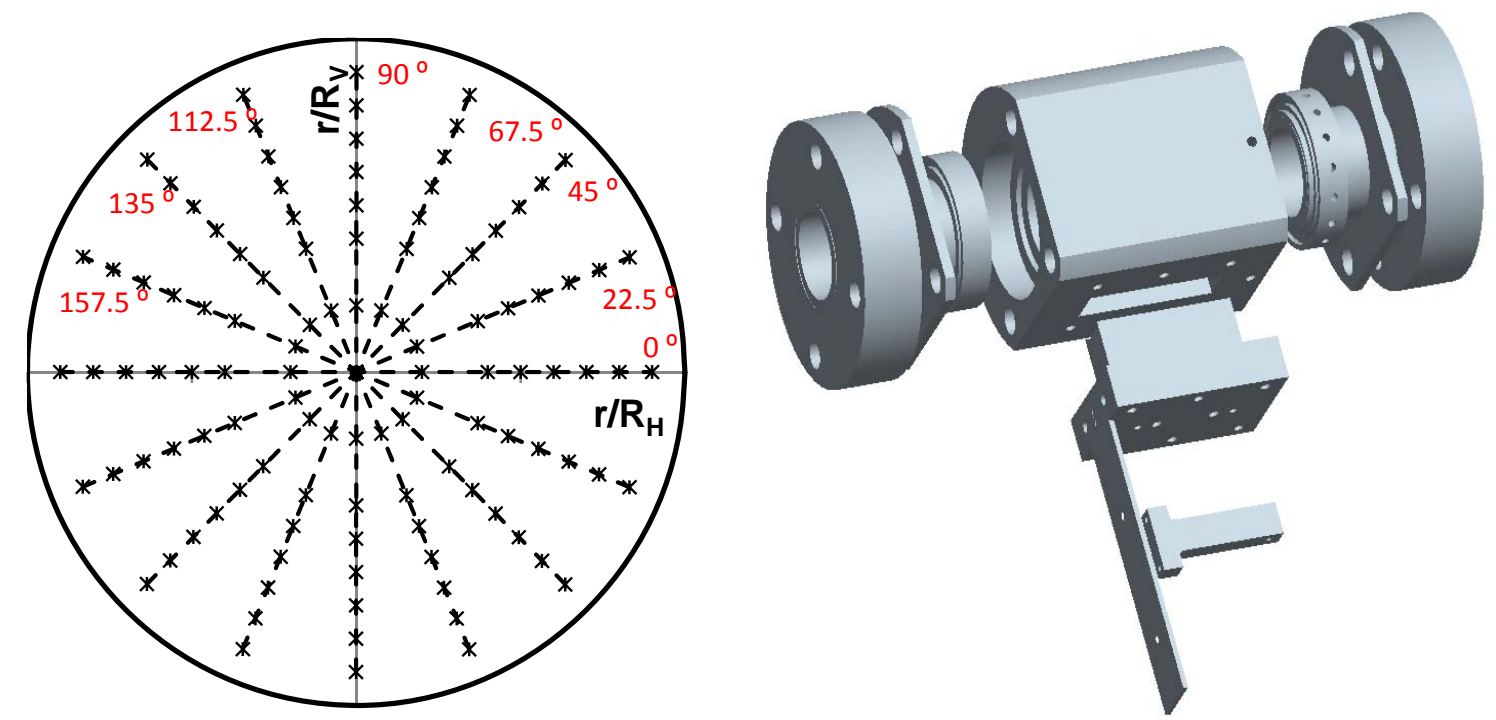

Figure 3.31 a) The measurement scheme used to obtain local two-phase flow parameters in the horizontal section b) Instrumentation port for horizontal two-phase flow measurements

Figure 3.32 shows the local profiles of void fraction and interfacial area concentration measured across the pipe cross-section at port $\mathrm{P} 4$ for liquid flow rate of $3.0 \mathrm{~m} / \mathrm{s}$ and gas flow rate of $0.35 \mathrm{~m} / \mathrm{s}$. Measurements along the azimuthal directions of 0-degree and 90-degree denote the 
horizontal and vertical axis of the pipe cross-section. It is interesting that most of the bubbles are distributed along the horizontal axis of the pipe cross-section and peak in the bubble distribution occurs approximately at $r / R= \pm 0.5$. Where, $r / R$ is the non-dimensional radial distance measured from the pipe centre. This creates a bimodal distribution along the horizontal axis of the pipe cross-section. The local profiles along the vertical radius indicate a higher bubble distribution in the top half of the pipe cross-section, which is due to the buoyancy force on the bubbles. Since the measurements are obtained under bubbly flow conditions, the local interfacial area concentration profiles are similar to the local void fraction profiles.
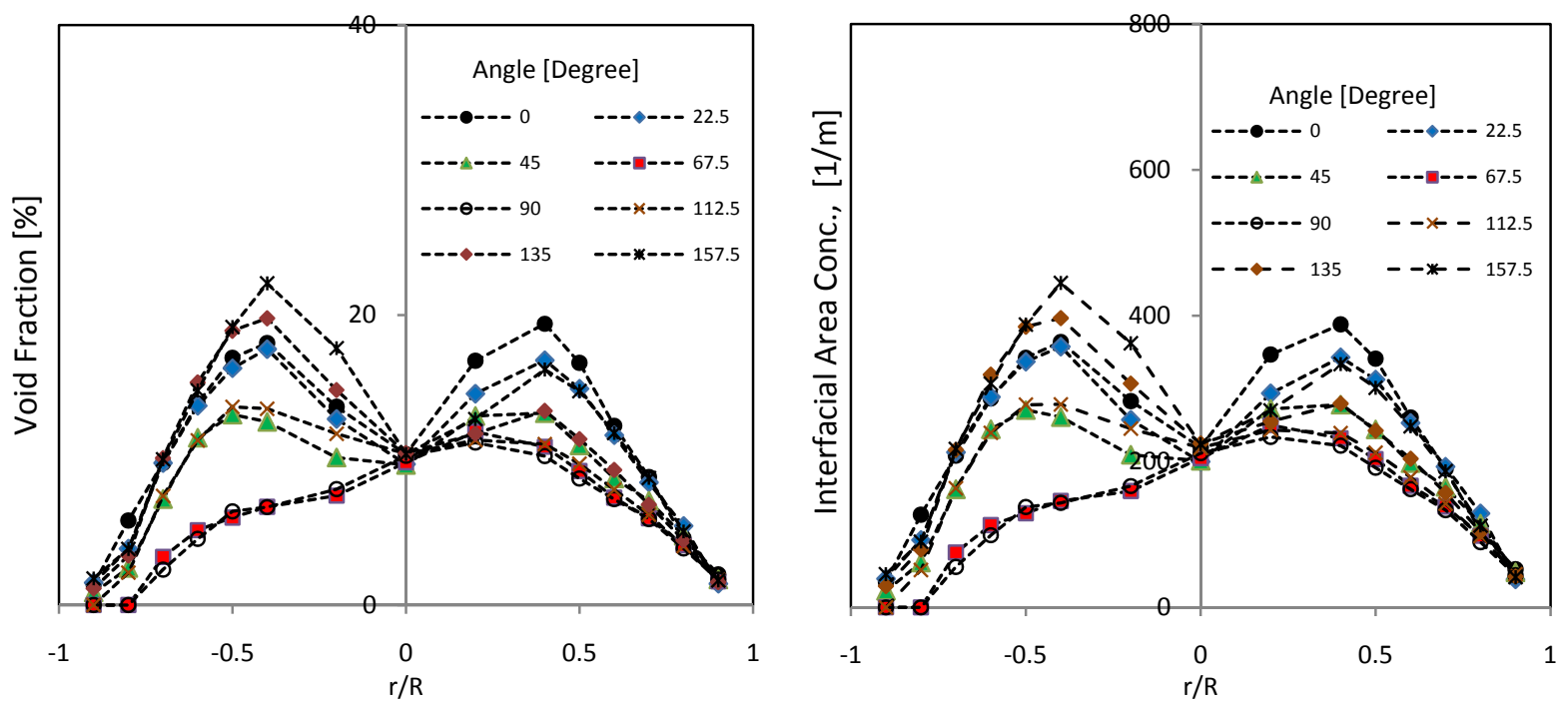

Figure 3.32 Local profiles of void fraction and interfacial area concentration for Run 4, jf $=3.0$ $\mathrm{m} / \mathrm{s}$ and $\mathrm{j}_{\mathrm{g}, \mathrm{atm}}=0.14 \mathrm{~m} / \mathrm{s}$, measured at port P4 (3D downstream of vertical elbow) for different azimuthal directions

These detailed measurements are then used to obtain three-dimensional profiles and contour plots of void fraction, interfacial area concentration, bubble velocity and bubble Sauter mean diameter. Figures 3.33 and 3.34 shows the three-dimensional profiles and contour plots of measured local void fraction and interfacial area concentration, respectively, at port P4. These three-dimensional profiles provide clear representation of bimodal void distribution immediately downstream of the elbow. It is speculated that this distribution is created by the secondary flow generated by the 90 -degree vertical elbow as explained later. 

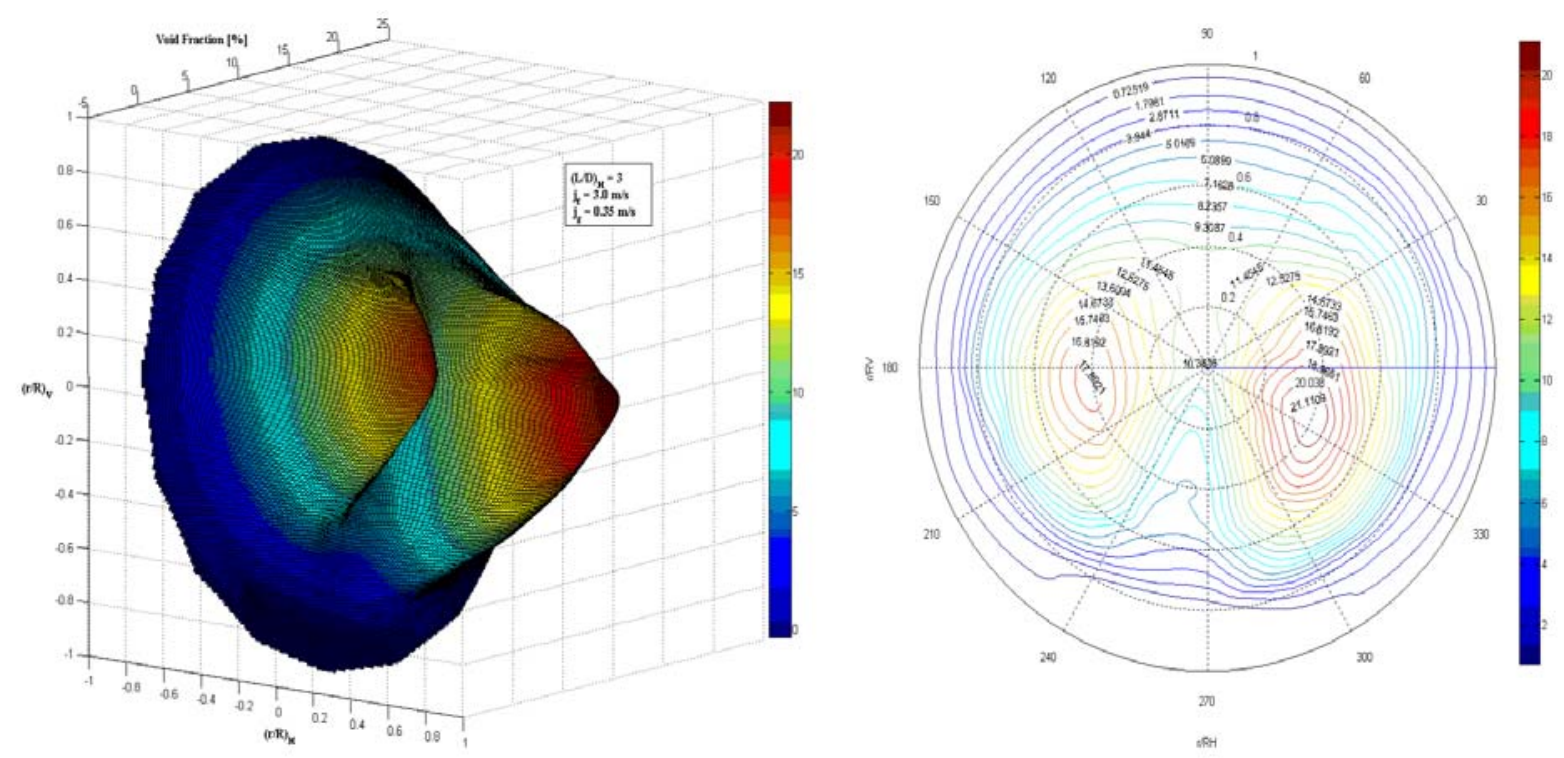

Figure 3.33 Three-dimensional profile and contour plot of void fraction at port P4 for Run6 $\left(\mathrm{j}_{\mathrm{f}}=\right.$ $3.0 \mathrm{~m} / \mathrm{s}$ and $\mathrm{j}_{\mathrm{g}, \mathrm{atm}}=0.35 \mathrm{~m} / \mathrm{s}$ )
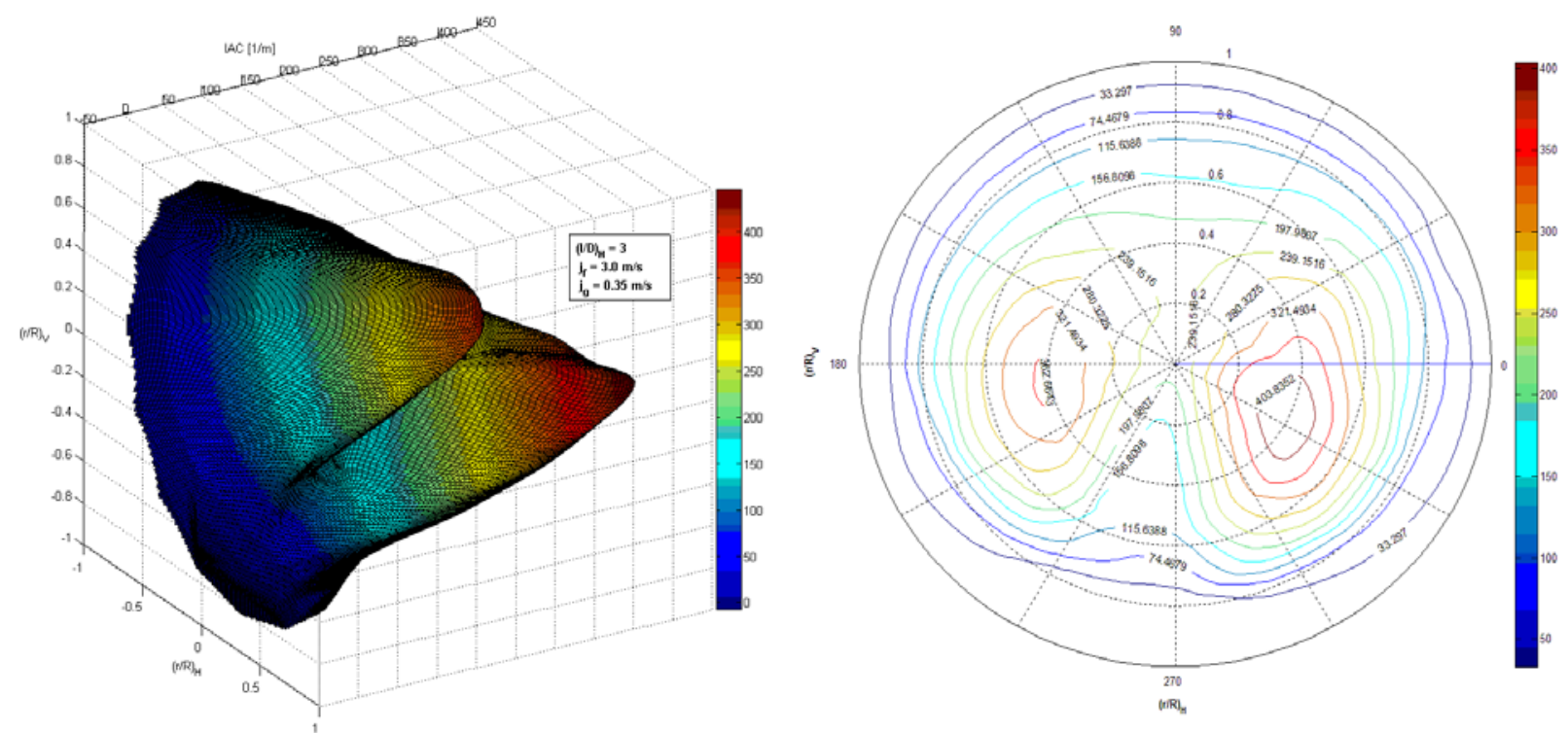

Figure 3.34 Three-dimensional profile and contour plot of interfacial area concentration at port $\mathrm{P} 4$ for Run6 $\left(\mathrm{j}_{\mathrm{f}}=3.0 \mathrm{~m} / \mathrm{s}\right.$ and $\left.\mathrm{j}_{\mathrm{g}, \mathrm{atm}}=0.35 \mathrm{~m} / \mathrm{s}\right)$

Moreover, flow visualization is performed from underneath the measurement port P4. Figure 3.35 shows typical high speed image for two flow conditions corresponding to a constant liquid 
flow rate, $\mathrm{j}_{\mathrm{f}}=3.0 \mathrm{~m} / \mathrm{s}$ and gas flow rates, $\mathrm{j}_{\mathrm{g}, \mathrm{atm}}=0.14 \mathrm{~m} / \mathrm{s}$ and $0.35 \mathrm{~m} / \mathrm{s}$. It is clear from the images that the bubbles are distributed in two distinct streaks moving parallel to each other.

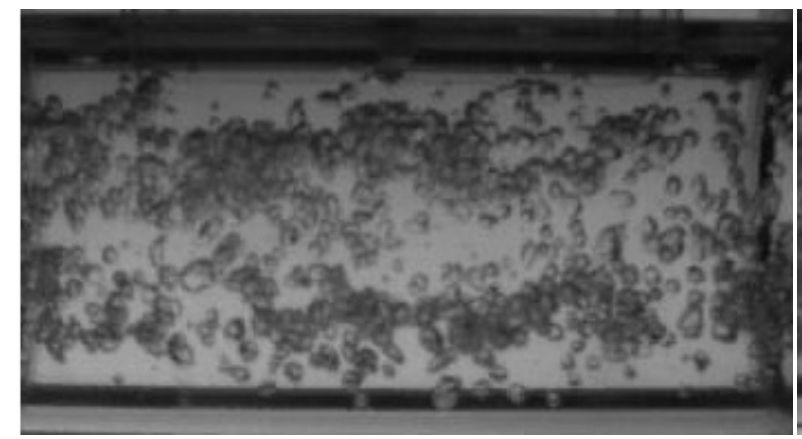

$\mathrm{j}_{\mathrm{f}}=3.0 \mathrm{~m} / \mathrm{s} ; \mathrm{j}_{\mathrm{g}, \mathrm{atm}}=0.14 \mathrm{~m} / \mathrm{s}$

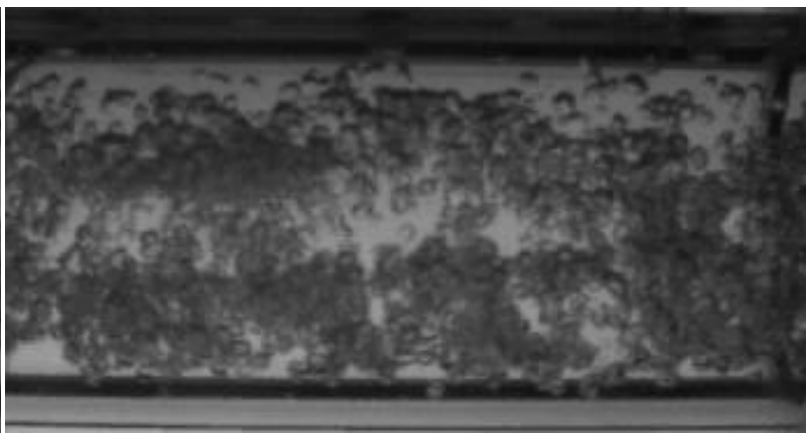

$\mathrm{j}_{\mathrm{f}}=3.0 \mathrm{~m} / \mathrm{s} ; \mathrm{j}_{\mathrm{g}, \mathrm{atm}}=0.23 \mathrm{~m} / \mathrm{s}$

Figure 3.35 Flow visualization at port P4 (3D downstream of the vertical-upward elbow) for two different flow conditions (Image taken from bottom of the measurement port)

During the fluid flow through elbows or pipe bends of any cross-section, secondary flow is observed in the plane perpendicular to the curved central axis of the pipe. The effect of curvatures and elbow bends on the flow structure for single phase-flow is well understood. Ito (1987) presented a comprehensive review on flow through various curved pipes and bends with different cross-sectional forms and various flow conditions. The theoretical explanation for the secondary flows was first given by Thompson (1879). During fluid flow in curved pipes or bends and elbows, the higher velocity fluid, moving near the centre of the pipe cross-section experiences a higher centrifugal force as compared to the slower moving fluid in the boundary layer. This causes the fluid at the centre to move outward and the fluid flowing in the boundary layer to move inward, which creates a secondary flow in a plane perpendicular to the axial velocity (Schlichting, 1960). However, there is a lack of experiments and hence knowledge on the effect of secondary flow on two-phase flow structure. In present study, the experiments are performed within the bubbly flow regime and the average bubble Sauter mean diameter at port P4 for all run conditions is approximately 3-4 $\mathrm{mm}$. It is speculated the bubbles entering the elbow are entrained along the secondary flow streamlines and hence are distributed in two vertical regions created by the secondary flow along the horizontal axis of the pipe cross-section in the plane perpendicular to the central axis of the elbow. At port P4, there is an additional 
force due the buoyancy on the bubbles which causes a higher local void fraction in the upper half of the pipe cross-section.

Three-dimensional profiles and contour plots of local void fraction measured at port P5, located 30D downstream of the vertical elbow is shown in Fig. 3.36. It is observed that the bimodal bubble distribution at port P4 changes to a single peak near the top wall of the pipe cross-section. This is because the secondary flow and hence the effect of the elbow on bubble distribution decays within the short development length of 30 pipe diameters. Moreover, the buoyancy starts to dominate causing the bubbles to move towards the top wall of the pipe crosssection.
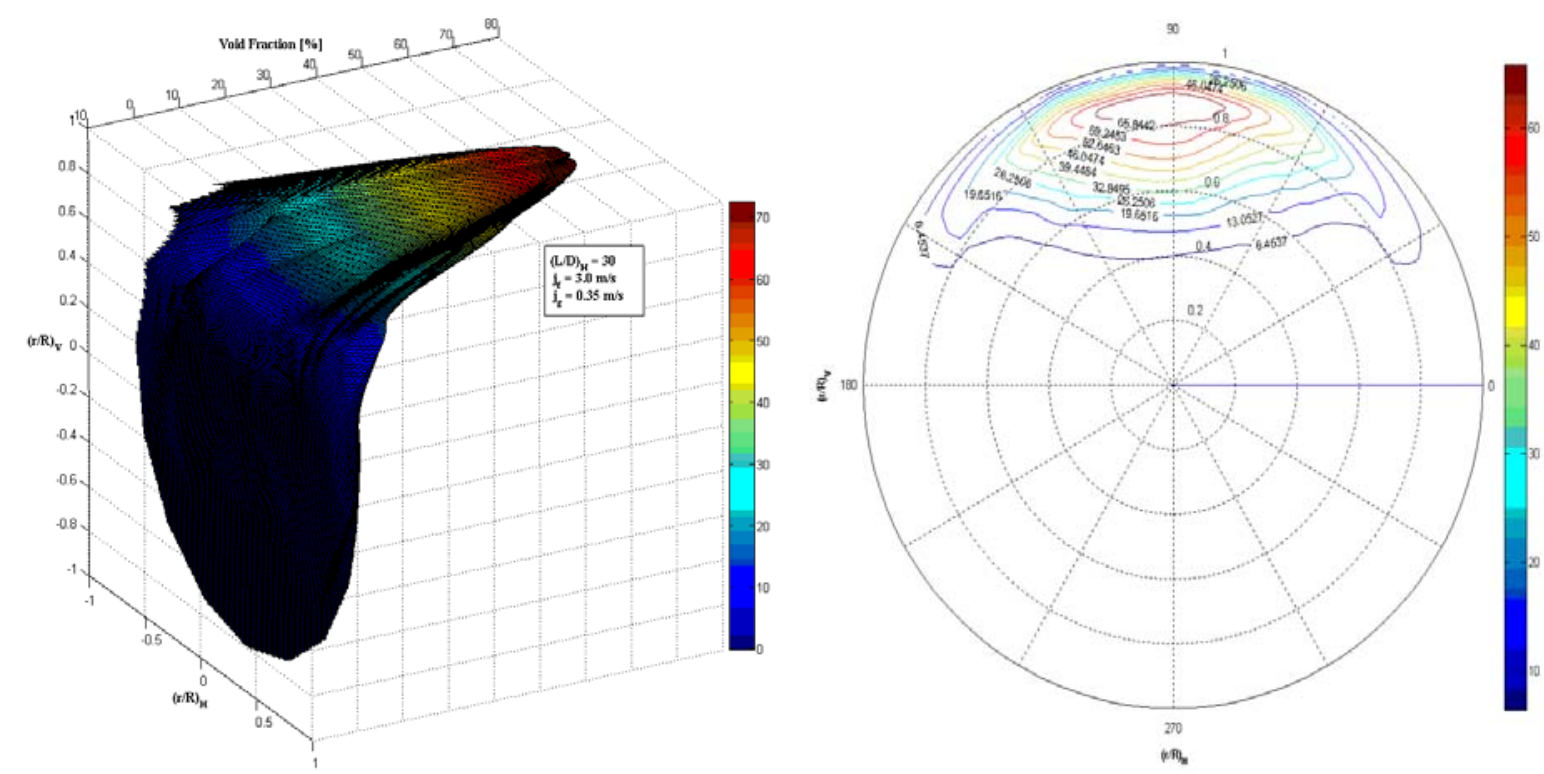

Figure 3.36 Three-dimensional profile and contour plot of interfacial area concentration at port P5 (L/D = 33 downstream of vertical-upward elbow) for Run6 $\left(\mathrm{j}_{\mathrm{f}}=3.0 \mathrm{~m} / \mathrm{s}\right.$ and $\left.\mathrm{j}_{\mathrm{g}, \mathrm{atm}}=0.35 \mathrm{~m} / \mathrm{s}\right)$

The effect of development length on the local interfacial structures is shown in Fig. 3.37. Here, three-dimensional profiles of void fraction at ports P7 and P10 located at 90D and 177D downstream of the vertical upward elbow, respectively, are shown. At these measurement locations the void distribution essentially remains concentrated in the upper half of the pipe cross-section, however the position of the minimum local void fraction moves towards the top wall. It is also observed that the void fraction contribution arising from group-II bubbles 
increases as we move downstream of the elbow. This suggests that bubbles start to coalesce as also demonstrated by the flow visualization studies.
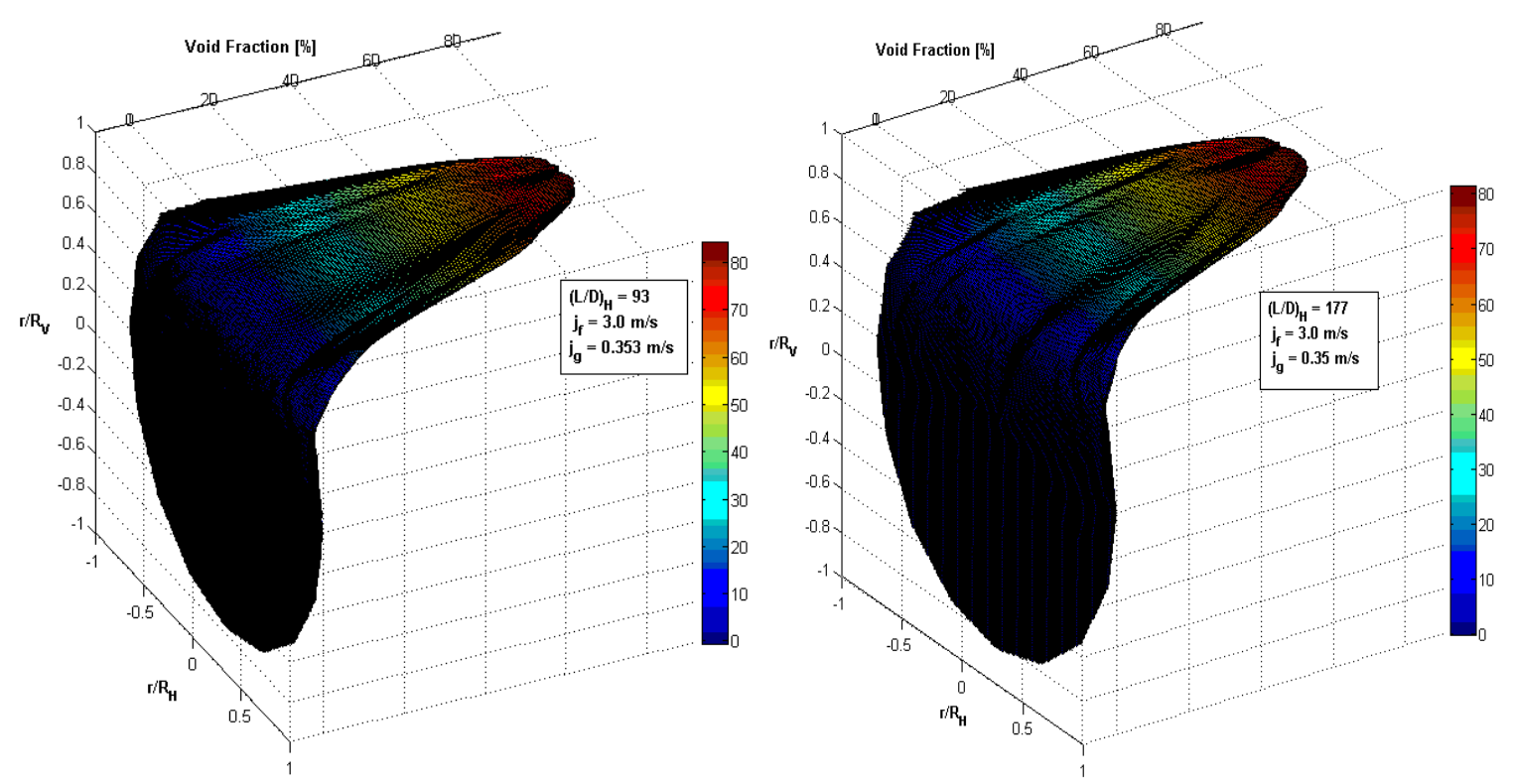

Figure 3.37 Three-dimensional profiles of measured local void fraction at ports P7 and P10 (93D and 177D downstream of vertical-upward elbow) for Run6 $\left(\mathrm{j}_{\mathrm{f}}=3.0 \mathrm{~m} / \mathrm{s}\right.$ and $\left.\mathrm{j}_{\mathrm{g}, \mathrm{atm}}=0.35 \mathrm{~m} / \mathrm{s}\right)$

\subsubsection{Vertical-Downward Section}

In the vertical downward section, the local two-phase flow parameters are measured at ports P11, P12 and P14 which are located 2.5D, 16.5D and 66.5D downstream of the vertical downward elbow. In order to capture the elbow effect, local data is acquired in four different radial directions by rotating the measurement port. For each radial direction 15 local measurements are made along the pipe diameter, leading to 60 data points across the crosssection. Figure 3.38 shows the co-ordinate system used to present the local data in the vertical downward section. The direction of flow is into the page and denoted by the cross on the pipe cross-section. Here, $r / R_{C}$ and $r / R_{P}$ denote the non-dimensional radial positions of measurement along the direction of curvature of the elbow and perpendicular to the direction of curvature of the elbow respectively. The outside of the elbow curvature is defined as positive. In order to define the universal co-ordinate system for the entire combinatorial channels, the fluid flow is taken as reference. 


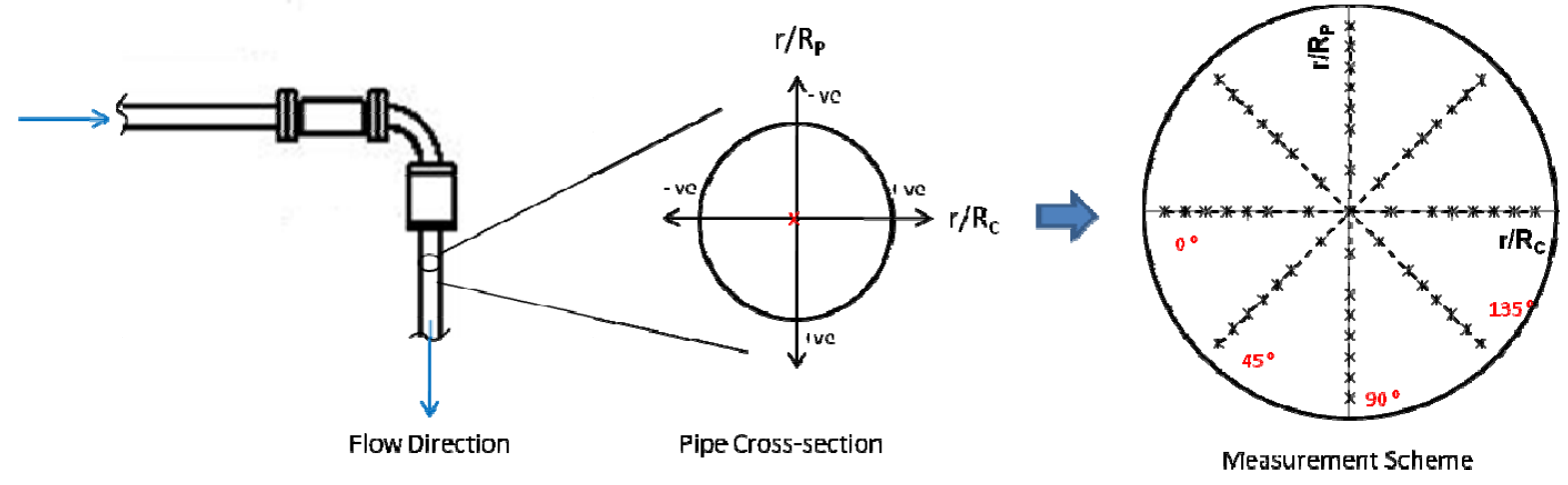

Figure 3.38 Co-ordinate system and measurement scheme for vertical downward two-phase flow (flow direction is into the page)
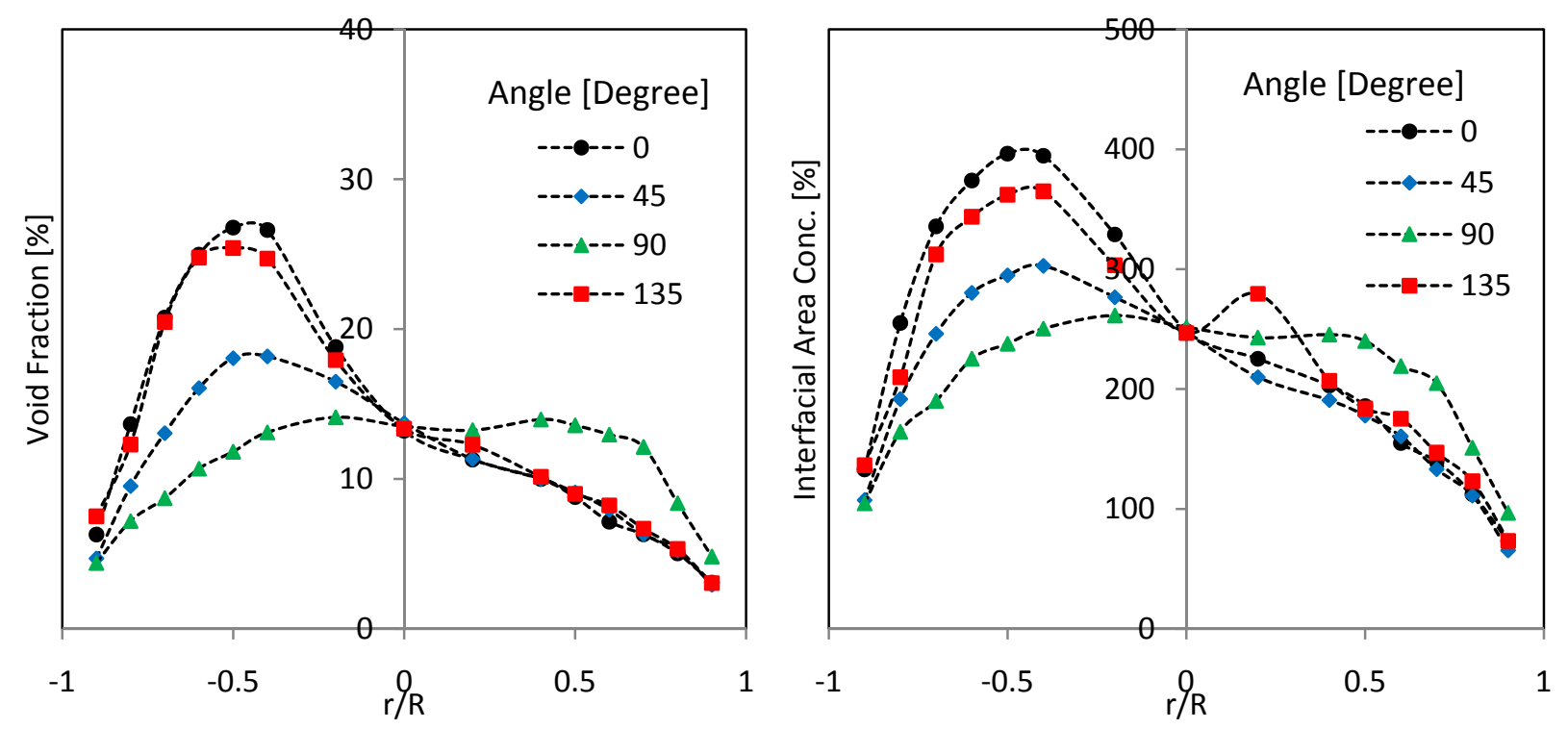

Figure 3.39 Local profiles of void fraction and interfacial area concentration for Run $6, \mathrm{j}_{\mathrm{f}}=3.0$ $\mathrm{m} / \mathrm{s}$ and $\mathrm{j}_{\mathrm{g}, \mathrm{atm}}=0.35 \mathrm{~m} / \mathrm{s}$, measured at port P11 (3D downstream of vertical-downward elbow) for different azimuthal directions

Figure 3.40 shows the three dimensional profiles of measured local void fraction and interfacial area concentration. As evident from the figures, the local profiles have a peak in towards the inside of the elbow curvature which suggests the migration of the bubbles in this 
region. Although, the secondary flow circulation is expected but the flow if dominated by the inertial forces. Hence, the higher inertia liquid falls along the outer curvature of the elbow radius and forces the gas towards the inner curvature of the elbow.
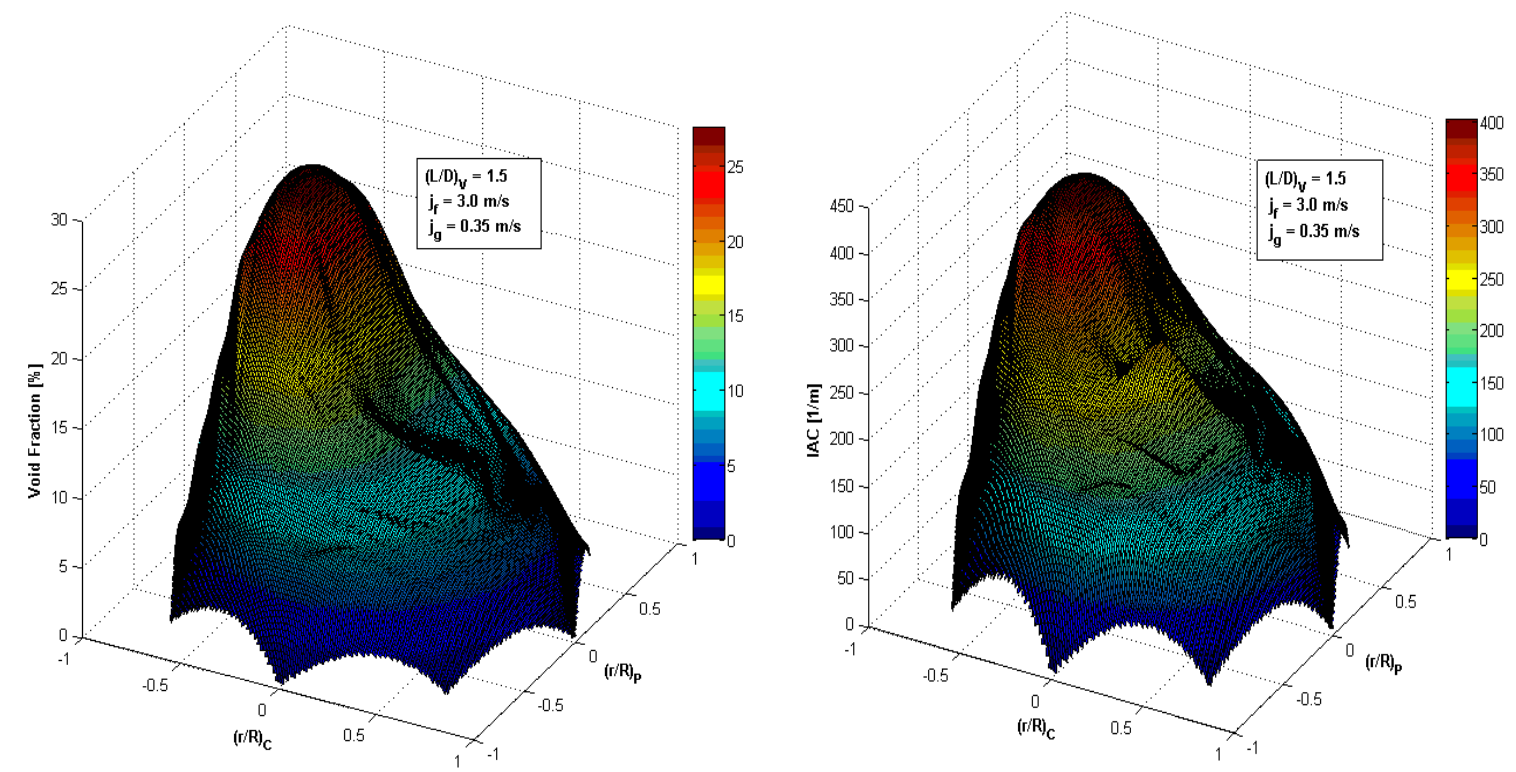

Figure 3.40 Three-dimensional profiles of measured void fraction and interfacial area concentration at port P11 for Run6 $\left(\mathrm{j}_{\mathrm{f}}=3.0 \mathrm{~m} / \mathrm{s}\right.$ and $\left.\mathrm{j}_{\mathrm{g}, \mathrm{atm}}=0.35 \mathrm{~m} / \mathrm{s}\right)$

Figures 3.41 and 3.42 show the local profiles of void fraction and interfacial area concentration at ports P12 and P14, located 16.5D and 66.5D downstream of the elbow. It is observed that the elbow effect decays by port P12 and the bubble distribution becomes symmetric. Further downstream at port P14 the bubbles start to accumulate in the centre of the pipe radius causing a steep centre peak in the local void fraction profile. This suggests coring of the bubbles in the centre of the pipe which is typical of the developed vertical downward twophase bubbly flow. 

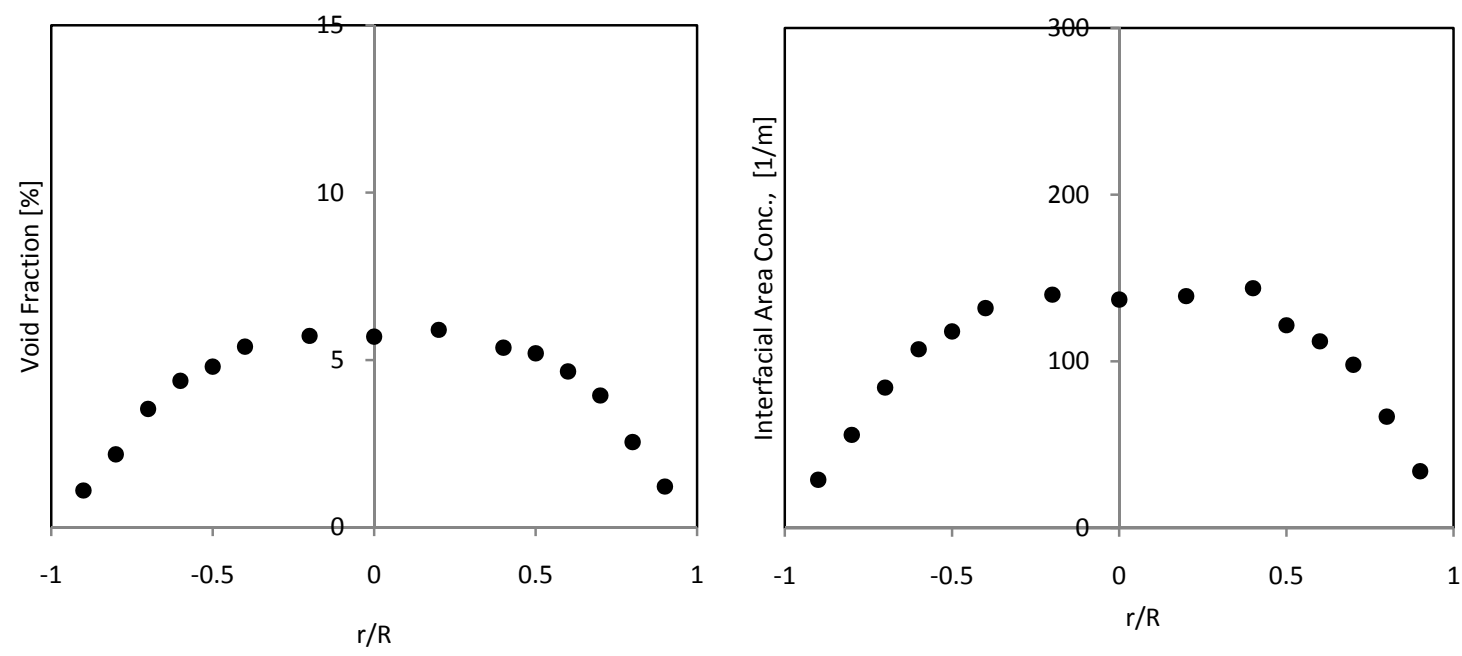

Figure 3.41 Radial profiles of local void fraction and interfacial area concentration at port P12 for Run4 $\left(\mathrm{j}_{\mathrm{f}}=3.0 \mathrm{~m} / \mathrm{s}\right.$ and $\left.\mathrm{j}_{\mathrm{g}, \mathrm{atm}}=0.35 \mathrm{~m} / \mathrm{s}\right)$
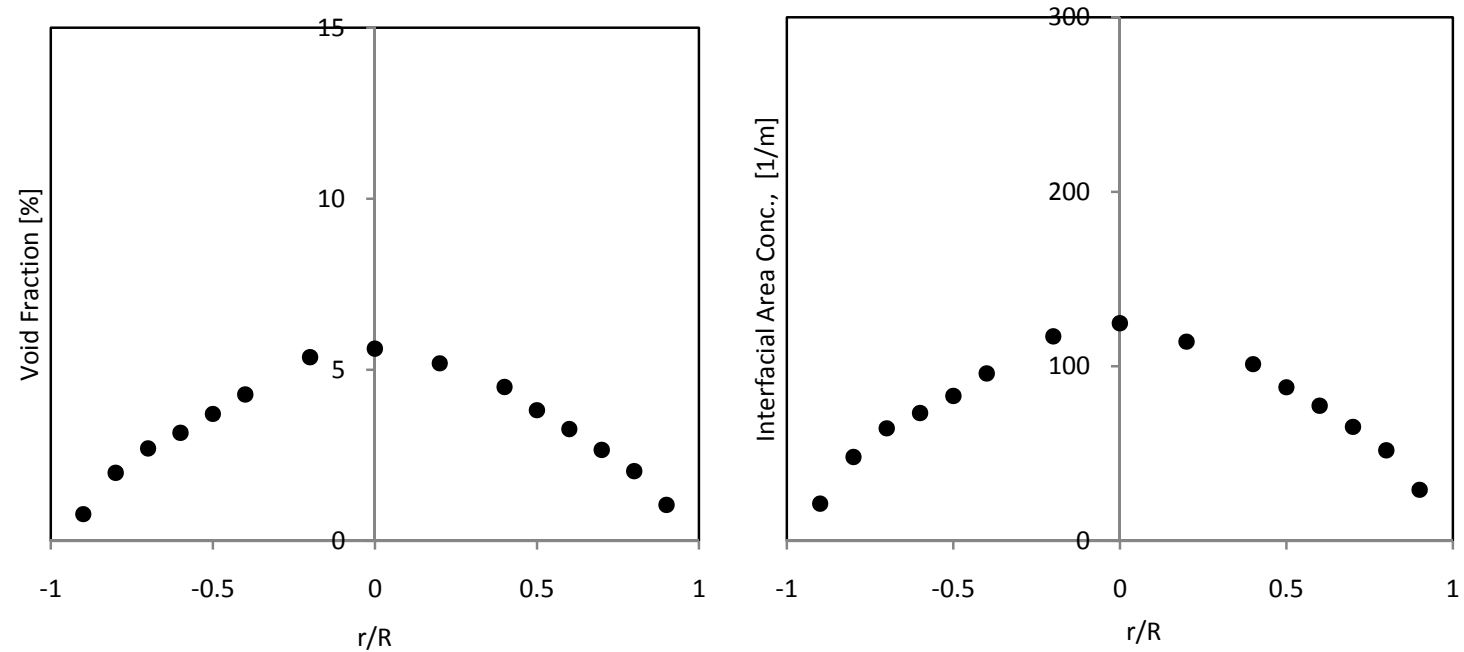

Figure 3.42 Radial profiles of local void fraction and interfacial area concentration at port P11 for Run4 $\left(\mathrm{j}_{\mathrm{f}}=3.0 \mathrm{~m} / \mathrm{s}\right.$ and $\left.\mathrm{j}_{\mathrm{g}, \mathrm{atm}}=0.35 \mathrm{~m} / \mathrm{s}\right)$

A comprehensive development of the local profiles of void fraction along the combinatorial channels is shown in Fig. 3.43. The figure shows the evolution of centre peaked bubbly twophase flow during different stages of development across the 90-degree vertical elbows. It is interesting that the elbows not only promote bubble interaction but also have a significant effect on the bubble distribution which can provide insights into the flow regime transitions. 


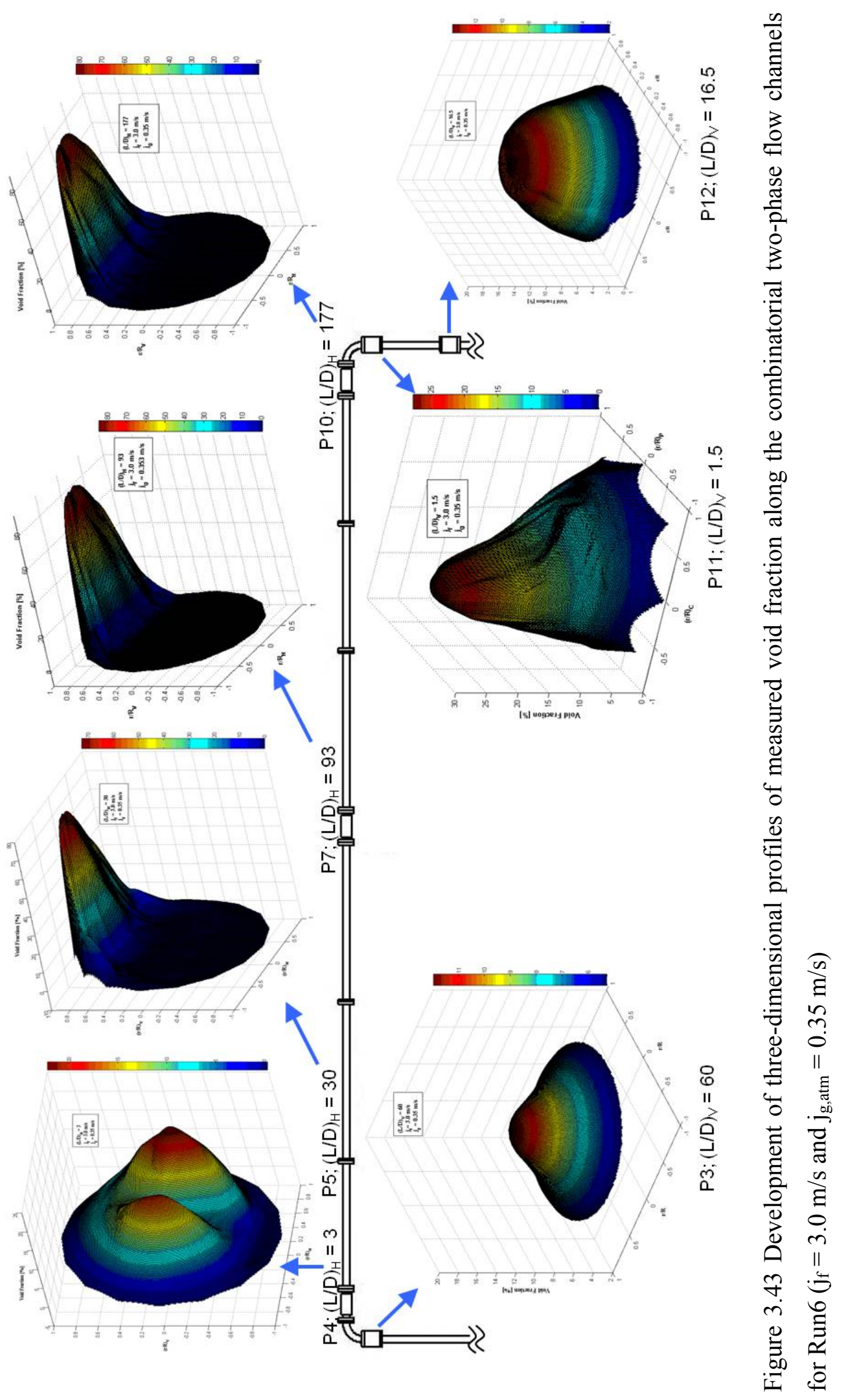




\subsection{One-Dimensional Transport of Interfacial Structures}

\subsubsection{Void Fraction and Interfacial Area Concentration}

The local measurements at each axial location are used to obtain area-averaged values of different two-phase flow parameters using the Simpson's rule of numerical integration. Figure 3.44 and 3.45 shows the one-dimensional transport of area-averaged void fraction, $<\alpha>$ and areaaveraged interfacial area concentration, $\left\langle\mathrm{a}_{\mathrm{i}}>\right.$ for constant liquid flow rate, $\mathrm{j}_{\mathrm{f}}$ of $2.0 \mathrm{~m} / \mathrm{s}$ and increasing gas flow rates. The vertical lines represent the location of the elbows and distinguish between the regions of vertical upward, horizontal and vertical downward two-phase flow respectively in the direction of increasing development length. It is observed that $\langle\alpha\rangle$ increases along the vertical upward section. This increase is attributed to the pressure drop along the vertical section which causes the bubbles to expand and hence effectively increasing $<\alpha>$. Moving further downstream it is observed that the $\langle\alpha\rangle$ decreases across the vertical upward elbow and becomes almost constant along the horizontal section after port P7, located 93D downstream of the elbow. The decrease in $\langle\alpha\rangle$ can be attributed to the local acceleration of the bubbles across the elbow. Further downstream of the elbow, the change in $\langle\alpha\rangle$ along the horizontal section is majorly due to the frictional pressure drop which is not significant. As the flow moves from horizontal-to-vertical downward section, a sharp rise in $\langle\alpha\rangle$ is observed across the vertical downward elbow. Conventional analysis would indicate that this can be caused by either a large pressure drop across the vertical downward elbow or a large deceleration across the elbow. However, the pressure drop data reveals that there is a net increase in the static pressure across the elbow and the transport of void-weighted bubble velocity shows that there is an acceleration of the gas-phase across the elbow. As such flow visualization is performed at port P11 ( $\mathrm{L} / \mathrm{D}=3$ from vertical downward elbow) to identify the cause of this unexpected rise in $\langle\alpha\rangle$. Flow visualization shows that there are regions of recirculation at port P11 and large bubbles moving across the elbow tend to stay at the measurement location for an extended period of time before being entrained by the liquid. The higher residence time of the large bubbles and the recirculation causes the $\langle\alpha\rangle$ to increase sharply. Further downstream in the vertical downward section $\langle\alpha\rangle$ decreases because pressure increases in the axial direction causing the bubbles to contract. 


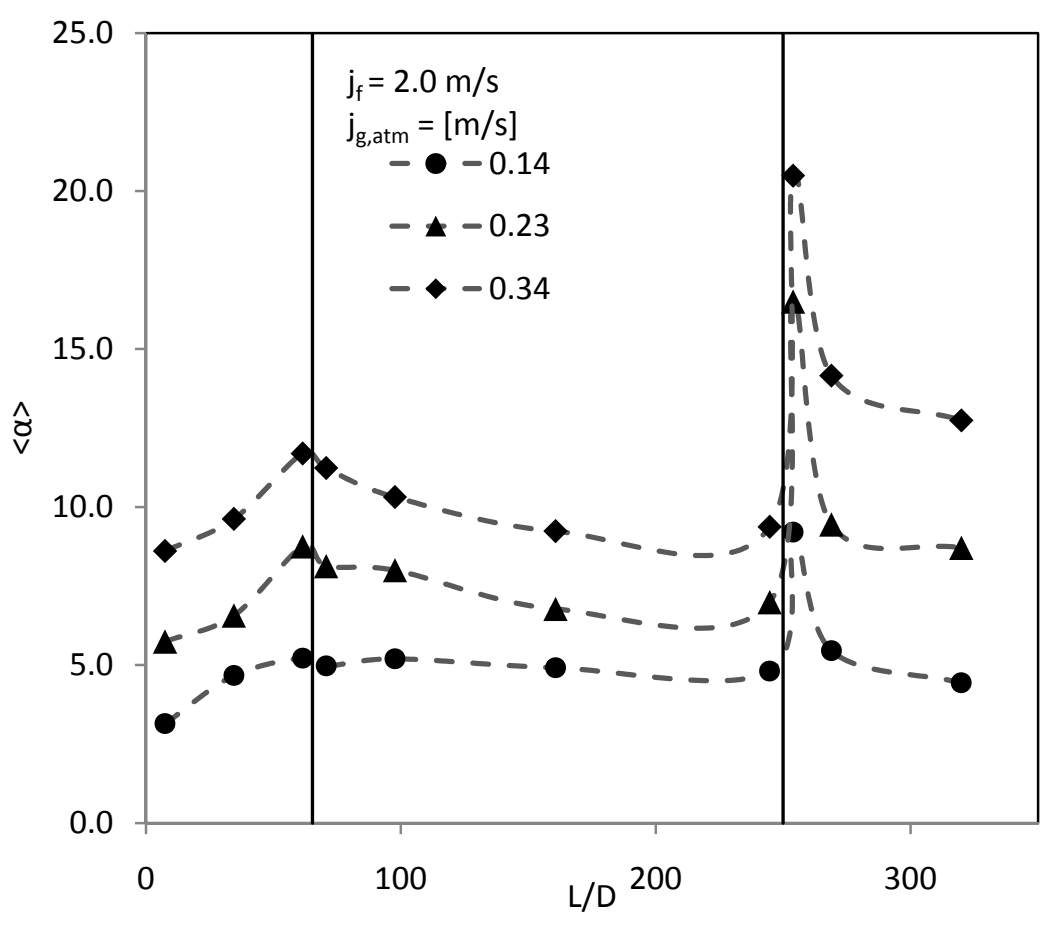

Figure 3.44 Axial development of area averaged void fraction for a constant liquid flow rate, $\mathrm{j}_{\mathrm{f}}=$ $2.0 \mathrm{~m} / \mathrm{s}$ and increasing gas flow rates

The transport of $<\mathrm{a}_{\mathrm{i}}>$ in the vertical upward section shows that with an exception of run condition with lowest gas flow rate, $<\mathrm{a}_{\mathrm{i}}>$ decreases between ports P1 and P2 and then increases between ports P2 and P3. Since, the two-phase flow is still developing at port P1 (L/D =6), the decrease of $\left\langle\mathrm{a}_{\mathrm{i}}\right\rangle$ can be attributed to the inlet effect. Between ports P2 and P3 transport of $\left.<\mathrm{a}_{\mathrm{i}}\right\rangle$ is similar to transport of $\langle\alpha\rangle$, which is characteristic of the bubbly flow. Similar to the vertical upward section, $\left.<\mathrm{a}_{\mathrm{i}}\right\rangle$ follows $\langle\alpha>$ across the vertical upward elbow. However, there is a sharp decline in $\left\langle\mathrm{a}_{\mathrm{i}}\right\rangle$ for all flow conditions along the horizontal section. This sharp decrease in $\left\langle\mathrm{a}_{\mathrm{i}}\right\rangle$ can be explained based on the fact that as the bubbles move along the horizontal section they migrate towards the top wall of the pipe and in the process coalesce to form larger plug or slug bubbles. Hence, coalescence of the bubbles along the horizontal section causes a decrease in $\left.<\mathrm{a}_{\mathrm{i}}\right\rangle$. An explanation similar to the transport of $\langle\alpha>$ across the vertical downward elbow follows for the transport of $<\mathrm{a}_{\mathrm{i}}>$ across the vertical downward elbow. Further downstream in the vertical downward section $<\mathrm{a}_{\mathrm{i}}>$ either decreases or increases depending on the gas flow rate. At the lowest gas flow rate, $\left\langle\mathrm{a}_{\mathrm{i}}\right\rangle$ has similar profile as that of $\langle\alpha\rangle$ which is characteristic of the bubbly flows. However, for the higher gas flow rates the flow is characterized by presence of larger 
bubbles. Hence, an increase in $<\mathrm{a}_{\mathrm{i}}>$ along the axial direction suggests breakup of the large bubbles.

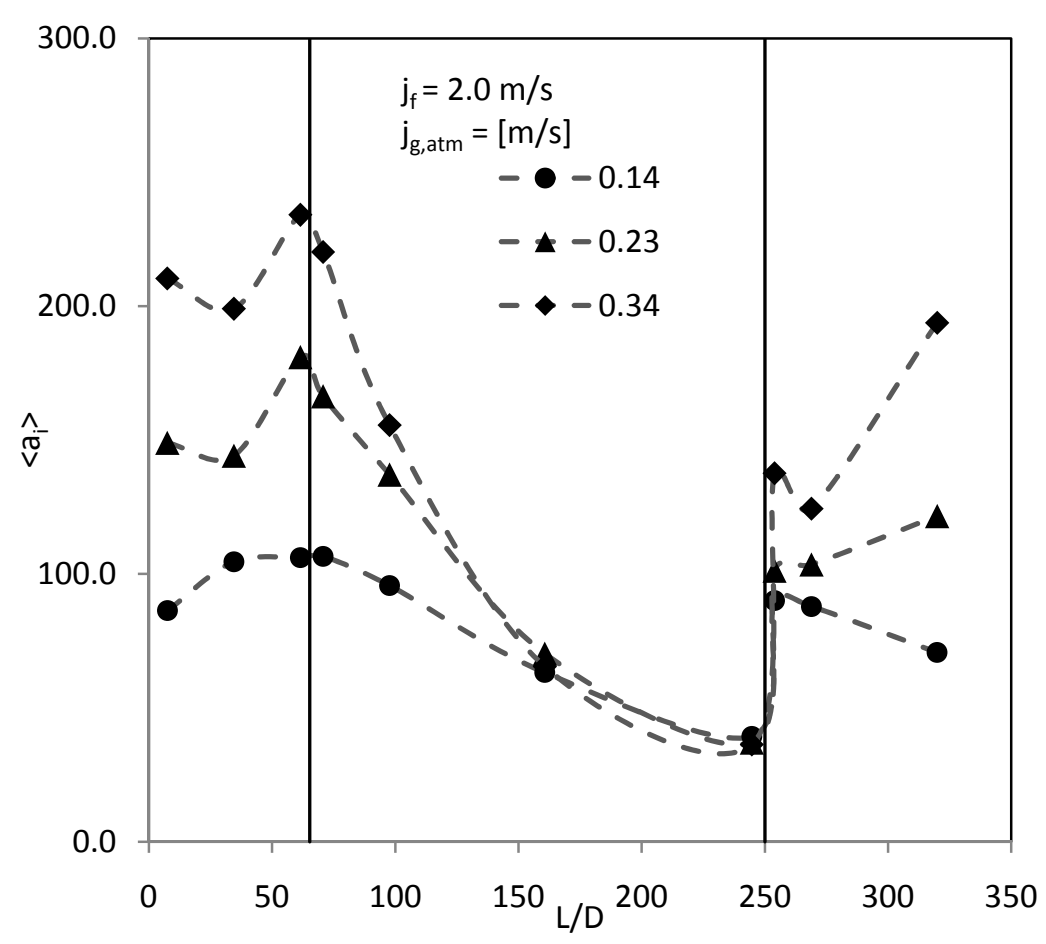

Figure 3.45 Axial development of area averaged interfacial area concentration for a constant liquid flow rate, $\mathrm{j}_{\mathrm{f}}=2.0 \mathrm{~m} / \mathrm{s}$ and increasing gas flow rates

The one-dimensional transport of $<\alpha>$ and $<\mathrm{a}_{\mathrm{i}}>$ for flow conditions with constant liquid flow rate of $3.0 \mathrm{~m} / \mathrm{s}$ and increasing gas flow rate are shown in Fig 3.46 and Fig 3.47 respectively. It is observed that the area-averaged void fraction increases along the axial direction in both vertical upward and horizontal section. This can be attributed to the pressure drop along the axial direction which is due to hydrostatic head loss in the vertical upward section, minor losses across the vertical elbow and frictional pressure loss along the length of the test section. Comparing the one-dimensional transport of $<\mathrm{a}_{\mathrm{i}}>$ along the vertical upward section, it is observed that for the flow condition with lower gas flow rate, $j_{g}$,atm of $0.139 \mathrm{~m} / \mathrm{s}$ the $<\mathrm{a}_{\mathrm{i}}>$ follows same trend as that of $<\alpha>$ which is consistent with the its behavior in bubbly flow regime. However, at flow conditions with higher gas flow rates, $<\mathrm{a}_{\mathrm{i}}>$ decreases between ports P2 and P3 in the vertical section, while $\langle\alpha\rangle$ increases. This indicates that bubbles coalesce between ports P2 and P3 leading to a decrease in the surface area. Moreover, there is a sharp increase in $\left\langle\mathrm{a}_{\mathrm{i}}\right\rangle$ across the 
vertical elbow while $\langle\alpha\rangle$ increases gradually. This can be attributed to the disintegration of the bubbles caused by the elbow. There is a gradual increase in $\langle\alpha\rangle$ along the axial direction in the horizontal section. The rate of rise in $\langle\alpha\rangle$ is smaller in the horizontal section compared to the vertical upward section. This is because the pressure loss in the horizontal section has contributions from frictional pressure drop only which are very small compared to the contributions from hydrostatic head and frictional drop in the vertical section. It can be seen that there is a slight decline in $\left\langle\mathrm{a}_{\mathrm{i}}>\right.$ along the horizontal section. This is caused by coalescence of the bubbles along the horizontal section.

Again, the transport of both $\left\langle\alpha>\right.$ and $<\mathrm{a}_{\mathrm{i}}>$ across the vertical downward elbow shows a sharp increase. Similar to the flow conditions with liquid flow rate of $2.0 \mathrm{~m} / \mathrm{s}$, recirculation and stagnation of the bubbles at port P11 causes this increase in the void fraction as well as interfacial area concentration. Further downstream of the vertical downward elbow, both $\langle\alpha\rangle$ and $<\mathrm{a}_{\mathrm{i}}>$ decrease along the axial direction. This happens because local static pressure increases in the axial direction in the vertical downward section causing the contraction of bubbles.

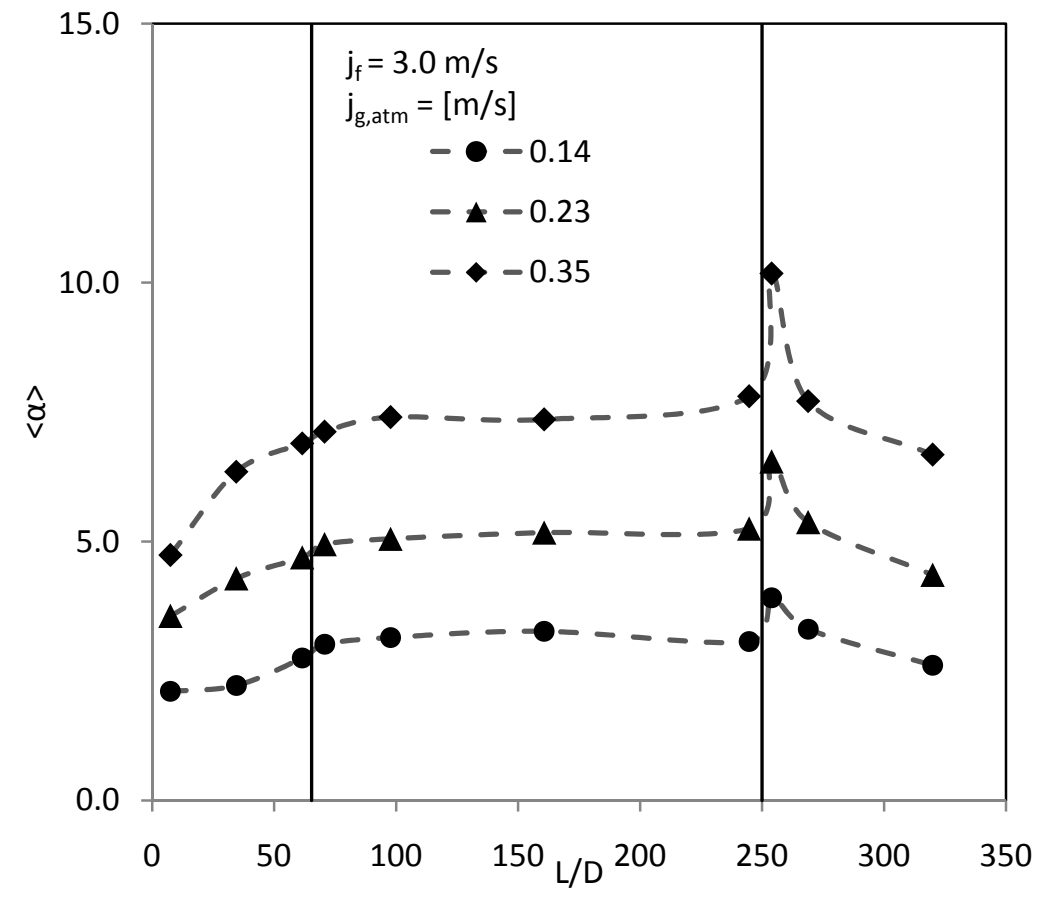

Figure 3.46 Axial development of area averaged void fraction for a constant liquid flow rate, $\mathrm{j}_{\mathrm{f}}=$ $3.0 \mathrm{~m} / \mathrm{s}$ and increasing gas flow rates 


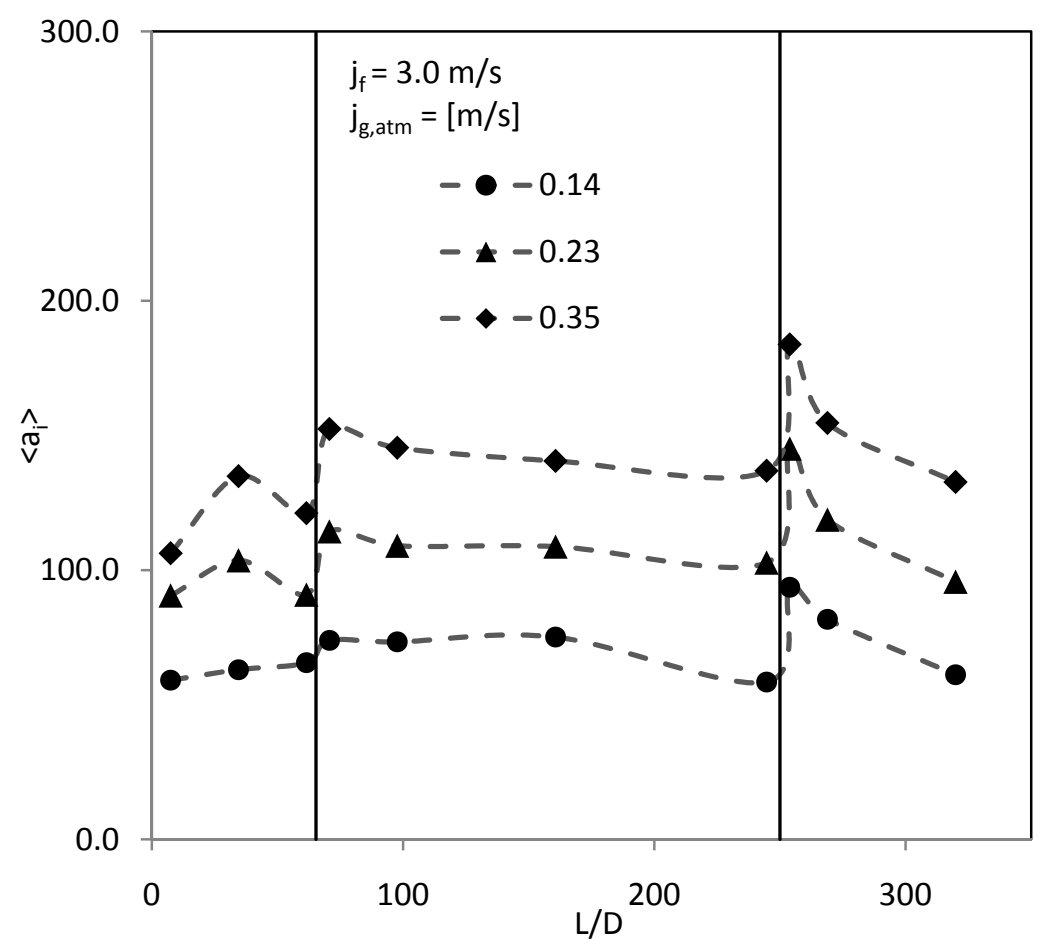

Figure 3.47 Axial development of area averaged interfacial area concentration for a constant liquid flow rate, $\mathrm{j}_{\mathrm{f}}=3.0 \mathrm{~m} / \mathrm{s}$ and increasing gas flow rates

\subsubsection{Void-Weighted Bubble Velocity and Bubble Sauter Mean Diameter}

Figure 3.48 shows the axial transport of void-weighted bubble velocity for flow conditions with constant liquid flow rate of $2.0 \mathrm{~m} / \mathrm{s}$ and $3.0 \mathrm{~m} / \mathrm{s}$ respectively. It is observed that in the vertical upward section, for all the flow conditions the bubbles first decelerate and then accelerate. The deceleration between ports $\mathrm{P} 1$ and $\mathrm{P} 2$ can be regarded as inlet effect. As the flow moves across the vertical elbow the bubbles accelerate for test conditions with constant liquid flow rate of $2.0 \mathrm{~m} / \mathrm{s}$ and decelerate for test conditions with liquid flow rate of $3.0 \mathrm{~m} / \mathrm{s}$. This suggests that the bubbles are entrained with the main flow for test conditions with $\mathrm{j}_{\mathrm{f}}=2.0$ $\mathrm{m} / \mathrm{s}$ but for test conditions with $\mathrm{j}_{\mathrm{f}}=3.0 \mathrm{~m} / \mathrm{s}$ the bubbles get accumulated in the elbow region. Further downstream of the elbow, in the horizontal section, $\left\langle<\mathrm{v}_{\mathrm{g}}\right\rangle>$ remains almost constant for all flow conditions. The transport of $\left\langle<\mathrm{v}_{\mathrm{g}}\right\rangle>$ across the vertical downward elbow shows that the bubbles accelerate irrespective of the flow condition. However, it would be difficult to analyze this behavior because of the stagnation of bubbles and recirculation at port P11 (L/D $=3$ 
downstream of vertical downward elbow). the bubble velocity in the vertical downward section remains almost constant at around $2.0 \mathrm{~m} / \mathrm{s}$ and $3.0 \mathrm{~m} / \mathrm{s}$ for the test conditions with $\mathrm{j}_{\mathrm{f}}=2.0 \mathrm{~m} / \mathrm{s}$ and $\mathrm{j}_{\mathrm{f}}=3.0 \mathrm{~m} / \mathrm{s}$ respectively. This shows that the bubbles are entrained at liquid velocity in the vertical downward section.
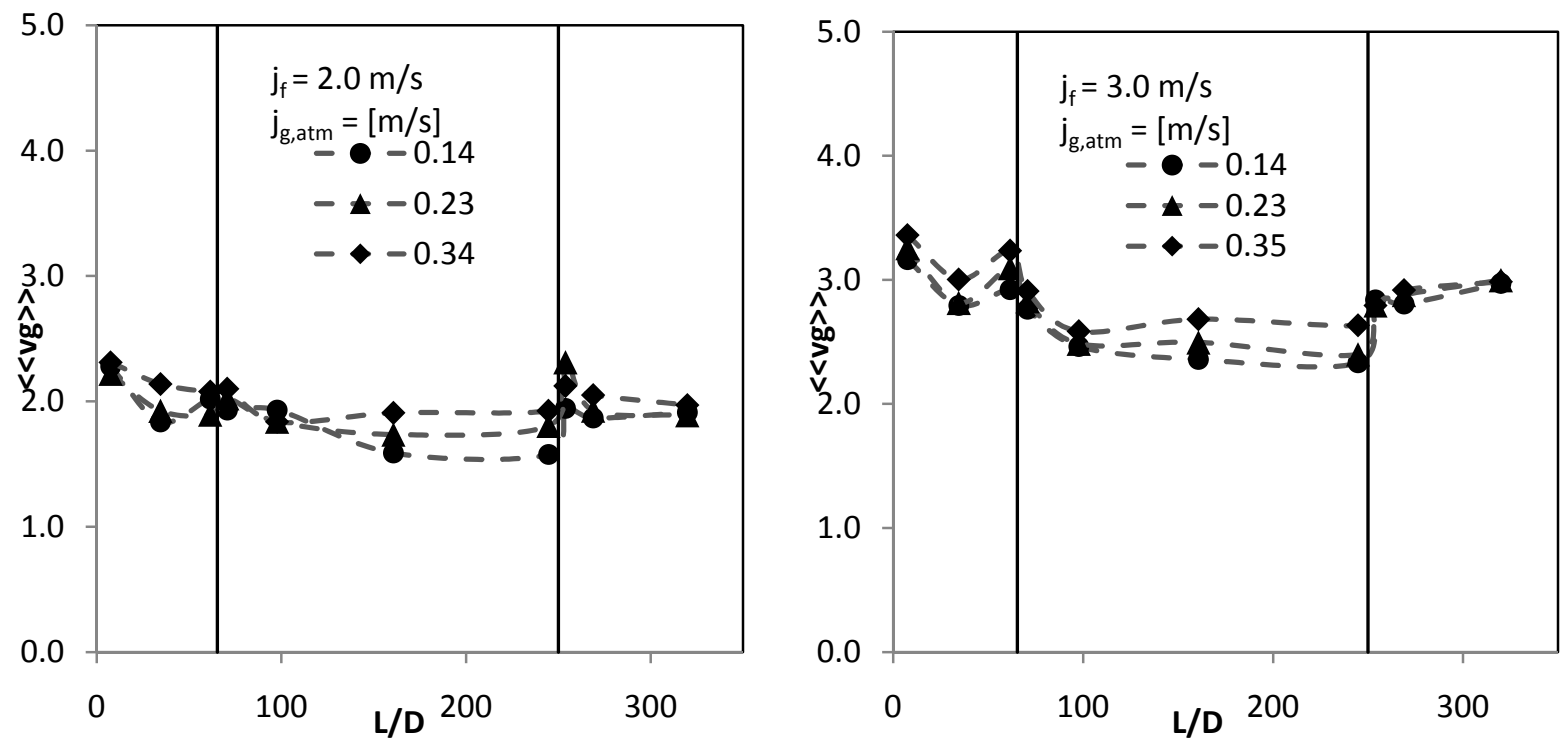

Figure 3.48 Axial development of void-weighted bubble velocity for flow conditions with a) constant liquid flow rate, $\mathrm{j}_{\mathrm{f}}=2.0 \mathrm{~m} / \mathrm{s} \mathrm{b}$ ) constant liquid flow rate, $\mathrm{j}_{\mathrm{f}}=3.0 \mathrm{~m} / \mathrm{s}$

The axial development of void-weighted bubble Sauter mean diameter of group-I bubbles for flow conditions with constant liquid flow rates, $\mathrm{j}_{\mathrm{f}}=2.0 \mathrm{~m} / \mathrm{s}$ and $\mathrm{j}_{\mathrm{f}}=3.0 \mathrm{~m} / \mathrm{s}$ are shown in Fig. $3.47 \mathrm{a}$ and $3.47 \mathrm{~b}$ respectively. In general for all the test conditions, the bubbles grow in size along the vertical upward section. This is caused by the pressure drop in the vertical upward section due to hydrostatic head loss and frictional pressure drop. Since, the elbow promotes disintegration of the bubbles, $<<\mathrm{D}_{\mathrm{SM}}>>$ drops across the vertical upward elbow. Along the horizontal section, $<<\mathrm{D}_{\mathrm{SM}}>>$ increases gradually which is caused by the frictional pressure drop and coalescence of the bubbles along the horizontal section. Similar to the vertical upward elbow, $<<\mathrm{D}_{\mathrm{SM}}>>$ drops across the vertical downward elbow due to disintegration of the bubbles. There is a very small change in $\left\langle<\mathrm{D}_{\mathrm{SM}}\right\rangle>$ along vertical downward section and the bubble size remains almost constant. 

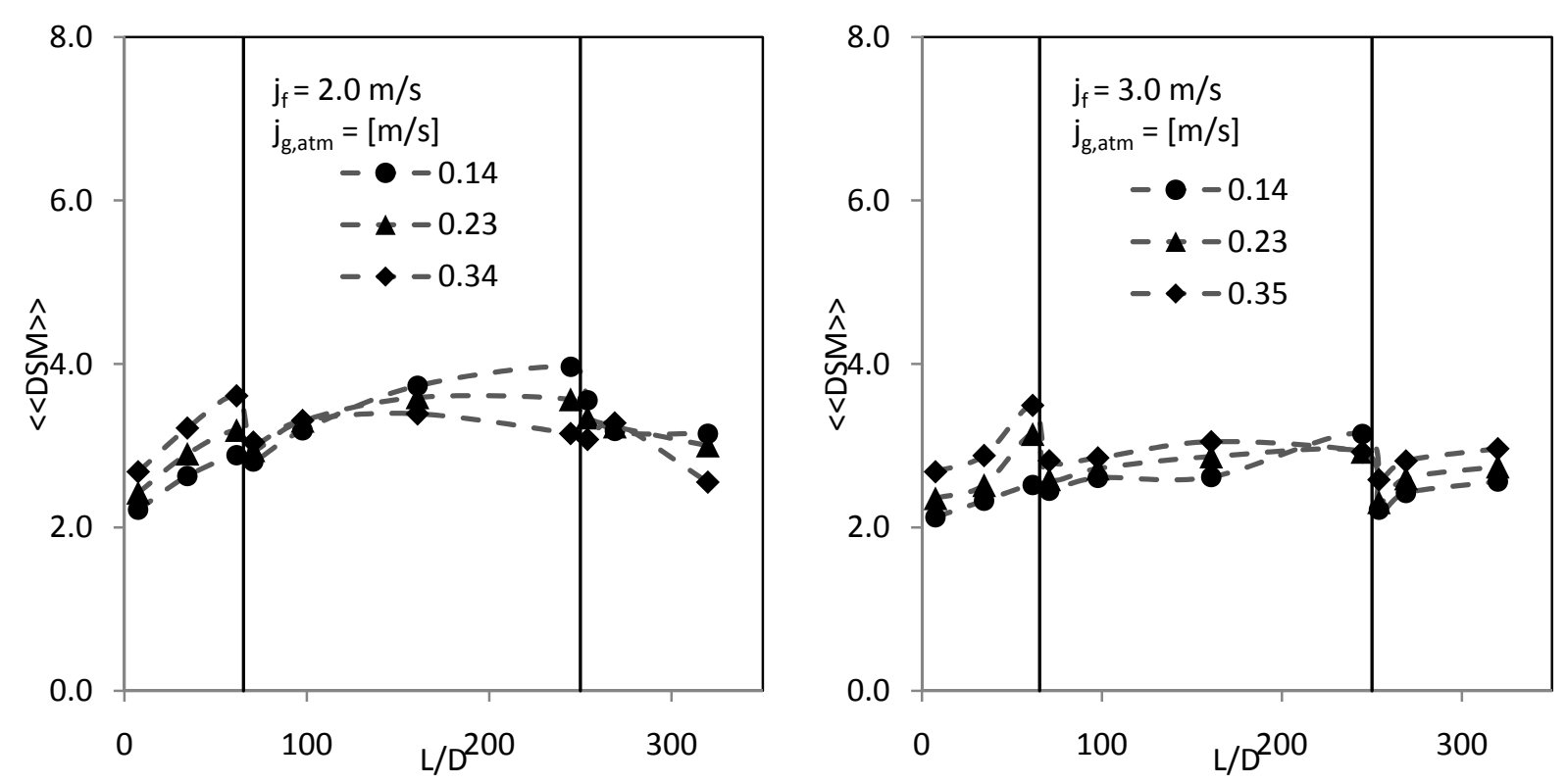

Figure 3.49 Axial development of void-weighted bubble Sauter mean diameter for flow conditions with a) constant liquid flow rate, $\mathrm{j}_{\mathrm{f}}=2.0 \mathrm{~m} / \mathrm{s}$ b) constant liquid flow rate, $\mathrm{j}_{\mathrm{f}}=3.0 \mathrm{~m} / \mathrm{s}$

\subsection{Counter-current Flow Limitation in Combinatorial Channels}

The aim of this study is to find an operating limit of the pump with respect to flooding in the vertical downward section of the combinatorial channels. Dispersed flow flooding is observed in the vertical downward section when at a constant pump head gas flow rate is increased gradually. This leads to counter-current flow in the vertical-downward section and eventually loop seal phenomena. The above process for the combinatorial channels can be explained as follows. Consider the flow of single-phase liquid in the combinatorial channels at a constant pump head. The liquid flow rate is then adjusted by employing the valves in the water line. Under such conditions increasing the gas flow rate in the test section decreases the liquid flow rate. If we consider the vertical downward section it is noticeable that the gas is entrained by the liquid. Increase in the gas flow rate causes the bubble size to increase and hence increasing the buoyancy force. Simultaneously, the liquid flow rate decreases and it does not have enough inertia to entrain the gas phase. This leads to a point when motion of the gas phase reverses the direction and hence moves in vertical upward direction. This is the beginning of the countercurrent flow. Under such conditions, a gas column builds up in the vertical downward section 
and hence prevents any liquid from entering. The pump head is not sufficient to push the gas column from vertical downward section and this condition is called loop seal.

\section{Experiment Procedure:}

Since, the experiment is very sensitive to the boundary conditions of the operation i.e. constant pump head or constant liquid flow rate, it is imperative to define a standard set of experimental procedures.

1. The bypass valve to the accumulator tank has constant opening for all the runs.

2. Run single-phase liquid in the combinatorial channels at a constant pump frequency. Constant pump frequency serves as the boundary condition.

3. Adjust the single-phase liquid flow rate to the required value using the valves in for the liquid injection. This constant liquid flow rate serves as the initial condition.

4. Inject gas and gradually increase the gas flow rate until flow reversal is achieved in the vertical downward section. After each increment in the gas flow rate, the system is allowed to achieve quasi-steady state.

5. Repeat the experiment for different pump frequencies.

It should be noted that the experiments are performed through flow visualization in the vertical downward section and hence the results presented demonstrate qualitative characteristics.

\subsubsection{Experimental Results}

Employing the above set of procedures, experiments are performed by varying the pump frequency from $10 \mathrm{~Hz}$ to $15 \mathrm{~Hz}$ with increments of $1 \mathrm{~Hz}$. For each pump frequency, the inlet single-phase liquid flow rate is varied within the range of $0.75 \mathrm{~m} / \mathrm{s}$ to $1.5 \mathrm{~m} / \mathrm{s}$. It is found that countercurrent flow in the vertical downward section will not occur at single-phase liquid flow rate above $1.25 \mathrm{~m} / \mathrm{s}$ and at pump frequencies above $14 \mathrm{~Hz}$. Figure 3.50 shows the plot of the gas flow rate required at the inlet for counter-current flow to occur versus the initial single-phase liquid flow rate for varying pump frequencies. It should be noted that only one data point corresponds to the pump frequency of $10 \mathrm{~Hz}$. This is because it is the maximum single-phase liquid flow rate that the pump can achieve for the current experiment. Moreover, at pump 
frequency of $14 \mathrm{~Hz}$ countercurrent flow will not occur above $1.0 \mathrm{~m} / \mathrm{s}$. The vertical lines of constant liquid flow rates demarcate the regions of countercurrent flow in the combinatorial twophase flow facility.

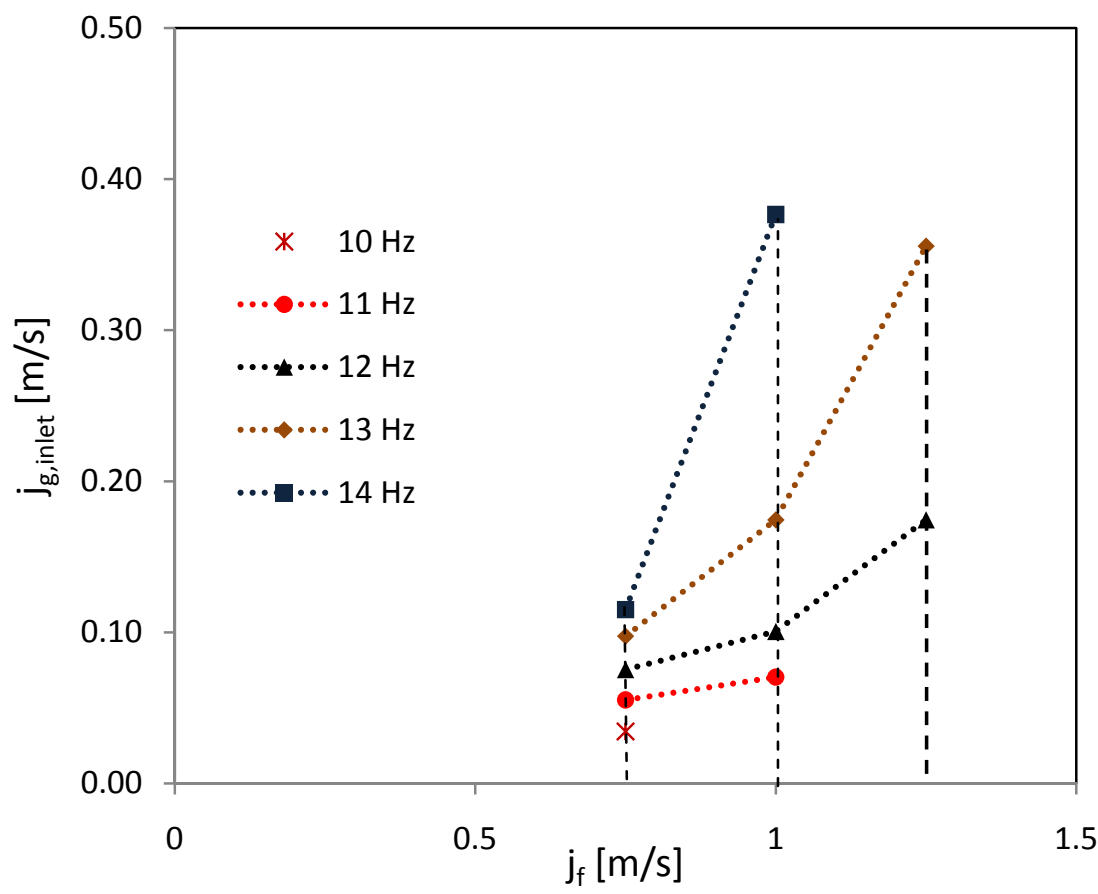

Figure 3.50 Curves of constant pump head required to achieve counter-current flow in the vertical-downward section of combinatorial channels

Figure 3.51 presents an example of counter-current flow region in the combinatorial flow channels for a particular pump frequency of $13 \mathrm{~Hz}$. As shown in the figure, the region bounded by the dashed lines represents the counter-current flow region. This signifies that while operating the pump at $13 \mathrm{~Hz}$ with the standard valve settings, counter-current flow condition can be achieved in the vertical downward section for any flow conditions within the region. It should be noted that this region is specific to certain operating conditions and to the combinatorial channels. The lower liquid flow rate boundary on this curve is the smallest liquid flow rate possible with the pump head corresponding to $13 \mathrm{~Hz}$ operating frequency. 


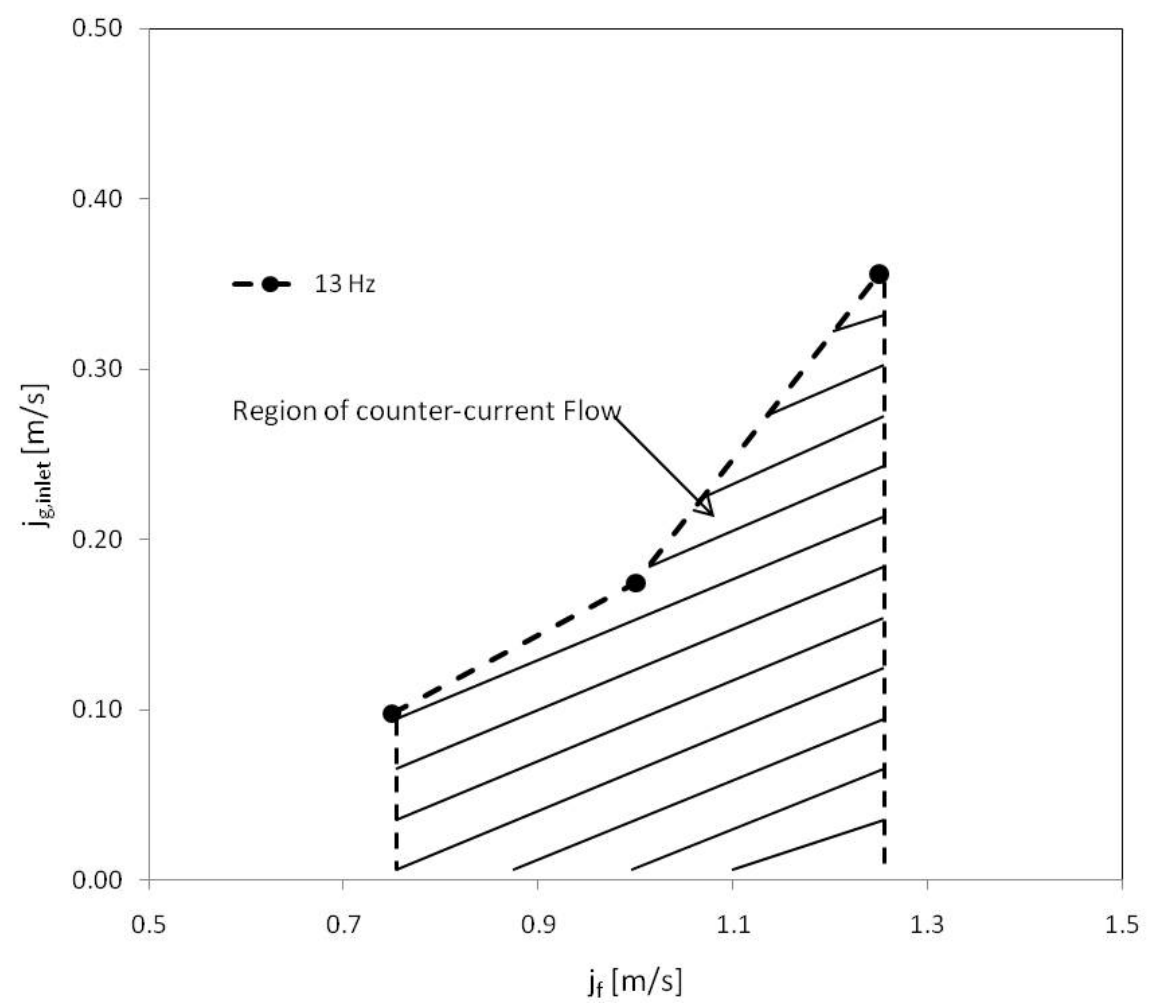

Figure 3.51 Curve of constant pump head required to achieve counter-current flow in vertical downward section of combinatorial channels 


\section{INTERFACIAL AREA TRANSPORT}

In two-fluid model formulation (Ishii, 1975), conservation equations are formulated separately for each phase. Proper averaging of the conservation equations leads to separate equations of mass, momentum and energy for each phase which are coupled through interfacial interaction terms. The interfacial transfer terms can be expressed in terms of a driving force and interfacial area concentration (Kocamustafaogullari and Ishii, 1995) as:

Interfacial Transfer Term $=a_{i} \times$ Driving Force

Hence, closure relation for interfacial area concentration is required. The closure relation can be provided in terms of interfacial area concentration equation, which was proposed by Ishii (1975) and Kocamustafaogullari and Ishii (1995). The interfacial area transport equation dynamically predicts the evolution of interfacial area concentration along the flow field due to various sources and sinks. The general form of the interfacial area transport model is given by,

$$
\frac{\partial a_{i}}{\partial t}+\nabla \cdot\left(a_{i} \vec{v}_{i}\right)=\frac{2}{3} \frac{a_{i}}{\alpha}\left(\frac{\partial \alpha}{\partial t}+\nabla \cdot\left(\alpha \vec{v}_{G}\right)-\eta_{p h}\right)+\sum_{j} \emptyset_{j}+\emptyset_{p h}
$$

Here, the first term on the right hand side of the equation is a source term for the interfacial area concentration due to change in the volume of the dispersed phase. In this term, $\eta_{p h}$ is the net rate of volume generated by nucleation and collapse of bubble due to condensation per unit mixture volume. The last two terms on the right hand side, $\emptyset_{j}$ and $\emptyset_{p h}$ represent the source and sink terms due to various bubble interaction mechanisms and phase change, respectively. The completion of the interfacial area transport model requires constitutive relations for source and sink terms arising from various bubble-interaction mechanisms in two-phase flows. Wu et. al (1998) and Kim (1999) developed one-group interfacial area transport equation for adiabatic airwater bubbly flows for pipe and channel flows, respectively. Three significant bubble interaction mechanisms for one-group bubbles are identified to be modeled for one-group interfacial area transport model. These include, bubble break-up due to impact of turbulent eddies in the continuous phase, bubble coalescence due to random collision of the bubbles driven by turbulent eddies in the continuous phase (RC), and bubble coalescence due to wake entrainment of the following bubble into the preceding bubble (WE). Final form of the one- 
group interfacial area transport equation for air-water two-phase flows given by Wu et. al. (1998) and Kim (1999), in one-dimensional, steady state is given as,

$$
\begin{gathered}
\frac{d\left(\left\langle a_{i}\right\rangle\left\langle\left\langle v_{G}\right\rangle\right\rangle\right)}{d z}=\left(\frac{2\left\langle a_{i}\right\rangle\left\langle\left\langle v_{G}\right\rangle\right\rangle}{3 p}\right)\left(\frac{d p}{d z}\right)+C_{T I} \frac{1}{18}\left(\frac{\left\langle a_{i}\right\rangle^{2}}{\langle\alpha\rangle}\left\langle u_{t}\right\rangle\right)\left(1-\frac{W e_{c r}}{W e}\right)^{\frac{1}{2}} \exp \left(-\frac{W e_{c r}}{W e}\right)- \\
C_{R C} \frac{1}{3 \pi} \frac{\left\langle a_{i}\right\rangle^{2}\left\langle u_{t}\right\rangle}{\langle\alpha\rangle_{\max }^{1 / 3}\left(\langle\alpha\rangle_{\text {max }}^{1 / 3}-\langle\alpha\rangle^{1 / 3}\right)}\left(1-\exp \left(-C \frac{\langle\alpha\rangle_{\max }^{1 / 3}\langle\alpha\rangle^{1 / 3}}{\langle\alpha\rangle_{\max }^{1 / 3}-\langle\alpha\rangle^{1 / 3}}\right)\right)-C_{W E} C_{D}^{1 / 3} \frac{\left\langle a_{i}\right\rangle^{2}\left\langle u_{t}\right\rangle}{3 \pi}
\end{gathered}
$$

In this equation, the first term on the right hand side represents the change in the interfacial area concentration due to compressibility of the dispersed phase, while the remaining three terms represent the change in the interfacial area concentration due to impact of turbulent eddies in the continuous phase (TI), random collision of the bubbles driven by the turbulent eddies in the continuous phase (RC), and bubble coalescence due to wake entrainment (WE) respectively. These interaction terms contain empirical coefficients, i.e. $\mathrm{C}_{\mathrm{TI}}, \mathrm{C}_{\mathrm{RC}}, \mathrm{C}$, and $\mathrm{C}_{\mathrm{WE}}$, which have to be found from experimental data. In this equation, $\mathrm{p}, \mathrm{u}_{\mathrm{t}}, \mathrm{We}$ and $\mathrm{C}_{\mathrm{D}}$ are the local pressure, rms turbulent velocity fluctuation in liquid phase, particle Weber number and particle drag coefficient respectively. The operators $<$. $>$ and $<<$. $>>$ represent the area averaged and voidweighted area averaged quantities respectively.

The objective of this section is to show the comparison of predictions from the interfacial area transport model with the experimental data from the four-sensor conductivity probe. The comparisons are obtained in the vertical-upward and vertical-downward sections. The interfacial area concentration along the test section is calculated by solving eq. 4.3 and the boundary conditions are measured experimentally. The empirical coefficients for different bubbleinteraction mechanism were obtained experimentally by (Wu et. al.,1998 and Kim, 1999) and (Ishii et. al., 2004) for vertical-upward and vertical-downward bubbly two-phase flow, respectively. These coefficients are shown in Table -4.1 . 
Table 4.1 Coefficients in bubble interaction terms

\begin{tabular}{|l|l|l|l|}
\hline Flow Configuration & $\begin{array}{l}\text { Bubble breakup by } \\
\text { impact of turbulent } \\
\text { eddies (TI) }\end{array}$ & $\begin{array}{l}\text { Bubble coalescence } \\
\text { by wake entrainment } \\
\text { (WE) }\end{array}$ & $\begin{array}{l}\text { Bubble coalescence by } \\
\text { random collision (RC) }\end{array}$ \\
\hline Vertical-upward & $\mathrm{C}_{\mathrm{TI}}=0.085, \mathrm{We}_{\mathrm{cr}}=6.0$ & $\mathrm{C}_{\mathrm{WE}}=0.002$ & $\begin{array}{l}\mathrm{C}_{\mathrm{RC}}=0.0041, \mathrm{C}=3, \\
\alpha_{\max }=0.75\end{array}$ \\
\hline Vertical-downward & $\mathrm{C}_{\mathrm{TI}}=0.034, \mathrm{We}_{\mathrm{cr}}=6.0$ & $\mathrm{C}_{\mathrm{WE}}=0.002$ & $\begin{array}{l}\mathrm{C}_{\mathrm{RC}}=0.0041, \mathrm{C}=3, \\
\alpha_{\max }=0.75\end{array}$ \\
\hline
\end{tabular}

\subsection{Model Predictions in Vertical-Upward Section}

The comparison of the development of area-averaged interfacial area concentration with the model prediction in the vertical-upward two-phase flow is shown in Figs. 4.1 and 4.2. The error bars shown are $\pm 10 \%$ of the measured value. As mentioned in the chapter. 3 , all the flow conditions in the vertical-upward section are within bubbly flow regime. Hence, one-group interfacial area transport model is used to predict the development of the interfacial area concentration. It is found that there is a reasonably good agreement between the model prediction and experimental data for all the flow conditions in vertical-upward section.

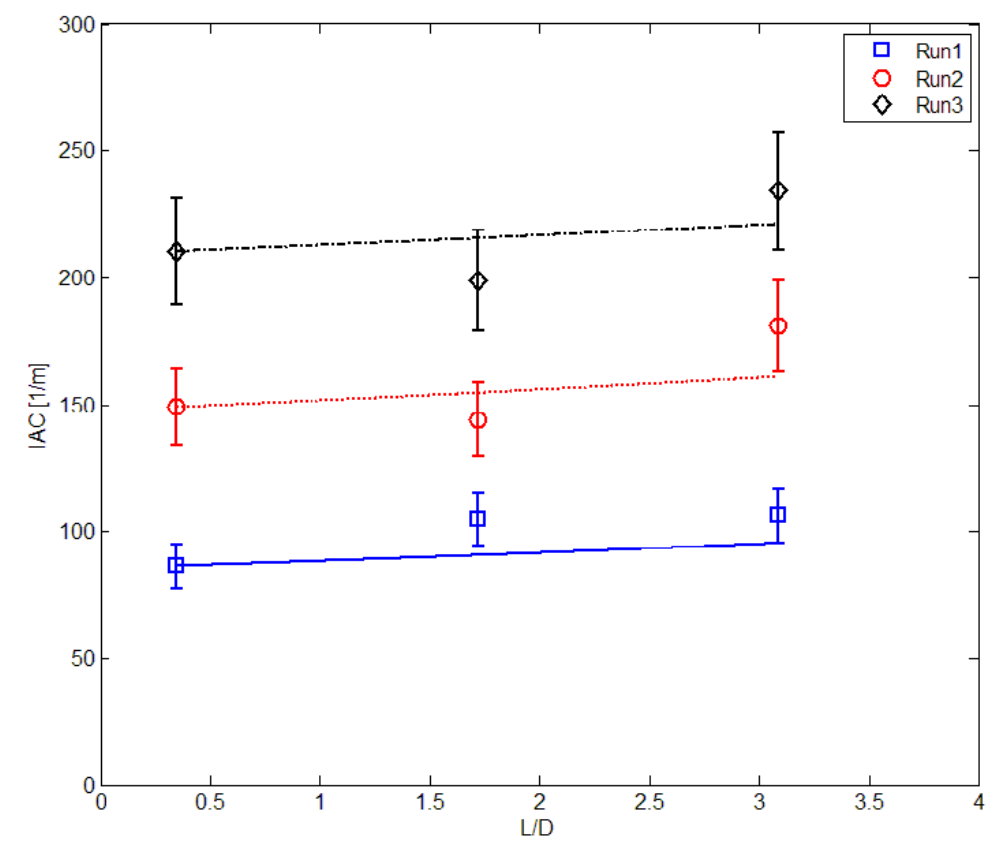

Figure 4.1 Comparison of model and data for Runs 1, 2 and 3 in vertical-upward section 


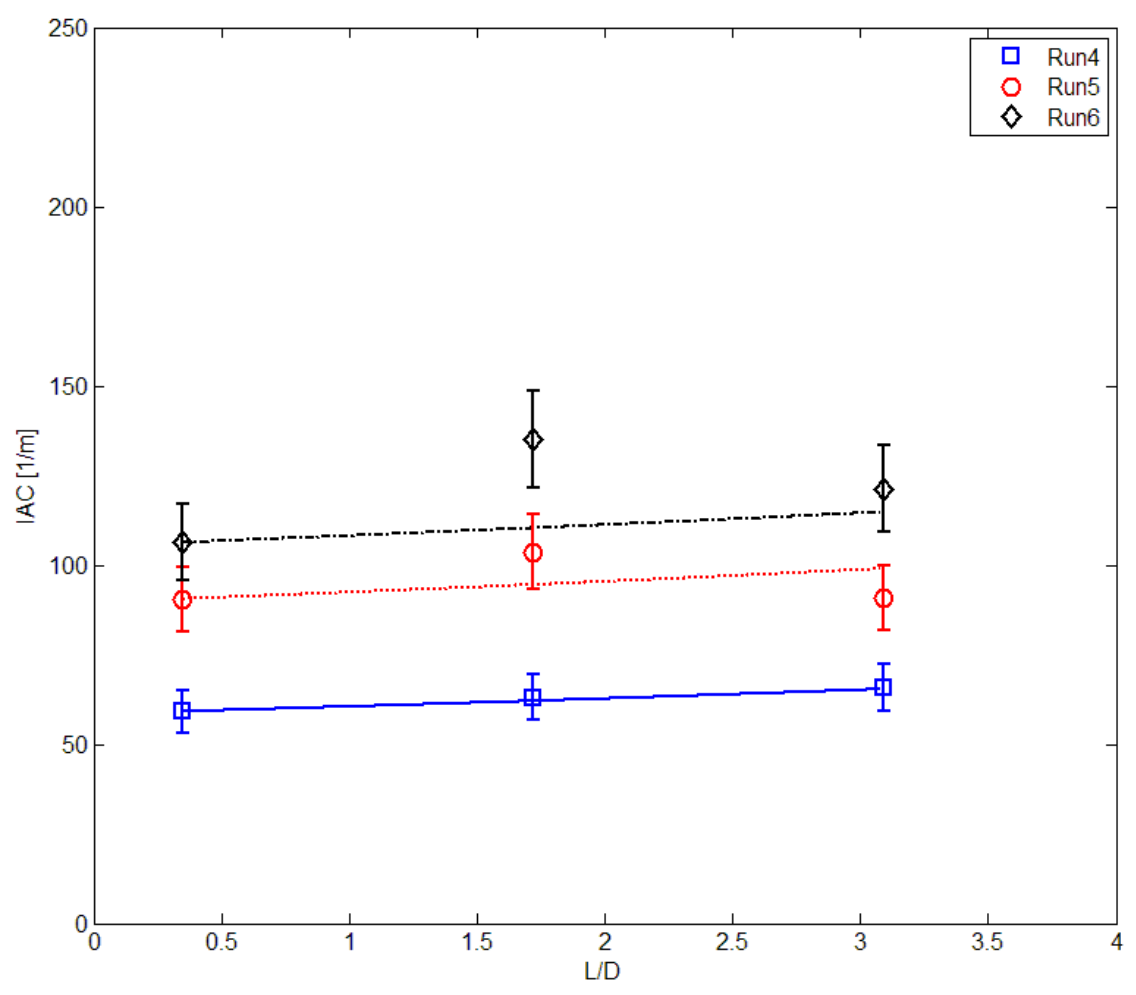

Figure 4.2 Comparison of model and data for Runs 4, 5 and 6 in vertical-upward section

\subsection{Model Predictions in Vertical-Downward Section}

Figs. 4.3 and 4.4 show the comparison of model prediction and experimental measurements for area-averaged interfacial area concentration in the vertical downward section. For Runs 1, 2 and 3 which corresponds to flow conditions with a constant liquid flow rate of $2.0 \mathrm{~m} / \mathrm{s}$ and increasing gas flow rates, there is a higher disagreement between the model predictions and the experimental measurements. As observed in chapter. 3, Runs 1, 2 and 3 do not correspond to bubbly flow regime in the vertical-downward section. Since, one-group IATE model is used, the presence of group-two flow conditions leads to disagreement with the model. For Runs 4, 5 and 6 , it is speculated that the disagreement from the model can arise from the measurement error at port P11 in the vertical downward section. 


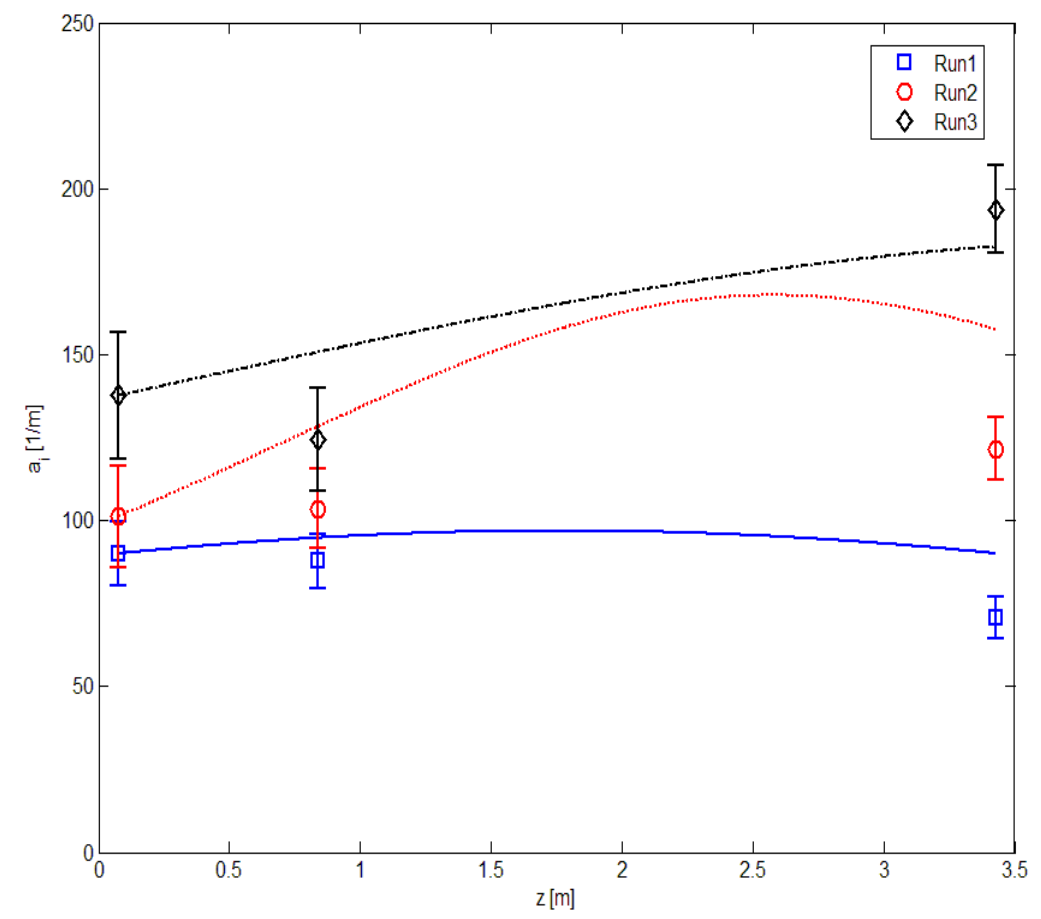

Figure 4.3 Comparison of model and data for Runs 1, 2 and 3 in vertical-downward section

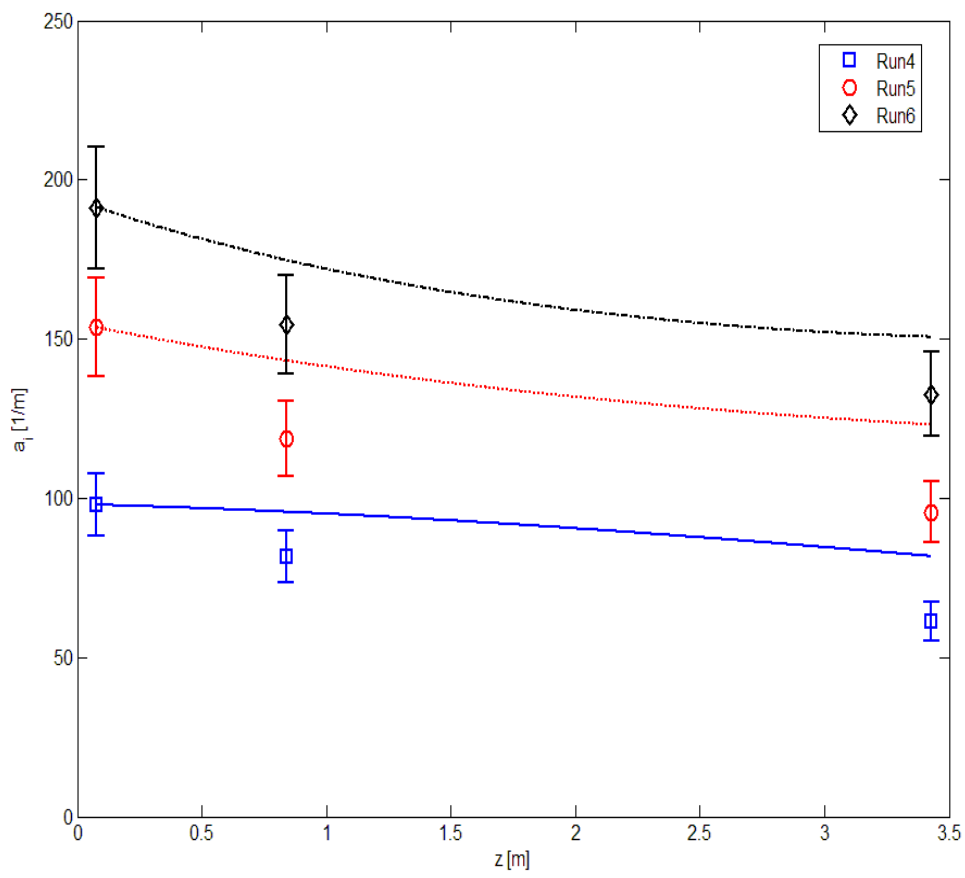

Figure 4.4 Comparison of model and data for Runs 4, 5 and 6 in vertical-downward section 


\section{SUMMARY AND RECOMMENDATIONS}

The geometric effects of 90-degree vertical elbows and flow configurations in two-phase flow are investigated. In the course of research, the following objectives are achieved:

- Design and construction of various components of combinatorial two-phase flow facility

- Generating experimental database on the geometric effect of 90-degree vertical elbows in two-phase flow

- Prediction of the experimental results using interfacial area transport model in vertical-upward and vertical-downward section

During the course of experimental investigation and data collection, the following characteristics are studied and analyzed:

- Pressure drop across the 90-degree vertical elbows in both single-phase and twophase flow conditions

- Flow regime identification via flow visualization in vertical-upward, horizontal and vertical-downward sections

- Development of local two-phase flow parameters and their transport characteristics across the 90-degree elbows

- Transport of one-dimensional two-phase flow parameters along the combinatorial channels

- Examination of the CCFL conditions for the present experimental facility

The geometric effects of 90-degree vertical elbows on two-phase flow structure are clearly demonstrated in flow regime transition and in the profiles of two-phase flow parameters. Flow regime identification is performed via flow visualization. It is found that the 90 -degree vertical elbows have significant impact on the flow regime transition in the corresponding downstream sections. As such modified flow regime maps are proposed for both horizontal and verticaldownward section. Furthermore, it is found that horizontal two-phase flow is not fully developed even at approximately 180 pipe diameters downstream of the vertical-upward elbow.

The effect of the 90-degree vertical elbows on pressure is shown by an additional pressure drop across the elbows in both single-phase and two-phase flow conditions. A preliminary 
correlation analogous to the Lockhart-Martinelli correlation is developed to predict pressure drop across the elbows. The new correlation predicts the data well within an average error of $\pm 5 \%$.

A four-sensor conductivity probe is used to obtain local two-phase flow parameters along the combinatorial channels. The effect of the elbow is demonstrated by a bimodal bubble distribution at measurement location immediately downstream of the vertical-upward elbow. It is speculated that the bubbles are entrained into two counter-rotating vortices generated by secondary flow in the vertical upward elbow and hence causing a bi-peaked profile for local void fraction and interfacial area concentration. Furthermore, it is found that the elbow effect on bubble distribution decays by $30 \mathrm{D}$ downstream of the elbow and bubbles migrate to the top wall of the pipe cross-section.

The axial transport of area-averaged void fraction and interfacial area concentration across the elbows show that the elbows promote bubble disintegration. For the 90-degree vertical upward elbow, it is found that while the bubbles accelerate across the elbow for flow conditions with liquid flow rate of $2.0 \mathrm{~m} / \mathrm{s}$ they decelerate across the elbow for flow conditions with liquid flow rate of $3.0 \mathrm{~m} / \mathrm{s}$. Preliminary one-group IATE model predictions are presented for verticalupward and vertical-downward two-phase flow. It is found that for model predictions are in good agreement with the experimental measurements in the vertical-upward section within $\pm 10 \%$. However, the disagreement between model prediction and measurements is found to be higher for vertical-downward two-phase flow. It should be noted that in the vertical downward section the first measurement location includes the elbow effect and the current IATE model does not have mechanisms accounting for the elbow effect.

Additional experimental investigation is performed to study the counter-current flow limitation (CCFL) characteristics specific to the current experimental facility. The experiments are performed through flow visualization in the vertical downward section and hence the results presented demonstrate qualitative characteristics.

Based on the study to date the following recommendations are made:

- Additional database for two-phase pressure drop will be valuable to improve and validate the current model to predict two-phase pressure drop across the elbows. Current study 
shows that the current model provides best results when the flow conditions are within bubbly flow regime. As such the model needs improvement in order to provide accurate prediction in other flow regimes too.

- The elbow effect on the bubble distribution decays rapidly downstream of the elbow. Additional local measurements between 3D and 30D downstream of the vertical-upward elbow will be valuable to develop a model for decay length of the elbow.

- The current local database, although very large, is limited to flow conditions in bubbly flow regime. Additional local database in both one-group and two-group conditions will be important to develop an interfacial area transport (IATE) model accounting for the vertical elbows in the combinatorial channels applicable to wider flow regimes.

- In order to develop an IATE model accounting for the elbow effect, additional bubble interaction mechanisms should be identified and included in the model. 


\section{REFERENCES}

H., Blasius, 1913, Das Ähnlichkeitsgesetz bei reibungsyorgängen in flüssigkeiten, Ver. Dtsch. Ing. Forschungsh, pp. 131.

Chisholm, D., A 1967, Theoretical basis for the Lockhart-Martinelli correlation for two-phase flow, Int. J. Heat Mass Transfer, Vol. 10, pp. 1767-1778.

Fu, X. Y., 2001, Interfacial area measurement and transport modeling in air-water two-phase flow, Ph. D. Thesis, School of Nuclear Engineering, Purdue University.

Ishii, M, 1975, Thermo-fluid dynamic theory of two-phase flow, Eyrolles, Paris

Ishii, M., 1977, One-dimensional drift-flux model and constitutive equations for relative motion between phases in various two-phase flow regimes, Argonne National Laboratory Report ANL$77-47$.

Ishii, M., Paranjape, S. S., Kim S. and Sun X., 2004, Interfacial structures and interfacial area transport in downward two-phase bubbly flow, Int. J. of Multiphase Flow, Vol. 30, Nos, 7-8, pp $779-801$.

Ishii, M. and Kim, S., 2004, Development of one-group and two-group interfacial area transport equation, Nucl. Sci. and Eng., 146, pp. 257-273.

H., Ito, 1960, Pressure Loss in Smooth Pipe Bends, Journal of Basic Engineering, 82, 131-143

H., Ito, 1987, Flow in Curved Pipes, JSME International Journal, 30, 543-552.

Kelly, J. M, 1997, Thermal-hydraulic modeling needs for passive reactors, OECD/CSNI Specialist Meeting on Advanced Instrumentation and Measurement Techniques

Kim, S., 1999, Interfacial area transport equation and measurement of local interfacial characteristics, PhD. Thesis, Purdue University, West Lafayette, IN, USA.

Kim, S., Fu, X. Y., Wang, X and Ishii, M, 2000, Development of the miniaturized four-sensor conductivity probe and the signal processing scheme, Int. J. Heat Mass Transfer, Vol. 43, pp. 4101-4118. 
Kim, S., Ishii, M., Sun, X., and Beus, S. G., 2002, Interfacial area transport and evaluation of source terms for confined air-water bubbly flow, Nucl. Eng. Des., 219, No. 1, pp 61-65.

Kocamustafaogullari, G. and Ishii, M.,1995, Foundations of the interfacial area transport equation and its closure relations, International Journal of Heat and Mass Transfer, Vol. 38 No. 3, pp: 481-493.

Lockhart, R. W., and Martinelli, R. C., Proposed correlation of data for isothermal two-phase component flow in pipes, 1949, Chem. Eng. Prog. 45, No. 39.

Mandhane, J. M., Gregory, G. A., and Aziz, K., 1974, A flow pattern map for gas-liquid flow in horizontal pipes, Int. J. of Multiphase Flow, 1, 537-553.

Mishima, K. and Ishii,M., 1984, Flow Regime Transition Criteria for Upward Two-Phase Flow in Vertical Tubes, Int. J. Heat and Mass Transfer, 25, 5, 723-737.

Mortensen, G. A., 1995, Long term plan for NRC thermal-hydraulic code development, Report to USNRC under contract DE-AC07-94ID13223

H., Schlichting, 1960, Boundary Layer Theory, McGraw-Hill, 529-531.

Sparks, R.E., and Hoelscher, H.E., 1987, An experimental study of liquid-phase turbulent diffusion: part I, fluid mechanical data, A.I.Ch.E. Journal, Vol. 8, 1, pp. 103-108.

Sun, X., 2001, Two-group interfacial area transport equation for a confined test section, PhD. Thesis, Purdue University, West Lafayette, IN, USA.

Taitel, Y., and Duckler, A. E., 1976, A model for predicting flow regime transitions in horizontal and near horizontal gas-liquid flow, $A I C h E$, Vol. 22, 1, pp. 47-55.

Wang, S.K., Lee, S.J., Jones Jr, O.C., and Lahey Jr, R.T., 1987, 3-D Turbulence structure and phase distribution measurements in bubbly two-phase flows, International Journal of Multiphase Flow, Vol. 13, pp. 327-343.

White, F. M., Fluid Mechanics, 2008, $6^{\text {th }}$ Edition, McGraw-Hill Book Co.

Wu, Q., Kim, S., Ishii, M., Beus, S. G., 1999, One-group interfacial area transport in vertical bubbly flow, International Journal of Multiphase Flow, Vol. 41, pp. 1103-1112. 
Wu, Q. and Ishii, M., 1999, Sensitivity study on double-sensor conductivity probe for the measurement of interfacial area concentration in bubbly flow, International Journal of Multiphase Flow, Vol. 25, No. 1, pp. 155-173.

Zuber, N. and Findlay, J. A., 1965, Average volumetric concentration in two-phase flow systems, ASME Journal of Heat Transfer, Vol. 87, pp. 453-468. 
Appendix A1

Local interfacial structures in vertical upward section in combinatorial channels 

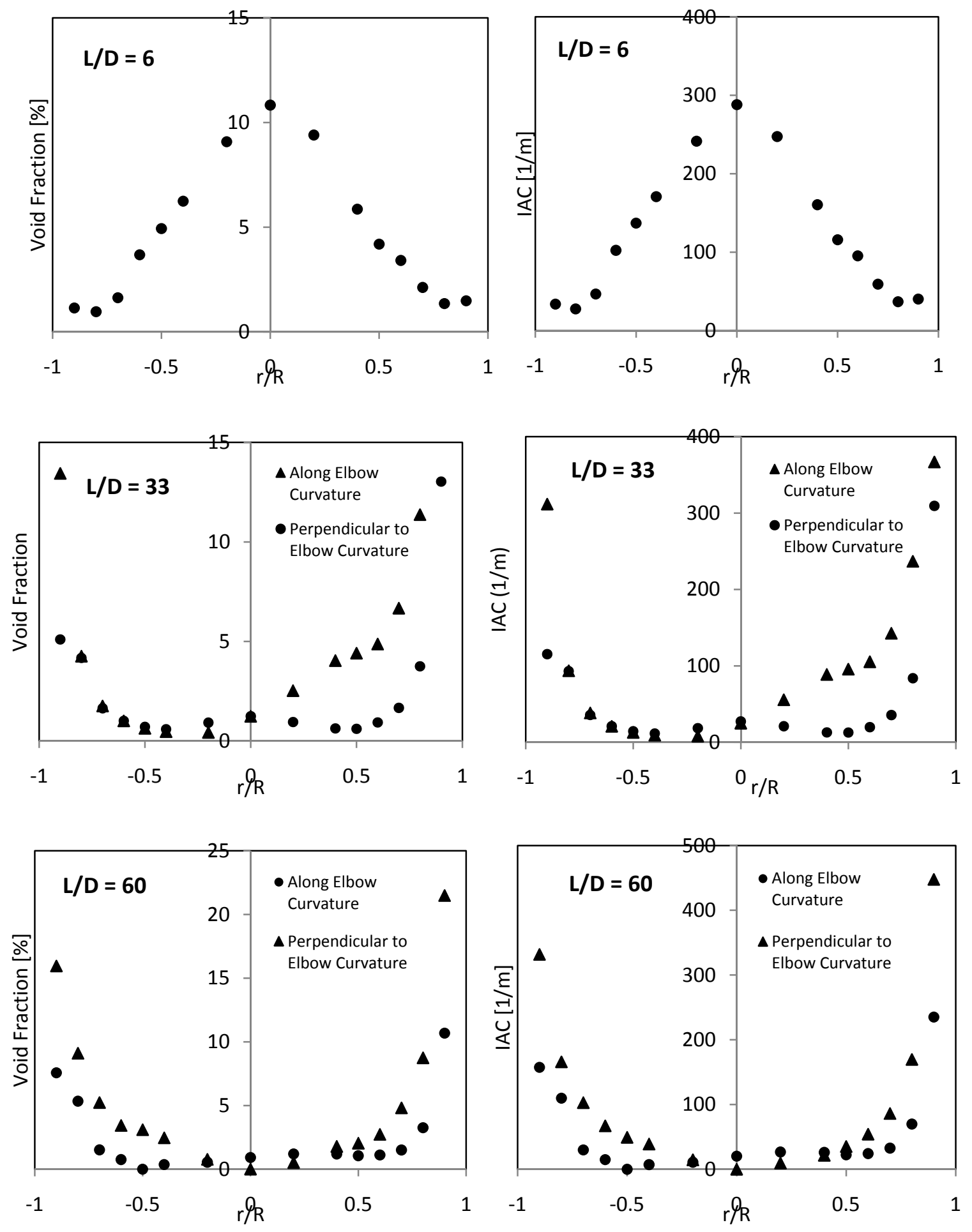

Figure A1-1: Local profiles of $\alpha$ and $a_{i}$ for $\mathrm{j}_{\mathrm{f}}=2.0 \mathrm{~m} / \mathrm{s}$ and $\mathrm{j}_{\mathrm{g}, \mathrm{atm}}=0.2136 \mathrm{~m} / \mathrm{s}$ along the vertical section 

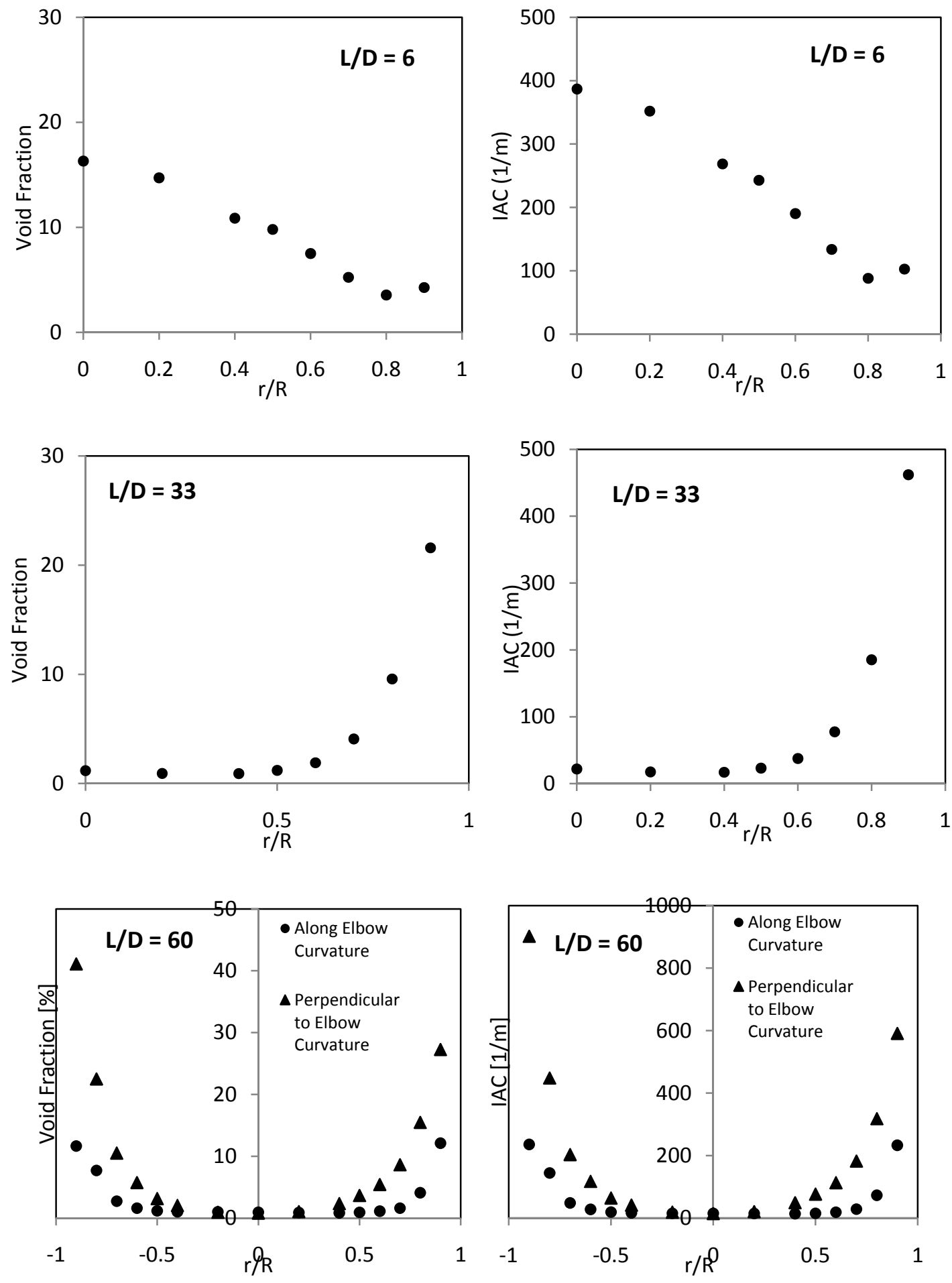

Figure A1-1: Local profiles of $\alpha$ and $a_{i}$ for $\mathrm{j}_{\mathrm{f}}=2.0 \mathrm{~m} / \mathrm{s}$ and $\mathrm{j}_{\mathrm{g}, \mathrm{atm}}=0.228 \mathrm{~m} / \mathrm{s}$ along the vertical section 

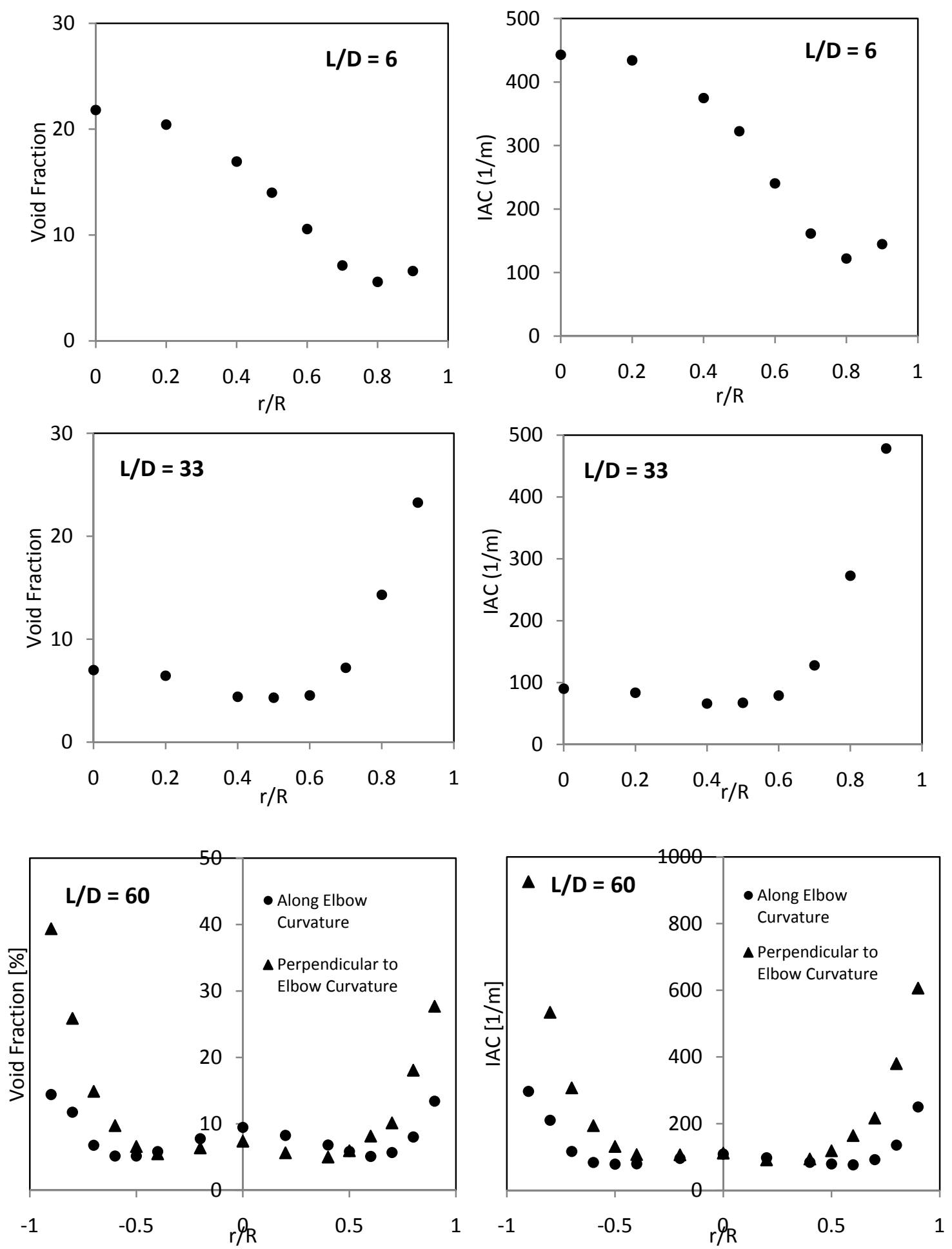

Figure A1-2: Local profiles of $\alpha$ and $a_{i}$ for $\mathrm{j}_{\mathrm{f}}=2.0 \mathrm{~m} / \mathrm{s}$ and $\mathrm{j}_{\mathrm{g}, \mathrm{atm}}=0.343 \mathrm{~m} / \mathrm{s}$ along the vertical section 

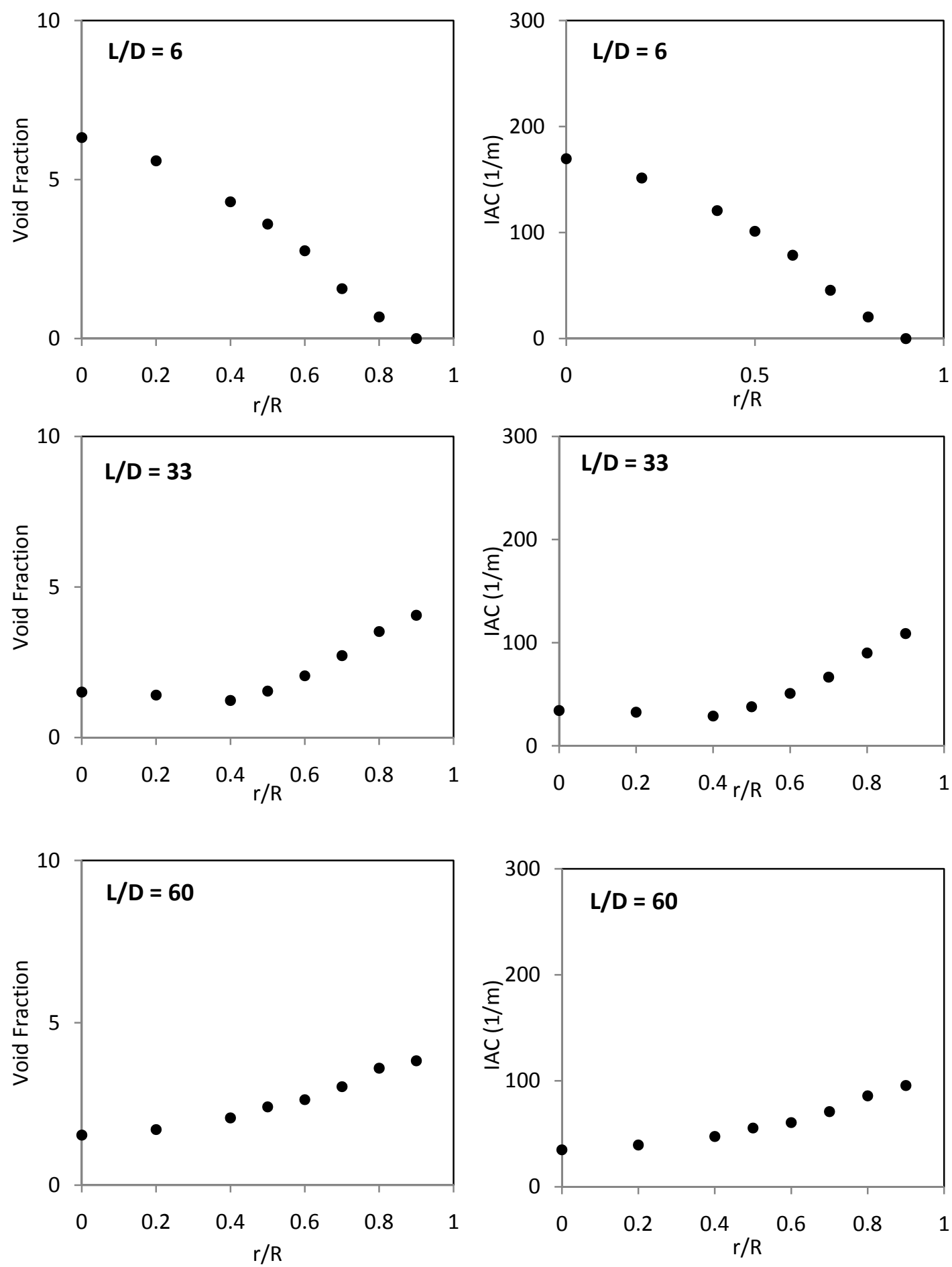

Figure A1-3: Local profiles of $\alpha$ and $a_{i}$ for $\mathrm{j}_{\mathrm{f}}=3.0 \mathrm{~m} / \mathrm{s}$ and $\mathrm{j}_{\mathrm{g}, \mathrm{atm}}=0.139 \mathrm{~m} / \mathrm{s}$ along the vertical section 

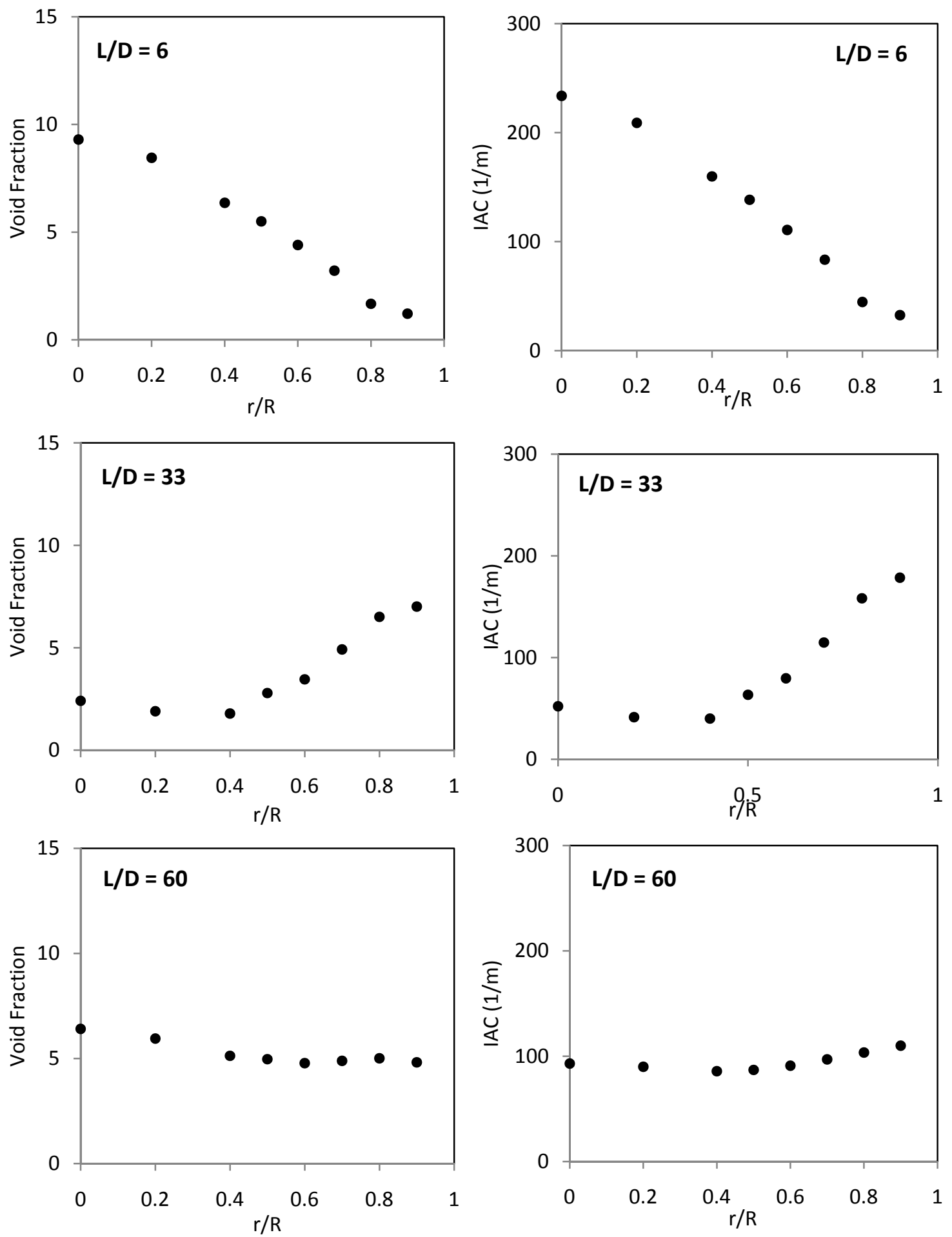

Figure A1-4: Local profiles of $\alpha$ and $a_{i}$ for $\mathrm{j}_{\mathrm{f}}=3.0 \mathrm{~m} / \mathrm{s}$ and $\mathrm{j}_{\mathrm{g}, \mathrm{atm}}=0.232 \mathrm{~m} / \mathrm{s}$ along the vertical section 

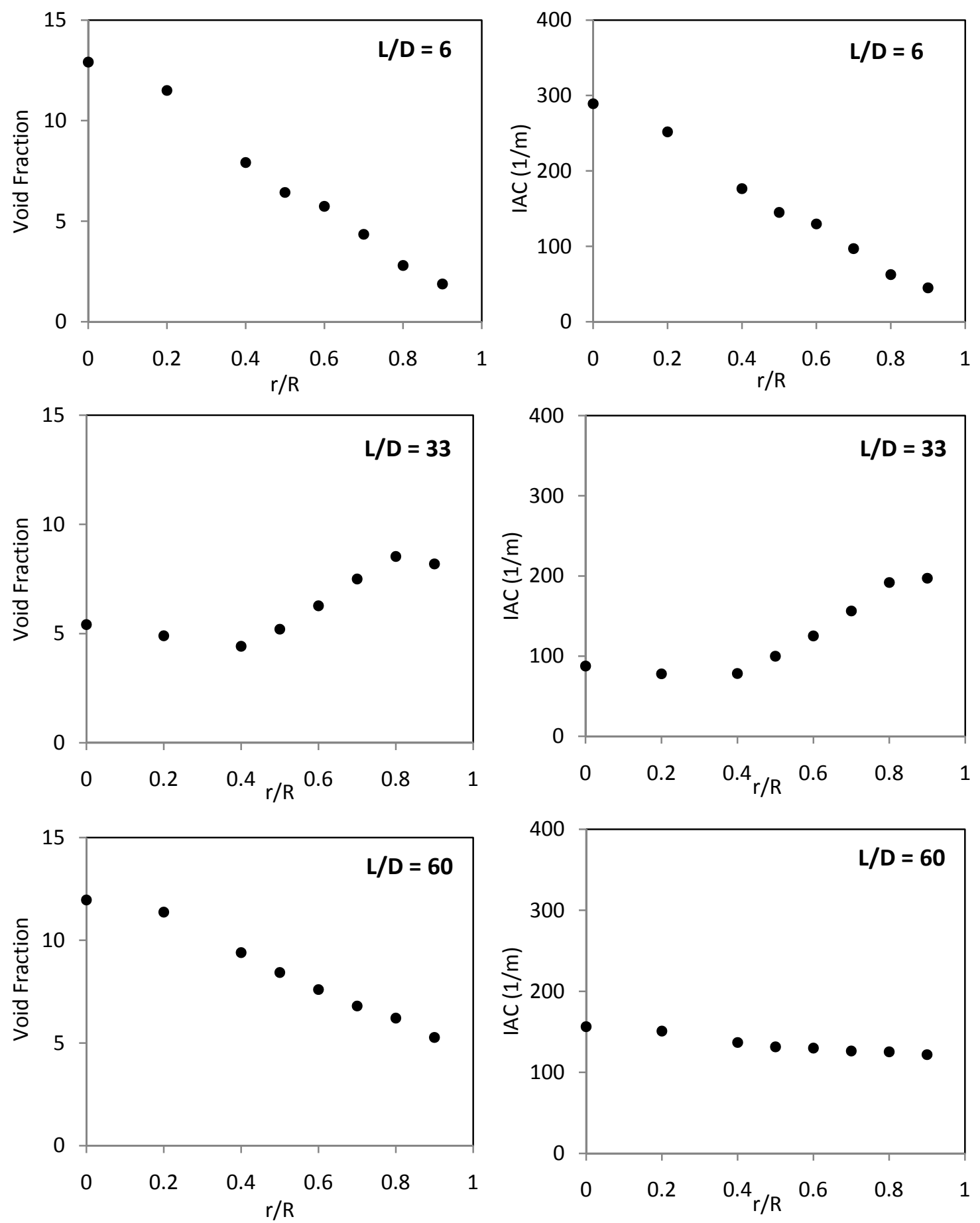

Figure A1-5: Local profiles of $\alpha$ and $a_{i}$ for $\mathrm{j}_{\mathrm{f}}=3.0 \mathrm{~m} / \mathrm{s}$ and $\mathrm{j}_{\mathrm{g}, \mathrm{atm}}=0.353 \mathrm{~m} / \mathrm{s}$ along the vertical section 
Appendix A2

Local interfacial structures in horizontal section in combinatorial channels 

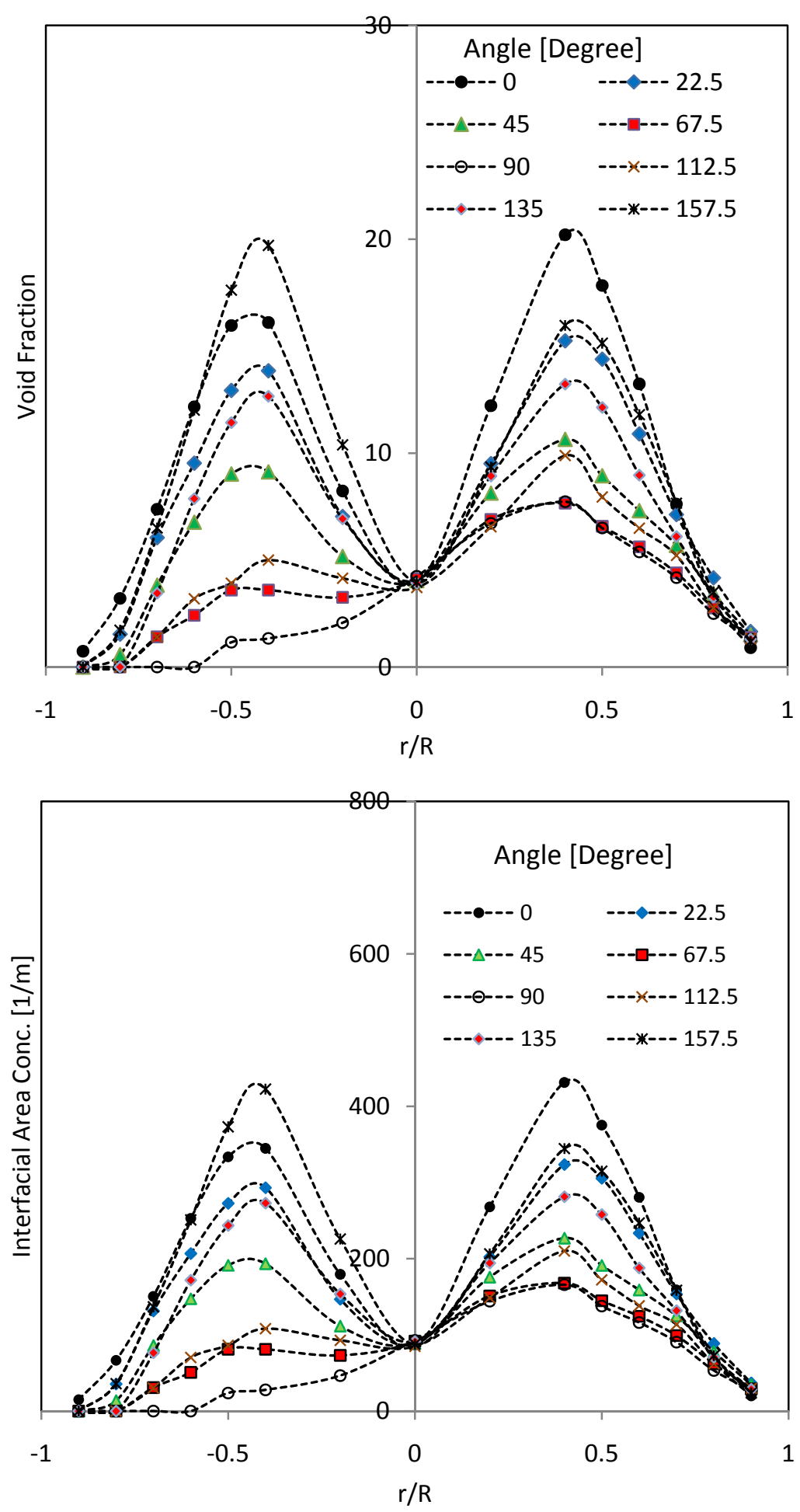

Figure A 2-1: Local profiles of $\alpha$ and $a_{i}$ at different angles of measurement at port P4, $L / D=3$ from the 90-degree vertical elbow at Run- $1 ; \mathrm{j}_{\mathrm{f}}=2.0 \mathrm{~m} / \mathrm{s}$ and $\mathrm{j}_{\mathrm{g}, \mathrm{atm}}=0.136 \mathrm{~m} / \mathrm{s}$ 

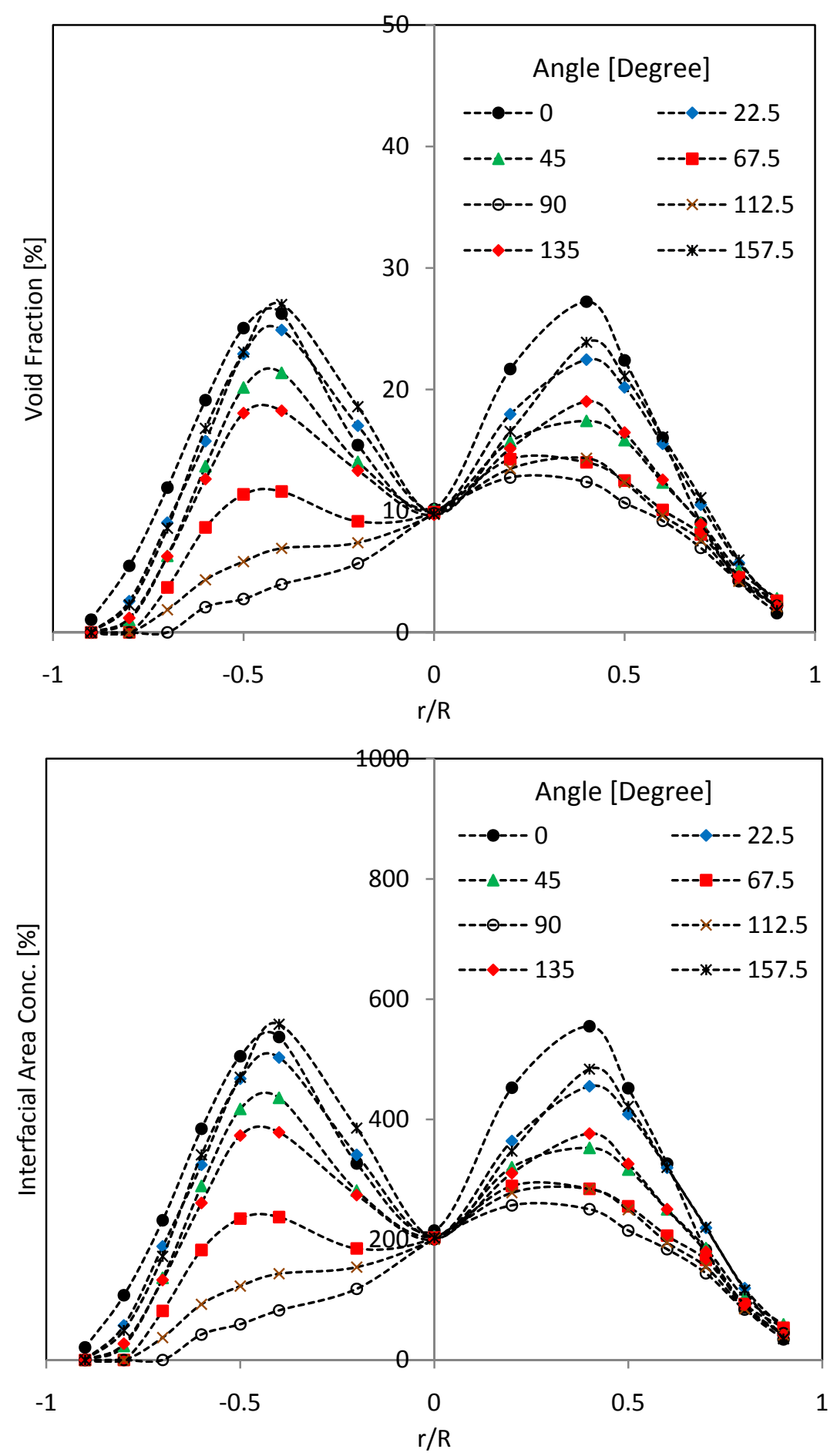

Figure A 2-2: Local profiles of $\alpha$ and $a_{i}$ at different angles of measurement at port P4, $L / D=3$ from the 90-degree vertical elbow at Run- $2 ; \mathrm{j}_{\mathrm{f}}=2.0 \mathrm{~m} / \mathrm{s}$ and $\mathrm{j}_{\mathrm{g}, \mathrm{atm}}=0.136 \mathrm{~m} / \mathrm{s}$ 

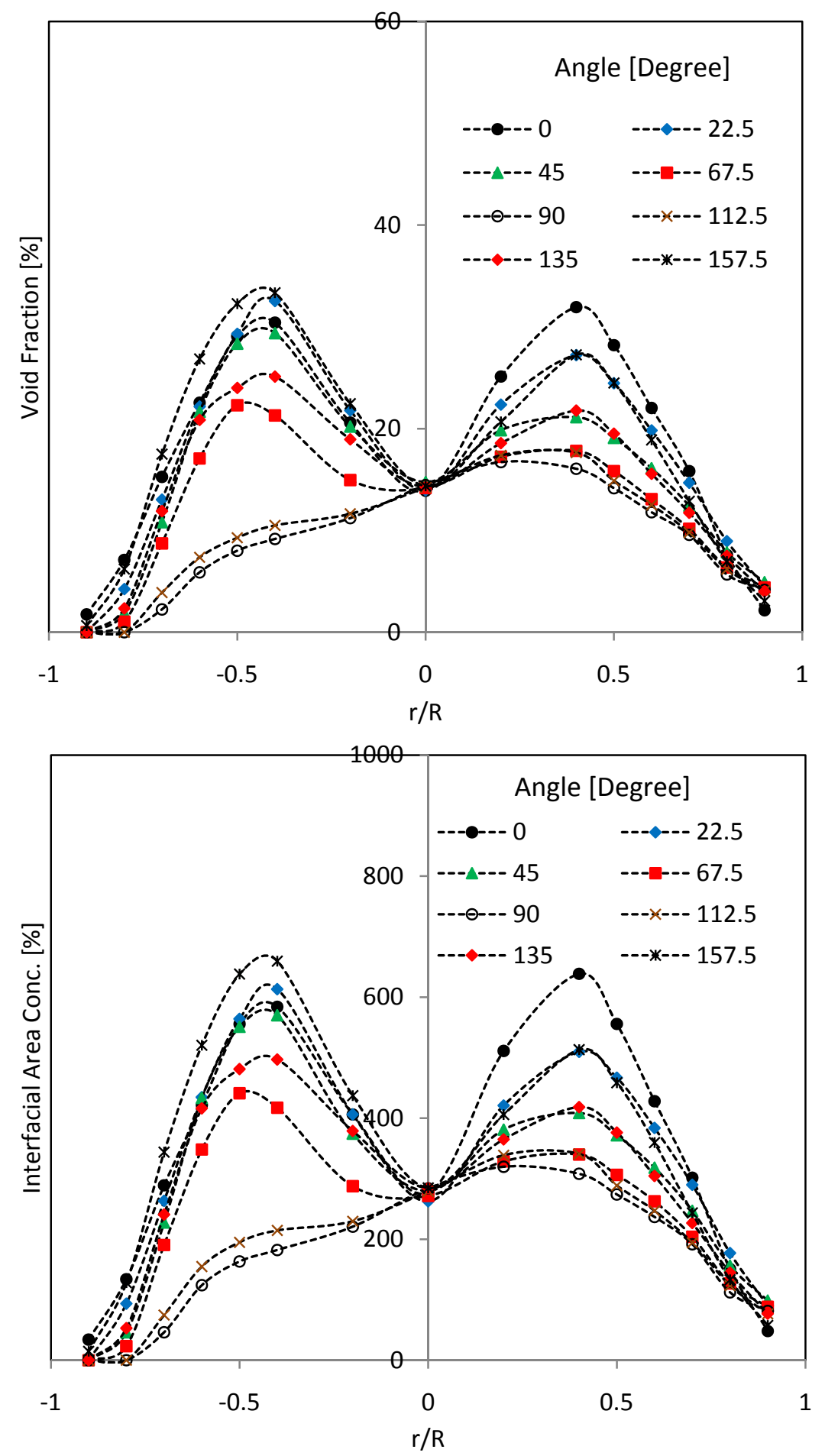

Figure A 2-3: Local profiles of $\alpha$ and $a_{i}$ at different angles of measurement at port P4, L/D $=3$ from the 90-degree vertical elbow at Run-3; $\mathrm{j}_{\mathrm{f}}=2.0 \mathrm{~m} / \mathrm{s}$ and $\mathrm{j}_{\mathrm{g}, \mathrm{atm}}=0.136 \mathrm{~m} / \mathrm{s}$ 

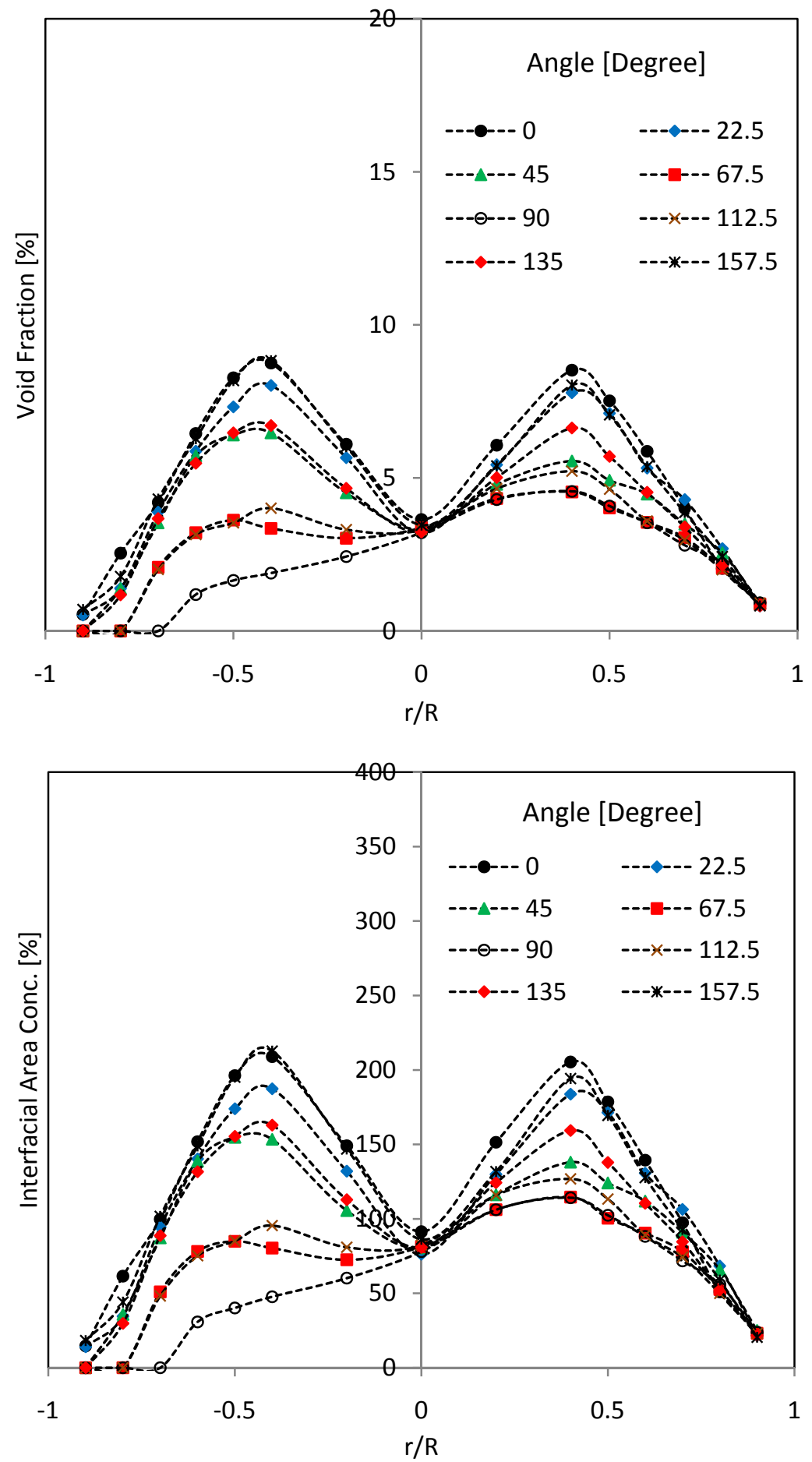

Figure A 2-4: Local profiles of $\alpha$ and $a_{i}$ at different angles of measurement at port P4, L/D = 3 from the 90-degree vertical elbow at Run- $4 ; j_{\mathrm{f}}=3.0 \mathrm{~m} / \mathrm{s}$ and $\mathrm{j}_{\mathrm{g}, \mathrm{atm}}=0.139 \mathrm{~m} / \mathrm{s}$ 

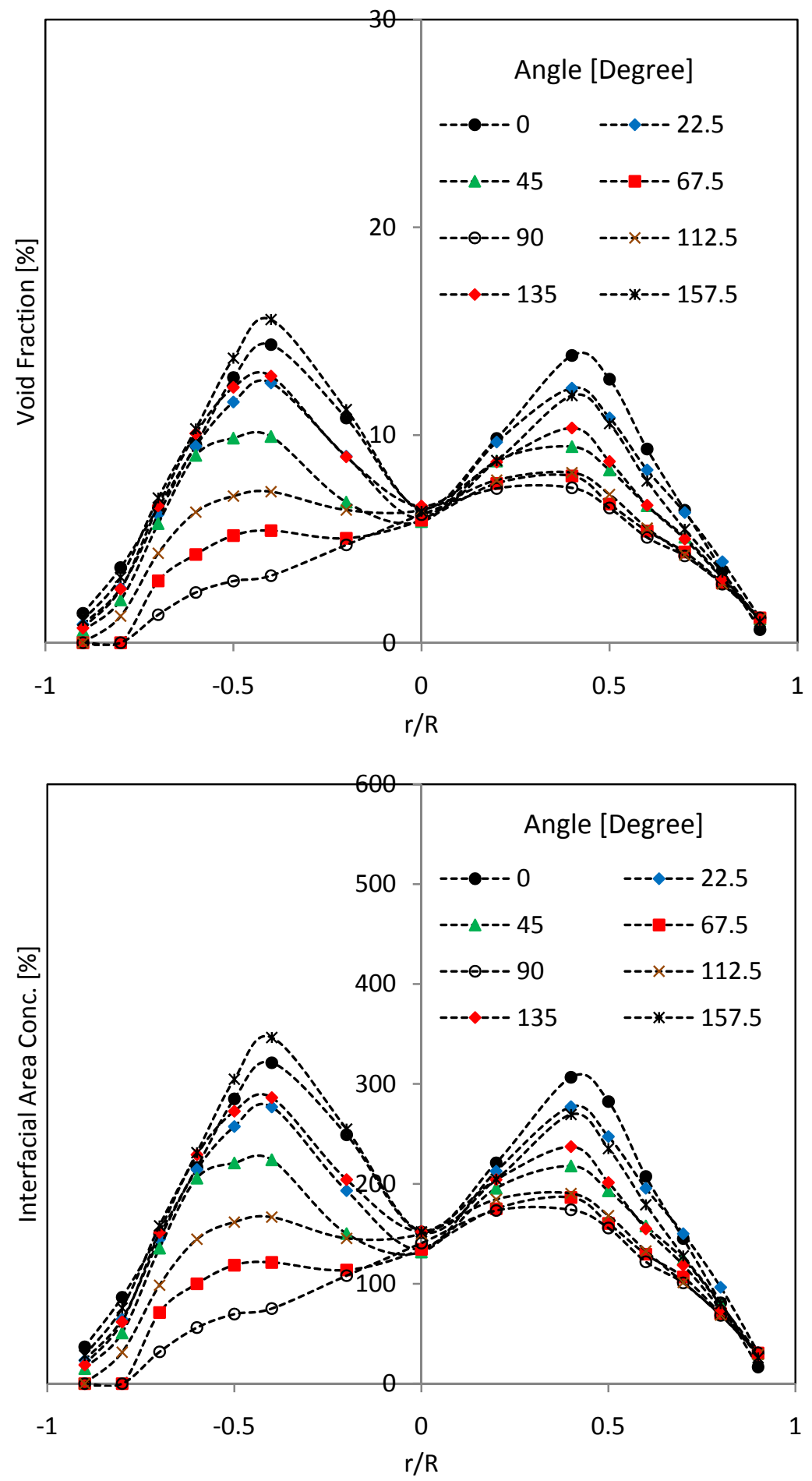

Figure A 2-5: Local profiles of $\alpha$ and $a_{i}$ at different angles of measurement at port P4, $L / D=3$ from the 90-degree vertical elbow at Run-5; $j_{\mathrm{f}}=3.0 \mathrm{~m} / \mathrm{s}$ and $\mathrm{j}_{\mathrm{g}, \mathrm{atm}}=0.232 \mathrm{~m} / \mathrm{s}$ 

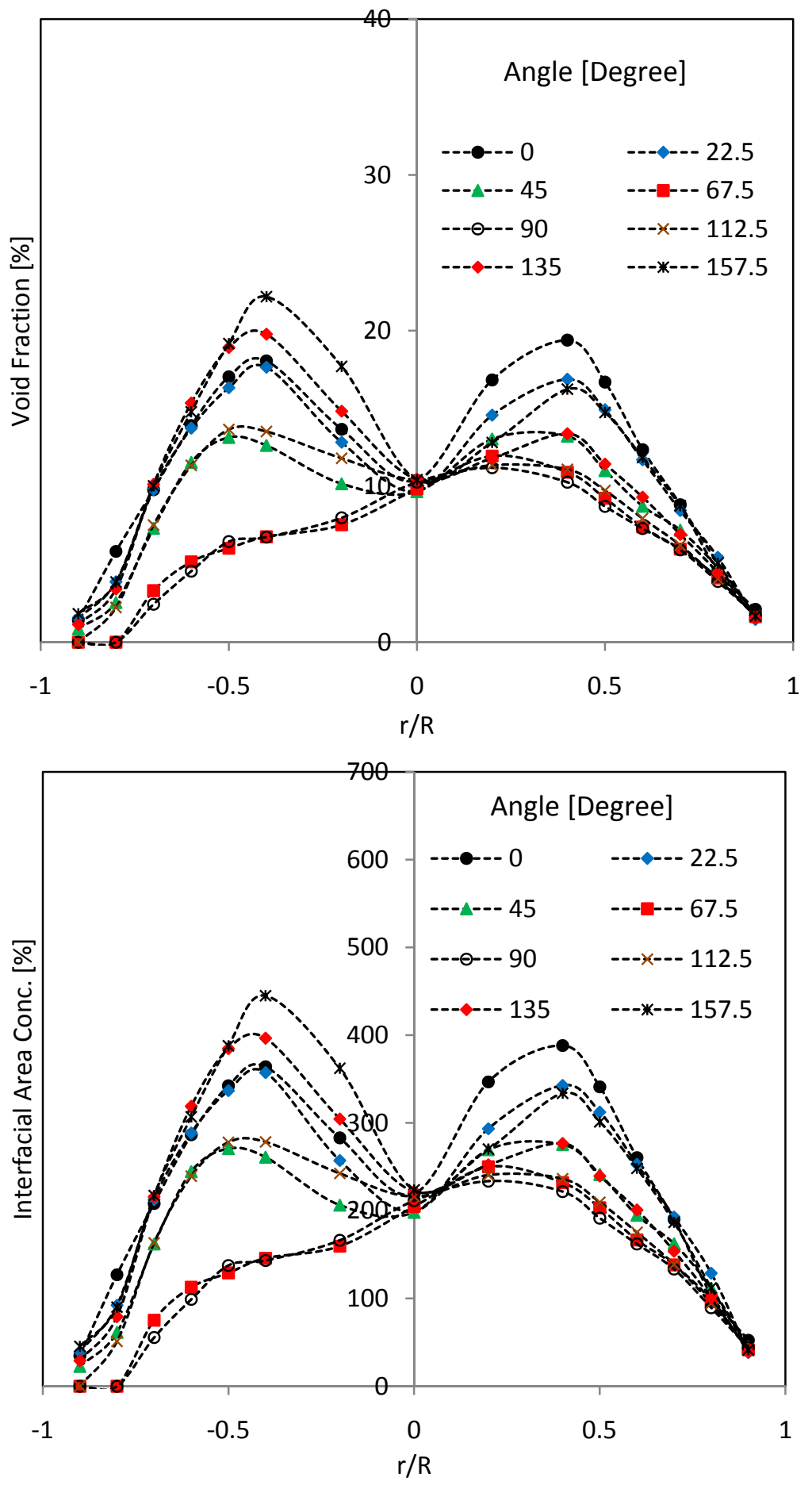

Figure A 2-6: Local profiles of $\alpha$ and $a_{i}$ at different angles of measurement at port $P 4, L / D=3$ from the 90-degree vertical elbow at Run- $6 ; \mathrm{j}_{\mathrm{f}}=3.0 \mathrm{~m} / \mathrm{s}$ and $\mathrm{j}_{\mathrm{g}, \mathrm{atm}}=0.232 \mathrm{~m} / \mathrm{s}$ 

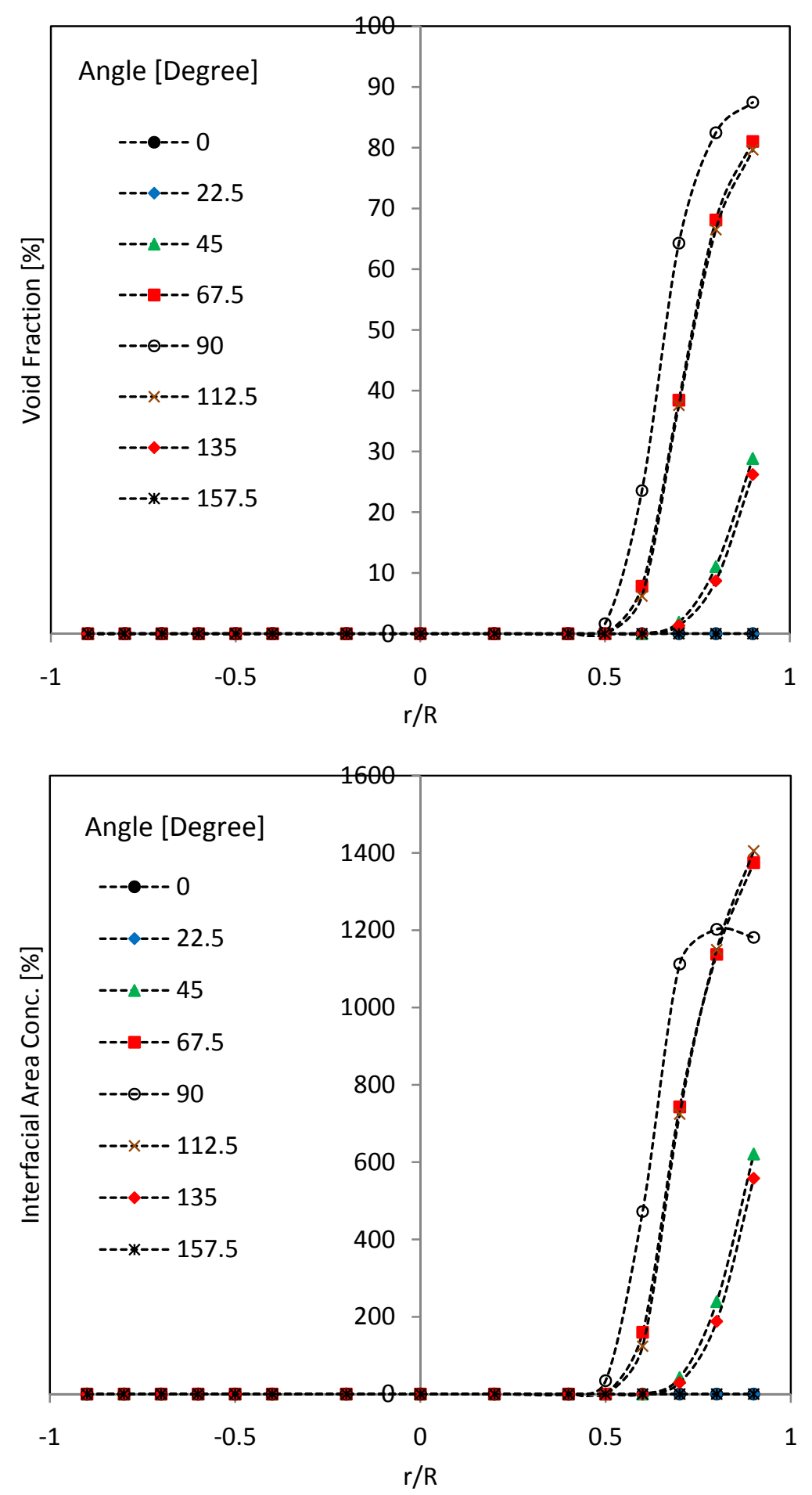

Figure A 2-7: Local profiles of void fraction at different angles of measurement at port P5, L/D = 30 from the 90 -degree vertical elbow at Run- $2 ; \mathrm{j}_{\mathrm{f}}=3.0 \mathrm{~m} / \mathrm{s}$ and $\mathrm{j}_{\mathrm{g}, \mathrm{atm}}=0.139 \mathrm{~m} / \mathrm{s}$ 

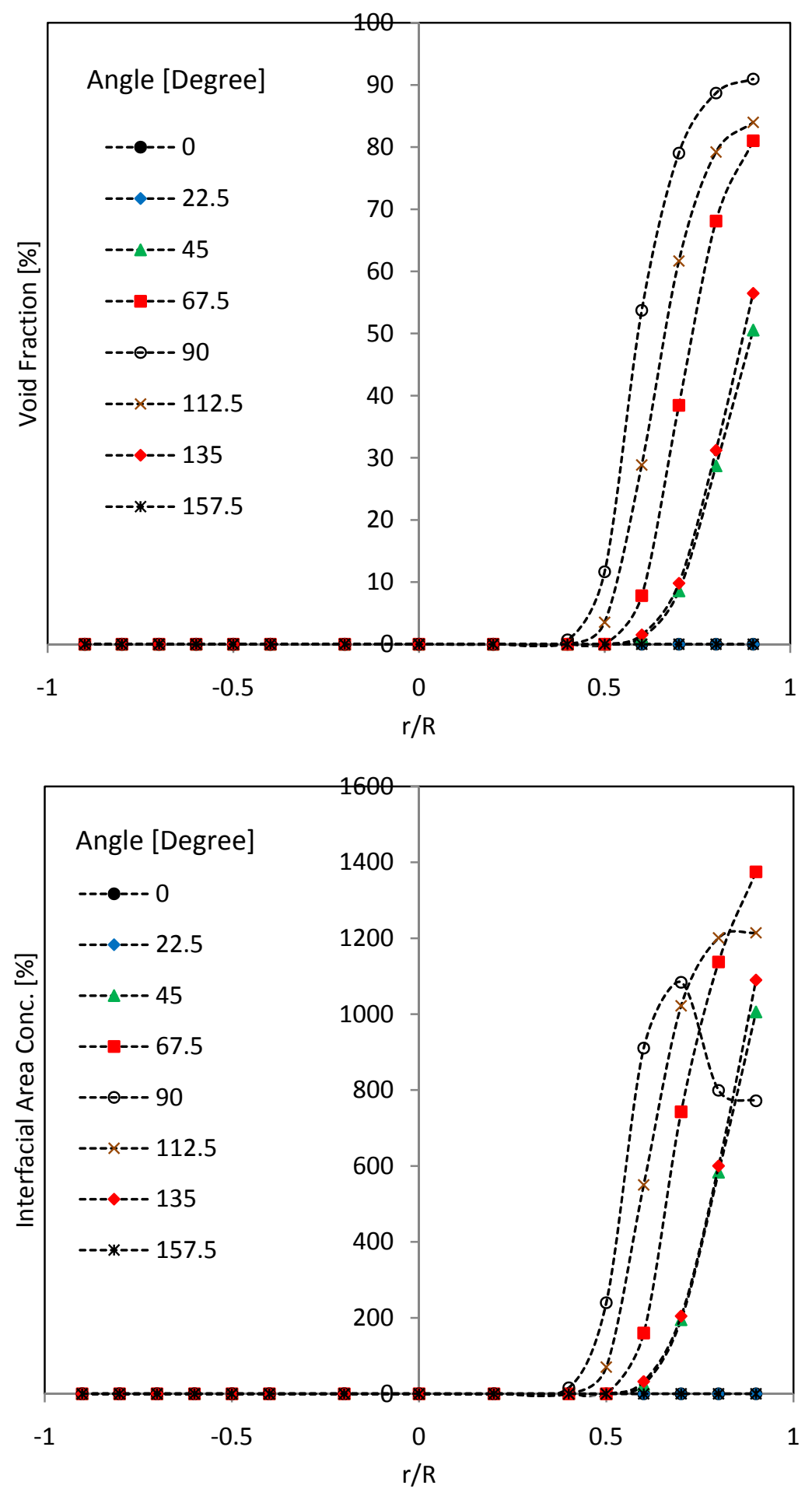

Figure A 2-8: Local profiles of void fraction at different angles of measurement at port $\mathrm{P} 5, \mathrm{~L} / \mathrm{D}=30$ from the 90 -degree vertical elbow at Run- $3 ; \mathrm{j}_{\mathrm{f}}=3.0 \mathrm{~m} / \mathrm{s}$ and $\mathrm{j}_{\mathrm{g}, \mathrm{atm}=}=0.139 \mathrm{~m} / \mathrm{s}$ 

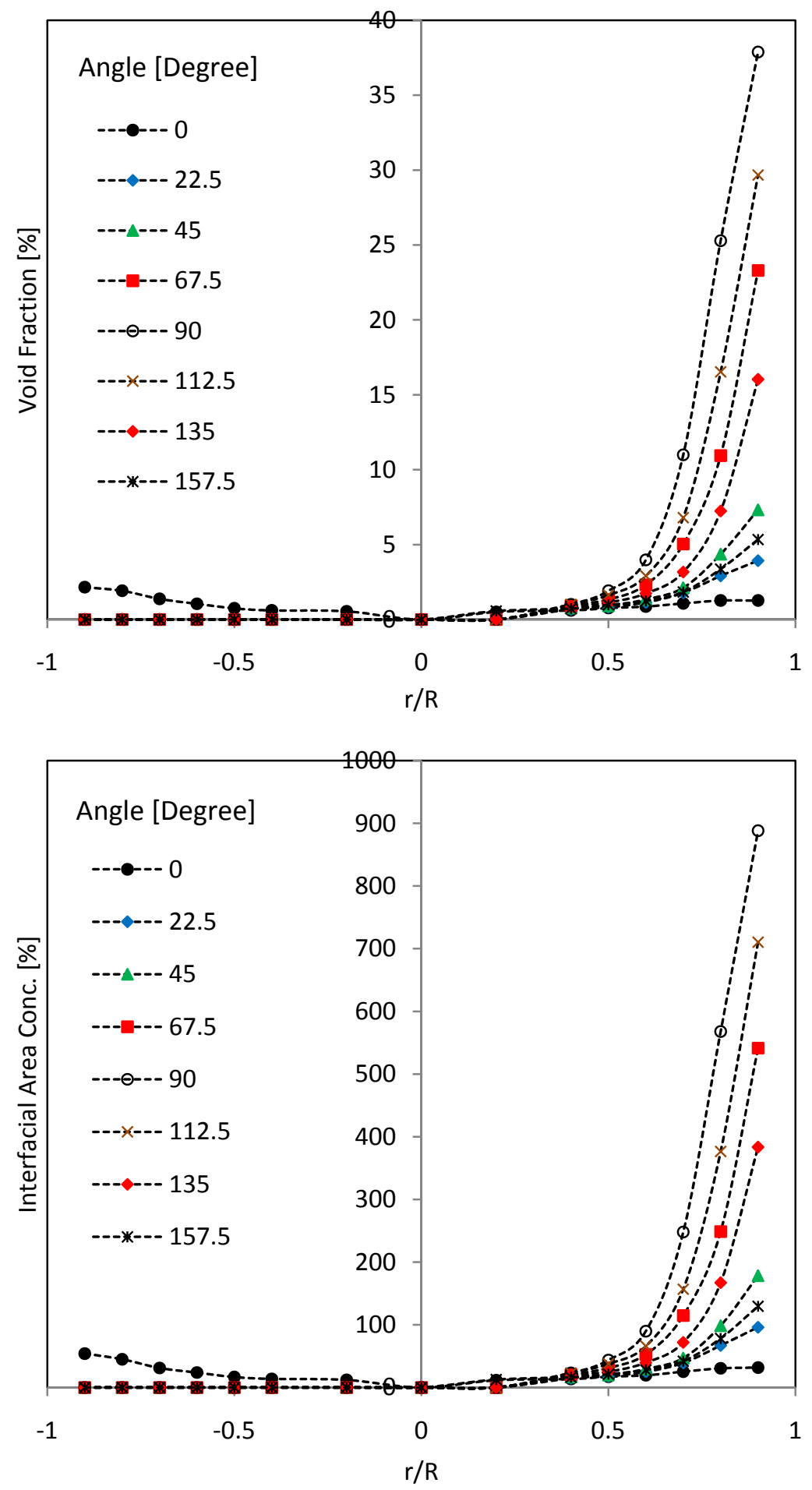

Figure A 2-9: Local profiles of void fraction at different angles of measurement at port $\mathrm{P} 5, \mathrm{~L} / \mathrm{D}=30$ from the 90 -degree vertical elbow at Run- $4 ; \mathrm{j}_{\mathrm{f}}=3.0 \mathrm{~m} / \mathrm{s}$ and $\mathrm{j}_{\mathrm{g}, \mathrm{atm}}=0.139 \mathrm{~m} / \mathrm{s}$ 

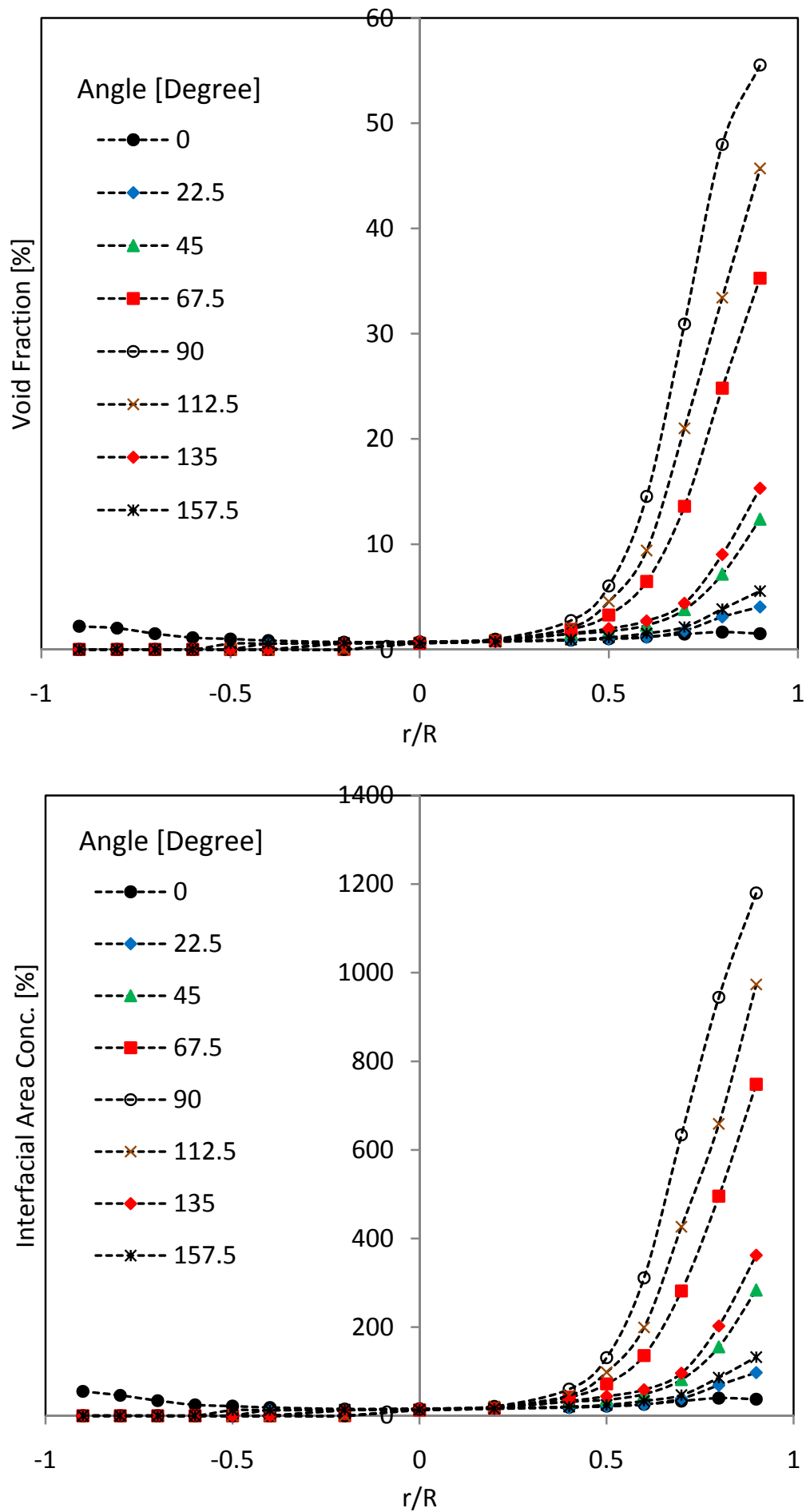

Figure A 2-10: Local profiles of void fraction at different angles of measurement at port P5, L/D $=30$ from the 90 -degree vertical elbow at Run- $5 ; \mathrm{j}_{\mathrm{f}}=3.0 \mathrm{~m} / \mathrm{s}$ and $\mathrm{j}_{\mathrm{g}, \mathrm{atm}}=0.139 \mathrm{~m} / \mathrm{s}$ 

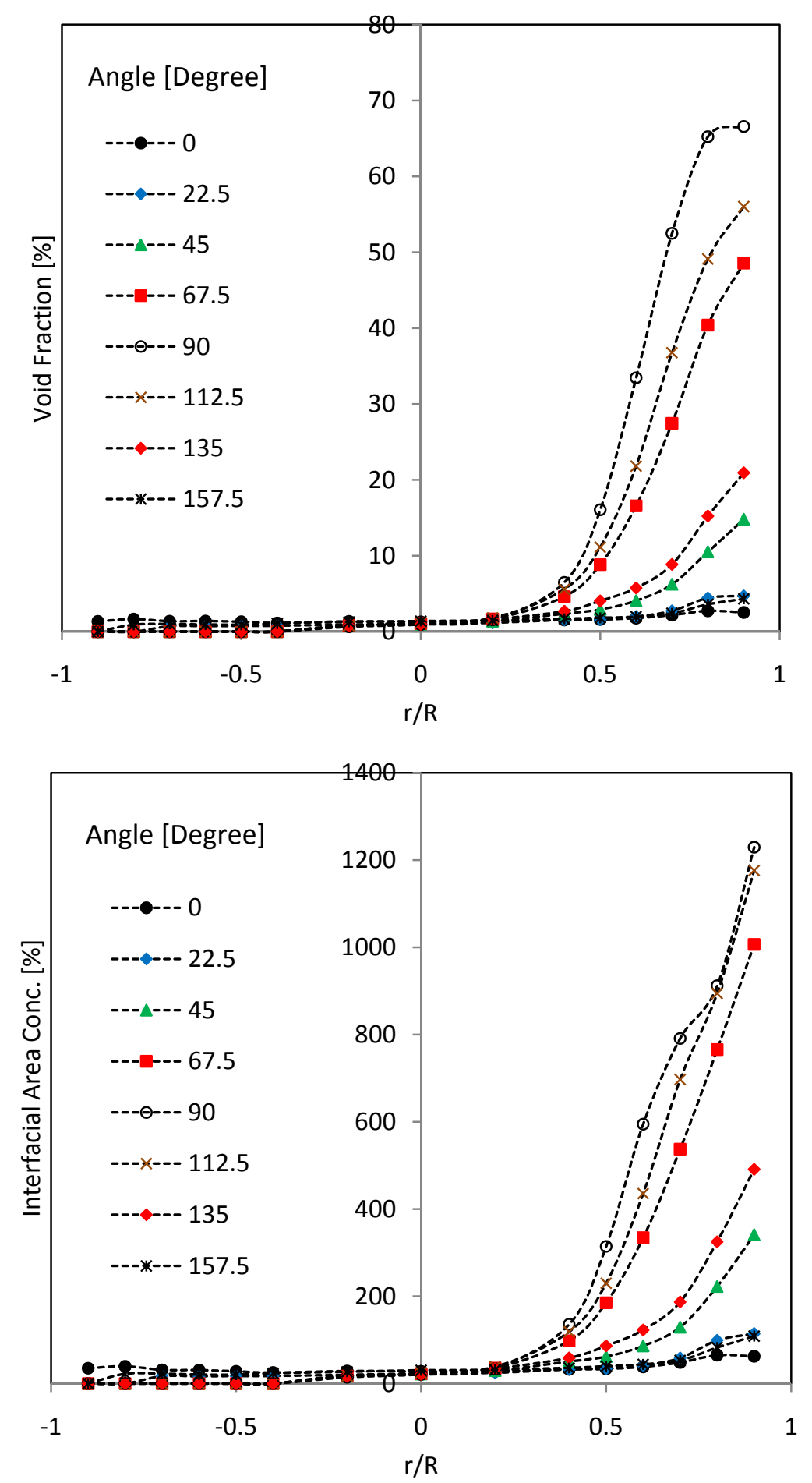

Figure A 2-11: Local profiles of void fraction at different angles of measurement at port P5, L/D $=30$ from the 90 -degree vertical elbow at Run- $6 ; \mathrm{j}_{\mathrm{f}}=3.0 \mathrm{~m} / \mathrm{s}$ and $\mathrm{j}_{\mathrm{g}, \mathrm{atm}}=0.139 \mathrm{~m} / \mathrm{s}$ 

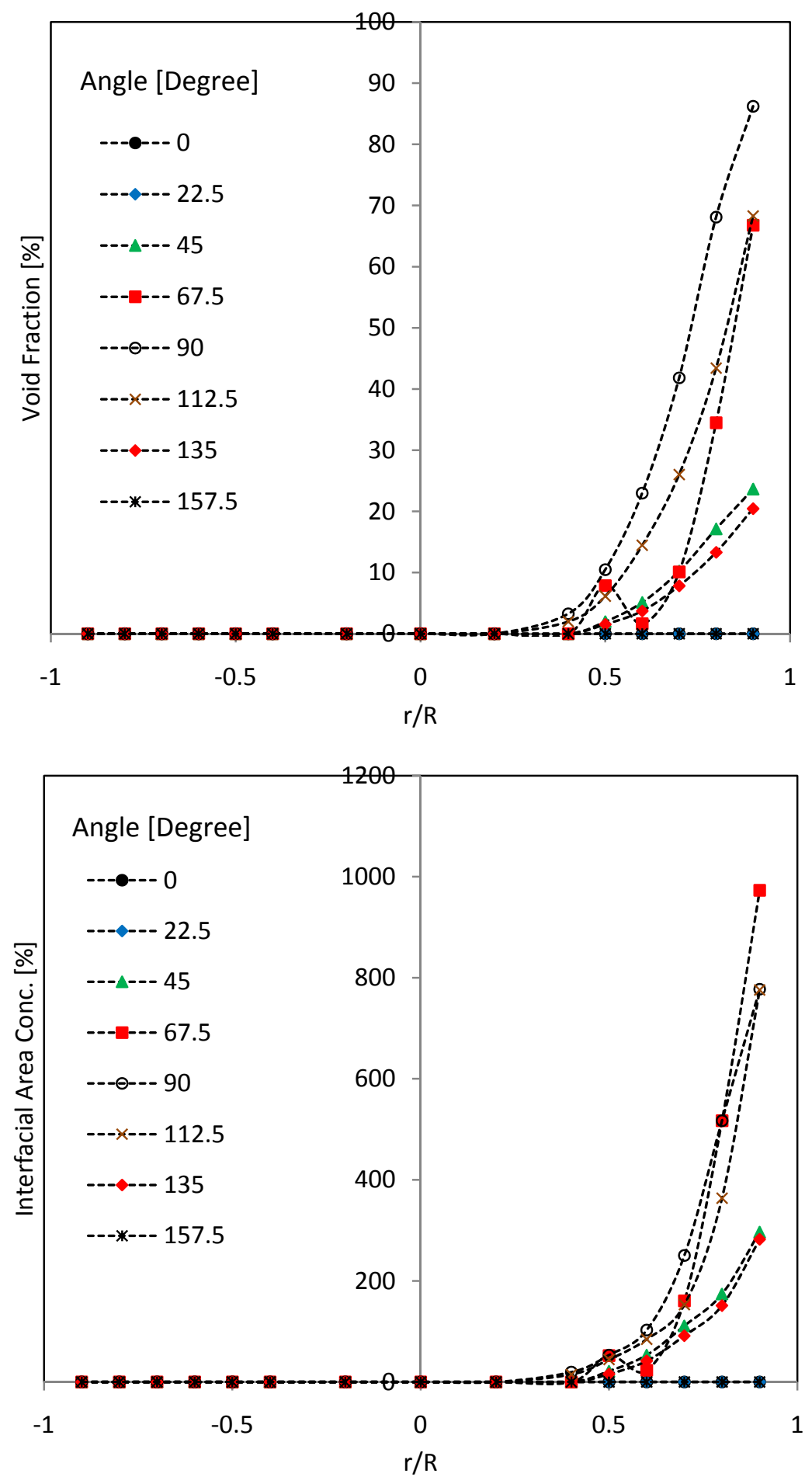

Figure A 2-12: Local profiles of void fraction at different angles of measurement at port P7, L/D $=93$ from the 90 -degree vertical elbow at Run- $2 ; \mathrm{j}_{\mathrm{f}}=3.0 \mathrm{~m} / \mathrm{s}$ and $\mathrm{j}_{\mathrm{g}, \mathrm{atm}}=0.139 \mathrm{~m} / \mathrm{s}$ 

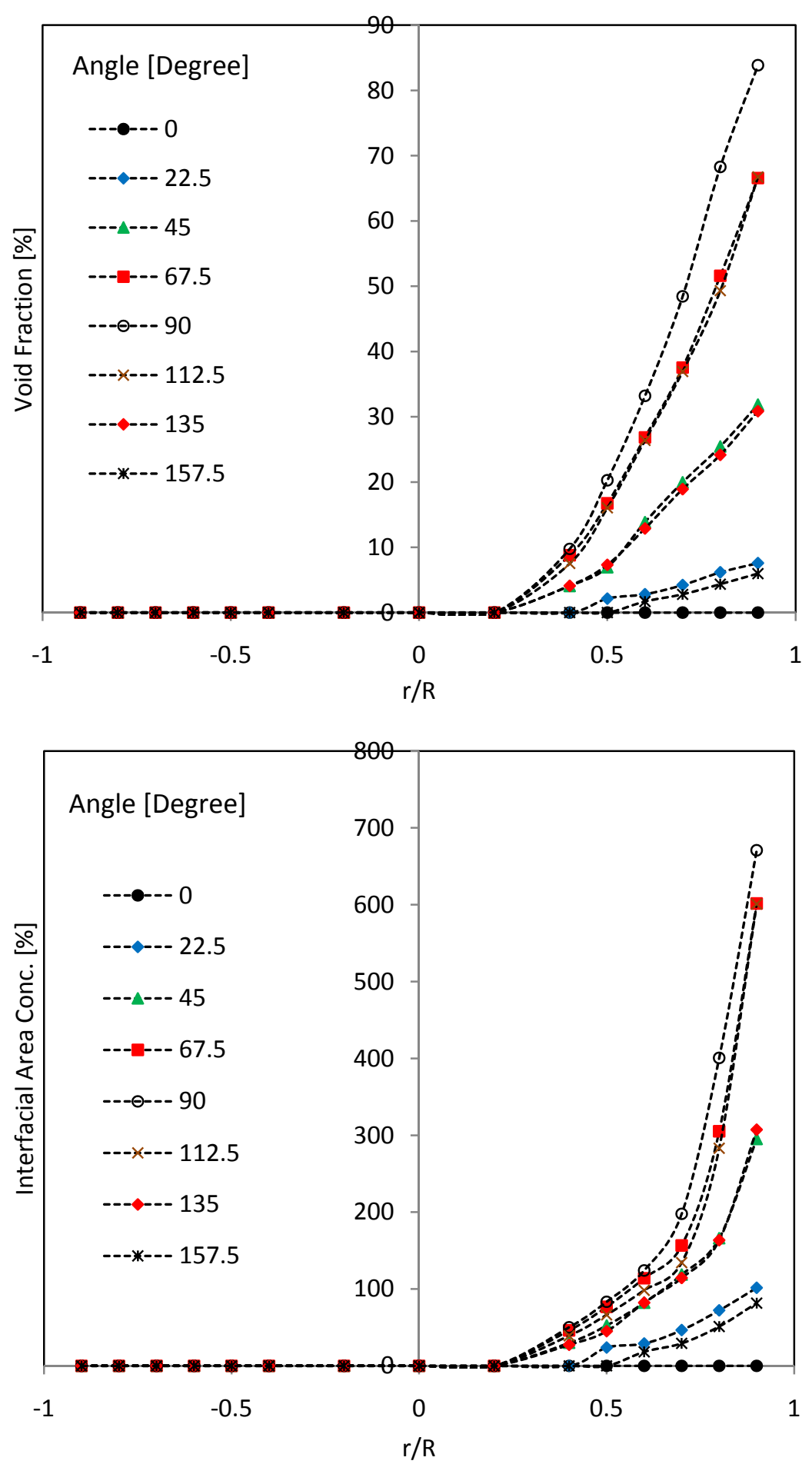

Figure A 2-13: Local profiles of void fraction at different angles of measurement at port P7, L/D $=93$ from the 90 -degree vertical elbow at Run- $3 ; j_{\mathrm{f}}=3.0 \mathrm{~m} / \mathrm{s}$ and $\mathrm{j}_{\mathrm{g}, \mathrm{atm}}=0.139 \mathrm{~m} / \mathrm{s}$ 

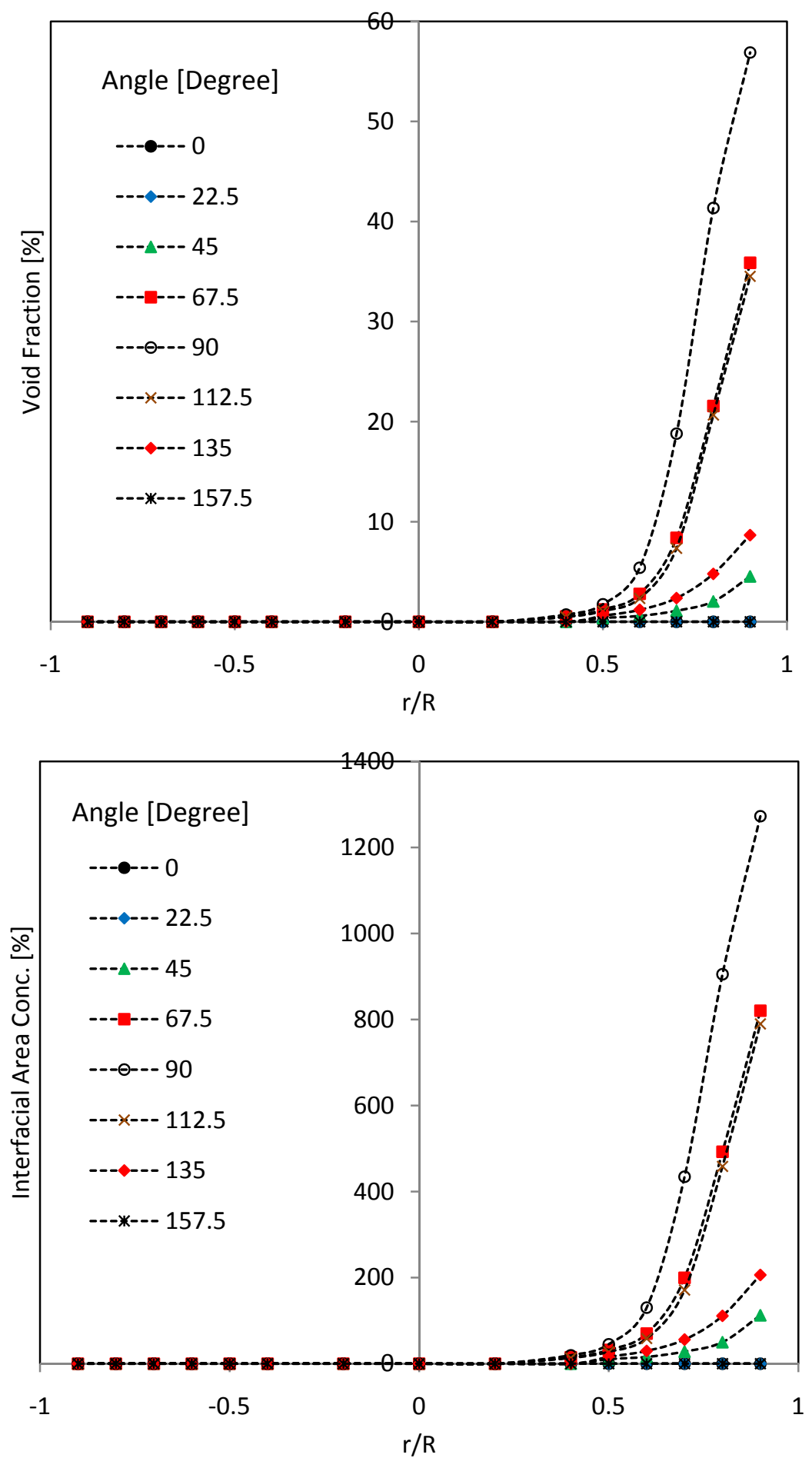

Figure A 2-14: Local profiles of void fraction at different angles of measurement at port P7, L/D = 93 from the 90 -degree vertical elbow at Run- $4 ; \mathrm{j}_{\mathrm{f}}=3.0 \mathrm{~m} / \mathrm{s}$ and $\mathrm{j}_{\mathrm{g}, \mathrm{atm}}=0.139 \mathrm{~m} / \mathrm{s}$ 

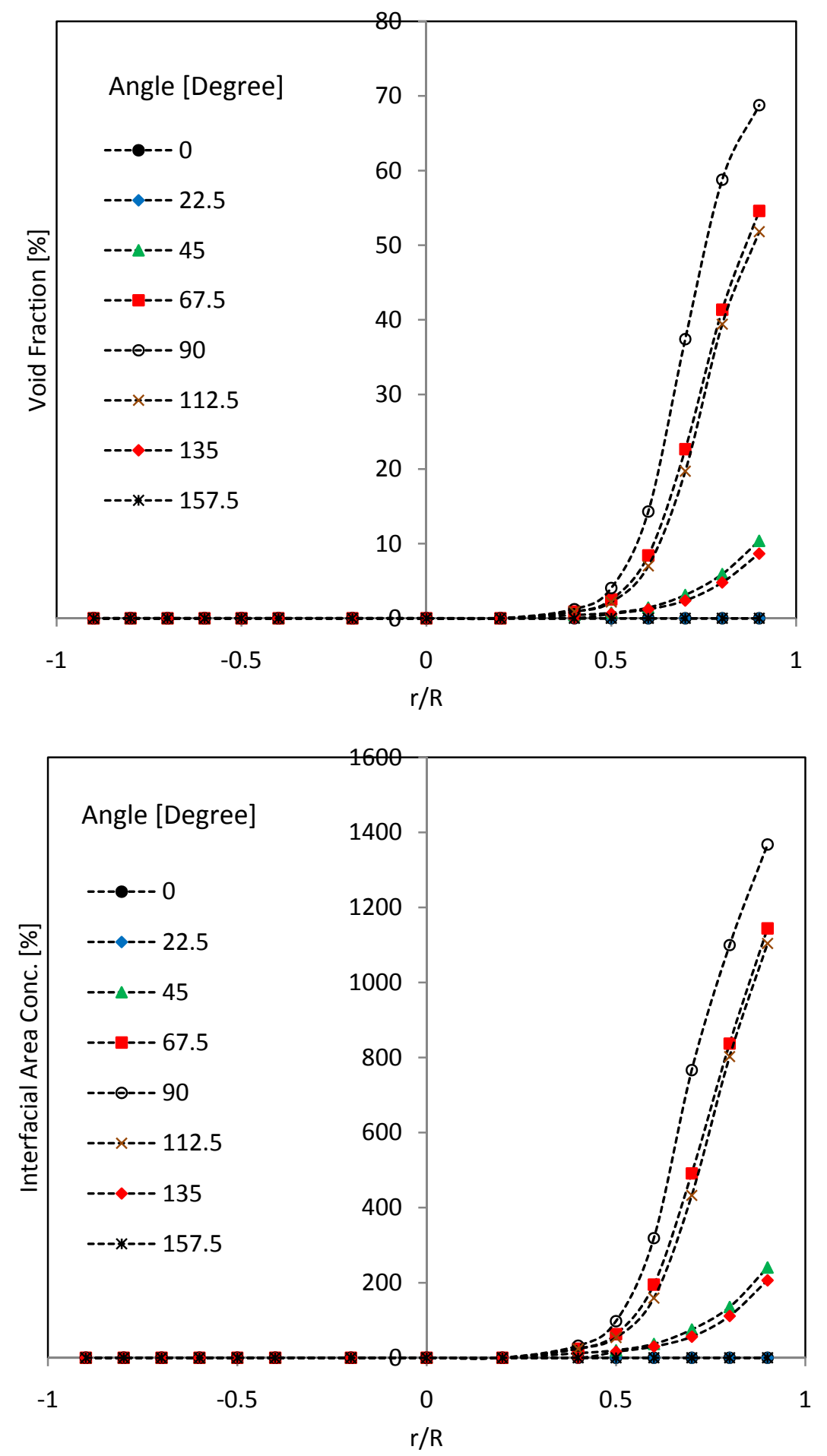

Figure A 2-15: Local profiles of void fraction at different angles of measurement at port P7, L/D = 93 from the 90 -degree vertical elbow at Run-5; $\mathrm{j}_{\mathrm{f}}=3.0 \mathrm{~m} / \mathrm{s}$ and $\mathrm{j}_{\mathrm{g}, \mathrm{atm}}=0.139 \mathrm{~m} / \mathrm{s}$ 

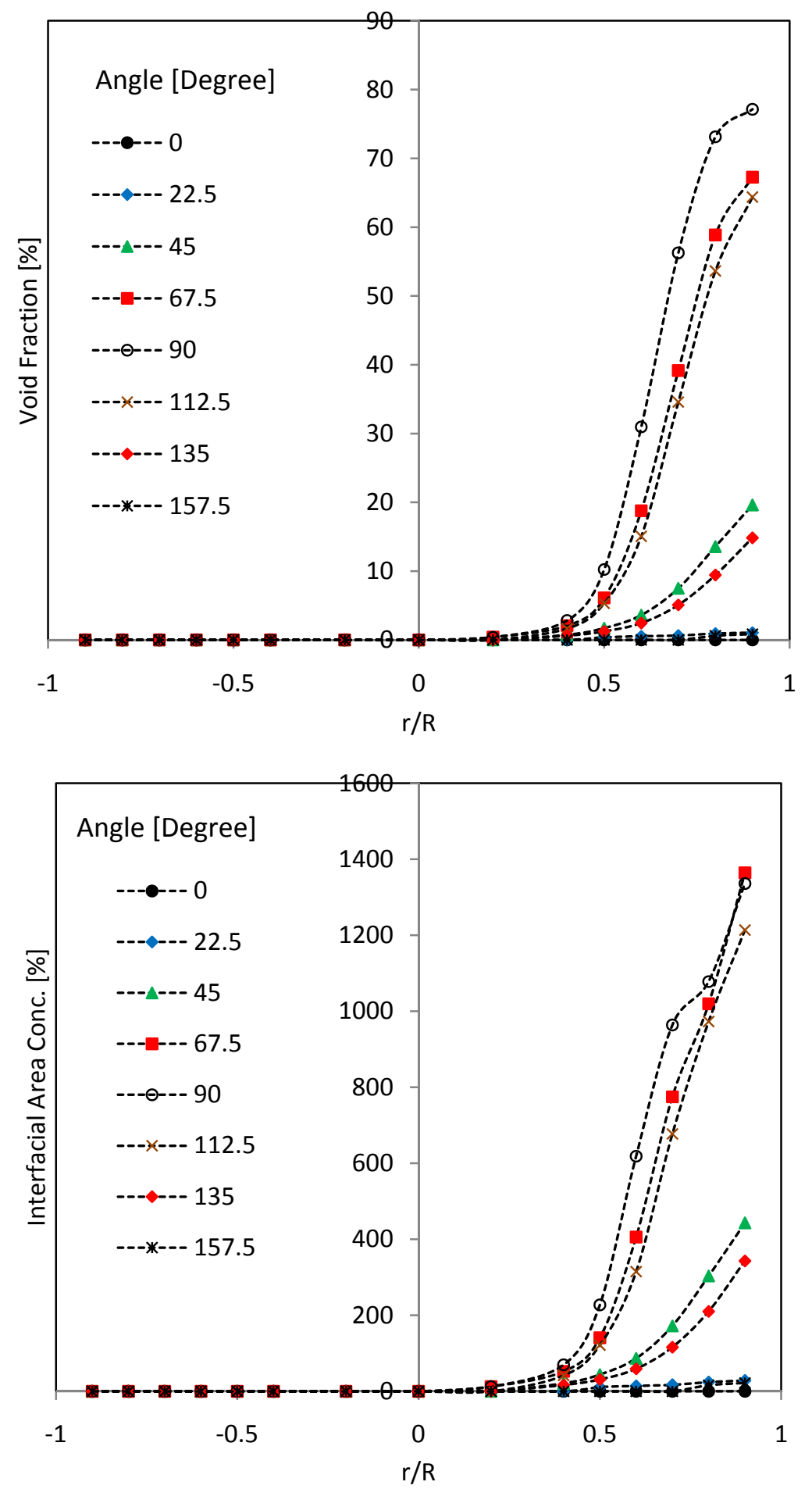

Figure A 2-16: Local profiles of void fraction at different angles of measurement at port P7, L/D = 93 from the 90-degree vertical elbow at Run- $6 ; \mathrm{j}_{\mathrm{f}}=3.0 \mathrm{~m} / \mathrm{s}$ and $\mathrm{j}_{\mathrm{g}, \mathrm{atm}}=0.139 \mathrm{~m} / \mathrm{s}$ 

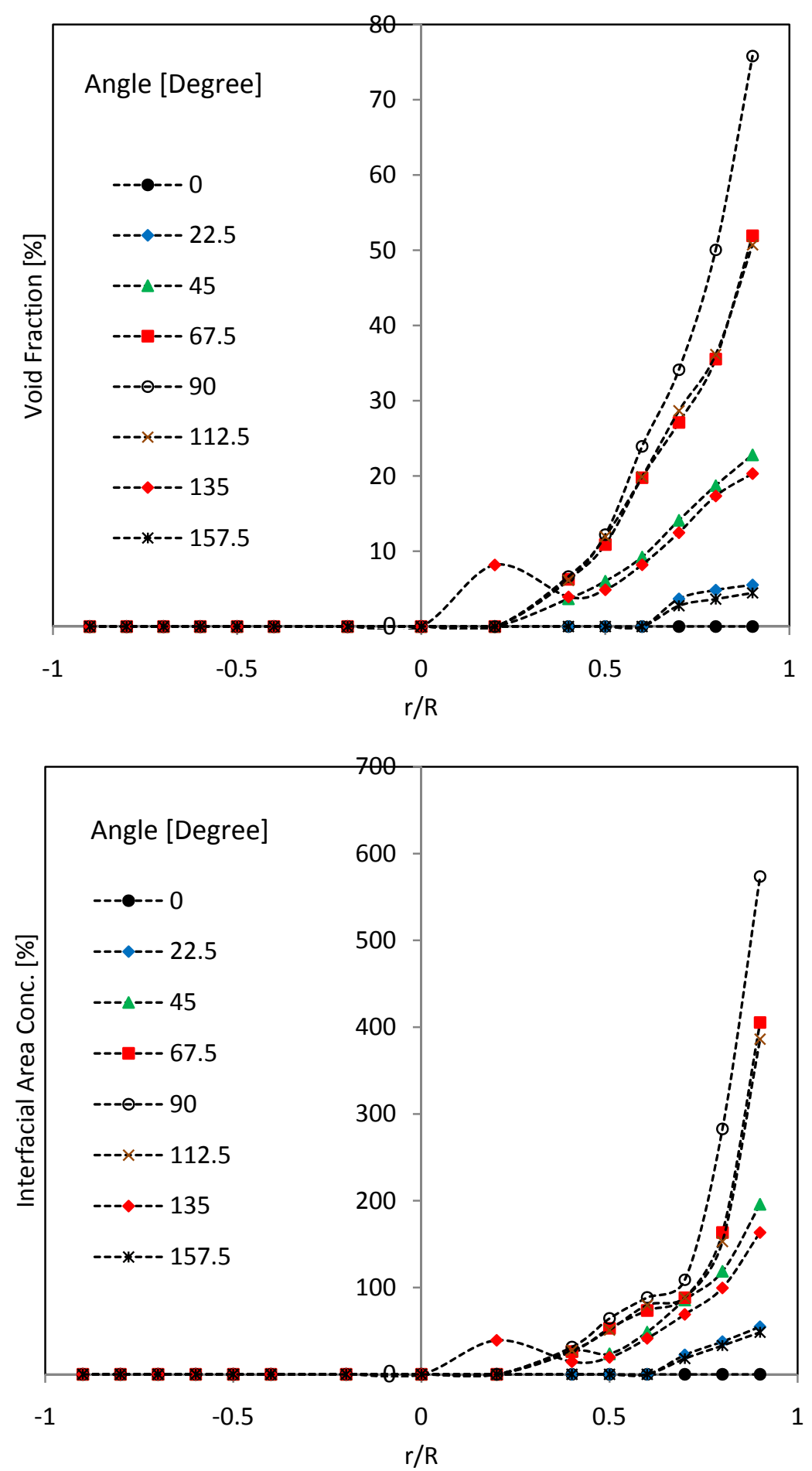

Figure A 2-17: Local profiles of void fraction at different angles of measurement at port P10, L/D = 177 from the 90 -degree vertical elbow at Run- $2 ; \mathrm{j}_{\mathrm{f}}=3.0 \mathrm{~m} / \mathrm{s}$ and $\mathrm{j}_{\mathrm{g}, \mathrm{atm}}=0.139 \mathrm{~m} / \mathrm{s}$ 

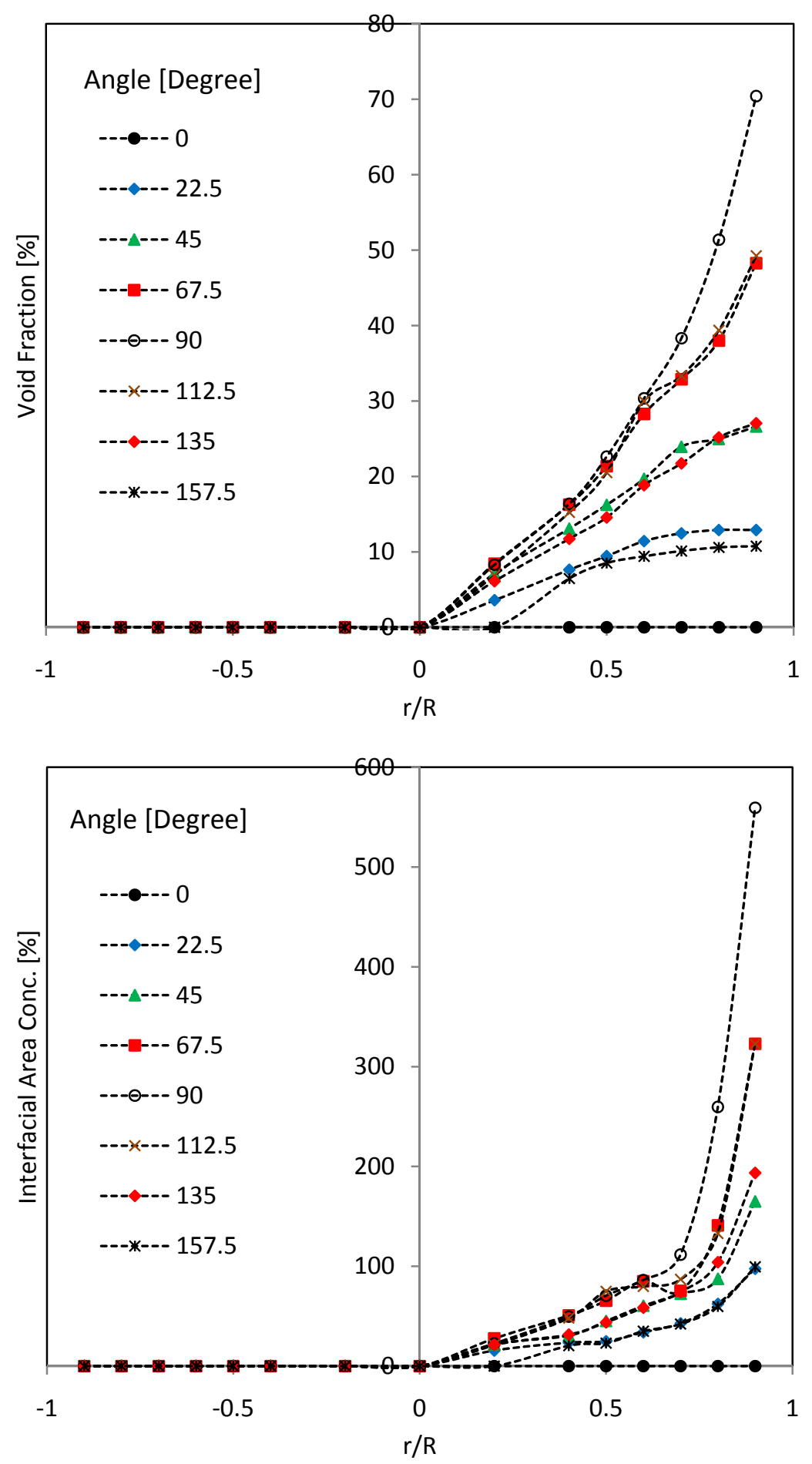

Figure A 2-18: Local profiles of void fraction at different angles of measurement at port P10, L/D $=177$ from the 90 -degree vertical elbow at Run- $3 ; \mathrm{j}_{\mathrm{f}}=3.0 \mathrm{~m} / \mathrm{s}$ and $\mathrm{j}_{\mathrm{g}, \mathrm{atm}}=0.139 \mathrm{~m} / \mathrm{s}$ 

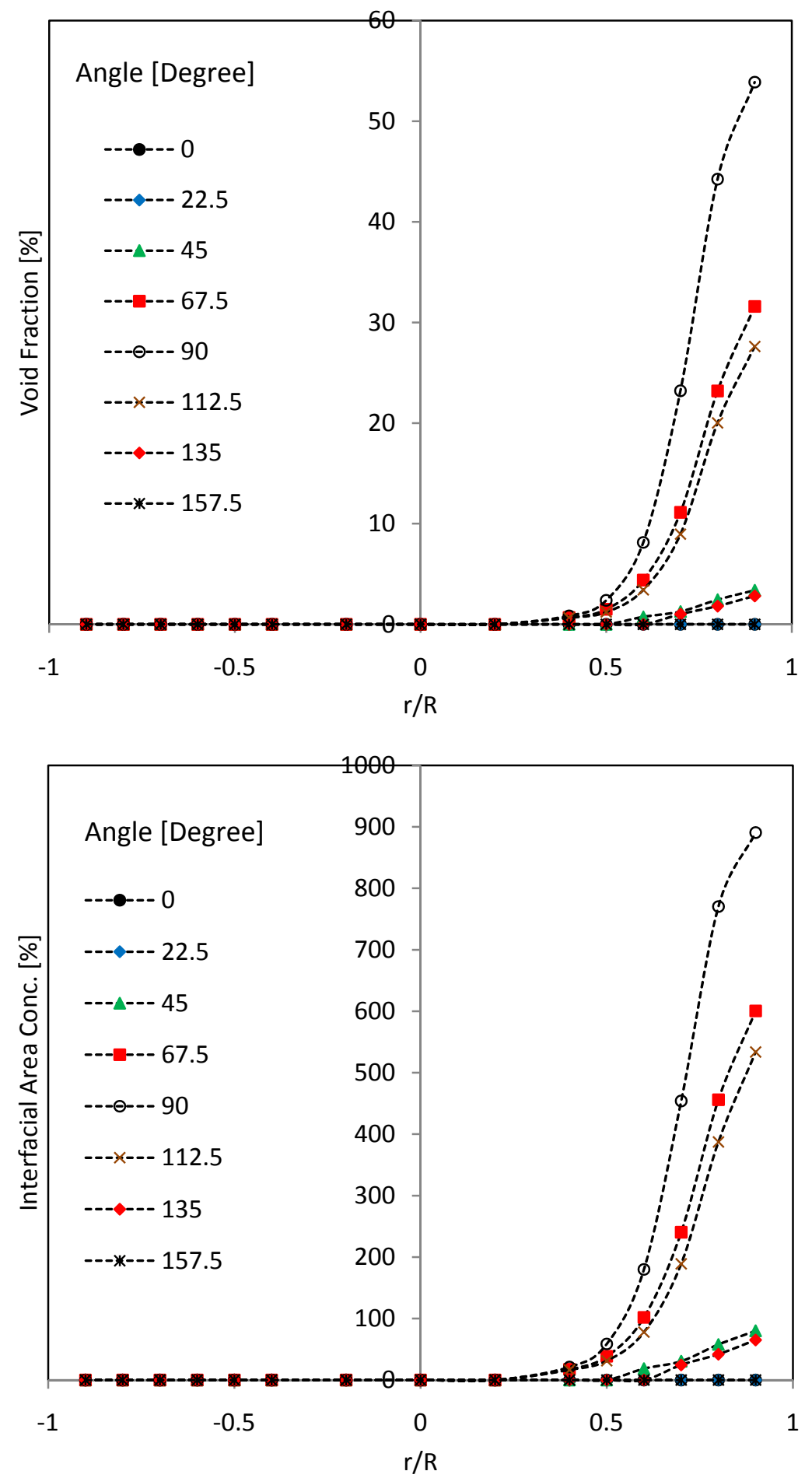

Figure A 2-19: Local profiles of void fraction at different angles of measurement at port P10, L/D = 177 from the 90 -degree vertical elbow at Run- $4 \mathrm{j}_{\mathrm{f}}=3.0 \mathrm{~m} / \mathrm{s}$ and $\mathrm{j}_{\mathrm{g}, \mathrm{atm}}=0.139 \mathrm{~m} / \mathrm{s}$ 

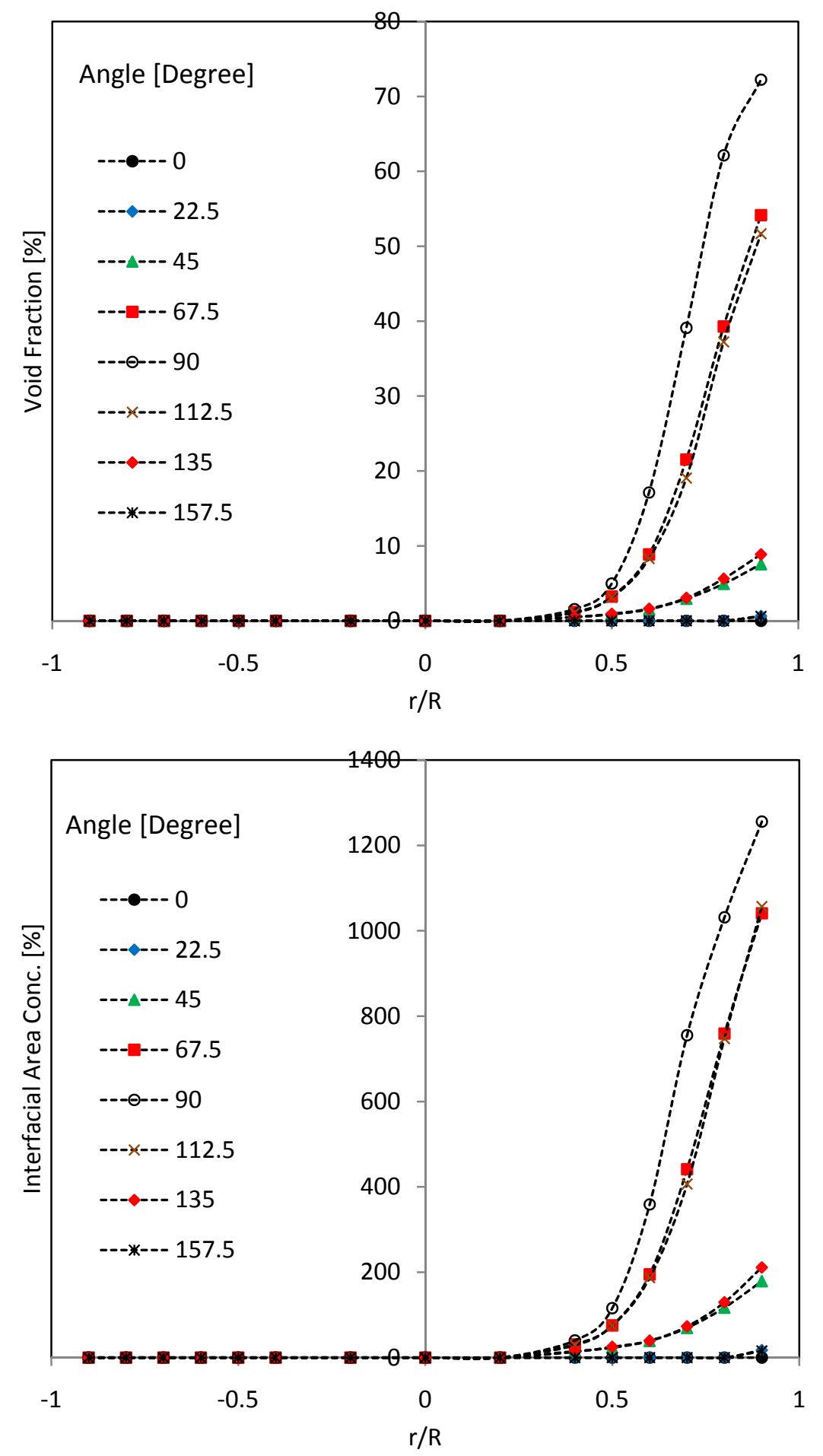

Figure A 2-20: Local profiles of void fraction at different angles of measurement at port P10, L/D = 177 from the 90 -degree vertical elbow at Run- $5 ; \mathrm{j}_{\mathrm{f}}=3.0 \mathrm{~m} / \mathrm{s}$ and $\mathrm{j}_{\mathrm{g}, \mathrm{atm}}=0.139 \mathrm{~m} / \mathrm{s}$ 

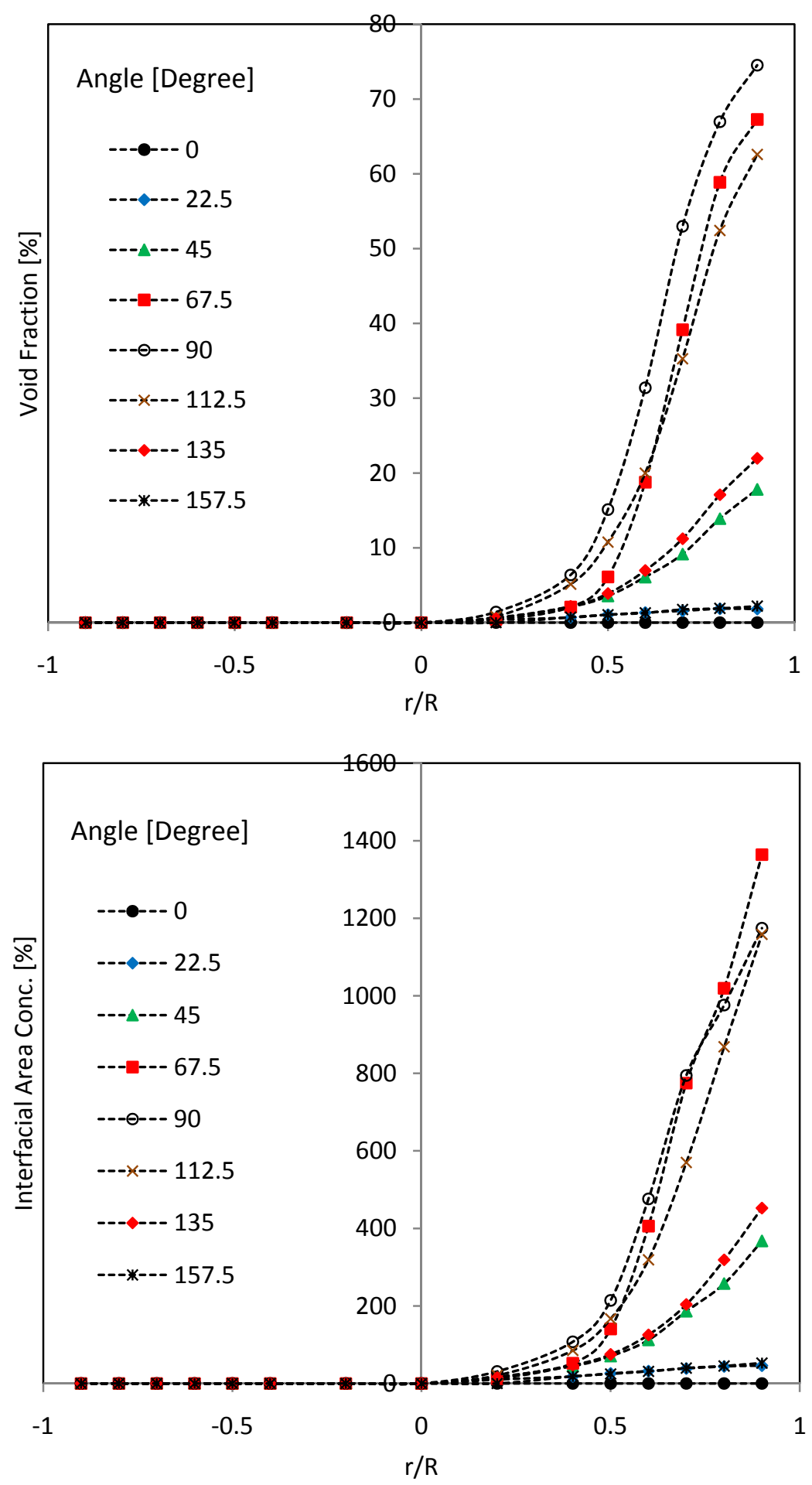

Figure A 2-21: Local profiles of void fraction at different angles of measurement at port P10, L/D = 177 from the 90 -degree vertical elbow at Run- $6 ; \mathrm{j}_{\mathrm{f}}=3.0 \mathrm{~m} / \mathrm{s}$ and $\mathrm{j}_{\mathrm{g}, \mathrm{atm}}=0.139 \mathrm{~m} / \mathrm{s}$ 
Appendix A3

Local interfacial structures in vertical-downward section in combinatorial channels 

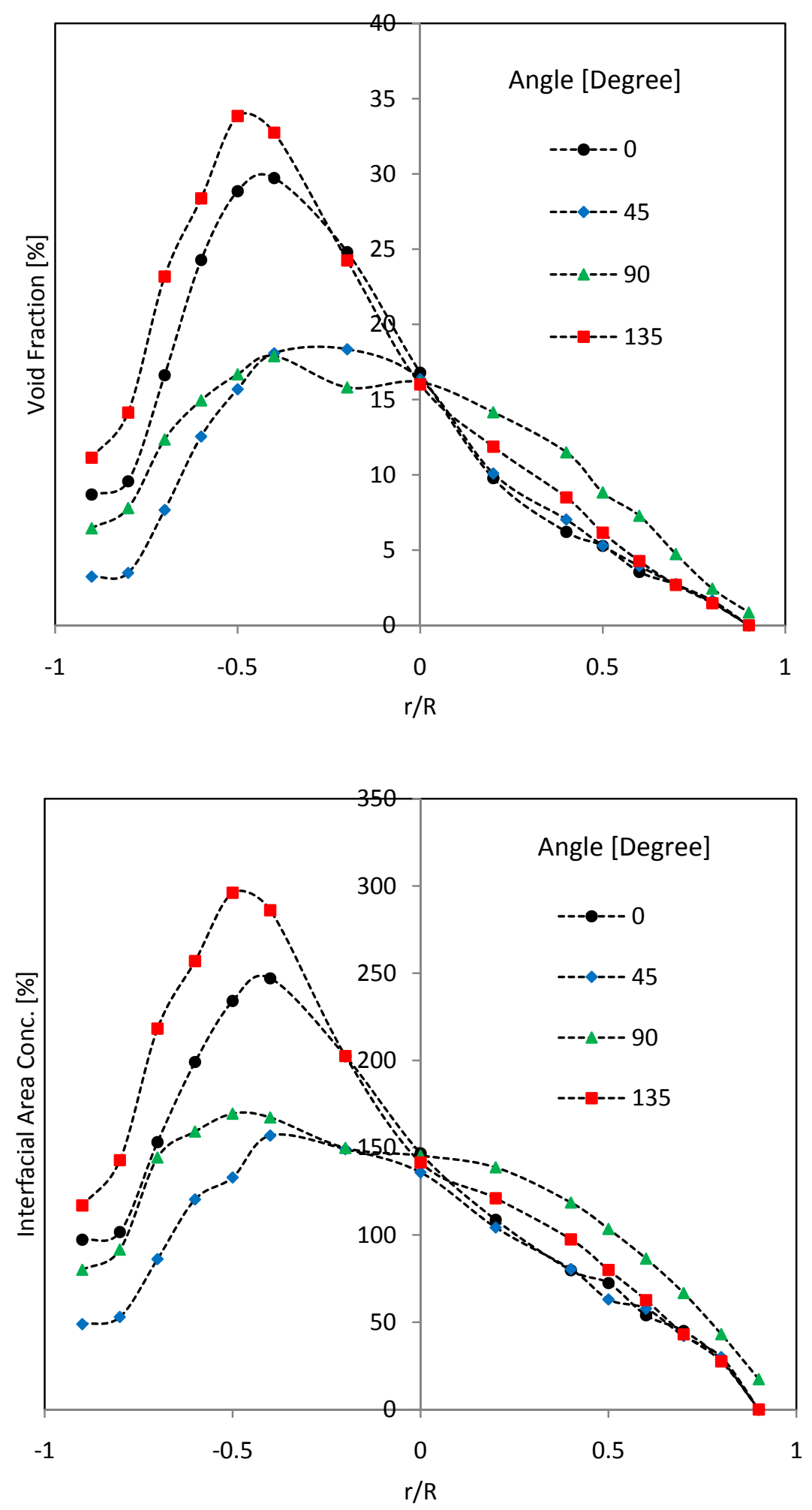

Figure A 3-1: Local profiles of void fraction at different angles of measurement at port P11, L/D = 1.5 from the 90 -degree vertical-downward elbow for Run- $1 ; \mathrm{j}_{\mathrm{f}}=3.0 \mathrm{~m} / \mathrm{s}$ and $\mathrm{j}_{\mathrm{g}, \mathrm{atm}}=0.139 \mathrm{~m} / \mathrm{s}$ 

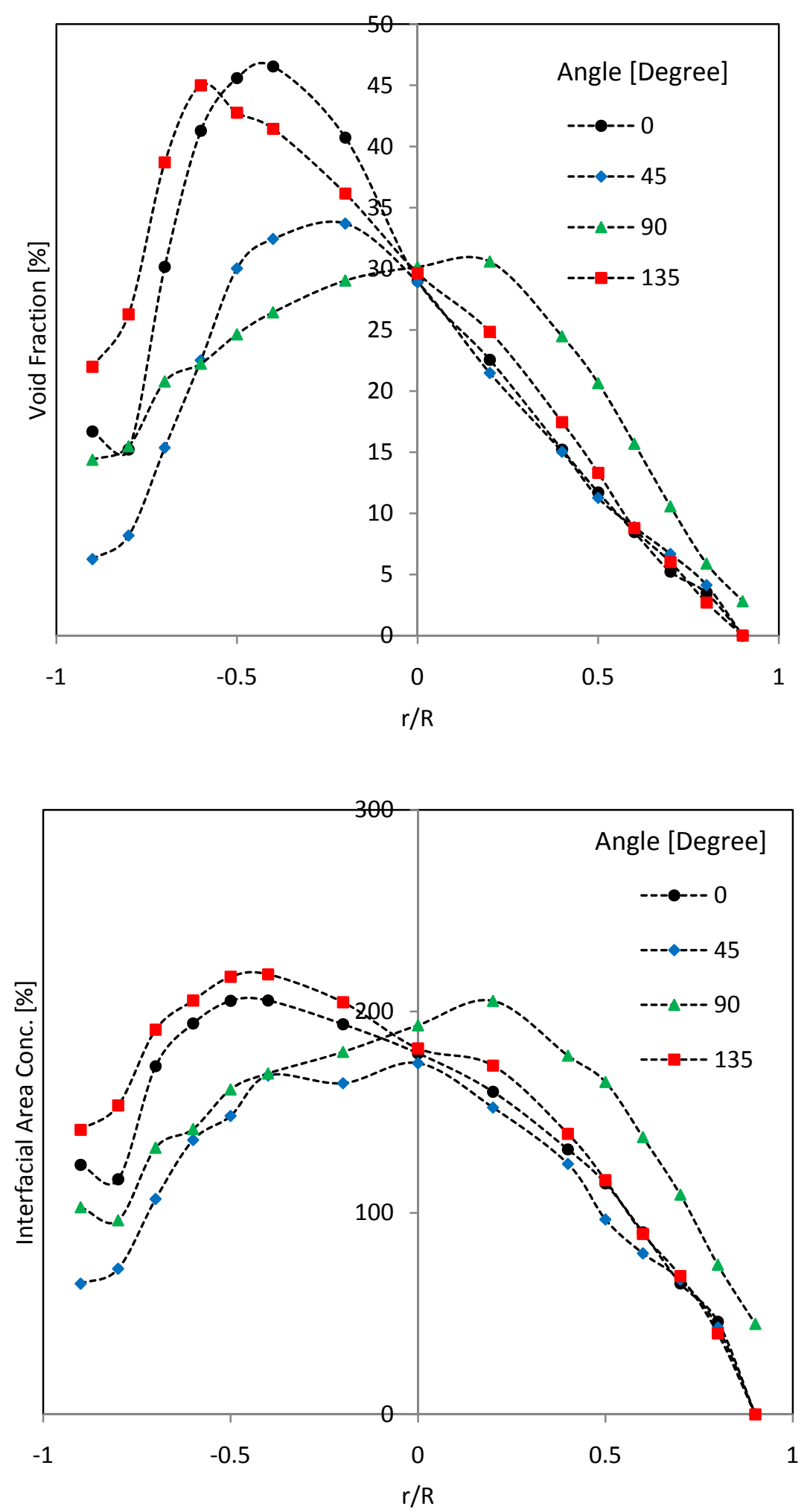

Figure A 3-2: Local profiles of void fraction at different angles of measurement at port P11, L/D = 1.5 from the 90 -degree vertical-downward elbow for Run- $2 ; \mathrm{j}_{\mathrm{f}}=3.0 \mathrm{~m} / \mathrm{s}$ and $\mathrm{j}_{\mathrm{g}, \mathrm{atm}}=0.139 \mathrm{~m} / \mathrm{s}$ 

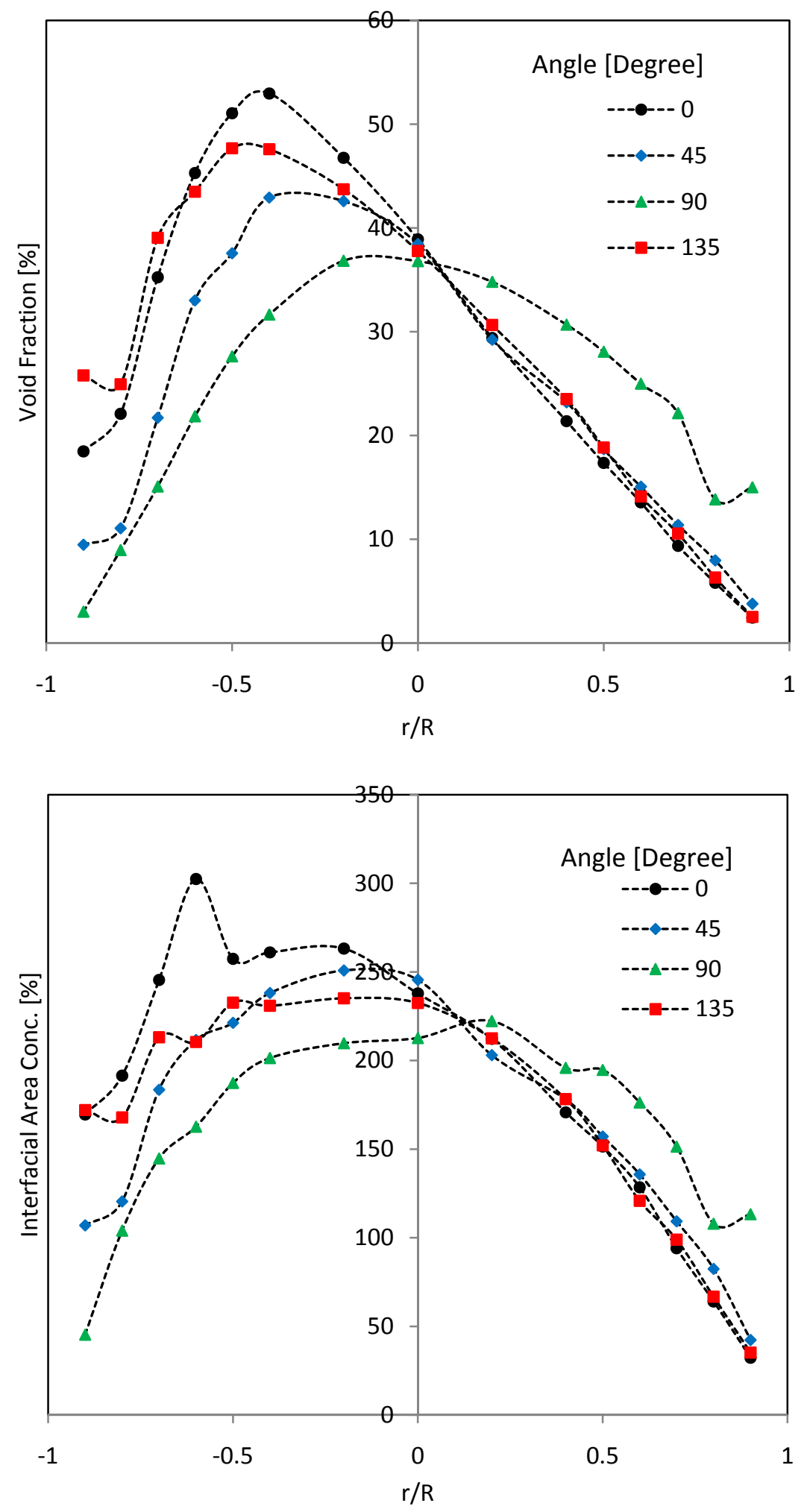

Figure A 3-3: Local profiles of void fraction at different angles of measurement at port P11, L/D = 1.5 from the 90 -degree vertical-downward elbow for Run- $3 ; \mathrm{j}_{\mathrm{f}}=3.0 \mathrm{~m} / \mathrm{s}$ and $\mathrm{j}_{\mathrm{g}, \mathrm{atm}}=0.139 \mathrm{~m} / \mathrm{s}$ 

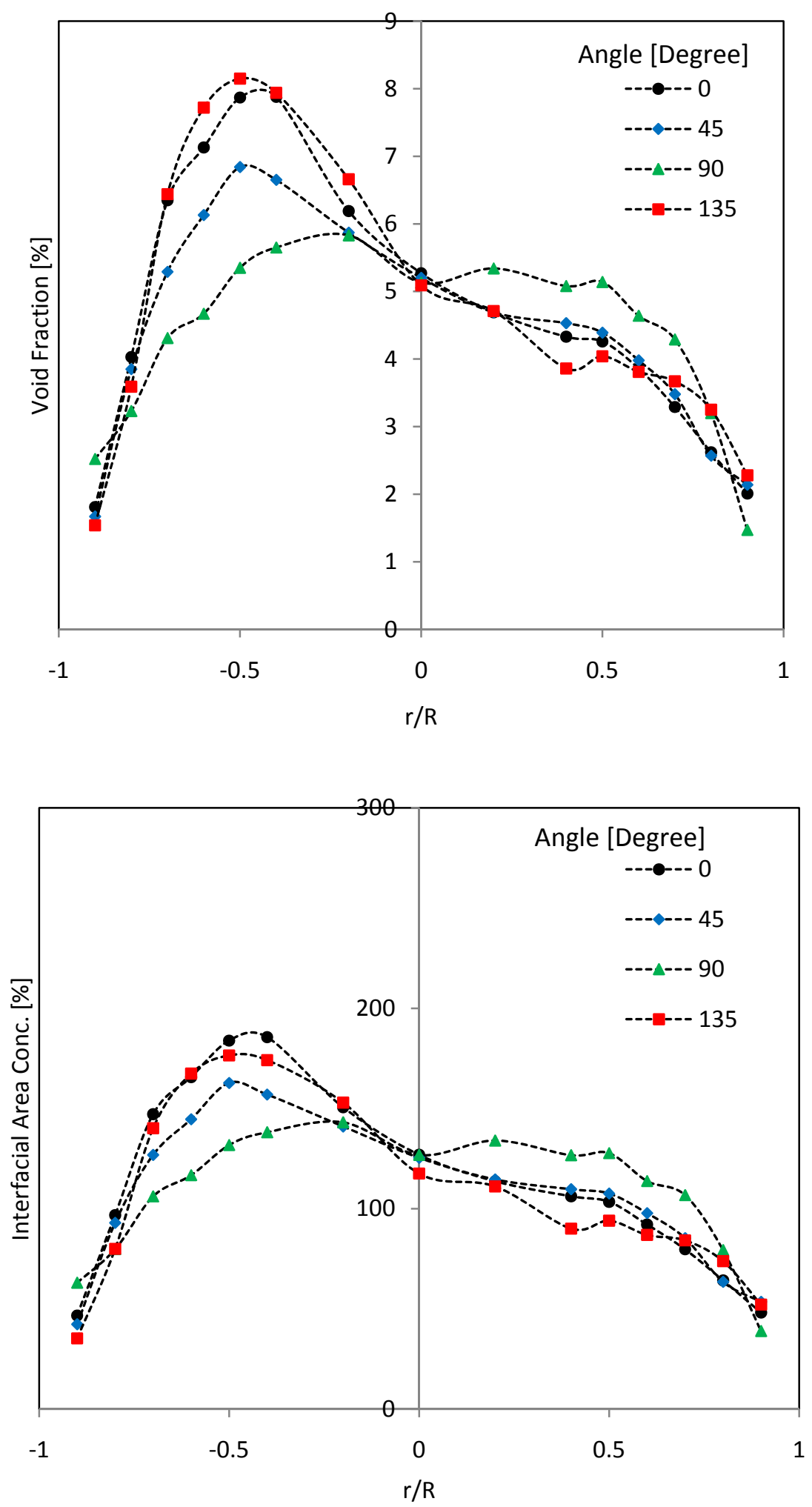

Figure A 3-4: Local profiles of void fraction at different angles of measurement at port P11, L/D = 1.5 from the 90 -degree vertical-downward elbow for Run- $4 ; \mathrm{j}_{\mathrm{f}}=3.0 \mathrm{~m} / \mathrm{s}$ and $\mathrm{j}_{\mathrm{g}, \mathrm{atm}}=0.139 \mathrm{~m} / \mathrm{s}$ 

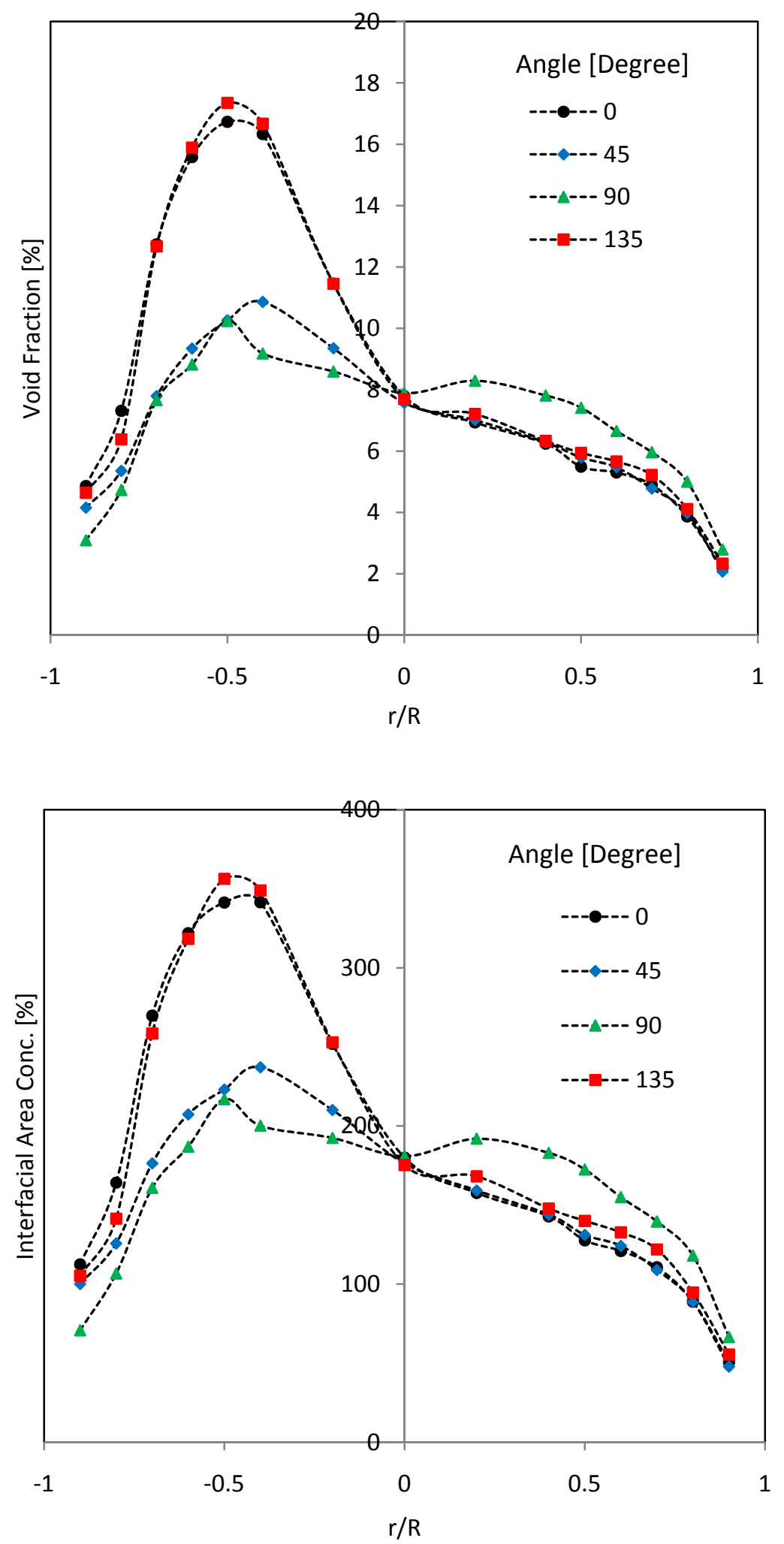

Figure A 3-5: Local profiles of void fraction at different angles of measurement at port P11, L/D = 1.5 from the 90 -degree vertical-downward elbow for Run-5; $\mathrm{j}_{\mathrm{f}}=3.0 \mathrm{~m} / \mathrm{s}_{\text {and }} \mathrm{j}_{\mathrm{g}, \mathrm{atm}}=0.139 \mathrm{~m} / \mathrm{s}$ 

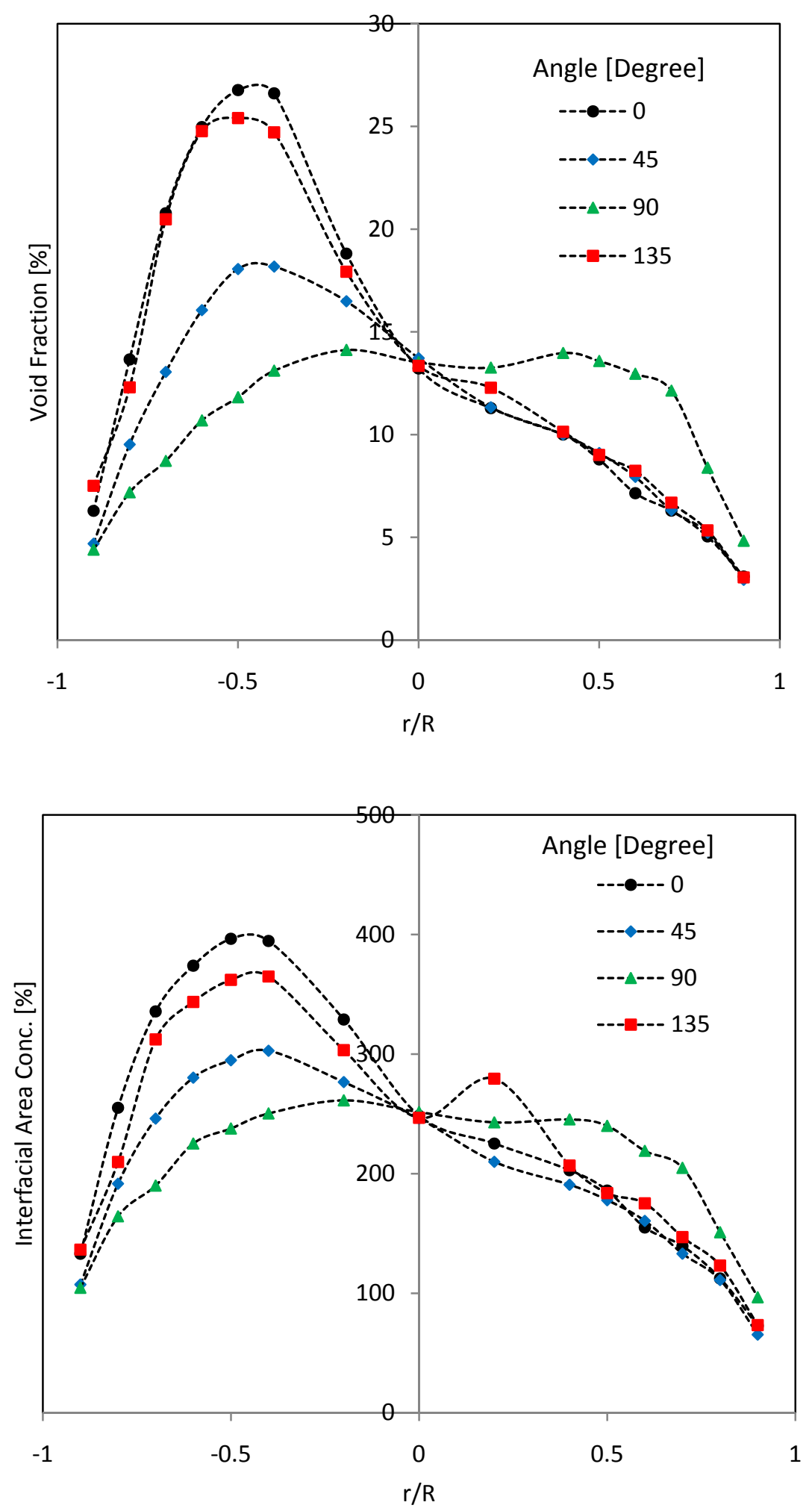

Figure A 3-6: Local profiles of void fraction at different angles of measurement at port P11, L/D = 1.5 from the 90 -degree vertical-downward elbow for Run- $6 ; j_{\mathrm{f}}=3.0 \mathrm{~m} / \mathrm{s}$ and $\mathrm{j}_{\mathrm{g}, \mathrm{atm}}=0.139 \mathrm{~m} / \mathrm{s}$ 

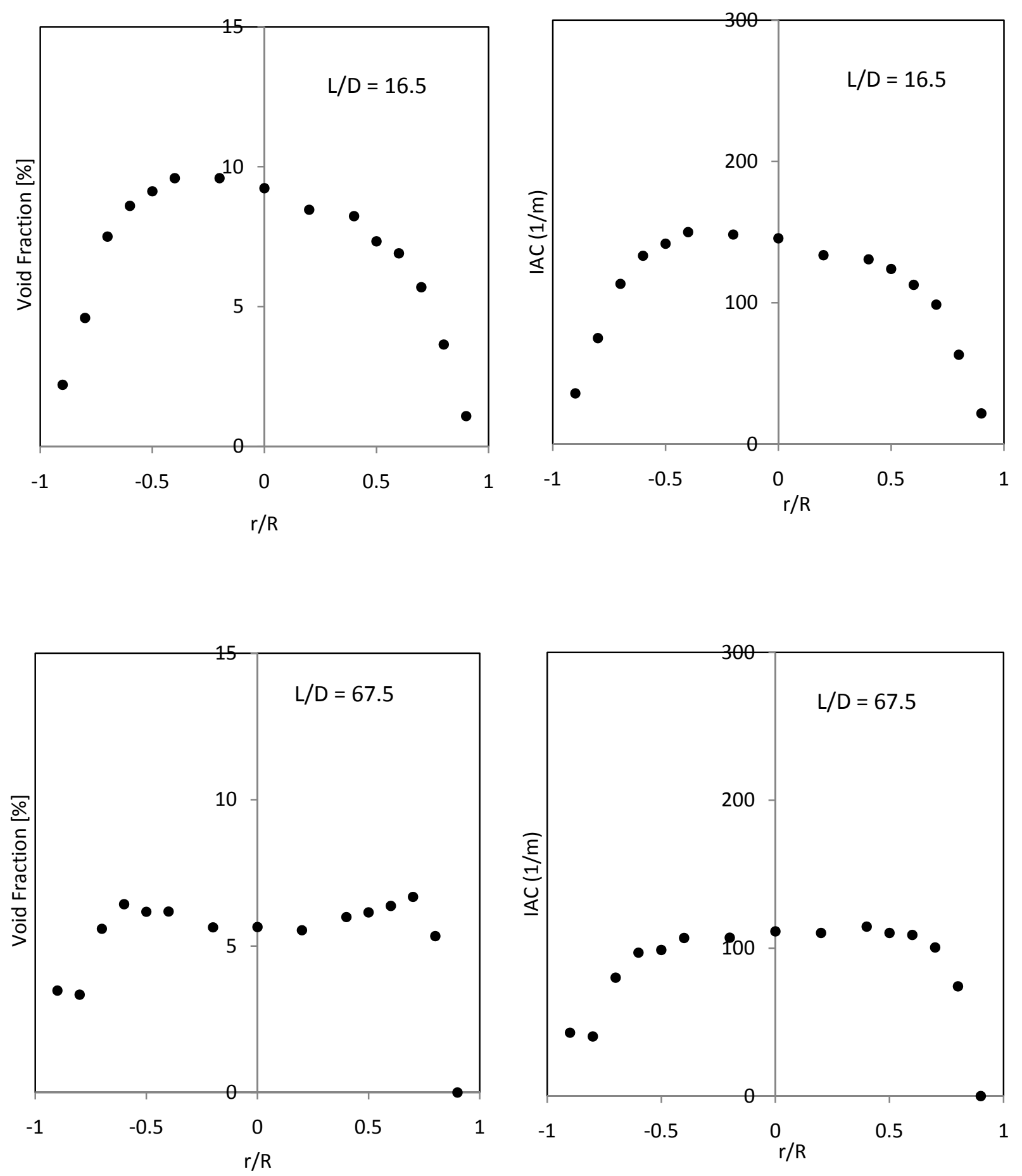

Figure A3-7: Local profiles of $\alpha$ and $a_{i}$ for $\mathrm{j}_{\mathrm{f}}=2.0 \mathrm{~m} / \mathrm{s}$ and $\mathrm{j}_{\mathrm{g}, \mathrm{atm}}=0.14 \mathrm{~m} / \mathrm{s}$ along the vertical downward section 

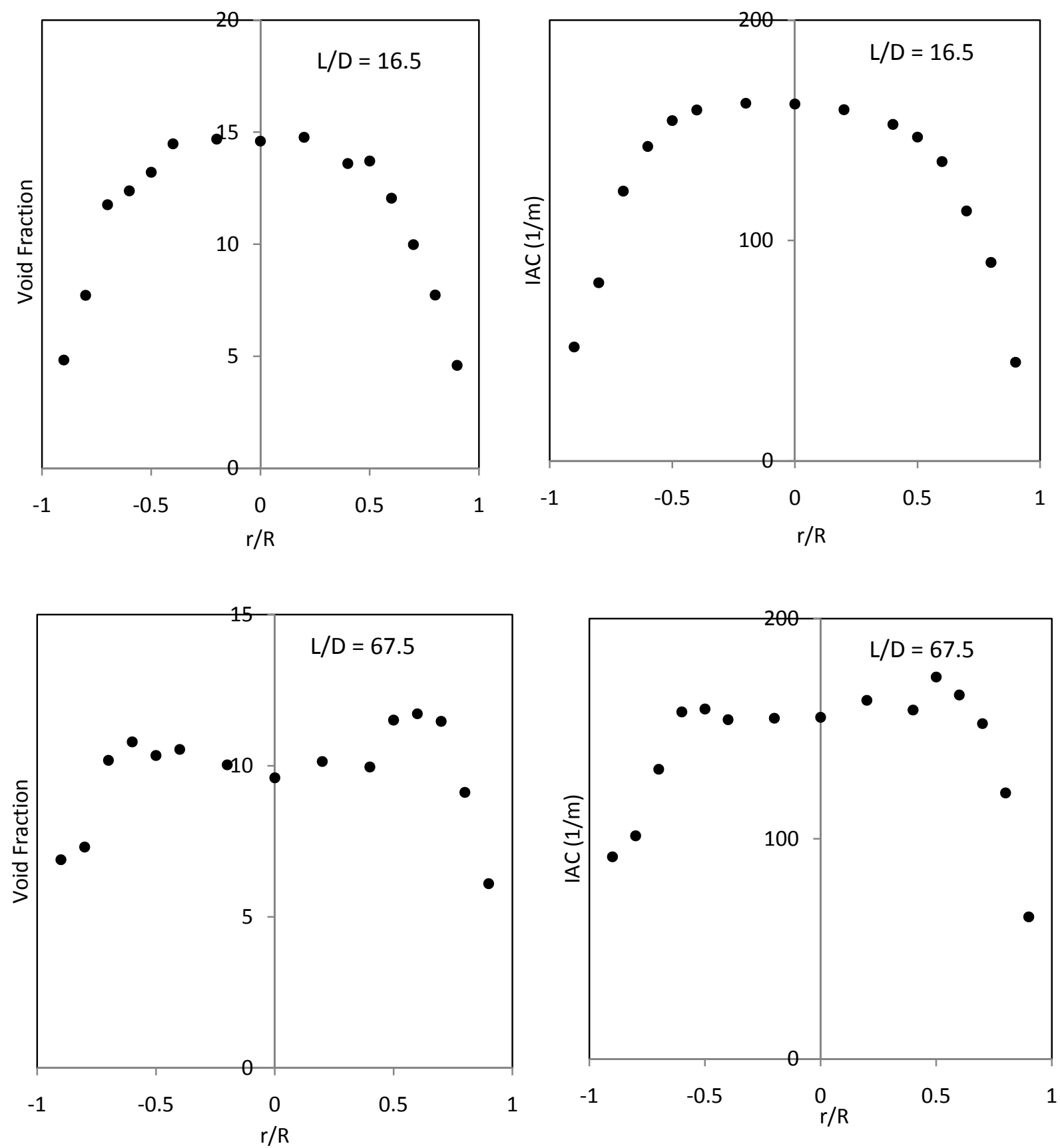

Figure A3-8: Local profiles of $\alpha$ and $a_{i}$ for $\mathrm{j}_{\mathrm{f}}=2.0 \mathrm{~m} / \mathrm{s}$ and $\mathrm{j}_{\mathrm{g}, \mathrm{atm}}=0.23 \mathrm{~m} / \mathrm{s}$ along the vertical downward section 

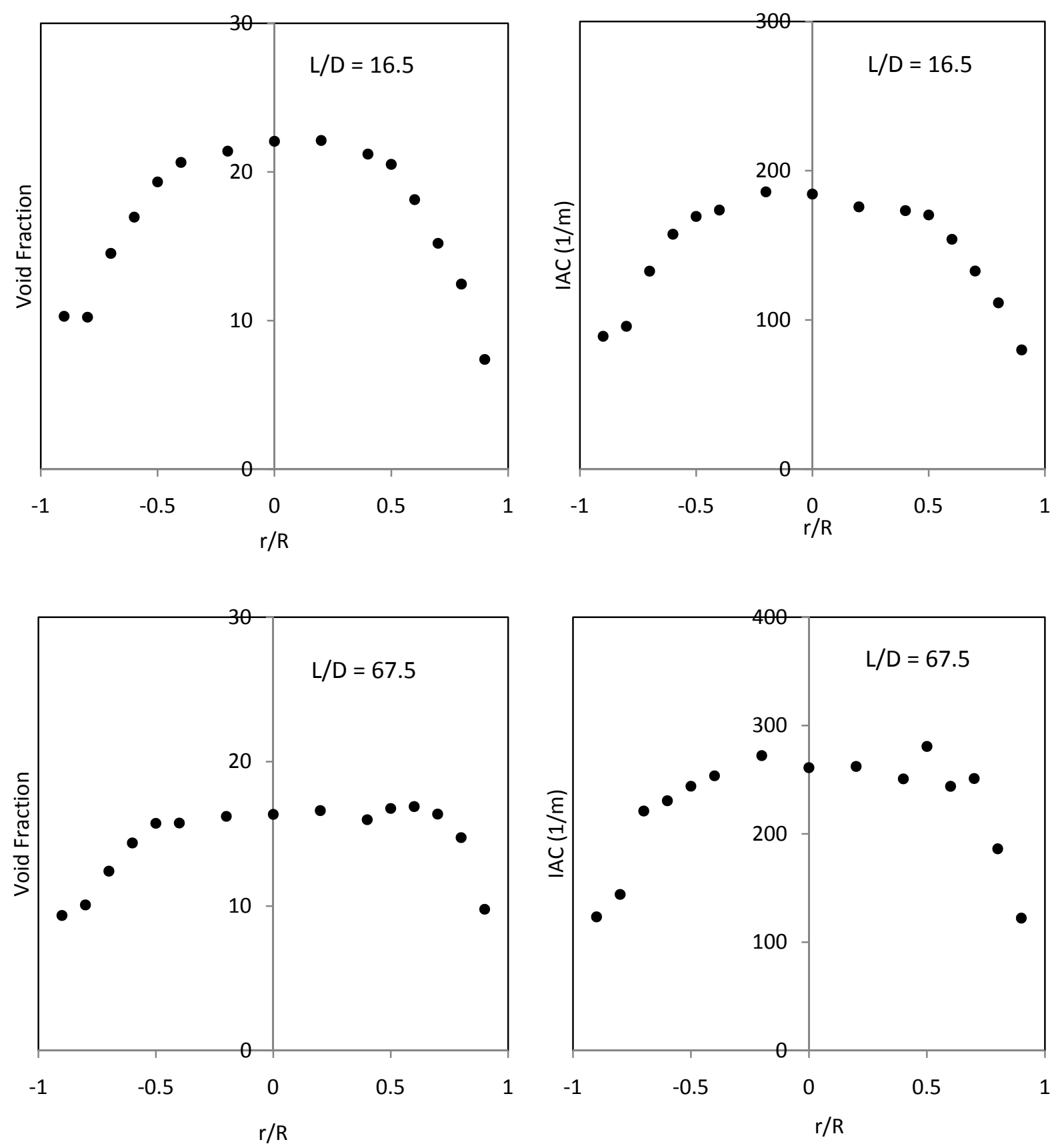

Figure A3-9: Local profiles of $\alpha$ and $a_{i}$ for $\mathrm{j}_{\mathrm{f}}=2.0 \mathrm{~m} / \mathrm{s}$ and $\mathrm{j}_{\mathrm{g}, \mathrm{atm}}=0.34 \mathrm{~m} / \mathrm{s}$ along the vertical downward section 

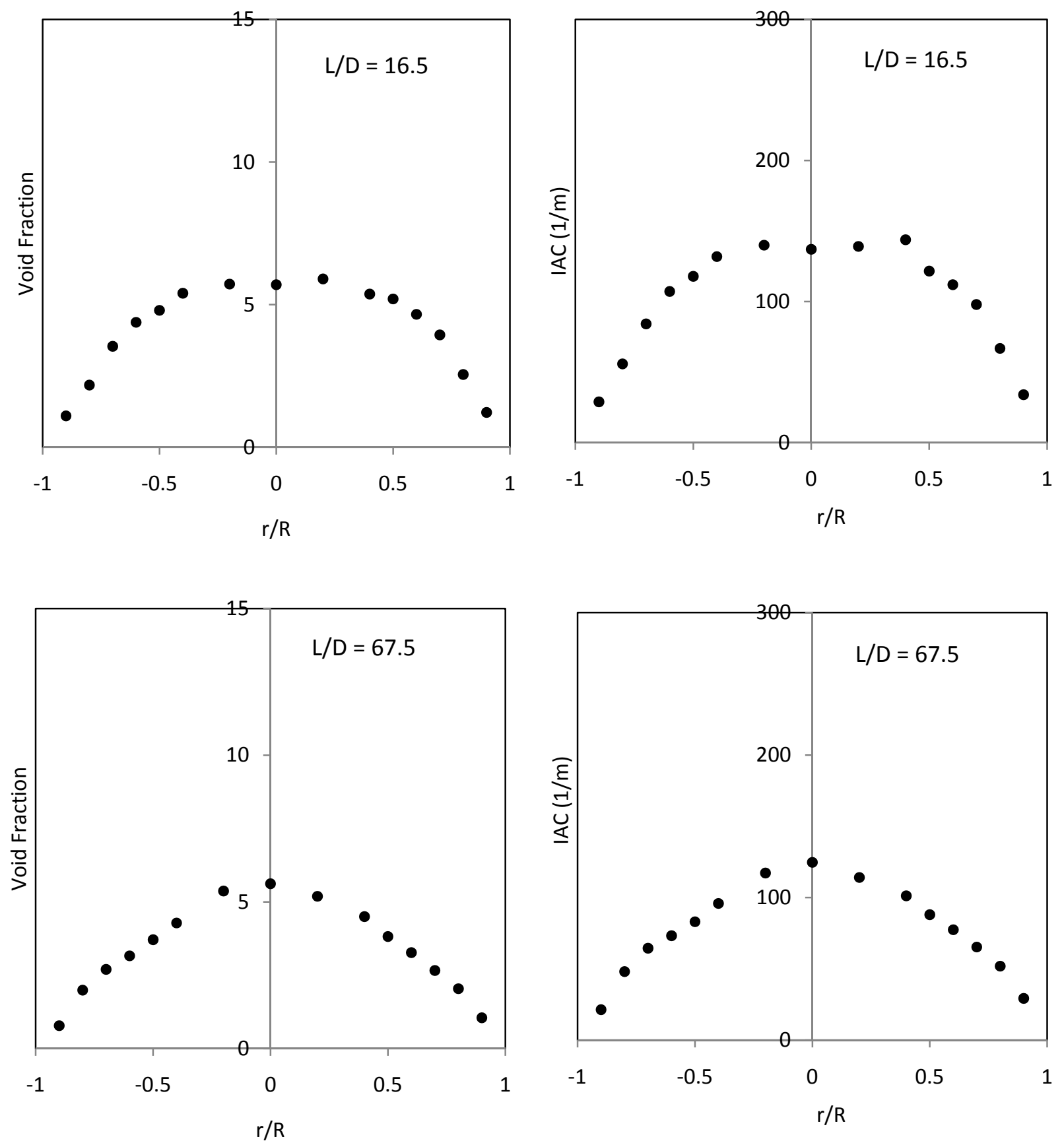

Figure A3-10: Local profiles of $\alpha$ and $a_{i}$ for $\mathrm{j}_{\mathrm{f}}=3.0 \mathrm{~m} / \mathrm{s}$ and $\mathrm{j}_{\mathrm{g}, \mathrm{atm}}=0.14 \mathrm{~m} / \mathrm{s}$ along the vertical downward section 

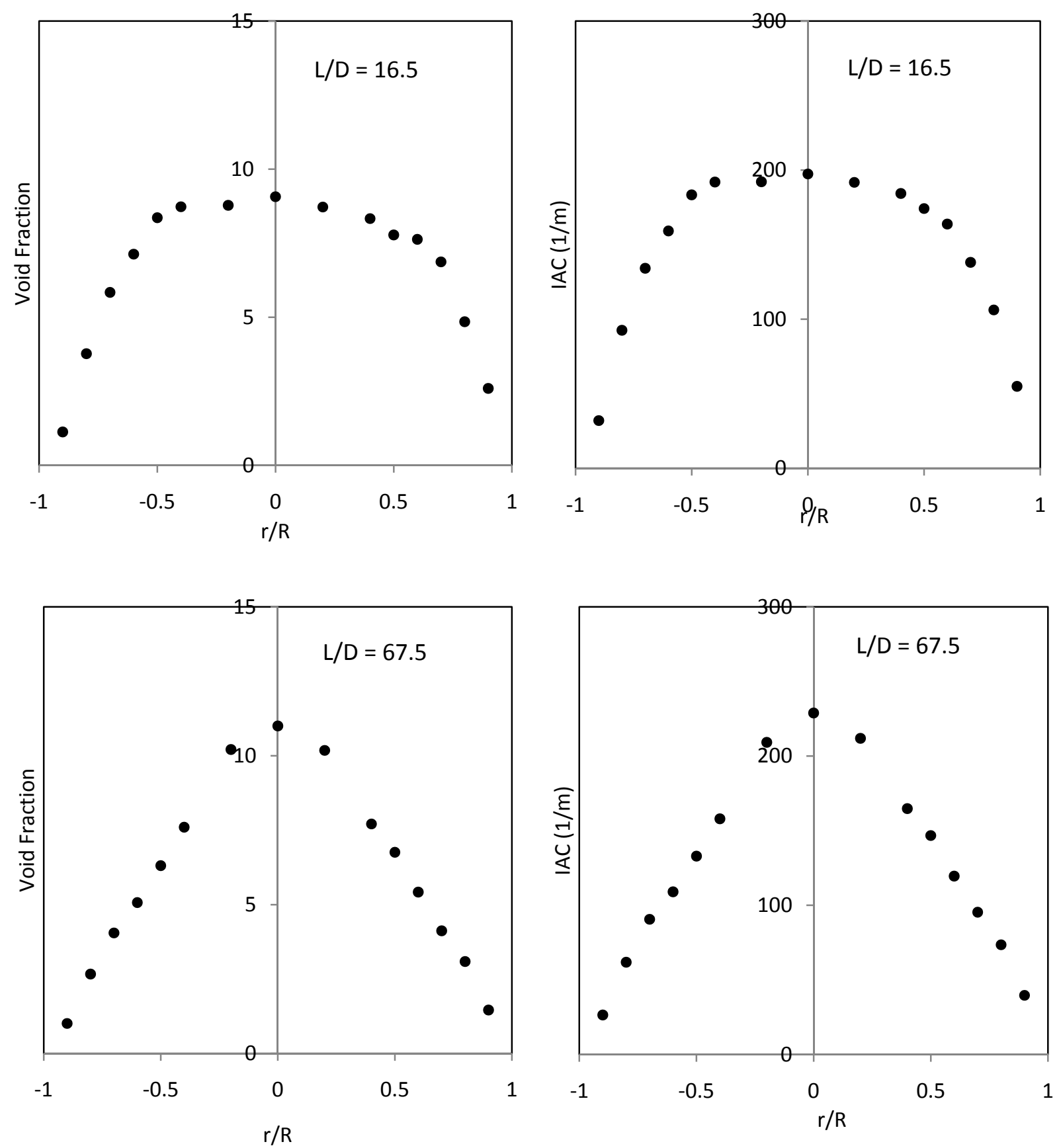

Figure A3-11: Local profiles of $\alpha$ and $a_{i}$ for $\mathrm{j}_{\mathrm{f}}=3.0 \mathrm{~m} / \mathrm{s}$ and $\mathrm{j}_{\mathrm{g}, \mathrm{atm}}=0.23 \mathrm{~m} / \mathrm{s}$ along the vertical downward section 

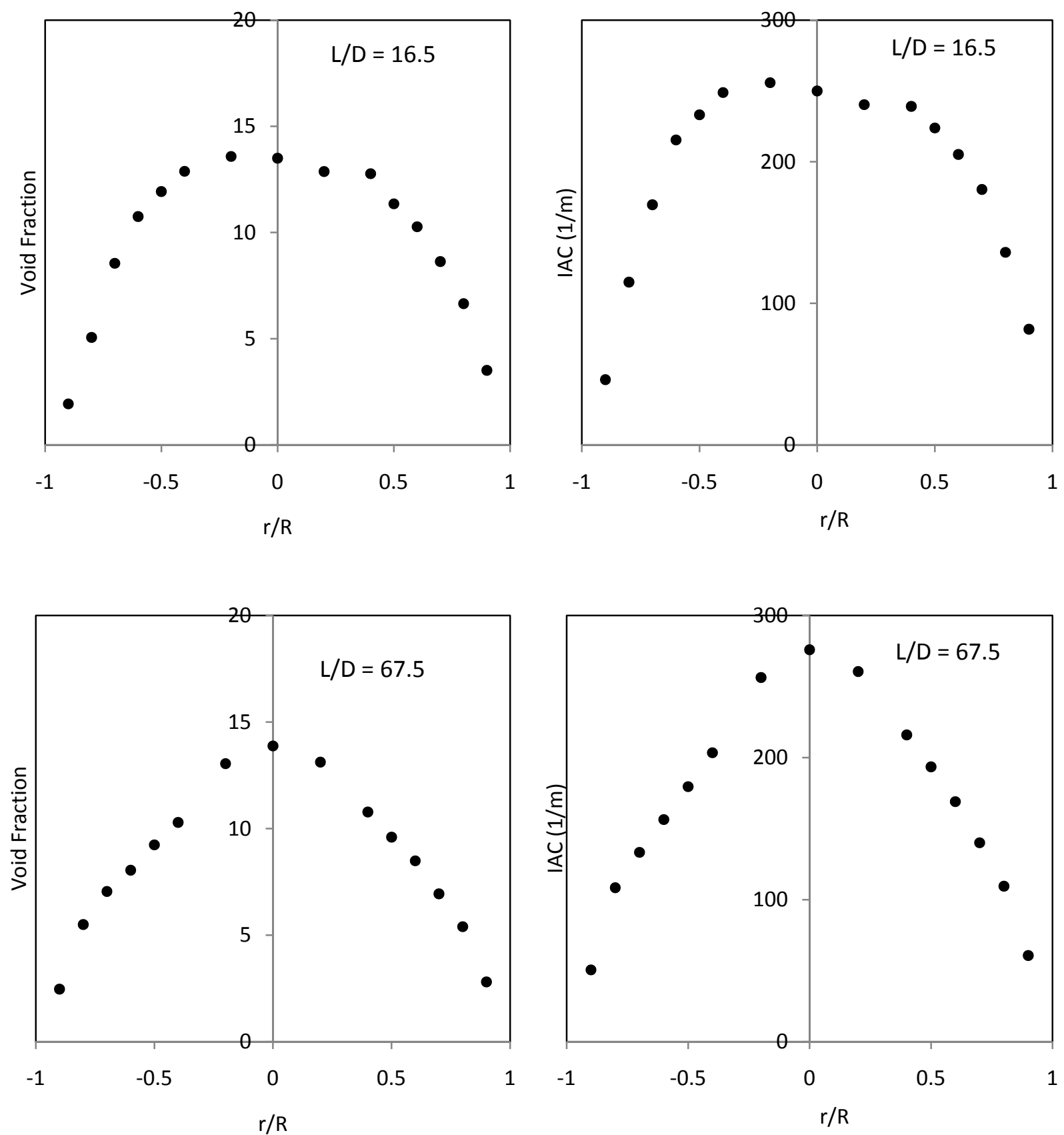

Figure A3-12: Local profiles of $\alpha$ and $a_{i}$ for $\mathrm{j}_{\mathrm{f}}=3.0 \mathrm{~m} / \mathrm{s}$ and $\mathrm{j}_{\mathrm{g}, \mathrm{atm}}=0.35 \mathrm{~m} / \mathrm{s}$ along the vertical downward section 
Appendix A4

Development of Three-Dimensional Profiles along the Combinatorial Channels 


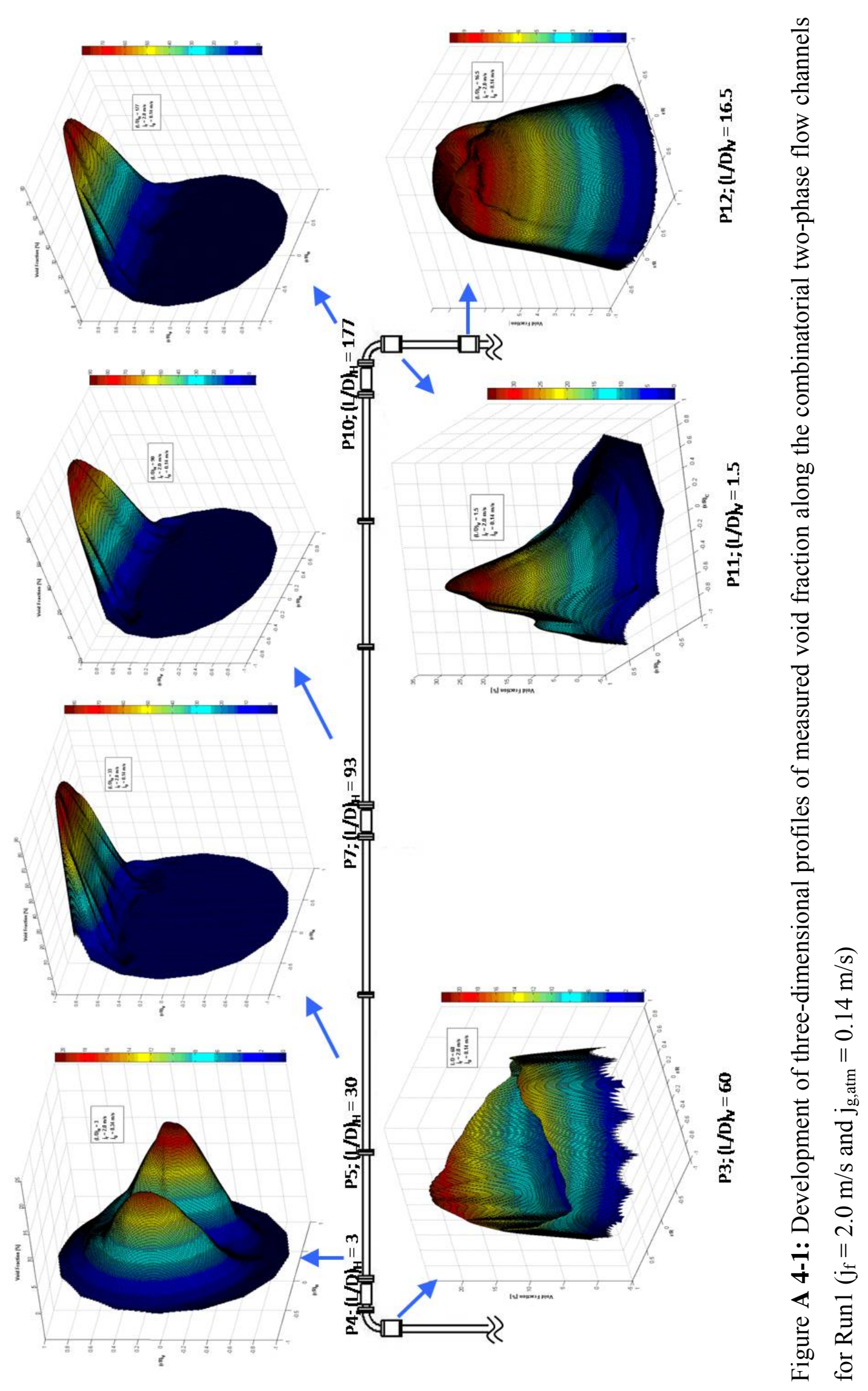




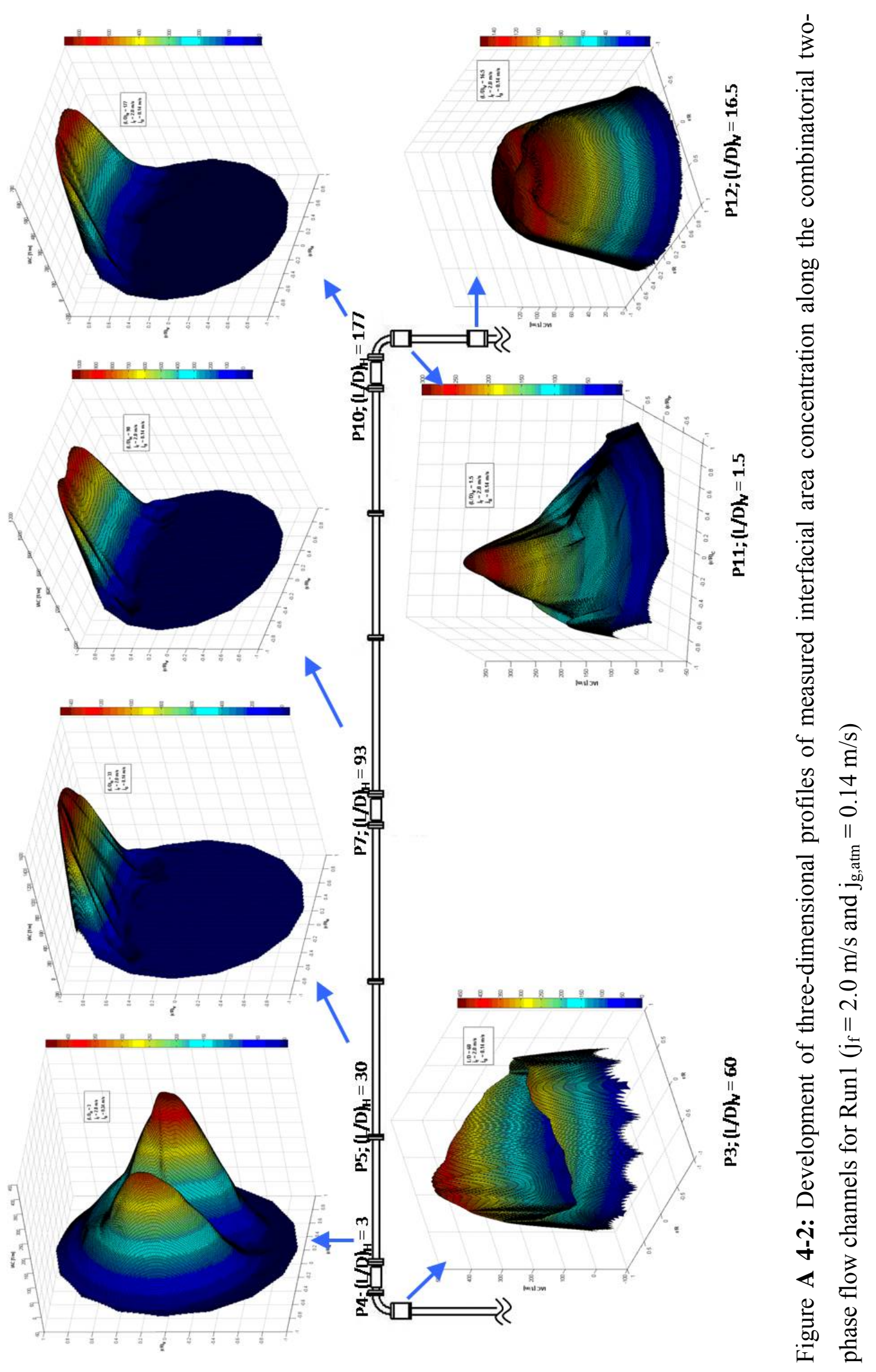




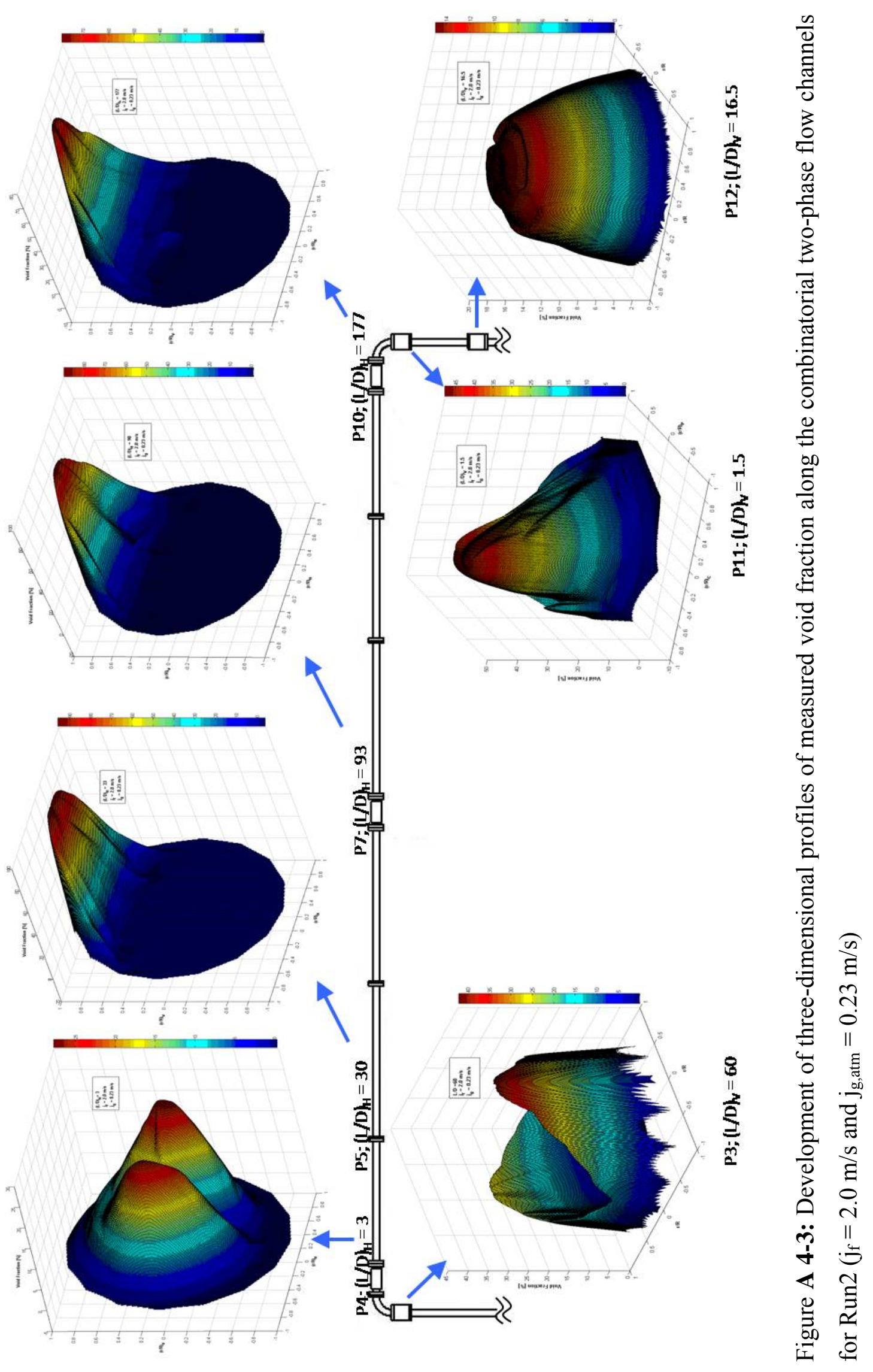




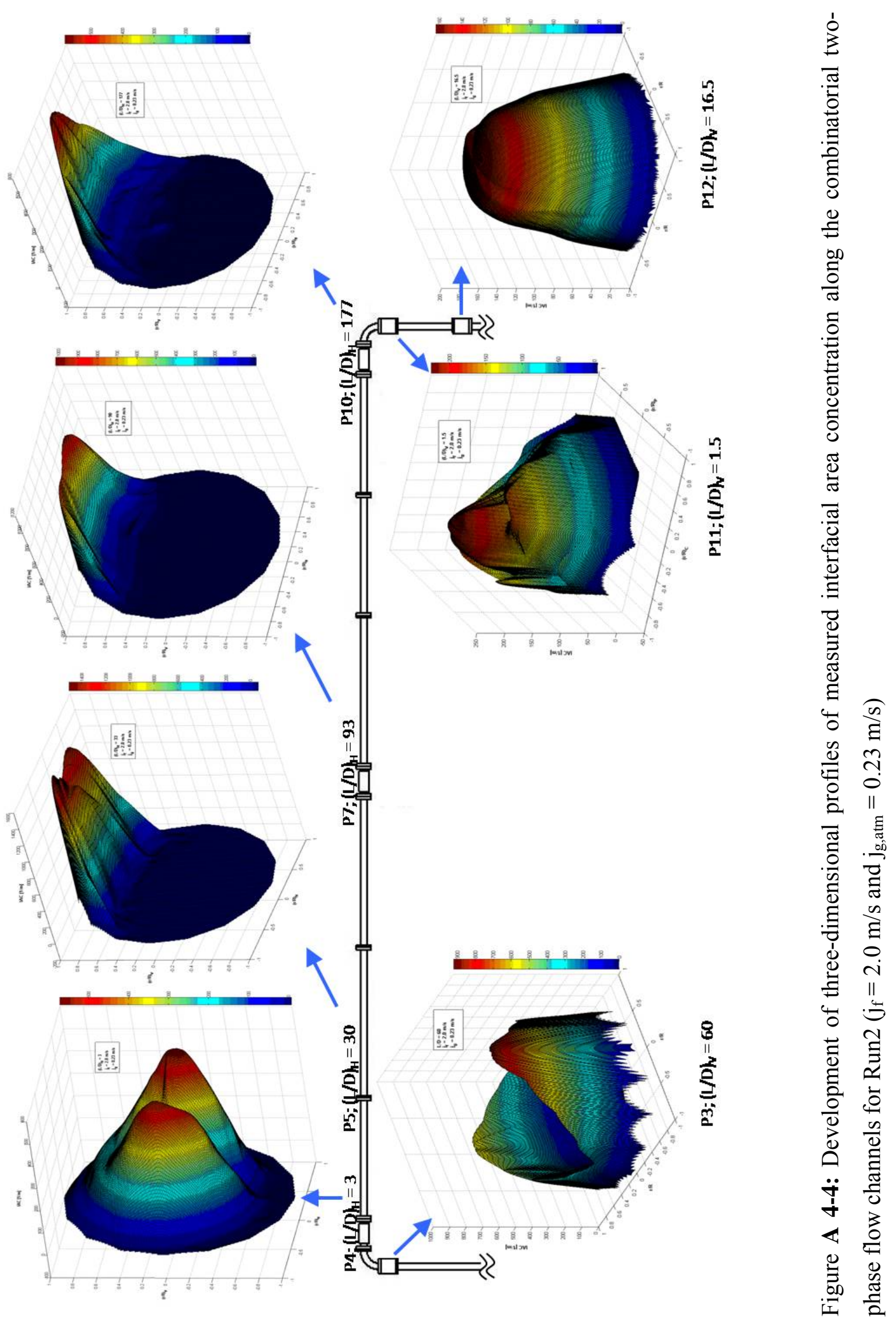




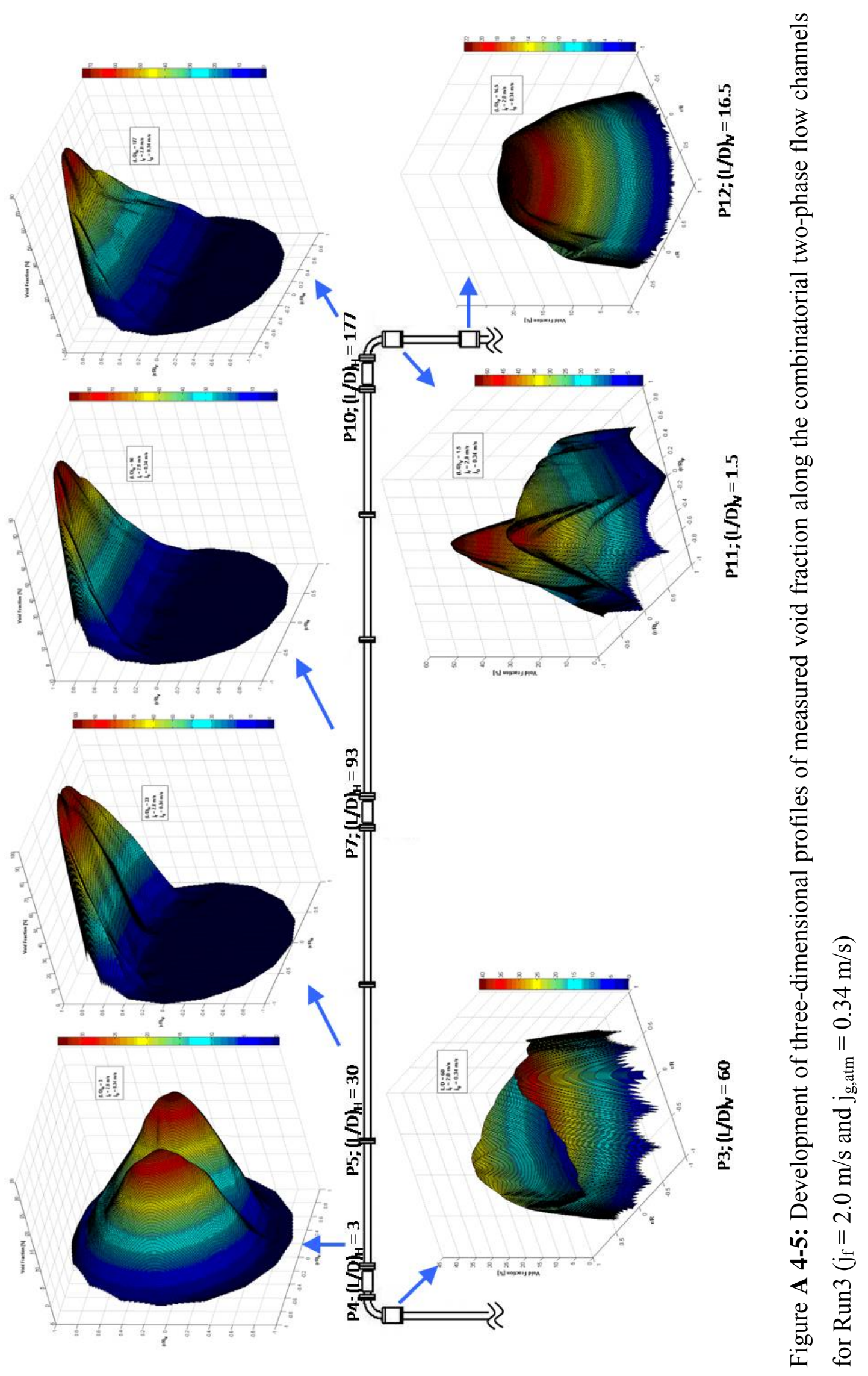



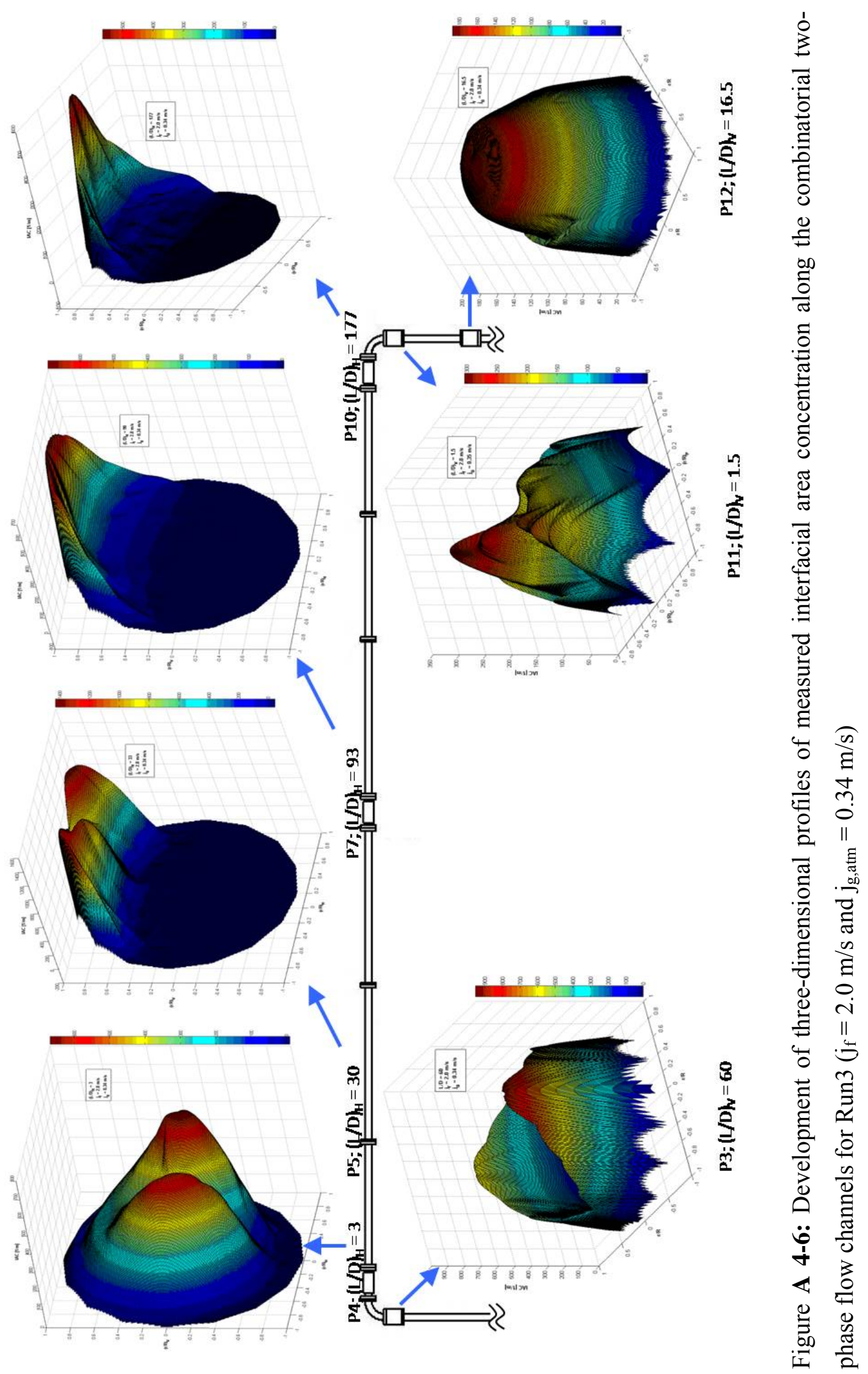


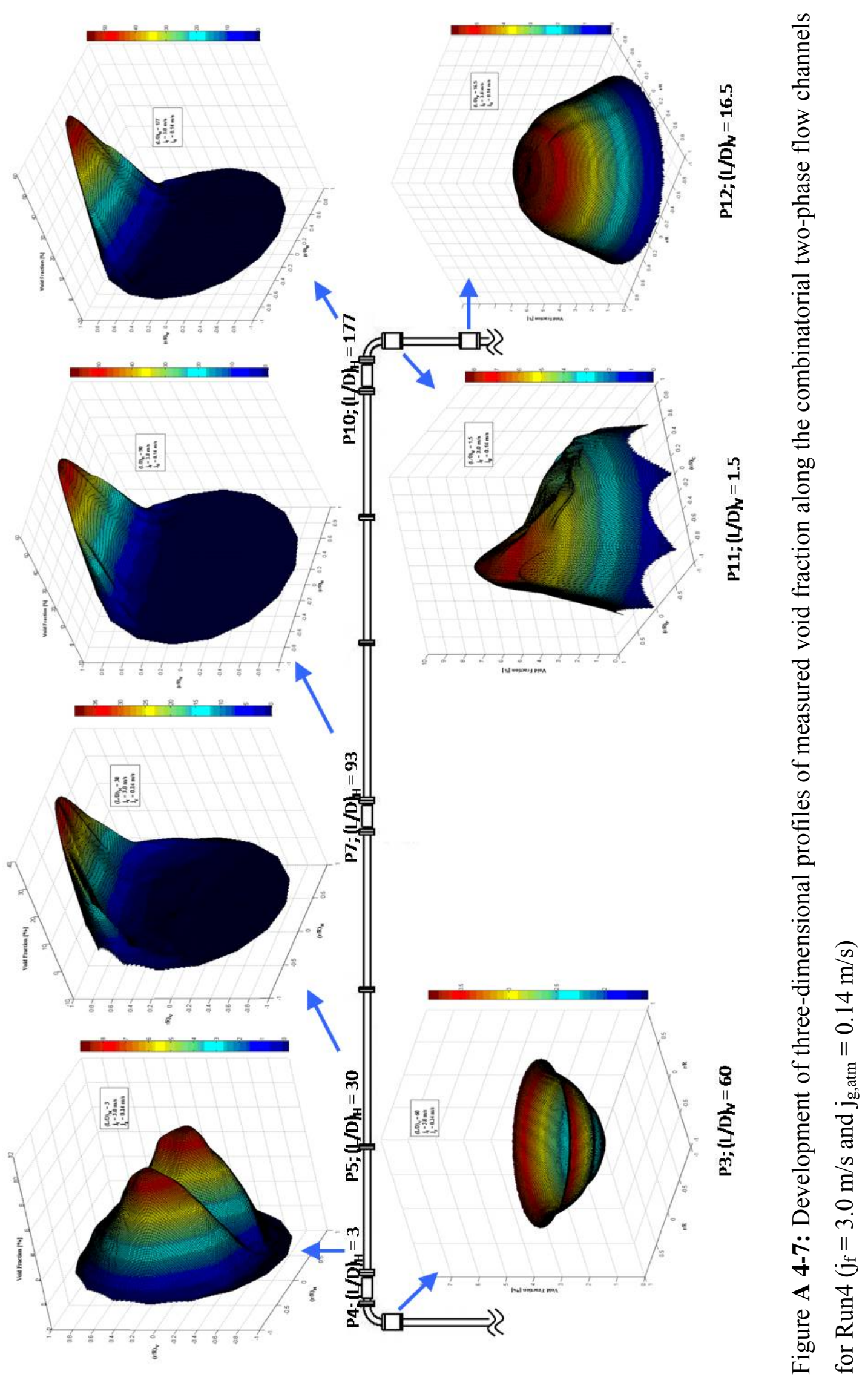




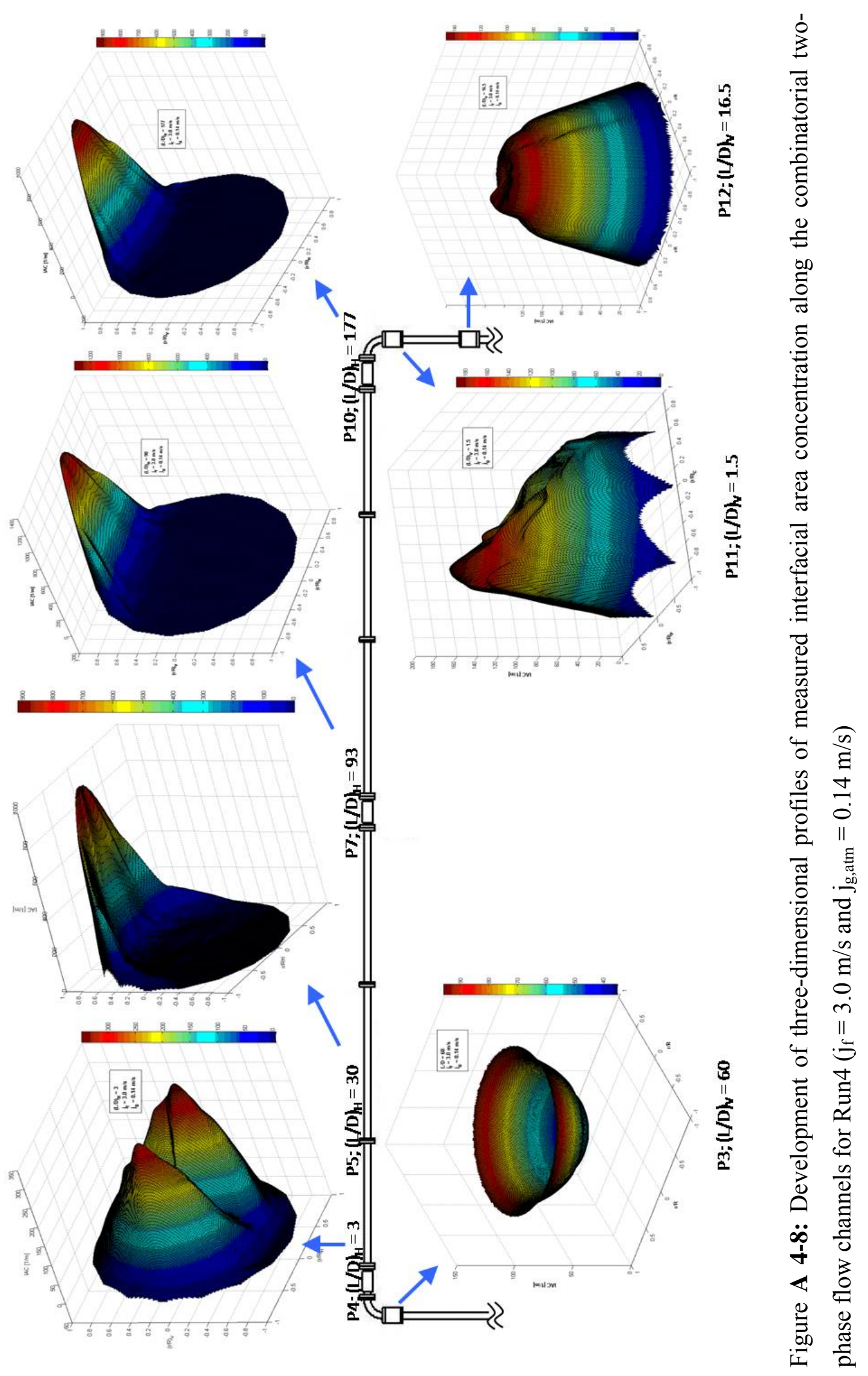




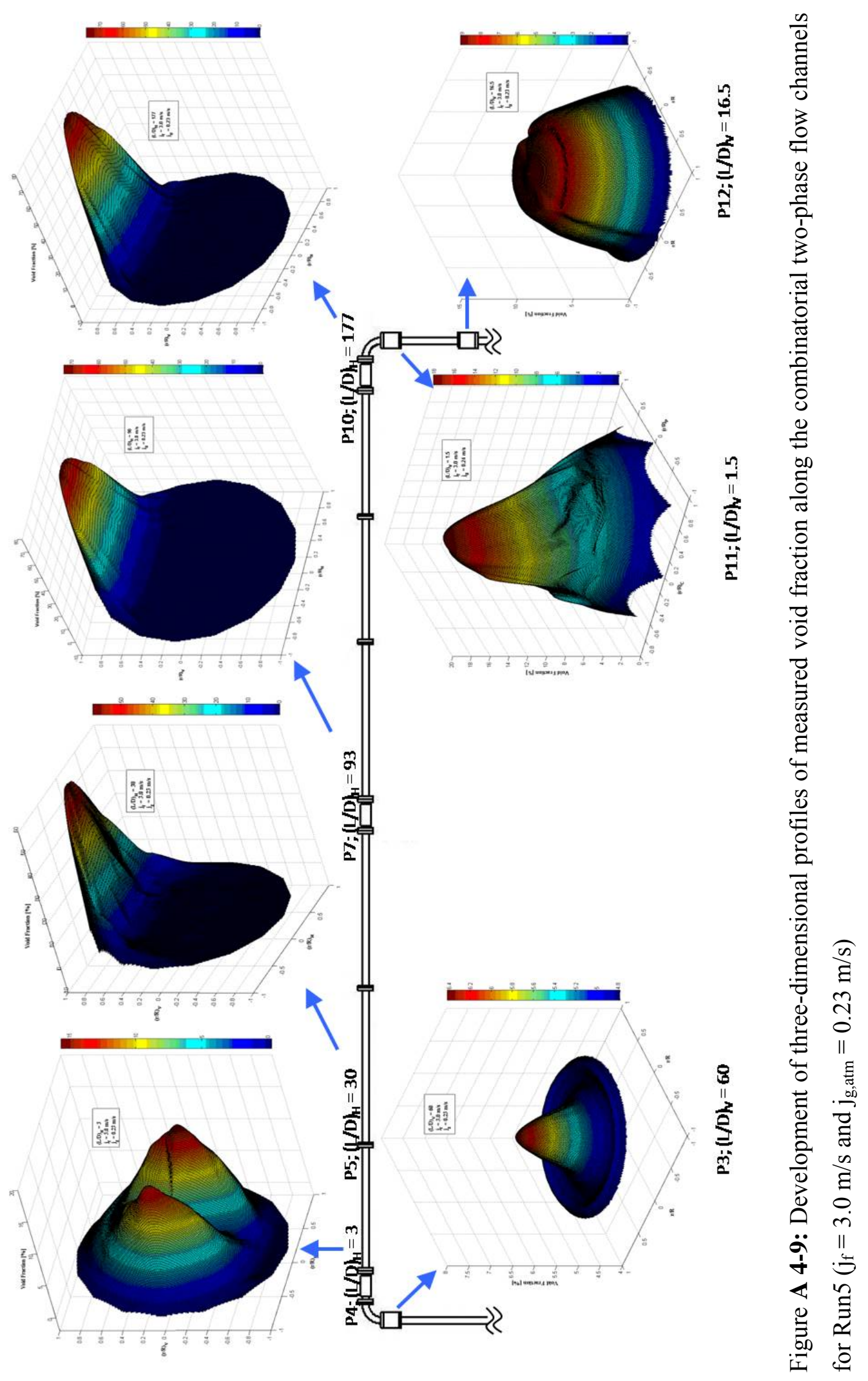




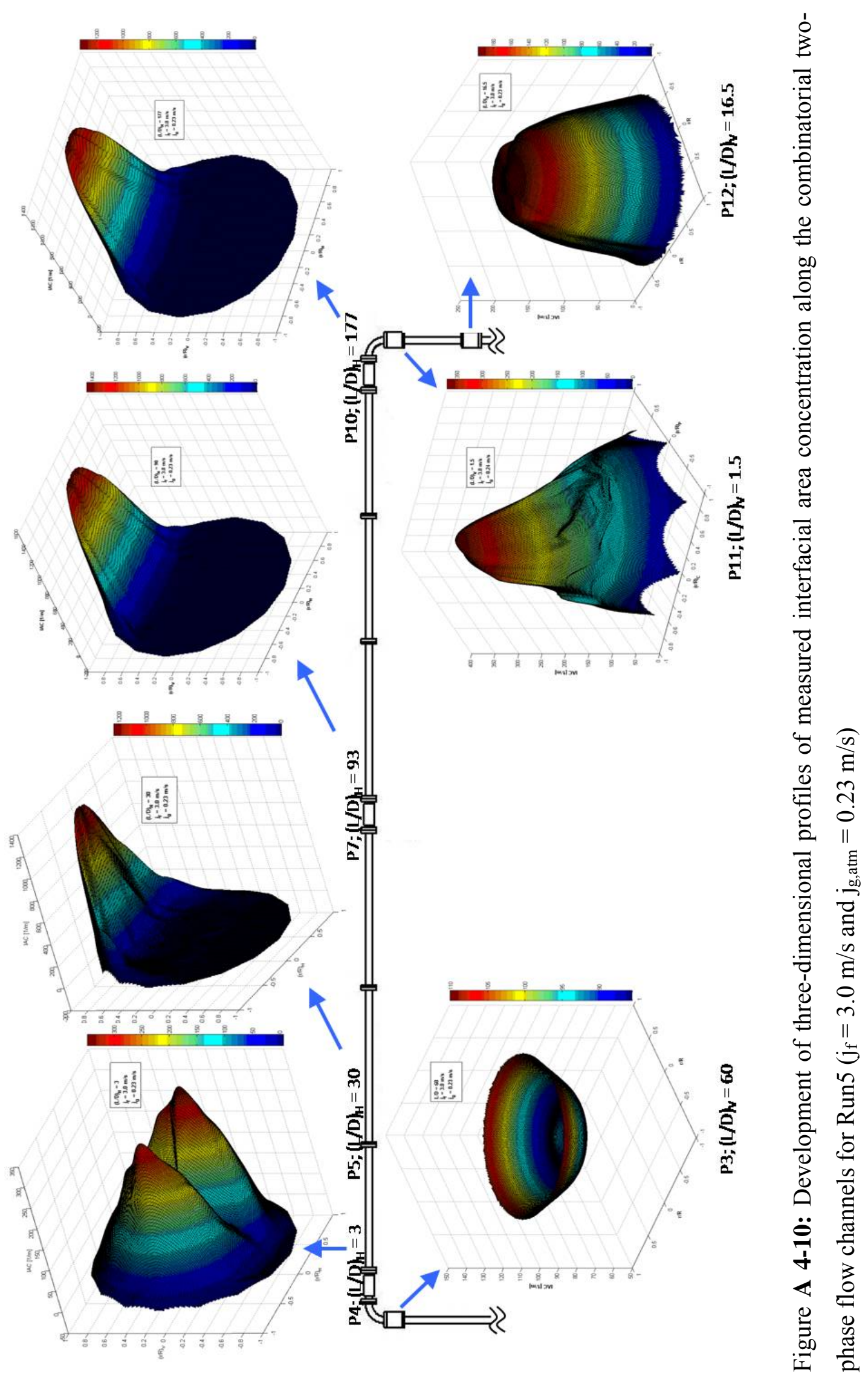




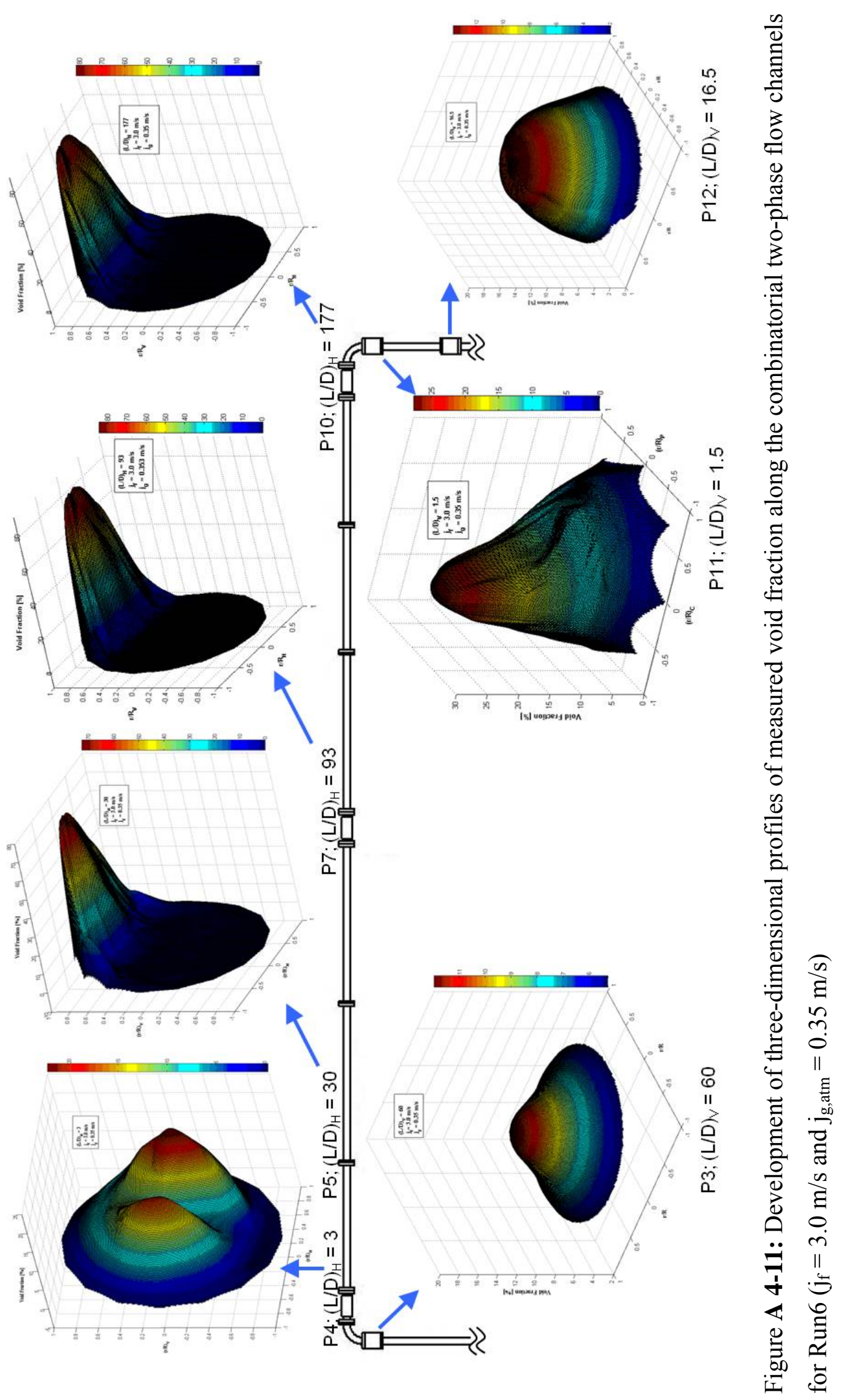




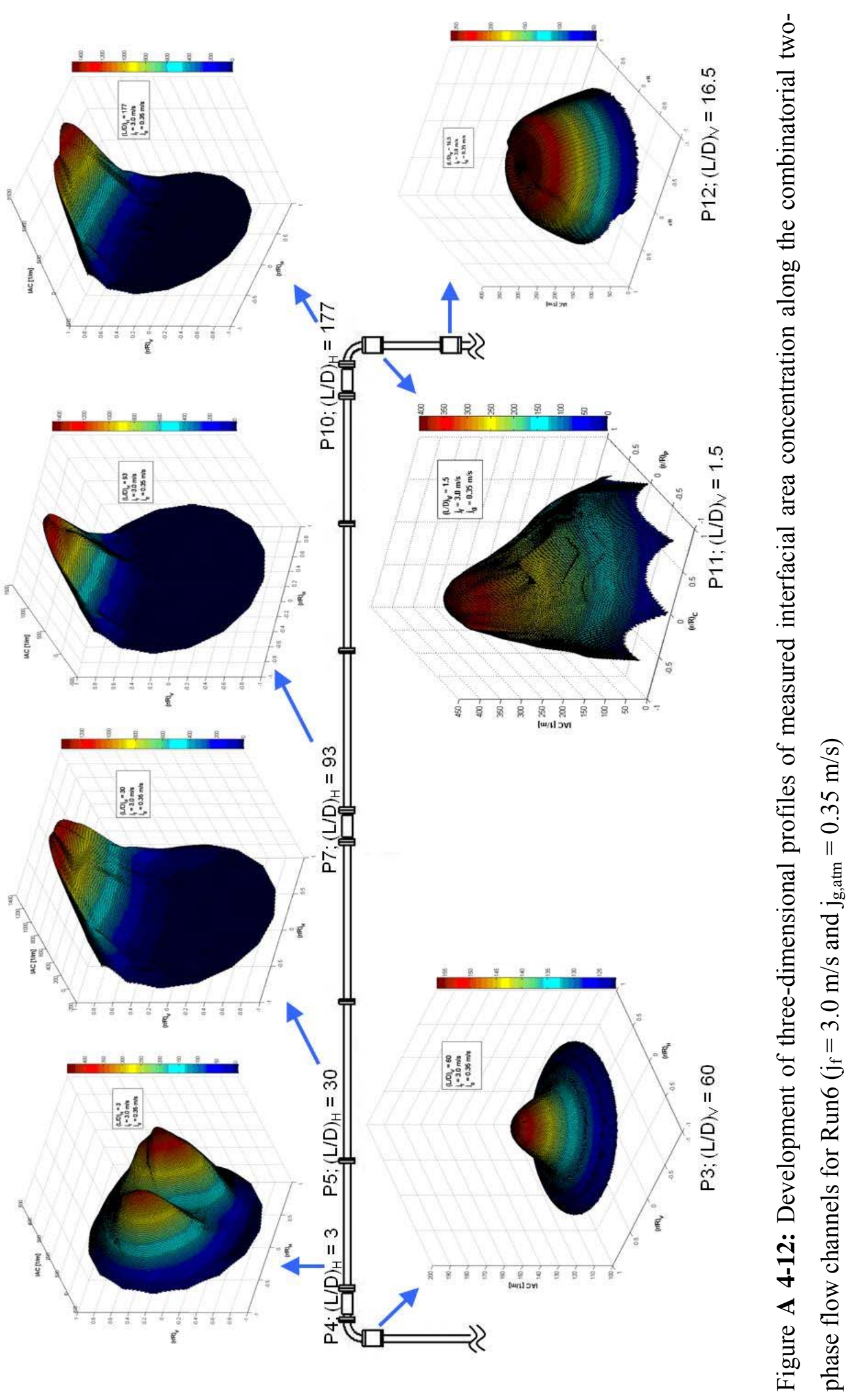

